\title{
Prevention of asthma in genetically susceptible children (PREVASC)? : a multi-faceted trial on environmental exposure reduction suitable for implementation in general practice
}

Citation for published version (APA):

Maas, T. (2008). Prevention of asthma in genetically susceptible children (PREVASC)? : a multi-faceted trial on environmental exposure reduction suitable for implementation in general practice. [Doctoral Thesis, Maastricht University]. Datawyse / Universitaire Pers Maastricht. https://doi.org/10.26481/dis.20081024tm

Document status and date:

Published: 01/01/2008

DOI:

10.26481/dis.20081024tm

Document Version:

Publisher's PDF, also known as Version of record

Please check the document version of this publication:

- A submitted manuscript is the version of the article upon submission and before peer-review. There can be important differences between the submitted version and the official published version of record. People interested in the research are advised to contact the author for the final version of the publication, or visit the DOI to the publisher's website.

- The final author version and the galley proof are versions of the publication after peer review.

- The final published version features the final layout of the paper including the volume, issue and page numbers.

Link to publication

\footnotetext{
General rights rights.

- You may freely distribute the URL identifying the publication in the public portal. please follow below link for the End User Agreement:

www.umlib.nl/taverne-license

Take down policy

If you believe that this document breaches copyright please contact us at:

repository@maastrichtuniversity.nl

providing details and we will investigate your claim.
}

Copyright and moral rights for the publications made accessible in the public portal are retained by the authors and/or other copyright owners and it is a condition of accessing publications that users recognise and abide by the legal requirements associated with these

- Users may download and print one copy of any publication from the public portal for the purpose of private study or research.

- You may not further distribute the material or use it for any profit-making activity or commercial gain

If the publication is distributed under the terms of Article $25 \mathrm{fa}$ of the Dutch Copyright Act, indicated by the "Taverne" license above, 


\section{Prevention of asthma in genetically susceptible children (PREVASC)?}

A multi-faceted trial on environmental exposure reduction suitable for implementation in general practice 
The studies presented in this thesis were performed at the Department of General Practice (Maastricht University), and were conducted under the auspices of the school for Public Health and Primary Care: CAPHRI at Maastricht University, The Netherlands. The school for Public Health and Primary Care: CAPHRI is part of the Netherlands School of Primary Care Research (CaRe), which has been acknowledged since 1995 by The Royal Netherlands Academy of Art and Sciences (KNAW).

(C) Tanja Maas, Maastricht 2008

ISBN: 978-90-5278-755-8

The study presented in this thesis was funded by the Dutch Asthma Foundation (3.2.99.38), The Netherlands Organization for Health Research and Development (ZonMw), Program of Innovative Prevention Research (Prevention Program 1, no. 2100.0091) and the University Hospital Maastricht (azM).

Industrial support for the PREVASC study was supplied by SanaLife, Wychen and Nutricia baby food, Zoetermeer

Layout: Tiny Wouters

Cover-illustration: Willem van de Nadort, Tilburg www.willemvandenadort.nl

Production: Datawyse | Universitaire Pers Maastricht 


\section{Prevention of asthma in genetically susceptible children (PREVASC)?}

A multi-faceted trial on environmental exposure reduction suitable for implementation in general practice

\section{PROEFSCHRIFT}

ter verkrijging van de graad van doctor aan de Universiteit Maastricht, op gezag van de Rector Magnificus, Prof. mr. G.P.M.F. Mols, volgens het besluit van het College van Decanen, in besloten kring te verdedigen op vrijdag 24 oktober 2008 om 14.00 uur

door

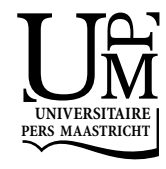




\section{Promotores}

Prof. dr. C.P. van Schayck

Prof. dr. J.A. Knottnerus

\section{Copromotores}

Dr. E. Dompeling

Dr. G. Wesseling

\section{Beoordelingscommissie}

Prof. dr. M. Prins (voorzitter)

Prof. dr. W.M.C. van Aalderen

Prof. dr. P.J.E. Bindels

Dr. I. Mesters

Prof. dr. L.J.I. Zimmermann
Emma Kinderziekenhuis,

AMC, Universiteit van Amsterdam

AMC, Universiteit van Amsterdam 
Aan: Xavier, Rafael en Isha 



\section{Contents}

Chapter 1 General introduction 9

$\begin{array}{lll}\text { Chapter } 2 & \text { Birth cohort studies on asthma development } & 17\end{array}$

Pediatr Asthma Allergy Immunol 2005;18:201-215

Chapter 3 Prevention of asthma in children (PREVASC) study:

design of a multifaceted prevention program

Pediatr Allergy Immunol 2005;16:321-331

Chapter 4 Meta-analyses of multi- and mono-faceted birth cohort randomised trials on prevention of asthma in children at risk Cochrane library 2007; accepted

Chapter 5 Distribution of house dust mite allergen; comparing house dust mite allergen level collected on different sites of living room floors with smooth coverings

Allergy 2003:58:500-502

Chapter 6 Do common infections influence the development of asthma and allergy?

About confirming or rejecting the hygiene hypothesis

Submitted

Chapter 7 Results of the PREVASC-OMEGA study on prevention of asthma in children: exposure and clinical effectiveness at age 4 and 6 years

Submitted

Chapter 8 General discussion

Summary

Samenvatting

Publications

Dankwoord

About the author 



\section{Chapter 1}

General introduction

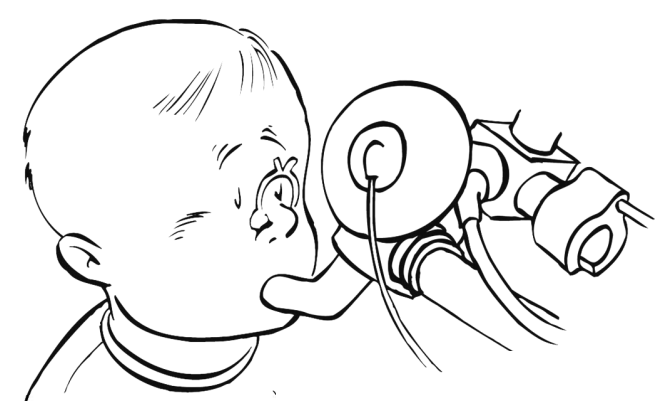




\section{General introduction}

The primary aim of this thesis was to investigate whether asthma could be prevented in children with a genetic predisposition by educating parents about multiple measures for simultaneously optimising their child's exposure to environmental exposures associated with asthma. The measures focused upon were lowering the exposure to inhalant allergens and food allergens, breastfeeding promotion and reducing exposure to environmental tobacco smoke.

\section{Asthma}

Asthma is a chronic disease of the respiratory system that is characterized by excessive inflammatory response to specific and non-specific exposures like allergens and physical exercise..$^{1,2}$ Wheezing, night-time coughing and dyspnoea are the symptoms that are associated with asthma.

Usually the treatment advised, is environmental control and medication use (inhaled corticosteroids, beta ${ }_{2}$ sympatico-mimetics, anticholinergics, antihistamines). ${ }^{2,3}$ Although asthma can often be treated successfully, it can have major consequences for children's well-being. ${ }^{4}$ It is the most common chronic disease in childhood that can lead to teasing in primary school. ${ }^{5}$ Growth and development can be disadvantaged by periods of symptoms and medication use, ${ }^{5,6}$ and often children are not able to go to school because of respiratory complaints and visits to doctors.

\section{Prevalence}

A five-fold increase in the prevalence of asthma has been observed in developed countries between 1980 and $2000{ }^{8}$ This tendency seems to have reversed thereafter. ${ }^{8}$ The most recently observed (2006) prevalence of asthma in children aged five to eight years was approximately 5.7 to $10.5 \%{ }^{9,10}$

Asthma is known to be a disease that is associated with both genetic and environmental factors. ${ }^{11}$ As a consequence, genetically predisposed children may not develop asthma when environmental exposures are adequately reduced. 


\section{Hypotheses concerning the primary prevention of asthma in children by means of environmental exposure}

There are several hypotheses concerning the prevention of asthma. One of these is the hygiene hypothesis, which assumes that a high infection load for children aged 0-2 years is associated with a proper development of the immune system. ${ }^{12}$ The hygiene hypothesis implies that in children exposed to infectious agents a skewing of the immune response towards a healthy balance of the T-helper cells (Th) type 1 and 2 will be reached. This view has been shown to be an over-simplification of the complexity of the immune system, since recently a third T-cell population (Treg) has been shown to regulate the function of both 'players' in the Th1/Th2 paradigm. ${ }^{13-15}$ One consequence of this hypothesis has been that some parents have decided not to vaccinate their child because they shared the opinion that the immune system of children needed to be exposed to infectious agents in order to eventually develop an adequately reacting immune system. The hygiene hypothesis has never been proved thus far. It seems plausible, however, that certain elements of the hygiene hypothesis may be correct.

Not only viruses and bacteria but also pro-biotics - products containing inactive infectious agents - are the subject of research. ${ }^{16}$ The major topic in recent research into pro-biotics is the prevention of atopy and more specifically atopic dermatitis. ${ }^{16,17}$ Pro-biotics are known for their presumed positive influence on the microbial balance of the intestine.

Another environmental factor that has been the focus of asthma research is the influence of the supplementation of poly-unsaturated fatty acids of the n-3 and $\mathrm{n}-6$ family. Most research on fatty acid supplementation is carried out in terms of its influence on atopic dermatitis, but asthma research regarding this topic is expanding. ${ }^{18-20}$

Allergen exposure is the main subject of research as far as the primary prevention of asthma is concerned. It is hypothesized that children raised in an environment with low exposure will less frequently develop asthma as compared to children exposed to high levels of allergens. The studies on interventions based on allergen reduction are aimed at reducing exposure to either 1) single allergen levels (mono-faceted interventions) or 2) multiple allergens simultaneously (multi-faceted interventions). Several studies have been carried out on allergen reduction as primary preventive intervention aimed at the development of asthma in children. Results so far suggest that multifaceted interventions have promising effects on reducing the prevalence of asthma. ${ }^{21-26}$ Mono-faceted interventions however were no more effective than controls in the reduction of asthma. ${ }^{27-30}$

Sometimes multi-faceted allergen-reducing interventions have been combined with reduction in other exposures like environmental tobacco smoke (ETS). ${ }^{31}$ It 
is known that ETS exposure has a negative influence on the development of the lungs. $^{32,33}$

Stimulation of exclusive breastfeeding during the first months of life is an oftenused intervention for reducing food allergens in mono- as well as multi-faceted intervention studies. Human milk contains immunological components such as immune globulin $\mathrm{G}(\mathrm{lgG})$, secretory immune globulin A (slgA) and cytokines. ${ }^{34-37}$ Non-immunological components in breastfeeding that might possibly influence the development of the immune system are the anti-bacterial enzyme lysosym, oligosaccharides (prebiotics), hormones and growth factors. ${ }^{34-37}$

\section{Main subject of the present thesis}

The study described in this thesis is the PREVASC study on the primary prevention of asthma in children susceptible to the development of asthma.

The intervention used in the PREVASC study was based on a simultaneous lowering of exposure to environmental factors such as inhalant and food allergens, as well as ETS. It is expected that these measures will reduce the risk of developing asthma in susceptible children.

Those children susceptible to developing asthma on grounds of familial predisposition were included during their prenatal life. These children were randomly assigned to an intervention group $(n=213)$ or a control group $(n=219)$ and followed from prenatal life until the age of six. The main outcome was the asthma status at age six as categorized by a predefined algorithm (no asthma, possible asthma, current asthma). Categorization of their asthma status was based on spirometry and symptoms, as prospectively reported by parents and general practitioners. The exposure outcome was evaluated by standardized measurements and questionnaires completed by parents.

Duration of intervention offered is one of the secondary research questions the PREVASC study focuses on.

The designs of (ongoing) birth cohort studies on the primary prevention of asthma through reduction in exposure to house dust mite allergens is described in Chapter 2. Chapter 3 focuses on the description of the PREVASC study design. The abbreviation PREVASC (PREVention of Asthma in Children) refers not only to the current trial, but also to the research programme on prevention of asthma in children. Two RCTs and one cohort study are part of the PREVASC programme. The study described in this thesis is the first project initiated in this research programme. Another trial carried out by Gijsbers et al. is part of the programme as well, and assessed whether optimising the breastfeeding intervention as used in the PREVASC project would lead to increased adherence. 
The cohort study included in the PREVASC-program is carried out by Kuiper et.al. Data on the PREVASC-trial control group (children familial predisposed for asthma in first degree family members) and the cohort of non-familial predisposed children was evaluated on differences related to familial predisposition by comparing group outcome.

The objective of the Cochrane review described in Chapter 4 was to determine if there were any differences between the outcomes of two types of allergenreducing interventions for the primary prevention of asthma in children at high risk of developing asthma. The types of interventions we were interested in were interventions aimed at reducing exposure to 1) single allergen levels (mono-faceted intervention studies) and 2) multiple allergens simultaneously (multi-faceted intervention studies). Based on the theoretical consideration that asthma is a multi-factorial disease, it was hypothesized that prevention might only prove effective if most or all relevant environmental factors are simultaneously avoided.

Chapter 5 describes a pilot study on house dust mite allergen sampling in settled dust in homes with smooth floor coverings.

The results of a post-hoc research question on the influence of infections on the development of asthma, asthma symptoms and increase of total and specific $\mathrm{IgE}$ is described in Chapter 6. Episodes of the common cold and episodes of diarrhoea associated with fever were tested in this chapter as independent proxy variables for infection. The results did offer some information on the plausibility of the assumptions made in the hygiene hypothesis.

The outcomes at age four and six years are the subject of Chapter 7 . In this chapter the answer to the main research question is described concerning the effect of the PREVASC study intervention on preventing the development of asthma in susceptible children whose lung function measurements were taken at six years of age. Possible differences between these effects based on the differences in intervention duration have been described in this chapter as well (secondary research question). We also describe the results of a secondary research question on the influence on asthma outcome of the individual exposures the intervention was focussed on.

A general discussion is presented in Chapter 8. 


\section{References}

1. Halken S. Prevention of allergic disease in childhood: clinical and epidemiological aspects of primary and secondary allergy prevention. Pediatr Allergy Immunol 2004;15(S16):4-5,9-32.

2. Busse WW. Inflammation in asthma: the cornerstone of the disease and target of therapy. J Allergy Clin Immunol 1998;102:S17-22.

3. de Vries MP, van den Bemt L, Aretz K, Thoonen BP, Muris JW, Kester AD, Cloosterman S, van Schayck CP. House dust mite allergen avoidance and self-management in allergic patients with asthma: randomised controlled trial. Br J Gen Pract 2007;57:184-90.

4. von Mutius E. The burden of childhood asthma. Arch Dis Child 2000;82(S2):II2-5.

5. Blackman JA, Gurka MJ. Developmental and behavioural comorbidities of asthma in children. J Dev Behav Pediatr 2007;28:92-9.

6. Dahl R. Systemic side effects of inhaled corticosteroids in patients with asthma. Respir Med 2006;100:1307-17.

7. van Gent R, van Essen LE, Rovers MM, Kimpen JL, van der Ent CK, de Meer G. Quality of life in children with undiagnosed and diagnosed asthma. Eur J Pediatr 2007;166:843-8.

8. van Schayck CP, Smit HA. The prevalence of asthma in children: a reversing trend. Eur Respir J 2005;26:647-50.

9. Bjerg-Backlund A, Perzanowski MS, Platts-Mills T, Sandstrom T, Lundback B, Ronmark E. Asthma during the primary school ages--prevalence, remission and the impact of allergic sensitization. Allergy 2006;61:549-55.

10. Hermann C, De Fine Olivarius N, Host A, Begtrup K, Hollnagel H. Prevalence, severity and determinants of asthma in Danish five-year-olds. Acta Paediatr 2006;95:1182-90.

11. Martinez FD. Complexities of the genetics of asthma. Am J Respir Crit Care Med 1997; 156:S117-22.

12. Strachan DP. Hay fever, hygiene, and household size. BMJ 1989;299:1259-60.

13. Curotto de Lafaille MA, Lafaille JJ. CD4(+) regulatory T cells in autoimmunity and allergy. Curr Opin Immunol 2002;14:771-8.

14. Bernsen RM, Nagelkerke NJ, al-Ramadi BK. Does paternal antigen-induced secretion of interleukin-10 by $\mathrm{T}$ regulatory cells mediate the birth order effect? Med Hypotheses 2006; 67:740-3.

15. van den Broek HH, Damoiseaux JG, De Baets MH, Hupperts RM. The influence of sex hormones on cytokines in multiple sclerosis and experimental autoimmune encephalomyelitis: a review. Mult Scler 2005;11:349-59.

16. Del Giudice MM, Rocco A, Capristo C. Probiotics in the atopic march: highlights and new insights. Dig Liver Dis 2006;38(S2):S288-90.

17. Kalliomaki M, Salminen S, Arvilommi H, Kero P, Koskinen $\mathrm{P}$, Isolauri E. Probiotics in primary prevention of atopic disease: a randomised placebo-controlled trial. Lancet 2001;357:1076-9.

18. Dunstan JA, Mori TA, Barden A, Beilin LJ, Taylor AL, Holt PG, Prescott SL. Fish oil supplementation in pregnancy modifies neonatal allergen-specific immune responses and clinical outcomes in infants at high risk of atopy: a randomized, controlled trial. J Allergy Clin Immunol 2003;112:1178-84.

19. Das UN. Can perinatal supplementation of long-chain polyunsaturated fatty acids prevent atopy, bronchial asthma and other inflammatory conditions? Med Sci Monit 2006;12: RA99-111.

20. Peat JK, Mihrshahi S, Kemp AS, Marks GB, Tovey ER, Webb K,Mellis CM, Leeder SR. Threeyear outcomes of dietary fatty acid modification and house dust mite reduction in the Childhood Asthma Prevention Study. J Allergy Clin Immunol 2004;114:807-13.

21. Becker A, Watson W, Ferguson A, Dimich-Ward H, Chan-Yeung M. The Canadian asthma primary prevention study: outcomes at 2 years of age. J Allergy Clin Immunol 2004;113:650-6.

22. Chan-Yeung M, Ferguson A, Watson W, Dimich-Ward H, Rousseau R, Lilley M, Dybuncio A, Becker A. The Canadian Childhood Asthma Primary Prevention Study: outcomes at 7 years of age. J Allergy Clin Immunol 2005;116:49-55. 
23. Arshad SH, Bateman B, Matthews SM. Primary prevention of asthma and atopy during childhood by allergen avoidance in infancy: a randomised controlled study. Thorax 2003; 58:489-93.

24. Hide DW, Matthews S, Matthews L, Stevens M, Ridout S, Twiselton R, Gant C, Arshad SH. Effect of allergen avoidance in infancy on allergic manifestations at age two years. J Allergy Clin Immunol 1994; 93:842-6.

25. Hide DW, Matthews S, Tariq S, Arshad SH. Allergen avoidance in infancy and allergy at 4 years of age. Allergy 1996;51:89-93.

26. Schonberger HJ, Dompeling E, Knottnerus JA, Maas T, Muris JW, van Weel C, van Schayck $\mathrm{CP}$. The PREVASC study: the clinical effect of a multifaceted educational intervention to prevent childhood asthma. Eur Respir J 2005;25:660-70.

27. Marks GB, Mihrshahi S, Kemp AS, Tovey ER, Webb K, Almqvist C, Ampon RD, Crisafulli D, Belousova EG, Mellis CM, Peat JK, Leeder SR. Prevention of asthma during the first 5 years of life: a randomized controlled trial. J Allergy Clin Immunol 2006; 118:53-61.

28. Custovic A, Simpson BM, Murray CS, Lowe L, Woodcock A. The National Asthma Campaign Manchester Asthma and Allergy Study. Pediatr Allergy Immunol 2002;13(S15):32-7.

29. Mallet E, Henocq A. Long-term prevention of allergic diseases by using protein hydrolysate formula in at-risk infants. J Pediatr 1992;121:S95-100.

30. Zeiger RS, Heller S. The development and prediction of atopy in high-risk children: follow-up at age seven years in a prospective randomized study of combined maternal and infant food allergen avoidance. J Allergy Clin Immunol 1995;95:1179-90.

31. Maas T, Dompeling E, Schayck van CP, Muris J, Schonberger H, Wesseling G, Platts-Mills TAE, Knottnerus JA. Birth cohort studies on asthma development. Pediatr Asthma, Allergy, Immunol 2005; 18:201-15.

32. Stein RT, Holberg CJ, Sherrill D, Wright AL, Morgan WJ, Taussig L, Martinez FD. Influence of parental smoking on respiratory symptoms during the first decade of life: the Tucson Children's Respiratory Study. Am J Epidemiol 1999;149:1030-7.

33. Peat J, Bjorksten B. Primary and secondary prevention of allergic asthma. Eur Respir J Suppl 1998;27:28s-34s.

34. Schanler RJ, Oh W. Composition of breast milk obtained from mothers of premature infants as compared to breast milk obtained from donors. J Pediatr 1980;96:679-81.

35. Schanler RJ, Hurst NM, Lau C. The use of human milk and breastfeeding in premature infants. Clin Perinatol 1999;26:379-98, vii.

36. Penders J, Thijs C, Vink C, Stelma FF, Snijders B, Kummeling I, van den Brandt PA, Stobberingh EE. Factors influencing the composition of the intestinal microbiota in early infancy. Pediatrics 2006;118:511-21.

37. Schanler RJ, Garza C, Nichols BL. Fortified mothers' milk for very low birth weight infants: results of growth and nutrient balance studies. J Pediatr 1985;107:437-45. 


\section{chapter 2}

\section{Birth cohort studies on asthma development}
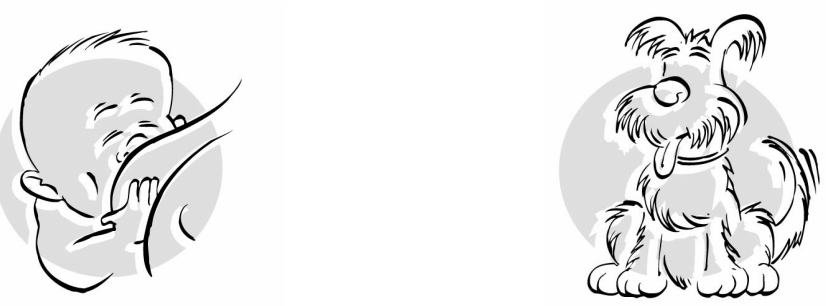

Maas T, Dompeling E, van Schayck CP, Muris JWM, Schönberger HJAM, Wesseling G, Platts-Mills TAE, Knottnerus JA Pediatric Asthma Allergy and Immunology 2005; 18:202-215 


\section{Abstract}

\section{Background}

In past decades the prevalence of asthma in children has substantially increased but this rising trend seems not tot have persisted into the twenty-first century. What could have caused the rise in prevalence is not well understood. With the expectation the prevalence may be decreased by reducing exposure to environmental factors, several birth cohort studies are being (or have been) carried out all over the world.

\section{Objectives}

Although many studies are still ongoing, decisions on data gathered by these studies will be of great importance for clinical practice. An overview of designs of available studies will be essential in constructing a meta-analysis.

We describe the similarities and differences between designs and variable sets of birth cohort studies focusing on the relationship between allergen exposure (solely or in combination with other environmental exposures) and development of childhood asthma. Also we evaluate which studies are particularly qualified for inclusion in a meta-analysis relating asthma prevention to environmental exposures.

\section{Method}

Ongoing birth cohort studies on allergen exposure (solely or in combination with other environmental exposures) in relation to asthma development in children were identified and all available information on study designs was collected and compared.

\section{Results}

From the 19 studies selected, 13 are prospective cohort studies and six are Randomised Clinical Trials (RCTs). All six RCTs included children during prenatal life whereas all but five prospective cohort studies started after birth. The exposures almost all studies focus on HDM allergens, pet allergens, food allergens and environmental tobacco smoke (ETS).

\section{Conclusions}

We concluded randomised clinical trials (RCTs) are best candidates for inclusion in a meta-analysis (an individual subject data analysis) in the future. Four RCTs we evaluated to be particularly suitable for inclusion in a meta-analysis on grounds of similarities in their study designs: The Isle of Wight study, the Canadian Allergy and Asthma Project (CAAP), the CAPS-study and the PREVASC-project. Of these four all recommend multifaceted interventions and differences in there designs are expected to be to overcome by stratification and restriction to homogeneous clusters. 


\section{Introduction}

In past decades the prevalence of asthma in children increased substantially ${ }^{1}$ but this rising trend seems not tot have persisted into the twenty-first century. ${ }^{2}$ What could have caused the rise in prevalence is not well understood.

Genetics as well as environmental factors play important parts in asthma development. $^{3}$ Children with genetic predisposition to develop asthma are therefore particularly at risk. Changing environmental factors could be an effective tool in preventing asthma.

The immune system and respiratory tract of humans mature and change greatly during early life, possibly even from the prenatal period on. ${ }^{4,5}$ Environmental factors may cause permanent changes in physiology of the respiratory tract and immune system, resulting in asthma. ${ }^{4,5}$ Which environmental factors are important in the aetiology of asthma in particular are not exactly known up until now. Some environmental factors are easy to adjust. Reducing exposure to certain environmental factors (tobacco smoke) have immediate health promoting effects. ${ }^{3,6,7}$ Birth cohort studies on asthma in children are carried out all over the world..$^{8-29}$ Some study one environmental factor, other studies follow a more multi-factorial approach. Designs vary from cohort studies to randomised clinical trials (RCTs). Cohort studies are of particular importance as explorative studies on the role of certain exposures. Knowledge resulting from these studies is used in RCTs primarily focused on effectiveness of specific interventions (mono- or multi-faceted). Meta-analysis of these RCT data will be valuable.

The current article does not describe a meta-analysis, as many studies did not yet publish the effects of certain exposures in relation to asthma development. Our aim here is to present an overview of similarities and differences of designs of ongoing birth cohort studies, including intervention studies, on the subject of the relationship between allergen exposure, (solely or in combination with other environmental exposures) and development of childhood asthma. This overview will be of use for carrying out a meta-analysis or collaborative individual subject data analysis in the future.

Next to presenting an overview of similarities and differences in designs of birth cohort studies focusing on the relationship between allergen exposure (solely or in combination with other environmental exposures) and development of childhood asthma, we evaluated which studies seem to be particularly qualified for inclusion in a meta-analysis relating asthma prevention to environmental exposures. 


\section{Method}

A Medline-database literature search was carried out for birth cohort studies focusing on allergen exposure (solely or in combination with other environmental exposures) in relation to asthma development in children. Keywords used were: birth cohort, asthma, and allergen*. Study centres we found as result of this literature search, as well as others known to the authors were approached by letter. An appendix containing all research groups we contacted was included, as well as a structured description of study designs of studies already published, prepared on base of literature. The description of study designs contained the research question(s), type of design RCT or cohort, recruitment (inclusion period, number of children included/needed and inclusion and exclusion criteria), as well as specifics about follow-up and variables measured in the scope of the study with special attention to the exposure variables. We asked the researchers of all groups contacted to check the appendix for completeness and, if not complete, to supply us with names of missed studies and corresponding researchers. All corresponding authors of selected studies were also asked to check and complete the description of their study design as drafted by the authors and to send back the revised description of their study design.

The final descriptions of study designs were used to compose chronologically numbered tables that contain the information on the study designs, recruitment, inclusion, and similarities and differences of the various studies. References of published study information used for gathering information are listed in Table 2.1. If no published information on the study design was available, no references are mentioned.

\section{Results}

The number of birth cohort studies relevant to this article on which information was available, is 19 of which six RCTs (four multi-faceted, two mono intervention studies) mainly focused on effectiveness, and 13 prospective cohort studies. Specifics on the studies included are presented in Table 2.1 Study designs, Table 2.2 Recruitment \& Inclusion and Table 2.3 Similarities \& Differences.

Birth cohort studies presented in the current article originated from all over the world except from the continents of Asia and Africa. The studies that started first are the prospective cohort studies named British cohort in 1976, Tucson children's Respiratory Study in 1980 and the Danish cohort (we indicated with A) in 1985. The ECA-study is the only included case control study nested in a cohort. 


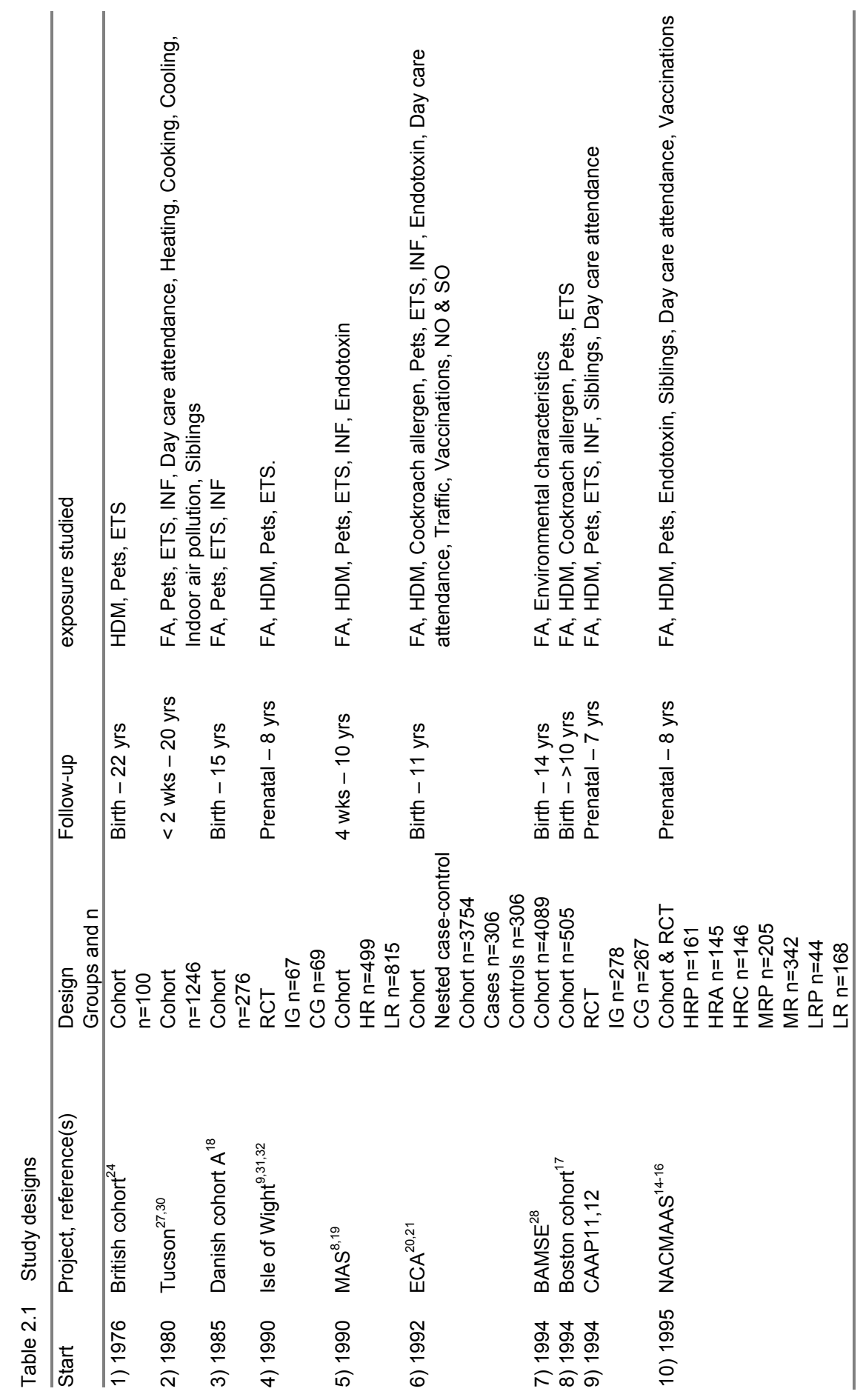




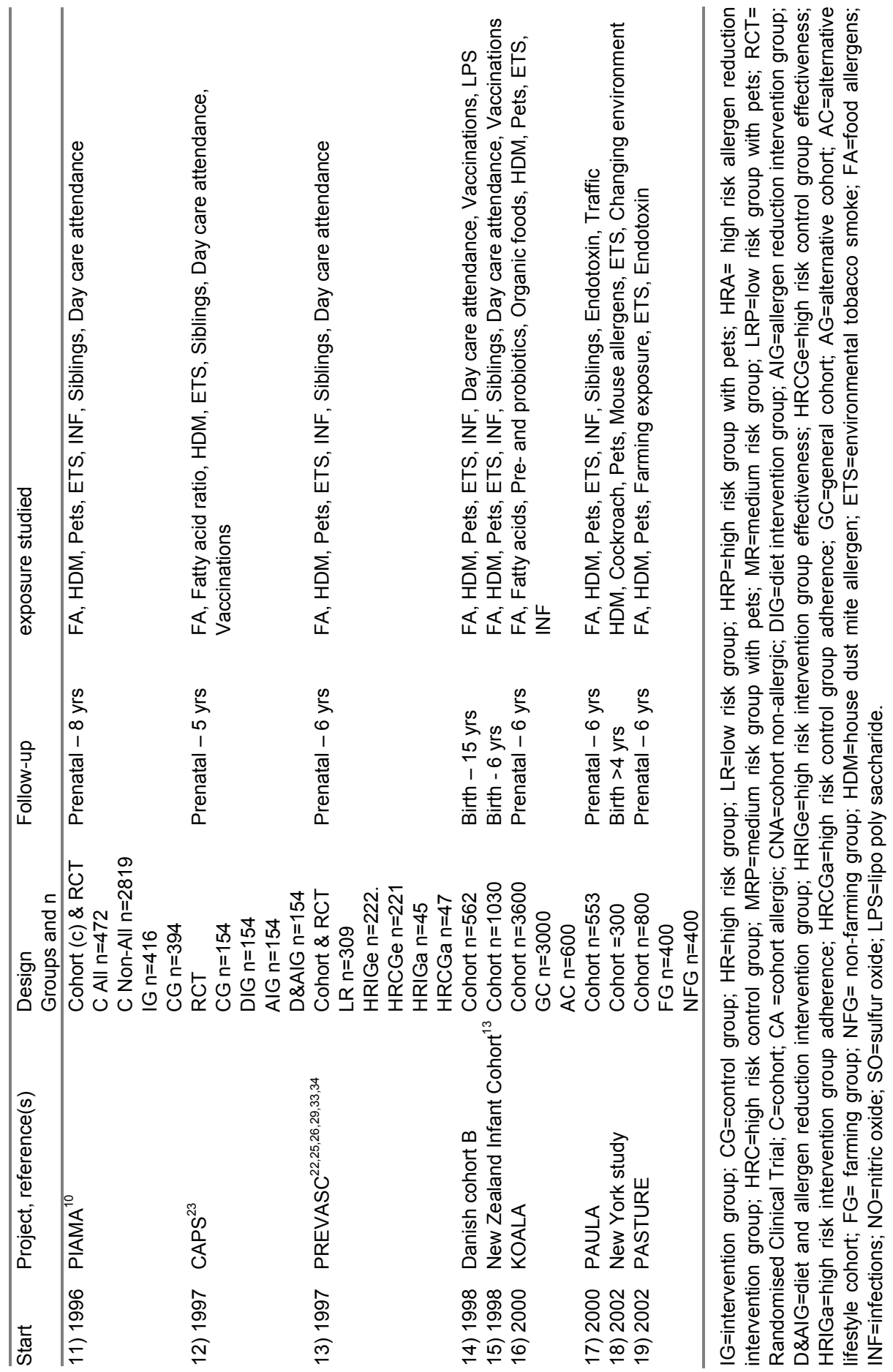




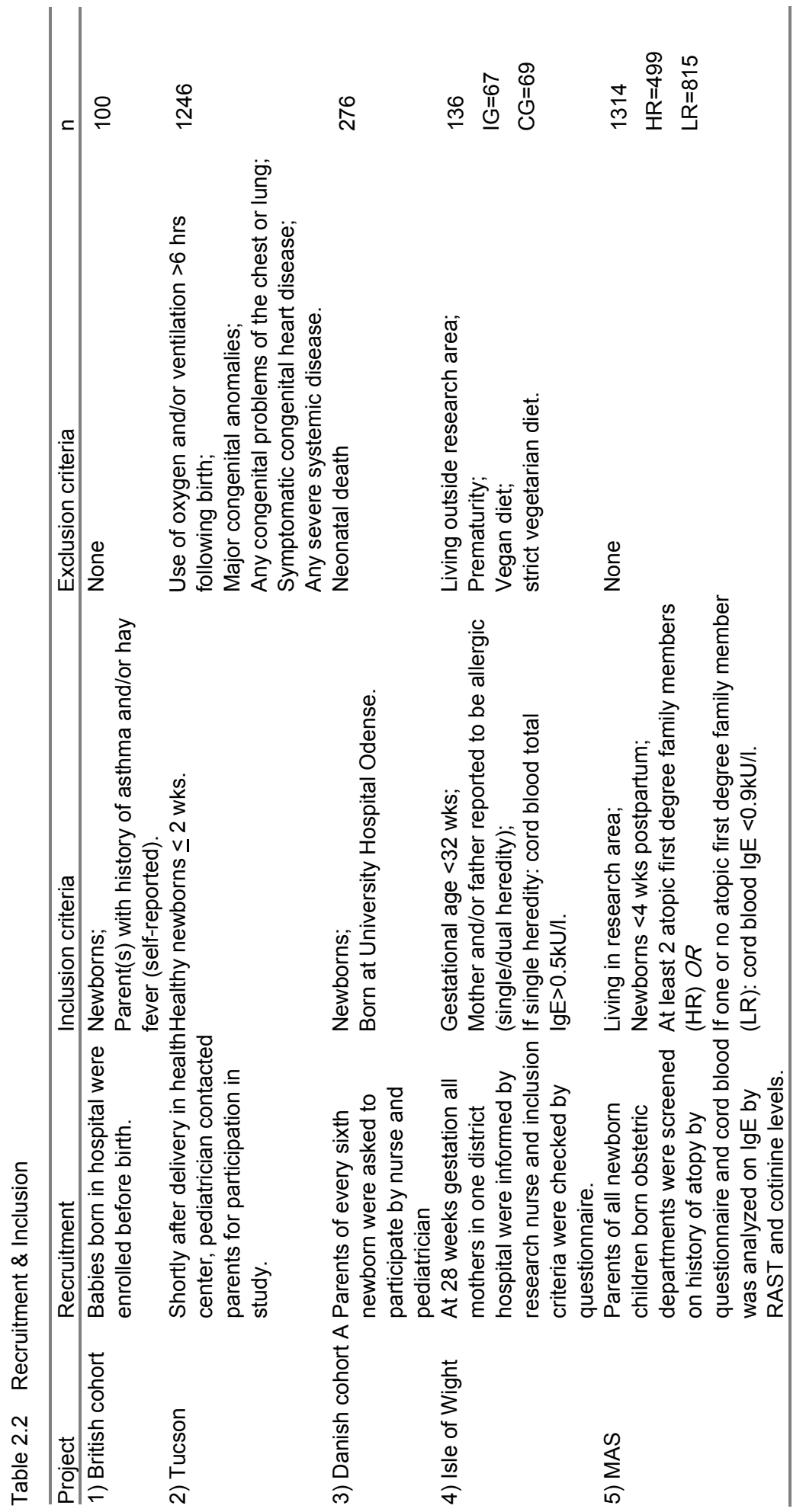




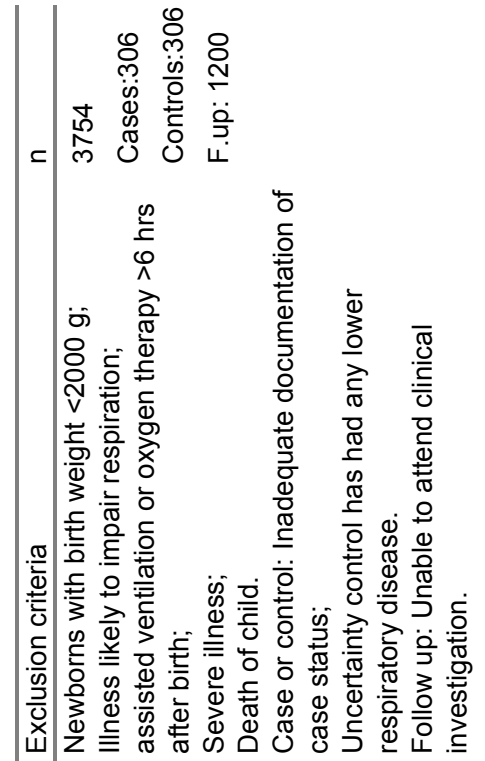

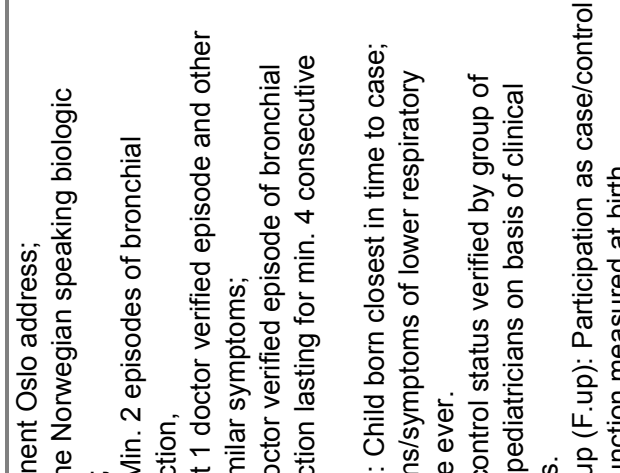

品 L

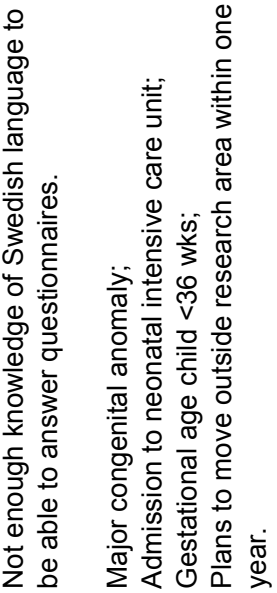

क

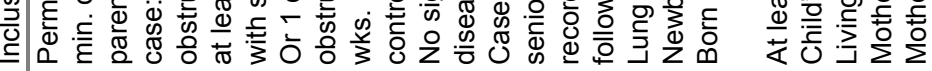

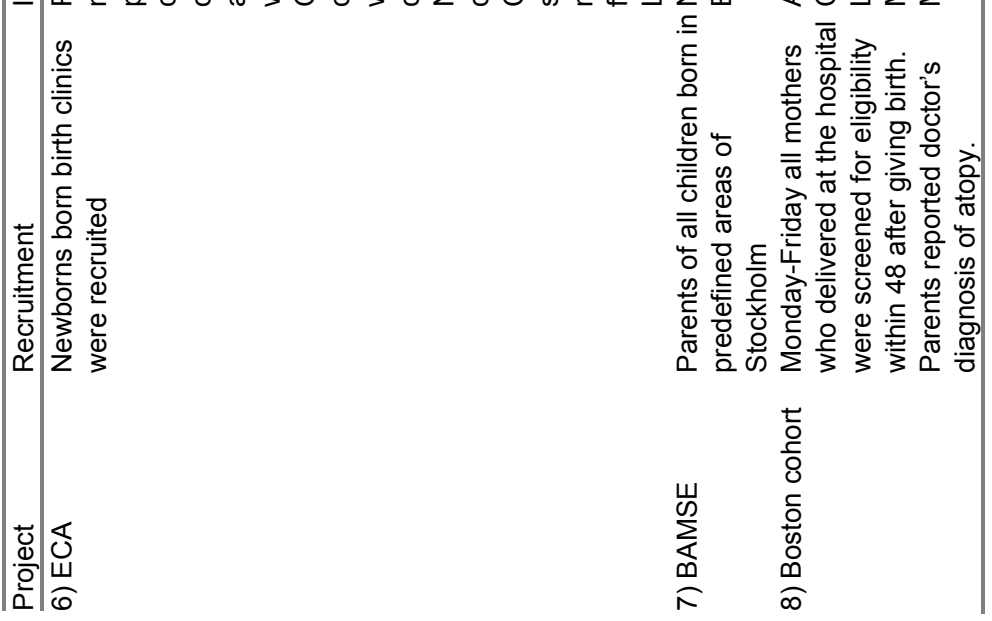




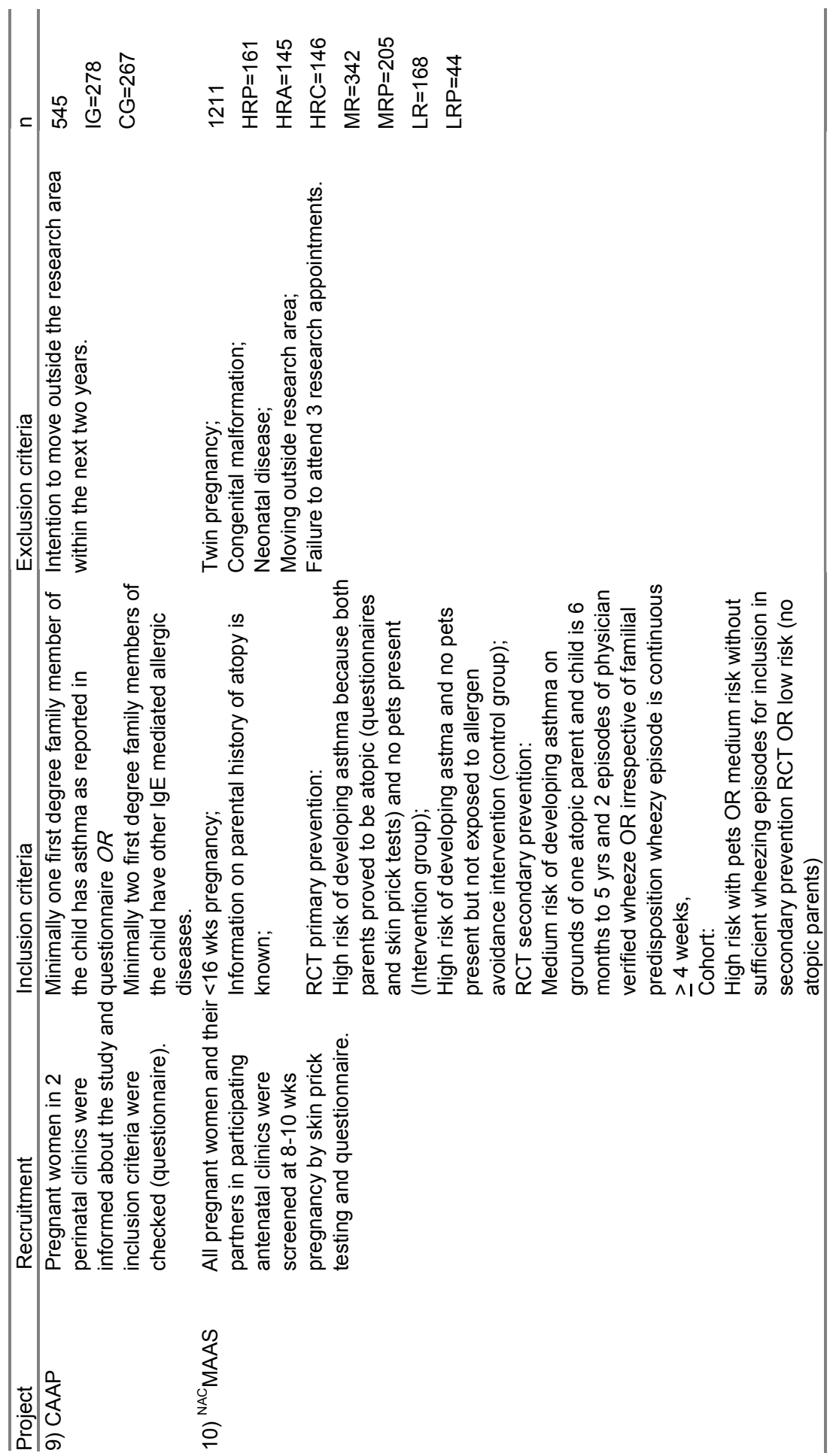




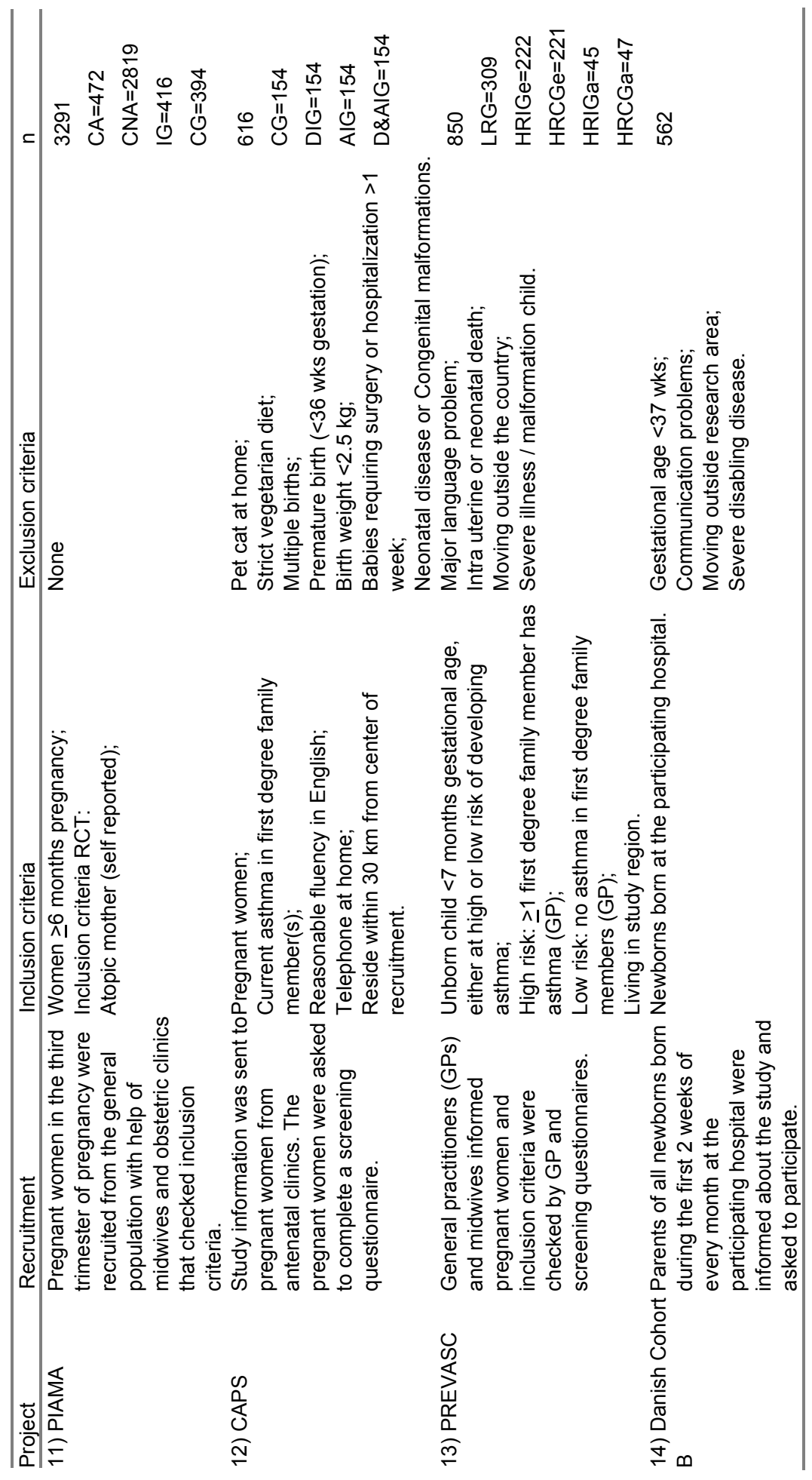




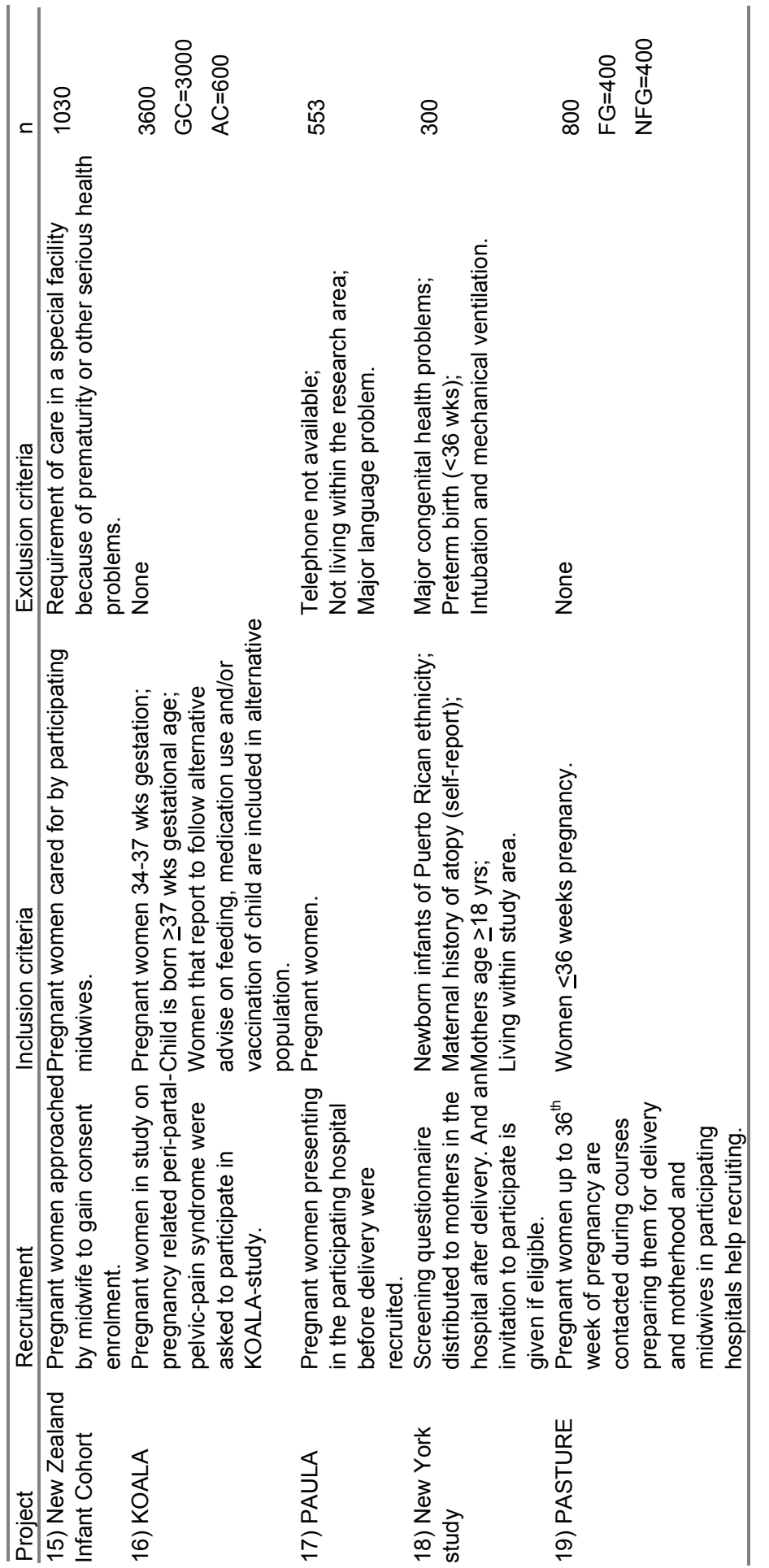


Table 2.3 Similarities \& differences

In this table a selection of topics studied in birth cohort studies is presented in the column named 'topic'. In the column 'is studied' the numbers of cohort studies that studied the corresponding topics are presented (according to the numbering as used in all tables in this article). In the column ' $n$ ' the number of studies that studied the corresponding topics are presented as N/total separate for prospective cohort studies (C) and RCTs (R)

\begin{tabular}{|c|c|c|}
\hline Topic & Is studied & $\mathbf{n}$ \\
\hline Intervention (RCT) & $4,9-13$ & 6 \\
\hline Multi-faceted intervention & $4,9,12,13$ & $4 / 6$ \\
\hline Mono intervention & 10,11 & $2 / 6$ \\
\hline Intervention \& cohort & $10,11,13$ & $3 / 6$ \\
\hline Intervention mainly focused on effectiveness & $4,9,11-13$ & $5 / 6$ \\
\hline Prospective cohort study & $1-3,5-8,14-19$ & 13 \\
\hline \multirow[t]{2}{*}{ TOPIC } & Is studied: & $\mathrm{N} /$ total \\
\hline & In RCTs (R) or Cohorts (C) & ) For $\mathrm{R}$ or $\mathrm{C}$ \\
\hline Inclusion of children during prenatal life & R: all C: $1,15-17,19$ & R: $6 / 6$ C: $5 / 13$ \\
\hline \multirow{2}{*}{$\begin{array}{l}\text { Presence or absence of family history of atopy is } \\
\text { inclusion criterion }\end{array}$} & R: all & $\mathrm{R}: 6 / 6$ \\
\hline & C: $1,5,8,18$ & C: $4 / 13$ \\
\hline \multirow{2}{*}{$\begin{array}{l}\text { Presence or absence of family history of asthma is } \\
\text { inclusion criterion }\end{array}$} & R: $10,12 \& 13$ & $\mathrm{R}: 3 / 6$ \\
\hline & C: none & C: $0 / 13$ \\
\hline $\begin{array}{l}\text { Asthma and/or atopy as diagnosed and reported by } \\
\text { medical doctor is inclusion criterion }\end{array}$ & R: 13 C: none & $\begin{array}{l}\text { R: } 1 / 6 \\
\text { C: } 0 / 13\end{array}$ \\
\hline \multirow{2}{*}{$\begin{array}{l}\text { Proven family history of atopy on grounds of } \lg E \\
\text { levels or skin prick testing in the scope of the study }\end{array}$} & $\mathrm{R}: 4,10$ & R: $2 / 6$ \\
\hline & C: none & C: $0 / 13$ \\
\hline \multirow{2}{*}{$\begin{array}{l}\text { Vegan or strict vegetarian or alternative diet is } \\
\text { inclusion or exclusion criterion }\end{array}$} & R: 4,12 & R: 2/6 \\
\hline & C: 16 & C: $1 / 13$ \\
\hline \multirow{3}{*}{$\begin{array}{l}\text { Usage of HDM impermeable covers } \\
\text { HDM allergens including Der } p 1 \text { measured in dust }\end{array}$} & R: 9-13 C: none & R: $5 / 6$ C: $0 / 13$ \\
\hline & R: 4, 9-11, 13 & R: $5 / 6$ \\
\hline & C: $1,5 \& 6,8,14-19$ & C: $9 / 13$ \\
\hline \multirow[t]{2}{*}{ HDM allergens Der $\mathrm{p} 1 \& \mathrm{f} 1$ measured in dust } & $\mathrm{R}: 9 \& 11$ & $\mathrm{R}: 2 / 6$ \\
\hline & C: $5,6,8,14,16,18,19$ & C: $7 / 13$ \\
\hline Breast feeding and formula feeding & R: all C: 2 \& 3, 5-8, 14-19 & R: $6 / 6$ C: $12 / 13$ \\
\hline \multirow[t]{2}{*}{ Introduction of solid foods } & R: 9-13 & R: $5 / 6$ \\
\hline & C: $3,6-8,14,15,17,19$ & C: $8 / 13$ \\
\hline \multicolumn{2}{|c|}{ Pet allergens measured in house dust samples Fel d1 R: 10, 11, 13} & $R: 3 / 6$ \\
\hline \& Can f1 & C: $5,6,14,16,19$ & C: $5 / 13$ \\
\hline \multirow[t]{2}{*}{ Of pet allergens solely Fel d1 measured in dust } & R: 9 & R: $1 / 6$ \\
\hline & C: $8,15,17,18$ & C: $4 / 13$ \\
\hline Pet exposure measured solely from parental report & R: none C: $1-3,16,19$ & R: 0/6 C: $5 / 13$ \\
\hline ETS exposure by self report parents & $\mathrm{R}$ and $\mathrm{C}$ : all & R: $6 / 6$ C: $13 / 13$ \\
\hline Cotinine levels measured as validation of ETS & R: none C: 2,5 & R: $0 / 62 / 13$ \\
\hline CO levels measured as validation of ETS & R: $13 \mathrm{C}:$ none & R: $1 / 6$ C: $0 / 13$ \\
\hline Nitric oxide exposure measured & R: none C: 6 & R: $0 / 6$ C: $1 / 13$ \\
\hline Fatty acid content of milk & R: 12 C: 16 & R: $1 / 6$ C: $1 / 13$ \\
\hline Endotoxin measured as exposure variable & R: none C: $15,17,19$ & R: 0/6 C: $3 / 13$ \\
\hline Special interest in pre and probiotics and organic & R: none & R: $0 / 6$ \\
\hline foods & C: 16 & C: $1 / 13$ \\
\hline Special interest in farming exposure & R: none C: 19 & R: 0/6 C: $1 / 13$ \\
\hline Special interest in traffic exposure & R: none C: 6 & R: $0 / 6$ C: $1 / 13$ \\
\hline Special interest in respiratory and/or gastro intestinal & R: 9 & $\mathrm{R}: 1 / 6$ \\
\hline infections objectified by laboratory analyses & C: $2 \& 16$ & C: $2 / 13$ \\
\hline
\end{tabular}




\section{Inclusion and exclusion criteria}

All RCTs started inclusion during prenatal life and used presence or absence of family history of atopy as inclusion criterion. More specific, the inclusion criterion presence or absence of family history of asthma is used in two of six RCTs here presented. Five of 13 cohort studies started inclusion during prenatal life, and four used presence or absence of atopy in first degree relatives as inclusion criterion. All other cohort studies did include children from the general population without selecting a high-risk group. The number of children included in the cohort studies varied from 100 in the British cohort to 4089 in the BAMSE study. Follow up in cohort studies varies from $>4$ years in the New York study to 22 years of age in the British cohort.

The use of a vegan or strict vegetarian or alternative diet was an inclusion criterion for a subgroup in the KOALA cohort but an exclusion criterion in the Isle of Wight and CAPS RCTs.

\section{Designs of specific RCTs}

Mono- and multi-faceted interventions: Mono-interventions are those interventions that include one measure, for example the use of house dust mite (HDM) allergen impermeable mattress encasings. Multi-faceted interventions include measures on a variety of exposures.

The nacMaas-study and the Dutch studies PREVASC and PIAMA are not only designed as RCT but have a cohort included in their design as well. These studies are not included in the total number of 13 prospective cohort studies as described in tables and results. The prospective cohorts in the studies PIAMA and nacMaas concern children from the general population, while in the PREVASC study, the prospective cohort is a low risk group.

\section{Isle of Wight study}

The Isle of Wight study started in 1990. One hundred thirty six children are followed from the prenatal period until the age of eight years. This study is a multi-faceted intervention study in which measures are focused on environmental tobacco smoke (ETS) exposure and food allergens as well as HDM allergens and pet allergens reduction. Extra attention is given to the food allergen intervention. The intervention is focused mainly on effectiveness, not efficacy, which makes the results of direct relevance for parents where implementation in daily life is concerned.

\section{The Canadian Allergy and Asthma Project (CAAP)}

This RCT again is a multi-faceted intervention study that is focused on reduction of exposure to indoor- (HDM and pets) and food allergens as well as ETS. Main 
goal of this study is establishing the effectiveness of the intervention. Five hundred forty-five children are being followed up from the prenatal period until the age of seven years.

\section{nacMAAS-study}

The nacMaas study is designed to study the efficacy of a HDM allergen avoidance intervention (mono intervention) in a high risk group (both parents are atopic) in which no pets are present from the time of inclusion as opposed to a group of high risk children not exposed to the allergen avoidance intervention. In total 291 children are included in this primary prevention part of the study and they are being followed up from the prenatal period until the age of 8 years. Efficacy and not effectiveness is the main focus of this intervention. Another mono intervention included is focused on the clinical effectiveness of corticosteroid use as compared to placebo medication in children at medium risk of developing atopy (one atopic parent). Children are allocated to the intervention group (fluticasone propionate) or control group (placebo medication) when they met inclusion criteria regarding number of wheezing episodes (stratified to treatment by exposure to ETS, pets exposure, maternal asthma and age of onset of wheeze). Early corticosteroid use is presumed to lessen the number of children that finally develop asthma (secondary prevention). None of the families included in the corticosteroid intervention part of the study are exposed to the allergen avoidance intervention. The total number of children at medium risk of developing atopy is 547 but not all of them were included in the secondary prevention study part because not all of them wheezed.

Next to these two RCTs the nacMaas-study contains a prospective cohort of children at low risk of developing atopy, children at medium risk without wheezing episodes and children at high risk with pets. All children in the nacMaas-study $(n=1065)$ are followed from the prenatal period until the age of eight years.

\section{Piama-study}

The Piama study is designed to study the clinical effect of the use of HDM allergen impermeable versus placebo covers on mattresses (mono intervention). This primary prevention intervention is mainly focused on effectiveness not efficacy and 810 children are followed from the prenatal period until the age of eight years. A total number of 3291 children are followed in two prospective cohorts (one of 472 children with atopic parent(s) and one of 2819 children with non-allergic parents) are part of the design as well. 


\section{CAPS-study}

The CAPS-study is designed not only as a multi-faceted intervention study focused on allergen avoidance as well as diet parameters $(n=308$, follow-up from prenatal period until age five years) but has included two mono interventions in the (factorial) design as well (each $n=308$, follow-up from prenatal period until age five years). One of these mono-interventions is focused on environmental allergen exposure and one includes only the diet-part of the multi-faceted intervention. Although composed of two mono intervention studies and one multi-faceted RCT, this study is included in the current article as multi-faceted intervention study as presented in the tables. All intervention parts of the study are focused mainly on effectiveness, not efficacy.

\section{PREVASC study}

This most recent started RCT as included in our tables (1997) can be distinguished from other designs as the effectiveness of two multi-faceted interventions is studied; one is focused on clinical effectiveness of the intervention ( $n=443$, follow-up from prenatal period until age six years) and one on the adherence to the intervention ( $n=92$, follow-up from prenatal period until age one year). In this study the general practitioner has a central role because he/she is involved in checking the inclusion criterion family history of asthma and registers all relevant outcome on symptoms and diagnoses of asthma and allergy prospectively. In the low risk cohort-part of the PREVASC-study 309 children are being followed-up from the prenatal period preferably until age 6 years.

\section{Indoor allergen exposure}

In all studies the exposure to HDM-allergens as well as allergens from cats and dogs are measured on grounds of questionnaire data and in 14 studies (five RCTs, nine cohorts) the HDM allergen Dermatophagoides Pteronyssinus (Der p1) exposure was also measured in dust samples. In nine studies (two RCTs, seven cohorts) the HDM allergen Dermatophagoides Farinae (Der f1) was measured in dust samples. Pet allergen exposure from cat (Fel d1) and/or dog (Can f1) is measured in dust samples in 13 out of 19 studies presented (four RCTs, nine cohorts).

\section{Food allergen exposure}

In all RCTs and in all cohort studies except for the British cohort, data on breast-feeding and formula feeding was measured using questionnaires. Time of introduction of solid foods is measured in 13 of 19 studies presented (five RCTs, eight cohorts). 


\section{Exposure to environmental tobacco smoke (ETS)}

In all studies the exposure to ETS is measured, at least by self-report of parents. Cotinine levels were measured as validation of parental reports in only two out of 19 studies (both prospective cohort studies). The PREVASC study is the only study that used carbon monoxide (CO) in exhaled air of mother and father expressed as $\% \mathrm{COHb}$ to validate the parental reports of smoking behaviour.

\section{Exposures seldom studied}

In cohort studies in particular, some parameters are less often studied. Exposure to Nitric Oxide for example is studied in only the ECA-study. Exposure to lipopolysaccharide (LPS) is another example of a seldom-studied parameter and is measured in only the KOALA study. Three of 13 cohort studies included exposure to endotoxin(s) in their study. This is the case in the New Zealand, PAULA and PASTURE cohorts, all studies that were started in 1998 or more recently. The PASTURE cohort is the only study with special interest in farming exposure. Special interest in vehicular (traffic) exposure is specific for the ECA-study.

Although all studies evaluate exposure to infections on basis of parental or general practitioners reports, only three studies (CAAP, Tuscon Respiratory Study and the KOALA cohort) measure exposure to respiratory- and gastrointestinal infections objectively by laboratory analysis.

The only seldom-studied parameter included in an RCT as part of an intervention is the Fatty Acid content of milk (CAPS-study). The KOALA-cohort study did also include this parameter.

\section{Discussion}

In this paper similarities and differences between designs and variable sets of birth cohort studies focusing on the relationship between allergen exposure (solely or in combination with other environmental exposures) and asthma development in children are described as basis for carrying out a meta-analysis in the future. Nineteen birth cohort studies were identified and their designs were compared. These studies concern RCTs as well as prospective cohort studies. These two different design types are both important. In cohort studies participants need not be selected as stringently as is the case in RCTs. Results of cohort studies can more often be translated to the general population what makes them suitable for finding out what exposures are of particular importance in asthma development. Results of cohort studies are often used as preliminary data on which RCTs can be based. RCTs have the advantage of yielding direct 
information on the effectiveness of interventions, of being substantially less biased, and of being more easily interpreted. However they usually have a more stringent inclusion policy and may thus have limited generalizability. RCTs probably are the best candidates for a meta-analysis.

Interventions on allergen reduction as presented in the current article that are used more often than others are multi-faceted interventions focused on exposure of high risk infants to indoor allergens (HDM- and pet allergens) as well as food allergens (focused on breastfeeding and/or hypoallergenic formula feeding and introduction of solid foods) and ETS. The studies, in which such an intervention is studied, although at some aspects slightly different, are the Isle of Wight study, CAAP, CAPS and PREVASC study. These studies might be suitable candidates for meta-analysis of multi-faceted interventions. All these studies use an intervention that aims at effectiveness more than efficacy, which makes the results of direct relevance for parents where implementation in daily life is concerned.

The differences in interventions studied in the four RCTs we considered as most suitable for inclusion in a meta-analysis concern mainly selection of highrisk children and the food allergen reduction part of multi-faceted interventions. In the CAPS and PREVASC study not presence of family history of atopy in first-degree relatives of the children, but more stringently, family history of asthma is used as inclusion criterion. The PREVASC study is the only RCT in which not only questionnaire data are used to screen eligible families on family history of asthma. In this study general practitioners recruited eligible families and checked this specific inclusion criterion. The Isle of Wight study based their inclusion criterion 'family history of atopy' initially on questionnaire data but if this indicated that no dual heredity was evident but only single heredity, total IgE in cord blood was measured as tool for determining eligibility for inclusion. In all selected RCTs but The Isle of Wight study single heredity of atopy or asthma in first-degree relatives is the primary inclusion criterion. Concerning the diet part of the intervention in the Isle of Wight study exclusive breast-feeding is advised in the first nine months, whereas this is the case until minimally four (CAAP) or six months (CAPS and PREVASC) in the other comparable RCTs. Use of partially hydrolysed formula feeding, as alternative for breast-feeding is advised in three of the four selected RCTs (CAAP, CAPS, PREVASC). Mothers of infants included in The Isle of Wight-study as well as the CAAP and CAPSstudy were advised to follow dietary instructions given as part of the intervention during the period they breast-fed their child. The dietary advice for mothers is very different because they are, respectively, focused on reduction of food allergen exposure of the children in the Isle of Wight and CAAP-study whereas achieving a desirable fatty acid ratio of breast milk by using fatty acid supplements is the main goal of the dietary intervention in the CAPS-study. In the PREVASC study no specific measures are advised on the mother's diet. 
Concerning the introduction of solid foods parents were advised to delay introduction until their children had reached the age of six months in the CAAP, CAPS and PREVASC study. In the Isle of Wight study solid foods were to be introduced stepwise where potentially allergenic foods were concerned, starting with introduction at age nine months. Before the age of nine months nonallergenic foods were allowed to be used without dietary restrictions other than usual care.

HDM impermeable covers were supplied as part of the intervention in all but one (The Isle of Wight study) of the four considered RCTs.

Interventions on allergen reduction more often used than others are multifaceted interventions focused on exposure of high-risk infants to indoor allergens as well as food allergens and ETS.

We conclude that the RCTs most suitable for inclusion in a meta-analysis or a collaborative individual subject data analysis on birth cohort studies focusing on allergen exposure (solely or in combination with other environmental exposures) in relation to asthma development are The Isle of Wight study, CAAP, CAPS and the PREVASC study. A few important differences in study design of these four studies might cause some difficulties when starting the pooling of data in a meta-analysis, but these difficulties are expected to be to overcome by making use of stratification and restriction to homogeneous clusters.

As most studies did not publish their results on asthma outcome yet, the metaanalysis could not be exerted at this moment in time. 


\section{References}

1. Warner JA, Jones AC, Miles EA, Colwell BM, Warner JO. Prenatal origins of asthma and allergy. Ciba Found Symp 1997;206:220-8; discussion 228-32.

2. Mommers M, Gielkens-Sijstermans C, Swaen GM, van Schayck CP. Trends in the prevalence of respiratory symptoms and treatment in Dutch children over a 12 year period: results of the fourth consecutive survey. Thorax 2005;60:97-9.

3. Mutius E. Towards prevention. Lancet 1997;350(SII):14-7.

4. Doershuk CF. The respiratory system-development of the lung. Nelson textbook of pediatrics. 13 ed. Philadelphia: Saunders CO, 1987: 854-942.

5. Hong R. Immunity, allergy and related diseases-the immunologic system. Nelson Textbook of pediatrics. 13 ed. Philadelphia: Saunders CO, 1987: 455-543.

6. Martinez FD. Maternal risk factors in asthma. Ciba Foundation Symposium 1997:233-9.

7. Doull IJM, Holgate S. Asthma: Early predisposing factors. Br Med Bull 1997;53:71-80.

8. Bergmann RL, Bergmann KE, Lau-Schadensdorf S, Luck W, Dannemann A, Bauer CP, Dorsch W, Forster J, Schmidt E, Schulz J, Wahn U. Atopic diseases in infancy. The German multicenter atopy study (MAS-90). Pediatr Allergy Immunol 1994;5(S6):19-25.

9. Arshad SH, Bateman B, Matthews SM. Primary prevention of asthma and atopy during childhood by allergen avoidance in infancy: a randomised controlled study. Thorax 2003; 58:489-93.

10. Brunekreef B, Smit J, de Jongste J, Neijens H, Gerritsen J, Postma D, Aalberse R, Koopman L, Kerkhof M, Wijga A, van Strien R. The prevention and incidence of asthma and mite allergy (PIAMA) birth cohort study: design and first results. Pediatr Allergy Immunol 2002;13(S15): 55-60.

11. Chan-Yeung M, Ferguson A, Dimich-Ward H, Watson W, Manfreda J, Becker A. Effectiveness of and compliance to intervention measures in reducing house dust and cat allergen levels. Ann Allergy Asthma Immunol 2002;88:52-8.

12. Chan-Yeung M, Manfreda J, Dimich-Ward H, Ferguson A, Watson W, Becker A. A randomized controlled study on the effectiveness of a multifaceted intervention program in the primary prevention of asthma in high-risk infants. Arch Pediatr Adolesc Med 2000;154:657-63.

13. Crane J, Duignan M, Fishwick D, Fitzharris P, Kelly R, Lane J, McDonald C, Siebers R, Town $\mathrm{I}$, Wickens $\mathrm{K}$, Wilson $\mathrm{H}$. House dust mite allergen exposure is associated with sensitisation and asthma in New Zealand. ERS 2002, Stockholm: 117s.

14. Custovic A, Simpson BM, Murray CS, Lowe L, Woodcock A. The National Asthma Campaign Manchester Asthma and Allergy Study. Pediatr Allergy Immunol 2002;13(S15):32-7.

15. Custovic A, Simpson BM, Simpson A, Kissen P, Woodcock A. Effect of environmental manipulation in pregnancy and early life on respiratory symptoms and atopy during first year of life: a randomised trial. Lancet 2001;358:188-93.

16. Custovic A, Simpson BM, Simpson A, Hallam C, Craven M, Brutsche M, Woodcock A. Manchester Asthma and Allergy Study: low-allergen environment can be achieved and maintained during pregnancy and in early life. J Allergy Clin Immunol 2000;105:252-8.

17. Gold DR, Burge HA, Carey V, Milton DK, Platts-Mills T, Weiss ST. Predictors of repeated wheeze in the first year of life: the relative roles of cockroach, birth weight, acute lower respiratory illness, and maternal smoking. Am J Respir Crit Care Med 1999;160:227-36.

18. Host A, Halken S, Jacobsen HP, Christensen AE, Herskind AM, Plesner K. Clinical course of cow's milk protein allergy/intolerance and atopic diseases in childhood. Pediatr Allergy Immunol 2002;13(S15):23-8.

19. Lau S, Illi S, Sommerfeld C, Niggemann B, Bergmann R, von Mutius E, Wahn U. Early exposure to house-dust mite and cat allergens and development of childhood asthma: a cohort study. Multicentre Allergy Study Group. Lancet 2000;356:1392-7.

20. Lodrup Carlsen KC. The environment and childhood asthma (ECA) study in Oslo: ECA-1 and ECA-2. Pediatr Allergy Immunol 2002;13(S15):29-31.

21. Lodrup Carlsen KC, Carlsen KH, Nafstad P, Bakketeig L. Perinatal risk factors for recurrent wheeze in early life. Pediatr Allergy Immunol 1999;10:89-95. 
22. Maas T, Schönberger H, Dompeling E, Muris J, Knottnerus JA, Schayck van C. Effectiveness of the PREVASC-intervention on reducing the allergen and environmental tobacco smoke exposure. Prim Care Resp J 2002;11:66.

23. Mihrshahi S, Peat JK, Webb K, Tovey ER, Marks GB, Mellis CM, Leeder SR. The childhood asthma prevention study (CAPS): design and research protocol of a randomized trial for the primary prevention of asthma. Control Clin Trials 2001;22:333-54.

24. Rhodes HL, Thomas P, Sporik R, Holgate ST, Cogswell JJ. A birth cohort study of subjects at risk of atopy: twenty-two-year follow-up of wheeze and atopic status. Am J Respir Crit Care Med 2002;165:176-80.

25. Schönberger HJ, Maas T, Dompeling E, Pisters J, Sijbrandij J, van der Heide S, Knottnerus AJ, van Weel C, van Schayck OP. Environmental exposure reduction in high-risk newborns: where do we start? Ann Allergy Asthma Immunol 2003;91:531-8.

26. Schönberger $\mathrm{H}$, Schayck $\mathrm{C} v$. Prevention of asthma in genetically predisposed children in primary care-from clinical efficacy to a feasible intervention programme. Clin. Exp. Allergy 1998;28:1325-31.

27. Taussig LM, Wright AL, Morgan WJ, Harrison HR, Ray CG. The Tucson Children's Respiratory Study. I. Design and implementation of a prospective study of acute and chronic respiratory illness in children. Am J Epidemiol 1989;129:1219-31.

28. Wickman M, Kull I, Pershagen G, Nordvall SL. The BAMSE project: presentation of a prospective longitudinal birth cohort study. Pediatr Allergy Immunol 2002;13(S15):11-3.

29. Gijsbers B, Mesters I, Knottnerus JA, Legtenberg AHG, Schayck van CP. Factors influencing breastfeeding practices and postponement of solid food to prevent allergic disease in high-risk children: results from an explorative study. Patient Education and Counseling 2004.

30. Taussig LM, Wright AL, Holberg CJ, Halonen M, Morgan WJ, Martinez FD. Tucson Children's Respiratory Study: 1980 to present. J Allergy Clin Immunol 2003;111:661-75; quiz 676.

31. Arshad SH, Matthews S, Gant C, Hide DW. Effect of allergen avoidance on development of allergic disorders in infancy. Lancet 1992;339:1493-7.

32. Arshad SH, Hide DW. Effect of environmental factors on the development of allergic disorders in infancy. J Allergy Clin Immunol 1992;90:235-41.

33. Gijsbers B, Mesters I, Legtenberg A, Knottnerus JA, Schayck van CP. Development and evaluation of an educational intervention targeted at optimising adherence with measures to prevent asthma in children with a familial allergic predisposition. ERS 2002, Stockholm: 329s.

34. Kuiper S, Maas T, van Schayck CP, Muris JW, Schönberger HJ, Dompeling E, Gijsbers B, van Weel C, Knottnerus JA; PREVASC group. The primary prevention of asthma in children study: design of a multifaceted prevention program. Pediatr Allergy Immunol 2005;16:321-31. 


\section{Chapter 3}

Prevention of asthma in children (PREVASC):

study: design of a multi-faceted prevention program

Kuiper S, Maas T, van Schayck CP, Muris JWM, Schönberger HJAM, Dompeling E, Gijsbers B, van Weel C, Knottnerus JA, on behalf of the PREVASC group.

Pediatr Allergy and Immunol 2005;16;321-331 


\section{Abstract}

The PREVASC study addresses the primary prevention of asthma in infants and small children. The objective of this study is to investigate whether a multifaceted prenatally started intervention strategy in high-risk infants leads to a decrease in the occurrence of (severe) asthma and whether a refinement of the prevention strategy leads to an increase in the adherence to the prevention program.

The primary prevention program includes house dust mite impermeable bed coverings, education on breastfeeding, hypoallergenic feeding, timing of introduction of solid food, and smoking cessation.

Eight hundred and eighty-eight infants were prenatally included. By the time of inclusion the mothers were 3-7 months pregnant. Twenty seven infants were excluded from the study and 18 dropped out. Of the remaining 843 infants 535 had a first-degree familial predisposition of asthma (high-risk group), whereas a reference group of 308 (162 boys) infants was not predisposed for asthma in the first degree (low-risk group). To evaluate the (cost-) effectiveness of the preventive intervention, 222 (118 boys) infants of the high-risk group allocated to the intervention group and 221 (112 boys) allocated to a control group are followed-up. The low-risk infants serve as controls to evaluate the predictive value of high risk ( $1^{\text {st }}$ degree familial predisposition of asthma). The infants are followed from the prenatal stage until they reach the age of six years. The remaining 92 highrisk infants were included in an optimised randomised clinical adherence trial' (RCAT). Of these 92 infants 45 (20 boys) were allocated to an intervention group and 47 (24 boys) to a control group. Until now all infants have been followed for at least 1 year. 


\section{Introduction}

Childhood asthma, a chronic disease of the airways, is predominantly newly diagnosed in infants and small children. Asthma is the main cause of school absence, ${ }^{1,2}$ nvolves high costs and is known to reduce the quality of life of children and their parents. During the last decades there has been a substantial increase in the prevalence of asthma worldwide, ${ }^{3,4}$ which emphasizes the need to prevent its development. It is generally thought that genetic as well as environmental factors are involved in the development of asthma. ${ }^{5,6}$ Since it is not yet possible to influence the genetic factors, prevention programs should focus on influencing the environmental factors. There are reasons to believe that the first signs of sensitisation occur already in the prenatal stage by the interaction between the maternal environment and the foetus. ${ }^{7}$ Therefore it is important to start intervention in the prenatal stage. Several primary prevention studies are being performed, and are still in progress. In most primary prevention studies only one ${ }^{8-10}$ intervention was tested whereas in others two single interventions with or without a factorial design were tested, ${ }^{11-13}$ which may lead to underestimation of the effect of prevention. To our knowledge there are three multifaceted primary prevention studies, ${ }^{14-16}$ in which several interventions are combined into one program and compared to one other modality, like usual care.

We report on the objectives and the design of the PREVASC (Prevention of Asthma in Children) program, a research program focused on primary prevention of asthma in children. The objectives of this program are to estimate the predictive value of a positive family history of asthma assessed in the prenatal period by the general practitioner (GP) for the development of childhood asthma and, to assess the effectiveness of a prenatally started multifaceted primary prevention program focused on reducing the exposure to indoor- and food allergens and environmental tobacco smoke in children at high-risk of developing asthma. Furthermore it will be assessed whether the duration of the prevention program has any effect on the development of asthma as measured at six years of age and whether optimising the intervention leads to increased adherence. Finally the health-economic benefits of high-risk identification and primary prevention of asthma will be assessed.

\section{Research plan}

\section{General design}

Our study comprised of three parts, one observational cohort and two intervention studies. 
To assess the clinical effectiveness of the PREVASC prevention program, a randomised clinical prevention trial (RCPT) was started in a group of prenatally selected high-risk infants. Additionally a cohort of prenatally selected low-risk infants was composed for a natural history study, to assess the clinical course of asthma and allergies in high- and low risk children and to assess the predictive value of 'high-risk'. To be able to identify whether (the parents of) the infants were compliant to the prevention program, the adherence to the intervention was evaluated. In addition, to get a better insight into the determinants of adherence and to improve the preventive program, a 'focus' group approach was applied in a subgroup of trial participants. In addition an 'optimised randomised clinical adherence trial' (RCAT) was evaluated in a newly recruited group of prenatally selected infants with a family history of asthma. Cost-effectiveness of the prevention program will be studied on the basis of the RCPT, taking adherence aspects and validity of screening into account.

In the participants section a general description will be given of how the participants were included in the study. In the section concerning the intervention studies and the natural history study the outline of both intervention studies and the natural history study will be described.

\section{Participants}

The infants were recruited prenatally when their mothers were in their first two trimesters of pregnancy. The community based recruitment started in January 1997 and continued until February 2000. For the RCPT this was performed by the primary caregivers (GP and midwives) and by advertisements. For the natural history study recruitment was exclusively performed by the GP, whereas for the optimised RCAT recruitment was performed by midwifes and by advertisements. These complementary ways of recruitment were necessary to include 888 participants.

'High-risk' was defined as 'at least one first-degree family member (i.e. the pregnant woman, the biological father of the unborn child or a sibling) suffering from GP registered asthma', whereas 'low-risk' was defined as 'absence of GP registered asthma in first-degree family members'. Asthma was defined according to the International Classification of Primary Care (ICPC) ${ }^{17}$ as recurrent episodes of reversible acute bronchial obstruction with wheeze and/or dry cough. This was checked by the GP and screening questionnaires.

For the RCPT, the natural history study and the RCAT, a family was excluded from the study when there was intra-uterine or neonatal death, major language problems, serious birth defects (illness or malformation) and moving abroad. 


\section{Intervention studies}

In the following specific elements of the various study parts are described. Thereafter aspects that relate to all the three study parts are presented together.

\section{Randomised Clinical Prevention Trial}

The goal of this study was to assess the effectiveness of (the duration of) a prenatally started multi-faceted primary prevention program in children at high risk for development of asthma. The study was designed to follow the high-risk children until they reach the age of six. By that time lung function measurement can reliably be performed which makes an objective diagnosis of asthma possible.

\section{Recruitment}

In the first part of the study (the period from the prenatal stage until the age of two) 476 pregnant women were included (Figure 3.1) and after randomisation equally divided over two study groups: an intervention group and a control group. Four hundred forty three of the descendants could be followed up, 222 (118 boys) of the intervention group and 221 (112 boys) of the control group.

\section{Intervention first part}

The intervention started prenatally in order to reach a low house dust mite and pet allergen exposure level at the time the child was born. In addition, the intervention focused on avoidance of prenatal and postnatal passive smoking and on avoidance of food allergens postnatal.

House dust mite (HDM) reduction intervention started before the $7^{\text {th }}$ month of pregnancy. This intervention consisted of advice on ventilation and cleaning as well as application of HDM impermeable covers on the parents and children's bed. To prevent exposure to pet allergens, the advice was given to keep pets outdoors from the $6^{\text {th }}$ month of pregnancy. Smoking intervention consisted of advice on smoking cessation of the mother as early as possible in pregnancy and no smoking of the father as well as the mother in the presence of the baby postnatal. Dietary intervention contained advice on exclusively breastfeeding (and/or hypo-allergen formula feeding) for at least six months and postponing introduction of solid food until six months after birth. The high-risk control group received usual care, according to the Guidelines of the Dutch College of General Practitioners that include criteria based diagnosis and an initial treatment with short acting bronchodilatators and when no adequate asthma control is achieved with a step-up approach with inhaled corticosteroids in increasing dosage. ${ }^{18}$ 
42 | Chapter 3

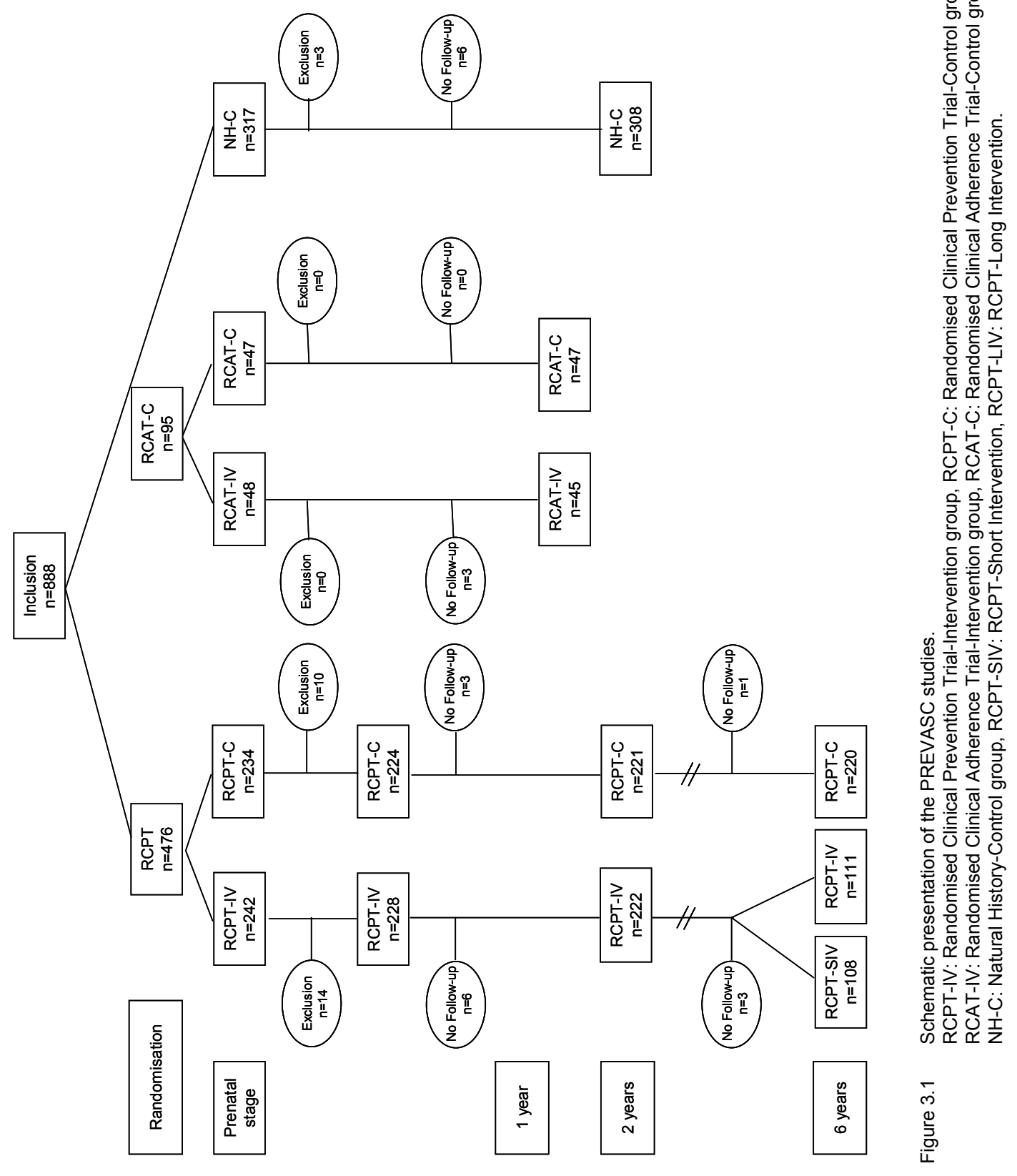


Intervention second part

In the second part of the study the children are followed from 2-6 years of age. For this part of the study the children in the original intervention group were randomised again into two groups (Figure 3.1). One group was no longer exposed to advice and HDM impermeable mattress covers (short intervention period). The other group still received an intervention program focused on diminishing allergen and irritant exposure and to keep on using HDM impermeable mattress covers (extended intervention period). The children that participated in the control group in the first part continue to participate in the control group in the second part of the study as well and receive usual care.

\section{Randomised Clinical Adherence Trial}

Eighty-one randomly selected families who participated in the intervention group of the RCPT received an invitation letter for a focus-group interview to investigate which determinants influenced the actual adherence behaviour. For these interviews the stepwise guidelines of van Assema et al. ${ }^{19}$ for conducting a focus-group interview were used.

\section{Recruitment focus groups}

43 Households (59 participants) were scheduled to meet at times and locations that might be convenient for the participants. Six groups were mixed as to gender and one group was formed containing only fathers, since fathers may have different opinions and thoughts about breastfeeding and postponement of solid foods, which might be missed in the presence of women.

\section{Focus group observations}

The reasons for the 39 non-respondent households were: interested, but date not convenient $(n=14)$, no time $(n=7)$, location of interview not convenient $(n=3)$, on holiday $(n=2)$, unknown $(n=13)$. No significant differences were found between the participation and no-participation group with respect to level of education, feeding behaviour and family history of asthma.

On the basis of the results of the determinant-analysis, a refined prevention educational program was developed.

\section{Recruitment refined intervention program}

In this phase, the RCAT study, 92 families expecting a child at high-risk of developing asthma were selected. 45 Families received intervention and 47 served as controls (Figure 3.1).

\section{Intervention measures}

Educational materials and the educational message to be provided orally by research nurses were refined. The effect of the renewed education on the degree of adherence with the advised measures (HDM, tobacco smoke, breastfeeding) was evaluated in the next phase of this program. 


\section{Natural history study}

The goal of this study was to assess the clinical course of asthma and allergies in high- and low risk children and to assess the predictive value of 'high-risk'.

\section{Recruitment}

For this study 317 pregnant women, without asthma or asthma in the family, were included. 308 (162 boys) of the descendants could be followed up (Figure 3.1).

\section{Clinical follow-up}

The clinical course of symptoms of asthma and allergies over the first two years of life in this cohort was compared with the RCPT control group in order to evaluate the predictive value of the family history. The low-risk infants received usual care.

\section{Randomisation, withdrawal procedures and blinding}

For those women who were recruited by the GP, randomisation was done in ZIP-code clusters on practice level and not on patient level in order to minimize the probability of exchange of information between participants.

Families who were recruited by the GP were screened by the GP. Families who were recruited for the RCPT study by midwives or advertisements completed questionnaires concerning the presence of asthma in their family. Whenever it turned out from the questionnaire that there was no asthma in a 'high-risk' family, the GP was contacted. When the GP confirmed the questionnaire outcome, the family was withdrawn from the study. Families who were recruited by midwives or advertisements for the RCAT study were screened by the GP. For the RCPT and the RCAT, blinding for group assignment was performed at family level.

\section{Economical evaluation}

To assess the efficiency of 'high-risk' identification and the cost effectiveness of the PREVASC intervention, it will be evaluated whether cost savings (associated with a decrease in (severe) asthma cases and an increase in the quality of life) outweigh the costs of the prevention program. This will be achieved in two steps, by assessing 1. the cost-effectiveness of the PREVASC intervention among the high-risk group, and 2. the cost-effectiveness of the complete PREVASC RCPT program including the high-risk identification at the population level. Ad (1): It will be assessed what the PREVASC preventive intervention with its allied costs yields in terms of health outcome and savings concerning direct and indirect health related costs in the high-risk group. For this purpose, the clinical course, health outcomes and costs of primary prevention of asthma (PREVASC intervention group) will be compared with the 
clinical course, health outcomes and costs of usual care (PREVASC control group). To be able to assess the cost-effectiveness, information concerning the direct and indirect medical costs, the costs of the prevention program, and the health status of the children will be collected, using information from questionnaires that will be completed by the parents. By use of these questionnaires the use of medical care and products can be measured. This use will be valued against national recommended prices ${ }^{20}$ to be able to determine the costs of care per individual. The health status of the children will be measured using the ISAAC questionnaire as well as the morbidity registration of the GP. When the children have reached the age of six years asthma will objectively be diagnosed, which makes it possible to express asthma as a dichotomous variable. In this way the costs per asthma case prevented can be determined.

Ad (2): By connecting the results ad (1) (the cost-effectiveness of the primary prevention program among the high-risk group) to the predictive value of the 'high-risk' identification, the costs of prenatal high-risk identification, the prevalence of a positive family history, and the observed disease course in the absence of intervention in both the high-risk control group and the low-risk group, the expected cost-effectiveness of the complete PREVASC program at population level will be assessed.

\section{Data collection procedure}

\section{Symptoms/diagnosis}

First-degree familial predisposition of asthma was determined by the GP and by use of a questionnaire directly at the inclusion. For the RCPT and the 'natural history' study this was re-evaluated at the age of two years. Information on complaints, diagnosis, laboratory tests and medication concerning respiratory morbidity are prospectively registered by the GP at every consultation. Additionally the parents were asked to complete weekly reports, concerning questions about asthma related complaints, OTC medication and asthma related costs, during the first two years of the infants' life and to complete the internationally accepted ISAAC questionnaire ${ }^{21}$ yearly until the age of six (Tables 3.1, 3.2, 3.3). 
Table 3.1 Timing schedule of the measurements of environmental exposures and outcome variables in the RCPT.

\begin{tabular}{|c|c|c|}
\hline Time point & Environmental exposures & Outcome measures \\
\hline $\begin{array}{l}3^{\text {rd }}-5^{\text {th }} \text { month of } \\
\text { pregnancy }\end{array}$ & $\begin{array}{l}\text { - Dust (derp1, canf1, feld1) } \\
\text { - Humidity } \\
\text { - CO }\end{array}$ & \\
\hline $\begin{array}{l}7^{\text {th }}-8^{\text {th }} \text { month of } \\
\text { pregnancy (intervention } \\
\text { group only) }\end{array}$ & $\begin{array}{l}\text { - Humidity } \\
\text { - CO }\end{array}$ & \\
\hline $\begin{array}{l}\text { Weekly from birth } \\
\text { until } 2 \text { years of age }\end{array}$ & $\begin{array}{l}\text { - Type of feeding } \\
\text { - Day-care attendance }\end{array}$ & $\begin{array}{l}\text { - Asthma related complaints } \\
\text { - Health-care consumption } \\
\text { - Absence from work }\end{array}$ \\
\hline $\begin{array}{l}\text { Around } 4 \text { weeks after } \\
\text { birth (intervention group } \\
\text { only) }\end{array}$ & $\begin{array}{l}\text { - Humidity } \\
\text { - CO }\end{array}$ & \\
\hline $3-5$ days after birth & & - Total lgE \\
\hline 6 months after birth & - Type of feeding & $\begin{array}{l}\text { - Amount of wheezing episodes in the last } 6 \text { months } \\
\text { - Nightly wheezing in the last } 6 \text { months } \\
\text { - Nocturnal coughing in the last } 6 \text { months } \\
\text { - Doctors diagnosed asthma } \\
\text { - Constitutional eczema } \\
\text { - Food allergy } \\
\text { - Non-viral rhinitis } \\
\text { - Other upper airway infections } \\
\text { - Other lower airway infections } \\
\text { - Dyspnoea }\end{array}$ \\
\hline $\begin{array}{l}\text { 7-9 months after birth } \\
\text { (exactly } 1 \text { year after first } \\
\text { dust sampling) }\end{array}$ & $\begin{array}{l}\text { - Dust (derp1, canf1, feld1) } \\
\text { - Humidity } \\
\text { - CO }\end{array}$ & \\
\hline 1 year after birth & $\begin{array}{l}\text { - Humidity } \\
\text { - CO } \\
\text { - ETS } \\
\text { - Exposure to house dust mite } \\
\text { and animal allergens }\end{array}$ & $\begin{array}{l}\text { - Amount of wheezing episodes in the last } 6 \text { months } \\
\text { - Nightly wheezing in the last } 6 \text { months } \\
\text { - Nocturnal coughing in the last } 6 \text { months } \\
\text { - Total lgE } \\
\text { - Specific IgE (derp1, feld1, canf1) } \\
\text { - Doctors diagnosed asthma } \\
\text { - Constitutional eczema } \\
\text { - Food allergy } \\
\text { - Non-viral rhinitis } \\
\text { - Other upper airway infections } \\
\text { - Other lower airway infections } \\
\text { - Dyspnoea }\end{array}$ \\
\hline 2 years after birth & $\begin{array}{l}\text { - Humidity } \\
\text { - CO }\end{array}$ & $\begin{array}{l}\text { - Amount of wheezing episodes in the last year } \\
\text { - Nightly wheezing in the last year } \\
\text { - Nocturnal coughing in the last year } \\
\text { - Specific IgE (derp1, feld1, canf1) } \\
\text { - Doctors diagnosed asthma } \\
\text { - Total lgE } \\
\text { - Constitutional eczema in the last year } \\
\text { - Food allergy in the last year } \\
\text { - Non-viral rhinitis in the last year } \\
\text { - Other upper airway infections } \\
\text { - Other lower airway infections } \\
\text { - Dyspnoea }\end{array}$ \\
\hline
\end{tabular}




\begin{tabular}{|c|c|c|}
\hline Time point & Environmental exposures & Outcome measures \\
\hline 3 years after birth & $\begin{array}{l}\text { - ETS } \\
\text { - Allergen exposure }\end{array}$ & $\begin{array}{l}\text { - Amount of wheezing episodes in the last year } \\
\text { - Nightly wheezing in the last year } \\
\text { - Nocturnal coughing in the last year } \\
\text { - Doctors diagnosed asthma } \\
\text { - Doctors diagnosed cows milk allergy } \\
\text { - Other food related allergies diagnosed by a doctor } \\
\text { - Doctors diagnosed inhalation allergies } \\
\text { - Non-viral rhinitis in the last year } \\
\text { - Other upper airway infections in the last year } \\
\text { - Other lower airway infections in the last year } \\
\text { - Dyspnoea in the last year }\end{array}$ \\
\hline 4 years after birth & $\begin{array}{l}\text { - Dust (derp1, canf1, feld1) } \\
\text { - Humidity } \\
\text { - CO } \\
\text { - ETS }\end{array}$ & $\begin{array}{l}\text { - Tidal airway resistance (microRint) } \\
\text { - Amount of wheezing episodes in the last year } \\
\text { - Nightly wheezing in the last year } \\
\text { - Nocturnal coughing in the last year } \\
\text { - Specific IgE (derp1, feld1, canf1) } \\
\text { - Doctors diagnosed asthma } \\
\text { - Doctors diagnosed cows milk allergy } \\
\text { - Other food related allergies diagnosed by a doctor } \\
\text { - Doctors diagnosed inhalation allergies } \\
\text { - Total IgE } \\
\text { - Non-viral rhinitis in the last year } \\
\text { - Other upper airway infections in the last year } \\
\text { - Other lower airway infections in the last year } \\
\text { - Dyspnoea in the last year }\end{array}$ \\
\hline 5 years after birth & $\begin{array}{l}\text { - ETS } \\
\text { - Allergen exposure }\end{array}$ & $\begin{array}{l}\text { - Amount of wheezing episodes in the last year } \\
\text { - Nightly wheezing in the last year } \\
\text { - Nocturnal coughing in the last year } \\
\text { - Doctors diagnosed asthma } \\
\text { - Doctors diagnosed cows milk allergy } \\
\text { - Other food related allergies diagnosed by a doctor } \\
\text { - Doctors diagnosed inhalation allergies } \\
\text { - Non-viral rhinitis in the last year } \\
\text { - Other upper airway infections in the last year } \\
\text { - Other lower airway infections in the last year } \\
\text { - Dyspnoea in the last year }\end{array}$ \\
\hline 6 years after birth & $\begin{array}{l}\text { - ETS } \\
\text { - Allergen exposure }\end{array}$ & $\begin{array}{l}\text { - Asthma } \\
\text { - Specific IgE (derp1, feld1, canf1) }\end{array}$ \\
\hline
\end{tabular}

\section{Mite collection and humidity}

Dust samples were collected (Table 3.1) to measure the compliance with the intervention advice in the intervention group (RCPT and RCAT) and to correlate the intensity of exposure to inhalant allergens with respiratory morbidity (RCPT, RCAT and natural history study) and to evaluate the validity of using the lowrisk infants as control group. The collection was performed in a standardized manner. Samples were taken, using a vacuum cleaner (Bosch BSA1100 1300 Watt) with a special cassette (ALK Abello) containing a Whatman GF/F $70 \mathrm{~mm}$ 
filter, from the living room floor $\left(2 \times 1 \mathrm{~m}^{2}\right)$, the parents' mattress $\left(1 \mathrm{~m}^{2}\right)$ and the mattress of the baby (whole mattress). The samples were kept on $4^{\circ} \mathrm{C}$ until they were analysed for mite, cat and dog allergens by use of ELISA. ${ }^{22-24}$ Humidity was measured by use of a hygrometer in the parents' bedroom and, when in use, the infants' bedroom.

Table 3.2 Timing schedule of the measurements of environmental exposures and outcome variables in the Natural history study.

\begin{tabular}{|c|c|c|}
\hline Time point & Environmental exposures & Primary (1) and secondary (2) outcome measures \\
\hline $\begin{array}{l}\text { Weekly from birth until } 2 \\
\text { years of age }\end{array}$ & - Day-care attendance & $\begin{array}{l}\text { - Asthma related complaints } \\
\text { - Health-care consumption } \\
\text { - Absence from work }\end{array}$ \\
\hline 3-5 days after birth & & - Total IgE \\
\hline 6 months after birth & - Type of feeding & $\begin{array}{l}\text { - Amount of wheezing episodes in the last } 6 \text { months } \\
\text { - Nightly wheezing in the last } 6 \text { months } \\
\text { - Nocturnal coughing in the last } 6 \text { months } \\
\text { - Doctors diagnosed asthma } \\
\text { - Constitutional eczema in the last } 6 \text { months } \\
\text { - Food allergy in the last } 6 \text { months } \\
\text { - Non-viral rhinitis in the last } 6 \text { months } \\
\text { - Other upper airway infections } \\
\text { - Other lower airway infections } \\
\text { - Dyspnoea }\end{array}$ \\
\hline 7-9 months after birth & - Dust (derp1, canf1, feld1) & \\
\hline 1 year after birth & $\begin{array}{l}\text { - ETS } \\
\text { - Exposure to house dust mite } \\
\text { and animal allergens }\end{array}$ & $\begin{array}{l}\text { - Amount of wheezing episodes in the last } 6 \text { months } \\
\text { - Nightly wheezing in the last } 6 \text { months } \\
\text { - Nocturnal coughing in the last } 6 \text { months } \\
\text { - Doctors diagnosed asthma } \\
\text { - Constitutional eczema in the last } 6 \text { months } \\
\text { - Food allergy in the last } 6 \text { months } \\
\text { - Non-viral rhinitis in the last } 6 \text { months } \\
\text { - Other upper airway infections } \\
\text { - Other lower airway infections } \\
\text { - Dyspnoea }\end{array}$ \\
\hline 2 years after birth & & $\begin{array}{l}\text { - Amount of wheezing episodes in the last year } \\
\text { - Nightly wheezing in the last year } \\
\text { - Nocturnal coughing in the last year } \\
\text { - Doctors diagnosed asthma } \\
\text { - Constitutional eczema in the last year } \\
\text { - Food allergy in the last year } \\
\text { - Non-viral rhinitis in the last year } \\
\text { - Other upper airway infections } \\
\text { - Other lower airway infections } \\
\text { - Dyspnoea }\end{array}$ \\
\hline
\end{tabular}

\section{Type of feeding and ETS exposure}

The parents completed questionnaires concerning the type of feeding, environmental allergen exposure and environmental tobacco smoke (ETS) exposure. 
Table 2.3 Timing schedule of the measurements of environmental exposures and outcome variables in the RCAT.

\begin{tabular}{|c|c|c|}
\hline Time point & Environmental exposures & Primary and secondary outcome measures \\
\hline $3^{\text {rd }}$ month of pregnancy & $\begin{array}{l}\text { - Dust (derp1) } \\
\text { - Humidity } \\
\text { - CO }\end{array}$ & \\
\hline $7^{\text {th }}$ month of pregnancy & $\begin{array}{l}\text { - Humidity } \\
\text { - CO }\end{array}$ & \\
\hline $2-3$ weeks after birth & $\begin{array}{l}\text { - Humidity } \\
\text { - CO }\end{array}$ & - Compliance with dietary advices \\
\hline 6 months after birth & $\begin{array}{l}\text { - Dust (derp1) } \\
\text { - Humidity } \\
\text { - CO }\end{array}$ & $\begin{array}{l}\text { - Compliance with dietary advices } \\
\text { - Amount of wheezing episodes in the last } 6 \text { months } \\
\text { - Nightly wheezing in the last } 6 \text { months } \\
\text { - Nocturnal coughing in the last } 6 \text { months } \\
\text { - Doctors diagnosed asthma } \\
\text { - Constitutional eczema in the last } 6 \text { months } \\
\text { - Non-viral rhinitis in the last } 6 \text { months } \\
\text { - Other upper airway infections } \\
\text { - Other lower airway infections }\end{array}$ \\
\hline 1 year after birth & $\begin{array}{l}\text { - Humidity } \\
\text { - CO }\end{array}$ & $\begin{array}{l}\text { - Amount of wheezing episodes in the last } 6 \text { months } \\
\text { - Nightly wheezing in the last } 6 \text { months } \\
\text { - Nocturnal coughing in the last } 6 \text { months } \\
\text { - Doctors diagnosed asthma } \\
\text { - Constitutional eczema in the last } 6 \text { months } \\
\text { - Non-viral rhinitis in the last } 6 \text { months } \\
\text { - Other upper airway infections } \\
\text { - Other lower airway infections }\end{array}$ \\
\hline
\end{tabular}

\section{$\lg E$}

Blood samples were collected in the RCPT and natural history group to measure the concentration of total immunoglobulin $\mathrm{E}(\mathrm{lgE})$. $\lg \mathrm{E}$ was analysed using the method of Aalberse et al. ${ }^{25}$

\section{Carbon Monoxide}

To study the compliance with the smoking advice in the intervention group, to detect spontaneous smoking cessation by the mother during pregnancy in the control groups and to correlate the intensity of exposure to smoke with respiratory morbidity, Carbon Monoxide was measured in expired air.

\section{Tidal airway resistance and lung function}

To assess the tidal airway resistance by means of an interrupter technique, microRint measurements are performed when the children are four and six years of age, while lung function (FEV1, FVC), reversibility on $\beta 2$-mimetics (change in FEV1 after $600 \mu \mathrm{g}$ salbutamol through a spacer) and bronchial responsiveness to increasing doses of histamine (PC20) will be assessed when the children reach the age of six years. 


\section{Statistical aspects}

\section{Power calculation}

The power calculation of the RCPT study was based on a study of Saarinen et al. ${ }^{26}$, the only longitudinal asthma prevention trial that reported results on objective asthma outcome by the time the PREVASC trial was designed. In the Saarinen study it was shown that breastfeeding as preventive measure, in a comparable group of infants as in the RCPT, resulted in a $30 \%$ reduction in the development of asthma. This percentage was chosen in the RCPT as the minimum clinically relevant difference. A minimum amount of 194 infants in the intervention as well as in the control group was required to reduce the asthma incidence with at least $30 \%$ (taking a type I error of 0.05 and a power of 0.80 into account).

The power calculation of the RCAT was based on the number of parents required to measure the compliance of the parents with the optimised prevention program. Based on literature studies ${ }^{27}$ an effect-size of 0.46 was expected. With a minimum of 38 participants in each group a power of 0.80 could be reached (taking a type I error of 0.05 and a drop out of at the most $18 \%$ into account).

The power calculation of the natural history study was based on a sample size that would be large enough to show a statistically significant difference, between the high- and low-risk groups, in the development of asthma at six years of age. ${ }^{28}$ An odds ratio of at least two was assumed for the association of a first-degree family history of asthma with the risk to develop asthma in descendants. Taking a cumulative asthma incidence of $10 \%$, a maximum drop out of $10 \%$ and a type I error of 0.05 into account a power of 0.80 could be reached with an addition of 308 low-risk infants.

\section{Data analysis}

In the RCPT compliance will be evaluated in terms of reduced exposure to HDM, cat and dog allergens as well as reduced smoking and increased breastfeeding.

Differences in proportions between groups in bi-variate analyses will be tested with the $x^{2}$ test. Differences in means for continuous normally distributed variables are analysed using the Student's t-test. Multiple logistic and linear regression techniques are used for multivariate analyses with a fixed follow-up time, while Cox proportion hazard analyses will be performed when the followup time is variable.

Concerning the cost-effectiveness one way sensitivity analyses regarding important assumptions will be performed. In addition, statistical uncertainty regarding the cost-effectiveness estimates will be assessed using non parametric bootstrap resample methods. By means of the analysis of effect 
modification it will be evaluated whether the effect differs between subgroups. For most analyses a p-value smaller than 0.05 is considered as significant. Statistical analyses are performed using the Statistical Package for the Social Sciences (SPSS) version 10.0.

\section{Ethics approval and informed consent}

Ethical approval for this study was obtained from the ethics committees of the participating institutes. All participants gave written, informed consent.

\section{Preliminary results of the RCPT}

Preliminary results indicate that infants in the intervention group were significantly more breast-fed $(p=0.001)$ and/or received significantly more hypoallergenic formula feeding than infants in the control group. The first intake of solid food was significantly more often postponed to the age of six months in the intervention group compared to the control group $(p=0.001)$. No difference was found in the intervention compared to the control group concerning the exposure to tobacco smoke. Measurement of environmental exposure to house dust mite, cat and dog allergens was performed during pregnancy (baseline) and exactly one year later. One year after baseline measurements the concentration of house dust mite, cat and dog allergens, measured at the living room floor (except for dog allergens), the mattress of the parents and the mattress of the baby, were statistically significant decreased in the intervention group, but not in the control group. ${ }^{29}$

\section{Discussion}

The PREVASC study is a longitudinal prospective birth cohort study with its focus on the development of a primary prevention program for asthma in children. The main goal of the PREVASC study is to assess the effectiveness of (the duration of) an intervention program focused on reducing the exposure to indoor and food allergens and environmental tobacco smoke in children at highrisk of developing asthma. This is investigated in a RCPT. To be able to define to what extent first-degree familial predisposition for asthma is predictive for the development of asthma, a natural history study was started with children with a high- or low-risk of developing asthma.

Whether the participants are compliant to the prevention program and whether optimising the intervention leads to an increase in adherence is investigated in a RCAT. The health-economic benefits of 'high-risk' identification and primary prevention of asthma will be assessed on the basis of the RCPT, taking compliance aspects and validity of screening into account. 
There are few prospective birth cohort studies in which the effect of primary prevention of asthma is studied. ${ }^{8-16}$ Most of these studies focus on one or two preventive measures. ${ }^{8-13}$ To our knowledge there are four multi-facetted intervention studies, the Isle of Wight study ${ }^{30}$ the study of Halken et al. ${ }^{14}$, the CAAP ${ }^{15}$ study and SPACE $^{16}$ study. The PREVASC study differs from these studies in several aspects. In contrast to these studies a low-risk group was included in the PREVASC study, which enables an estimation of the high-risk prediction and in addition facilitates the evaluation of the external validity of the primary prevention study. In the PREVASC study 'high-risk' was defined as presence of asthma in $1^{\text {st }}$ degree family members. This definition was chosen since asthma in $1^{\text {st }}$ degree family members is expected to be the most predictive risk factor for the development of asthma in descendants ${ }^{31}$ although this is often based on retrospective and cross-sectional data. We expect the strongest effect of the intervention program in children with a first-degree hereditary predisposition of asthma. Concerning the intervention program, in the PREVASC study the dietary advices for the baby were exclusively breastfeeding for at least six months as well as delay of solid food until six months of age. ${ }^{32}$ The mother was not advised to follow a diet. Since the goal of the prevention program was that it should be easy to implement into practice, prevention was based on easily applicable intervention measures. Recruitment was performed predominantly by the GP. The Dutch health care system is organized in such a way that the GP keeps complete medical records of all registered families which makes the GP the most appropriate health care worker to assess whether an unborn child is at high-risk of developing future asthma.

There are however some limitations to our study. Although there is a welldefined cleaning regimen some exposure could not be avoided. However by keeping the cleaning regimen close to daily practice, the HDM reduction that will be reached is realistic and can easily be obtained. In general, we expect that people will better adhere to the intervention program when the intervention is as close to daily practice as possible. In studying a multi-faceted intervention strategy it is impossible to directly investigate the effectiveness of all single intervention measures in all possible combinations (like would be done in a factorial design), since this should result in a sample size that is far too large for in one trial. Moreover synergistic effects can be missed in comparing single interventions only, while the most pronounced clinical effect possible should be expected from a combined intervention. Finally the GP and the parents could not be blinded to the intervention, which might result into classification bias and reporting bias with respect to medical records and questionnaires in relation to health outcome. Therefore it is important to follow the cohort until the children have reached the age of six years, at which age lung function measurement can be performed. 


\section{References}

1. Austin JB, Selvaraj S, Russell G. Childhood asthma in the highlands of Scotland - Morbidity and school absence. Scott Med J 2004;49:18-21

2. Vermeire PA, Rabe KF, Soraiano JB, Maier WC. Asthma control and differences in management practices across seven European countries. Respir Med 2002;96:142-9.

3. Peat JK, van den Berg RH, Green WF, Mellis CM, Leeder SR, Woolcock AJ. Changing prevalence of asthma in Australian children. BMJ 1994:308:1591-6.

4. Rona RJ, Chin S, Burney PG. Trends in the prevalence of asthma in Scottish and English primary school children 1982-92. Thorax 1995:50:992-3.

5. Heinzmann A, Deichmann KA. Genes for atopy and asthma. Curr Opinion Allergy Clin Immunol 2001:1:387-92.

6. Von Mutius E. The environmental predictors of allergic disease. J Allergy Clin Immunol 2000:105:9-19.

7. Warner JA, Jones CA, Jones AC, Warner JO. Prenatal origins of allergic disease. J All Clin Immunol 2000:105:S493-6.

8. Zeiger RS, Heller S, Mellon MH. Effect of combined maternal and infant food-allergen avoidance on development of atopy in early infancy: a randomized study. J All Clin Immunol 1989:84:72-89.

9. Custovic A, Simpson BM, Murray CS, Lowe L, Woodcock A. The national asthma campaign Manchester asthma and allergy study. J All Clin Immunol 2000:105:252-8.

10. Brunekreef B, Smit J, de Jongste J, Neijens H, Gerritsen J, Postma D, Aalberse R, Koopman $\mathrm{L}$, Kerkhof M, Wilga $A$, van Strien $R$. The prevention and incidence of asthma and mite allergy (PIAMA) birth cohort study: Design and first results. Pediatr Allergy Immunol 2002:13(S15): 55-60.

11. Arshad SH, Matthews S, Gant C, Hide DW. Effect of allergen avoidance on allergic disorders in infancy. Lancet 1992:339:1439-97.

12. Marini A, Agosti M, Motta G, Mosca F. Effects of a dietary and environmental prevention programme on the incidence of allergic symptoms in high atopic risk infants: three years' follow-up. Acta Paediatr Suppl 1996:414:1-21.

13. Mihrshahi S, Peat JK, Webb K, Tovey ER, Marks GB, Mellis CM, Leeder SR. The Childhood Asthma Prevention Study (CAPS): Design and research protocol of a randomised trial for the primary prevention of asthma. Control Clin Trials 2001:22:333-54.

14. Halken S, Host A, Hansen LG, Osterballe O. Effect of an allergy prevention programme on incidence of atopic symptoms in infancy. A prospective study of 159 "high-risk" infants. Allergy 1992:47:545-53.

15. Chan-Yeung M, Manfreda J, Kimich-ward H, Ferguson A, Watson W, Becker A. A Randomized Controlled Study on the Effectiveness of a Multifaceted Intervention Program in the Primary Prevention of Asthma in High-Risk Infants. Arch Pediatr Adolesc Med 2000:154:657-63.

16. Halmerbauer G, Gartner C, Schierl M et al. Study on the prevention of allergy in children in Europe (SPACE): allergic sensitization in children at 1 year of age in a controlled trial of allergen avoidance from birth. Pediatr Allergy Immunol 2002:13(S15):47-54.

17. The WONCA classification committee. ICPC-2. International Classification of Primary Care. Oxford University Press, 1998.

18. Dirksen WJ, Geijer RMM, de Haan M, de Koning G, Flikweert S, Kolnaar BGM. Astma bij kinderen. NHG-Standaard. Huisarts en Wetenschap 1998:41:130-43.

19. Van Assema P, Mesters I, Kok G. Het focusgroep-interview: een stappenplan [The focus group interview: stepwise guidelines]. Tijdschrift Sociale Gezondheidszorg. 1992:70:431-7.

20. Oostenbrink JB, Koopmanschap MA, Rutten FFH. Handleiding voor kostenonderzoek. Methoden en richtlijnprijzen voor economische evaluaties in de gezondheidszorg. Amstelveen: College voor zorgverzekeringen: 2000. 
21. Asher MI, Keil U, Anderson HR, Beasley R, Crane J, Martinez F, Mitchell EA, Pearce N, Sibbald B, Stewart AW, Strachan D, Weiland SK, Williams HC. International study of asthma and allergies in childhood (ISAAC): rationale and methods. Eur Respir J 1995:8:483-91.

22. Van der Heide S, van Aalderen WM, Kauffman HF, Dubois AE, de Monchy JG. Clinical effects of air cleaners in homes of asthmatic children sensitized to pet allergens. J Allergy Clin Immunol 1999:104:447-51.

23. Luczynska CM, Arruda LK, Platts-Mills TA, Miller JD, Lopez M, Chapman MD. A two-site monoclonal antibody ELISA for the quantification of the major Dermatophagoides spp. allergens, Der $\mathrm{p} \mathrm{I}$ and Der f I. J Immunol Methods 1989:118:227-35.

24. Ingram JM, Sporik R, Rose G, Honsinger R, Chapman MD, Platts-Mills TA. Quantitative assessment of exposure to dog (Can $\mathrm{f} 1$ ) and cat (Fel d 1) allergens: relation to sensitization and asthma among children living in Los Alamos, New Mexico. J Allergy Clin Immunol 1995:96:449-56.

25. Aalberse RC, Koshte V, Clemens JG. Immunoglobulin E antibodies that crossreact with vegetable foods, pollen en hymenoptera venom. J Allergy Clin Immunol 1981:68:356-64.

26. Saarinen UM, Kajosaari M. Breastfeeding as prophylaxis against atopic disease: prospective follow-up study until 17 years old. Lancet 1995;346:1065-9.

27. Kok G, van den Borne B, Mullen PD. Effectiveness of health education and health promotion: meta-analyses of effect studies and determinants of effectiveness 1997;30:19-27.

28. Martinez FD, Wright AL, Taussig LM, Holberg CJ, Halonen M, Morgan WJ. Asthma and wheezing in the first six years of life. New Engl J Med 1995;332:133-8.

29. Schönberger HJAM, Maas T, Dompeling E, Knottnerus JA, van Weel C, van Schayck CP. Compliance of asthmatic families with a primary prevention programme of asthma and effectiveness of measures to reduce inhalant allergens - a randomised trial. Clin Exp Allergy 2004;34:1024-31.

30. Arshad SH, Bateman B, Matthews SM. Primary prevention of asthma and atopy during childhood by allergen avoidance in infancy: a randomised controlled study. Thorax 2003; 58: 489-93

31. Burke W, Fesinmeyer M, Reed K, Hampson L, Carlsten Ch. Family history as a predictor of asthma risk. Am J Prev Med 2003:24:160-9.

32. Schönberger HJAM, van Schayck CP. Prevention of asthma in genetically predisposed children in primary care - from clinical efficacy to a feasible intervention programme. Clin Exp Allergy 1998:28:1325-31. 


\section{Chapter 4}

\section{Mono and multifaceted inhalant and/or food allergen reduction interventions for preventing asthma in children at high risk of developing asthma}
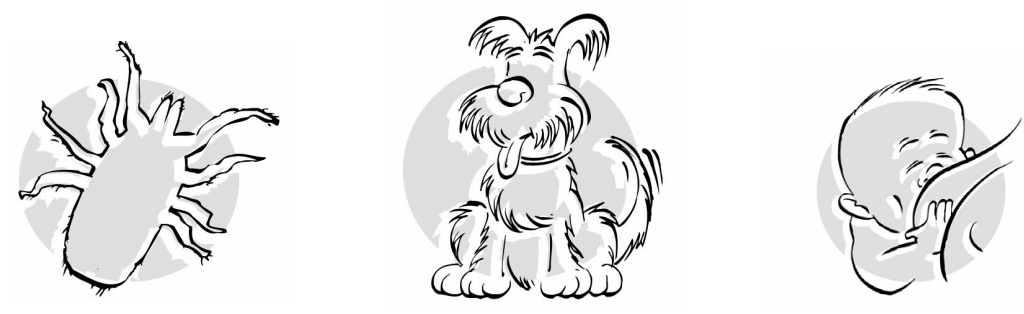

Maas T, Kaper J, Sheikh A, Knottnerus JA, Wesseling G, Dompeling E, Muris JWM, van Schayck CP 


\section{Synopsis}

Mono and multifaceted allergen reduction interventions for the primary prevention of asthma in children at high risk of developing asthma.

This review asks whether asthma, being a multi-factorial disease, can be prevented by reducing single allergen levels in children with genetic susceptibility, and whether reduction of multiple exposures lead to better outcome than control. In children who have a family history of atopy or asthma it is possible that early exposure to allergens may lead to their development of asthma. The objective of the current review was to determine if there were any differences between the outcomes of two types of allergen reducing interventions in primary prevention of asthma in children at high risk of developing asthma. The types of interventions we were interested in were interventions aiming at reducing exposure to 1) single allergen levels (mono-faceted intervention studies) 2) multiple allergens simultaneously (multifaceted intervention studies).

The current meta-analyses provide evidence that multi-faceted interventions, characterised by dietary allergen reduction and environmental remediation, reduce the odds of a physician diagnosis of asthma later in childhood, in children who are at risk of developing childhood asthma by a half. This translates to a number needed to treat (NNT) of 16. However, the effect of multi-faceted interventions on parent reported wheeze was inconsistent and it had no beneficial effect on nocturnal cough or dyspnoea. Mono-faceted interventions were no more effective than controls in the reduction of all outcomes but there remains uncertainty as to whether multiple interventions are more effective than mono-component interventions.

\section{Abstract}

\section{Background}

Based on the theoretical consideration that asthma is a multi-factorial disease, it is hypothesised that prevention might only prove effective if most or all relevant environmental factors are simultaneously avoided. Allergen exposure is one of the environmental factors seemingly associated with the development of asthma.

\section{Objectives}

The objective of this review was to assess effect(s) of mono-faceted and multi-faceted interventions when compared with control interventions, in preventing asthma and asthma symptoms in children.

\section{Search strategy}

A computer aided search was performed of the Cochrane Central Register of Controlled trials (Central) issue 1, 2006, Medline (from January 1966 to October 2006) and EMBASE (from January 1989 to October 2006) and the Cochrane Airways Trial Register (until January 2008).

\section{Selection criteria}

Randomised controlled trials on primary prevention of asthma in children by allergen exposure reduction were identified and results of mono-faceted and multi-faceted intervention studies were separately pooled. We stipulated that the follow-up had to be from birth (or even during pregnancy) up to a minimum of two years of age.

Data collection \& analysis

Eligible studies were screened on relevant results for the current meta-analysis. When the primary outcome 'current diagnosis asthma' and/or one of the secondary outcomes' current respiratory symptoms wheezing, nocturnal cough and dyspnoea' were described, studies were included in the analyses. Multi-faceted and mono-faceted intervention studies were pooled separately. We made an indirect comparison of their effects with Z-tests. 
Main results

Three multi-faceted and six mono-faceted intervention studies that described their results at various intervals met the entry criteria. These studies randomised 3271 children. Physician diagnosed asthma in children less than five years and asthma as defined by respiratory symptoms and lung function criteria in children aged five years and older both favoured treatment of multi-faceted intervention studies ( $<5$ years OR $0.73, \mathrm{Cl} 0.550 .97$ and $\geq 5$ years $\mathrm{OR} 0.52, \mathrm{Cl} 0.320 .84$ ). However, there was no difference in outcome between mono-faceted intervention and control study results ( $<5$ years $\mathrm{OR} 1.22, \mathrm{Cl} 0.831 .78$ and $\geq 5$ years $\mathrm{OR} 0.93, \mathrm{Cl} 0.661 .31$ ). Indirect comparison between these treatments via Z-test scores suggested that multiple interventions were more successful than mono-interventions in reducing the frequency of asthma diagnosis in children under five years (Z-score -2.118). Z-test comparison in diagnosis of asthma in children five years and older was not significant between multiple and mono-interventions (Z-score -1.925). There was no significant difference between either mono- and multi-faceted intervention and control in reducing the likelihood of symptoms at follow-up (multi: $0.7, \mathrm{Cl} 0.43$ to 1.17).

\section{Reviewers' conclusions}

The available evidence suggest that the reduction of exposure to multiple allergens reduces the likelihood of a current diagnosis of asthma at ages $<5$ years, whereas the evidence monointervention studies does not indicate a statistically significant difference with control. Multi-faceted interventions, characterised by dietary allergen reduction and environmental remediation, reduce the odds of a physician diagnosis of asthma later in childhood, in children who are at risk of developing childhood asthma by a half. This translates to a number needed to treat (NNT) of 16. However, the effect of multi-faceted interventions on parent reported wheeze was inconsistent and it had no beneficial effect on nocturnal cough or dyspnoea. Mono-faceted interventions were no more effective than controls in the reduction of all outcomes. There remains uncertainty as to whether multiple interventions are more effective than mono-component interventions. The non-significant between mono- and multi-faceted interventions on outcome diagnosis asthma at ages five years and older might be true but may have been caused by lack of power or the difference in study outcome used in the of studies compared. The findings warrant further direct comparison between multiple- and mono-faceted intervention at reducing the prevalence of asthma in children. Since the current meta analyses are not randomised comparisons, we recommend that a new study which assesses both types of interventions is undertaken. There are no studies ongoing to our knowledge in which both intervention strategies are randomly compared. Such a study will be of great importance for shedding new light on preventing the development of asthma in genetically susceptible children. 


\section{Background}

Asthma is a multi-factorial disease that in the main develops in individuals with genetic susceptibility. Genetically predisposed children exposed to specific environmental factors (such as allergens) are believed to be at increased risk of developing asthma. It is generally accepted that the interaction between genotype and environment plays a crucial role. ${ }^{1}$ In this line of thinking it is assumed that reduction of exposure to inhalant as well as food allergens could lead to a reduction in the risk of developing asthma, although current evidence on maternal dietary antigen avoidance is equivocal. ${ }^{2}$

Information leading to this assumption is mainly based on results of secondary prevention strategies. ${ }^{3,4}$ Many have speculated that reduction of exposure to inhalant or food allergens could lead to a reduction in the risk of developing asthma. It has however proven very difficult to translate these insights into effective primary prevention strategies. ${ }^{5-8}$ Up until now the reasons behind the lack of effectiveness of these carefully designed studies remain unclear. Based on theoretical considerations that asthma is a multi-factorial disease, prevention might only prove effective if most or all relevant environmental factors for a specific child are simultaneously avoided. To investigate this hypothesis we undertook a systematic review of mono- and multi-faceted allergen avoidance interventions compared with controls aiming to prevent asthma in high risk children. As we were aware that there are at present no randomised controlled trials directly comparing mono- and multi-faceted interventions we considered that this approach would offer the possibility of an indirect comparison between these two intervention strategies.

\section{Objectives}

The objective of this review was to compare the effectiveness of mono- and multi-faceted allergen reduction interventions in the primary prevention of asthma and asthma symptoms in children judged to be at high risk of developing asthma, by pooling the results of individual studies.

\section{Criteria for considering studies for this review}

\section{Types of studies}

Birth cohort randomised controlled trials (RCTs) with follow-up of children from birth onwards. The interventions tested are either multifaceted or mono faceted 
and focused on allergen exposure reduction (inhalant allergens and/or food allergens).

\section{Types of participants}

Children at high risk of developing atopy or asthma recruited at or before birth with the aim of preventing asthma. High risk of developing atopy or asthma was defined as a family history of atopy or asthma in at least one first degree (i.e. biologic parent or, full sibling) relative. We stipulated that the family history should be confirmed by parents, general practitioner (GP) or biological marker of hypersensitivity (specific IgE or skin prick test).

\section{Types of interventions}

Allergen reducing interventions focused on inhalant allergens and/or food allergens, either as part of a multi-faceted or mono-faceted intervention strategy. Co-interventions included in multi-faceted or mono-faceted interventions (not aimed at allergen reduction) were permitted.

We categorised studies as either multi-faceted or mono-faceted depending on whether they aimed at reducing exposure to inhalant allergens AS WELL AS food allergens (multi-faceted) or whether they aimed at reducing exposure to EITHER inhalant allergens OR food allergens (mono-faceted).

Allergen reduction measures started either during pregnancy or from birth onwards, and continued during postnatal life. Minimum duration of intervention was four months. We anticipated some variation in the length of follow-up beyond this time point.

For optimal contrast in interventions the control group measures were either placebo strategies or usual care.

Another Cochrane review of pre and post-natal dietary intervention focused on maternal diet. ${ }^{2}$ However, in the current review we extend the focus to post-natal intervention in infants, and prenatal environmental allergen reducing interventions.

\section{Types of outcome measures}

Outcomes of interest needed to be assessed at a minimum age of two years. At least one clinical outcome measure (asthma or respiratory symptoms wheezing, nocturnal cough and/or dyspnoea) had to be evaluated for studies to be eligible. As a diagnosis of asthma at ages younger than five years is driven more by symptoms than a diagnosis asthma at age five and older we did separate analyses for these outcomes. Asthma cannot be determined objectively children under five years of age since lung function measurements cannot be performed reliably in these children. Nevertheless we chose to include this outcome, 
because doctors do diagnose children as being asthmatic at these young ages. The diagnosis in these cases is usually confirmed by medication usage.

Current nocturnal cough is also included although it is known that nocturnal cough is likely to be a manifestation of asthma in only a minority of cases. This makes the use of the outcome nocturnal cough as asthma symptom less reliable. ${ }^{9}$ As most studies in the field of asthma prevention use this criterion however, we have included nocturnal cough in the current meta-analyses.

\section{Primary outcome}

1. Current Asthma (defined as doctor diagnosis) in children aged $<5$ years;

2. Current asthma (defined as current respiratory symptoms (wheeze and/or nocturnal cough and/or dyspnoea) plus lung function criteria corresponding with clinical diagnosis asthma (BHR and/or reversibility) in children aged $\geq 5$ years;

\section{Secondary outcome}

3. Current respiratory symptoms (wheeze, nocturnal cough and dyspnoea) as reported by parents in questionnaires;

4, Adverse events.

\section{Search strategy for identification of studies}

Eligible studies were identified by searching the Cochrane Central Register of Controlled trials (Central) issue 1, 2006, MEDLINE (from January 1966 to October 2006), EMBASE (from January 1989 to October 2006) and the Cochrane Airways Trial Register (until January 2008) no limitation on language of publication.

Design related terms: clinical trial, random (in Cochrane Central search only), intervention*, control*;

IIIness related terms: asthma;

Topic related terms: prevent*, ${ }^{*}$ reduct ${ }^{*}$, allergen*;

Screening references of relevant reviews and identified studies.

In order to retrieve unpublished or un-identified studies experts in the field were contacted via a letter and a standardized e-mail.

\section{Methods of the review}

Based on title and abstract one reviewer (TM) selected studies by applying the inclusion criteria to the studies identified by the literature search. In case of uncertainty, a second reviewer (CPvS) was consulted. Both reviewers did 
assess the full paper version of the selected studies. Disagreements about inclusion were resolved by consensus.

\section{Quality assessment}

The articles were not blinded for authors, institutions or journal title. The methodological quality of the included studies was assessed by using the Delphi List, ${ }^{10}$ which also contains all items of the list developed by Jadad. ${ }^{11}$ The Delphi List contains nine items: 1) method of randomisation performed, 2) allocation concealed, 3) blinding of 'patient' /parents, 4) blinding of health care provider 5) blinding of outcome assessor, 6) inclusion and exclusion criteria specified, 7) comparability at baseline regarding the most important prognostic indicators (e.g. gender, familial predisposition of child, number of older siblings, pets), 8) intention to treat analysis performed 9) point estimates and measures of variability presented for primary outcome measure(s). In addition to the Delphi List, we considered another item to be important: 10) specification of outcome measures. Two reviewers (TM and CPVS) independently assigned a score for criteria 1-10.

In a consensus meeting, disagreements between the two reviewers were discussed and resolved. If a study did not contain sufficient information on methodological criteria, the authors were contacted for additional information.

Inclusion criterion on methodological quality we used for the current metaanalyses is that at least item number 1, 2, 5 and 10 had to be described and fulfilled and of item nine point estimates had to be presented.

\section{Data extraction}

Data from the included studies were extracted by two reviewers (TM and CPvS). Any discrepancies between the two reviewers were resolved by discussion.

\section{Data were extracted according to the following criteria:}

- Methods: setting (location of intervention extramural, at home or hospital, country, year of study) and study design;

- Participants and /or health care providers: method of recruitment, inclusion criteria, characteristics of study population (gender, familial predisposition, number of older siblings); 
- Interventions: description of the intervention for each group (mono- versus multi-faceted interventions);

- Outcome measures: for each outcome measure (diagnosis asthma and respiratory symptoms (wheezing, night-time cough and dyspnoea) the definition of outcome and specific outcome assessor.

\section{Data analysis}

Review Manager 4.2 of the Cochrane Collaboration we used for pooling data to assess the effects of specific interventions and report data on the same outcome measure. A formal test for statistical heterogeneity, the natural approximate Chi square test, assessed whether the observed variability in effect sizes was greater than would be expected to occur by chance. For dichotomous endpoints, an Odds Ratio (OR) and 95\% Confidence Interval (Cl) was presented by using a random effects model. Also we re-analysed the data by using a fixed effects model and compared the two types of modelling. When no or only small differences were observed we presented the data using the random effects model.

We calculated a NNT to express the number of children required to be treated in order for one to avoid the outcome of interest (Visual Rx). ${ }^{12}$

Due to the nature of the question addressed in this review, it is likely that there would be some variation in the length of follow-up carried out in each of the studies. We therefore aimed to analyse data on diagnosis and symptoms of asthma in two ways. Firstly we analysed data from multiple age categories (as age-pooled subgroups). For every outcome we also analysed data from the last published observation available in each of the studies irrespective of time point. The results pooled as last observation available were the most recent results of every study resulting in a larger amount of studies pooled $(n / N)$, making the pooling of these results the most valid ones for every outcome presented.

We used intention to treat analyses for all studies, even if they did not report these data. For all studies we assumed that cases lost to follow-up did not satisfy the criteria for the outcome tested.

To test the difference between the two separate meta-analyses (mono- and multi-faceted) $Z$ tests were carried out for every outcome variable when data was available for both types of intervention studies. 


\section{Description of studies}

A total of 1184 articles were screened. 335 articles resulted from the literature search we did ourselves and 849 articles resulted from the Cochrane search in the Airways Group Register, including duplicates. After we screened on title and abstract 41 remained. We screened the full paper versions of these 41 on inclusion criteria as defined for the current meta-analyses and broadened our search by checking relevant references.

\section{Included studies}

A total of nine studies were included. Some studies reported results on multiple age-time moments. Of the included studies, three were classified as multifaceted intervention studies in the current Meta-analyses: Canadian study ${ }^{13,14}$, Isle of Wight study ${ }^{15-17}$, PREVASC $^{18}$ and six were classified as mono-faceted intervention studies $^{19-27}$ (Table 4.1).

\section{Excluded studies}

Two studies, Kjellman and Johnstone ${ }^{28,29}$ that did initially seem to fit the inclusion criteria were excluded because of insufficient methodological quality (outcome assessors not blinded). The study of Chandra ${ }^{30}$ initially did fit the inclusion criteria but was excluded because of evidence that the published data may have been fabricated. ${ }^{2}$ The study of Koopman et al. ${ }^{8}$ did fit the inclusion criteria but no information was supplied on prevalence of outcomes, the only results described in the paper were those of a multiple regression analysis. 
64 | Chapter 4

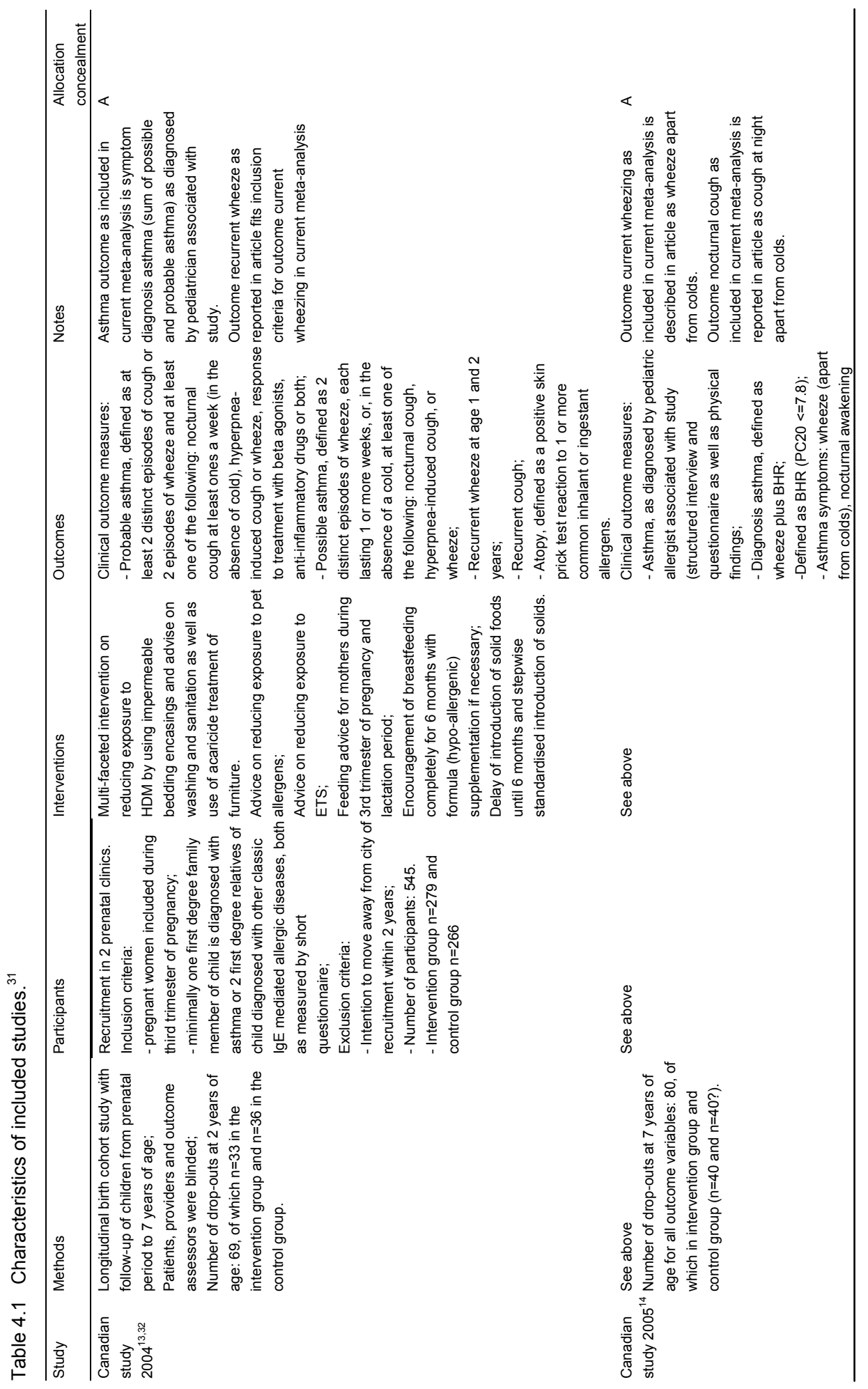




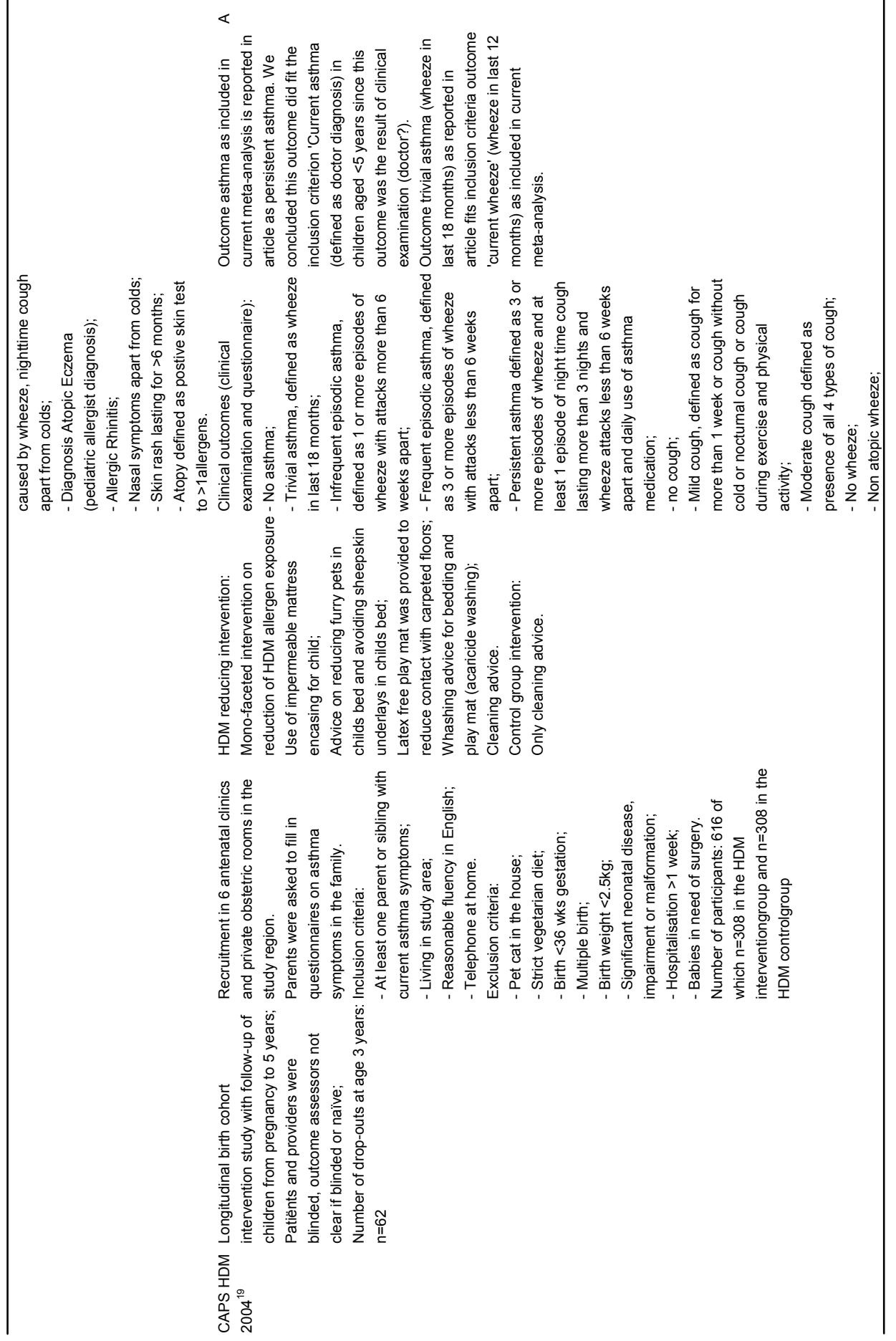


66 $\mid$ Chapter 4

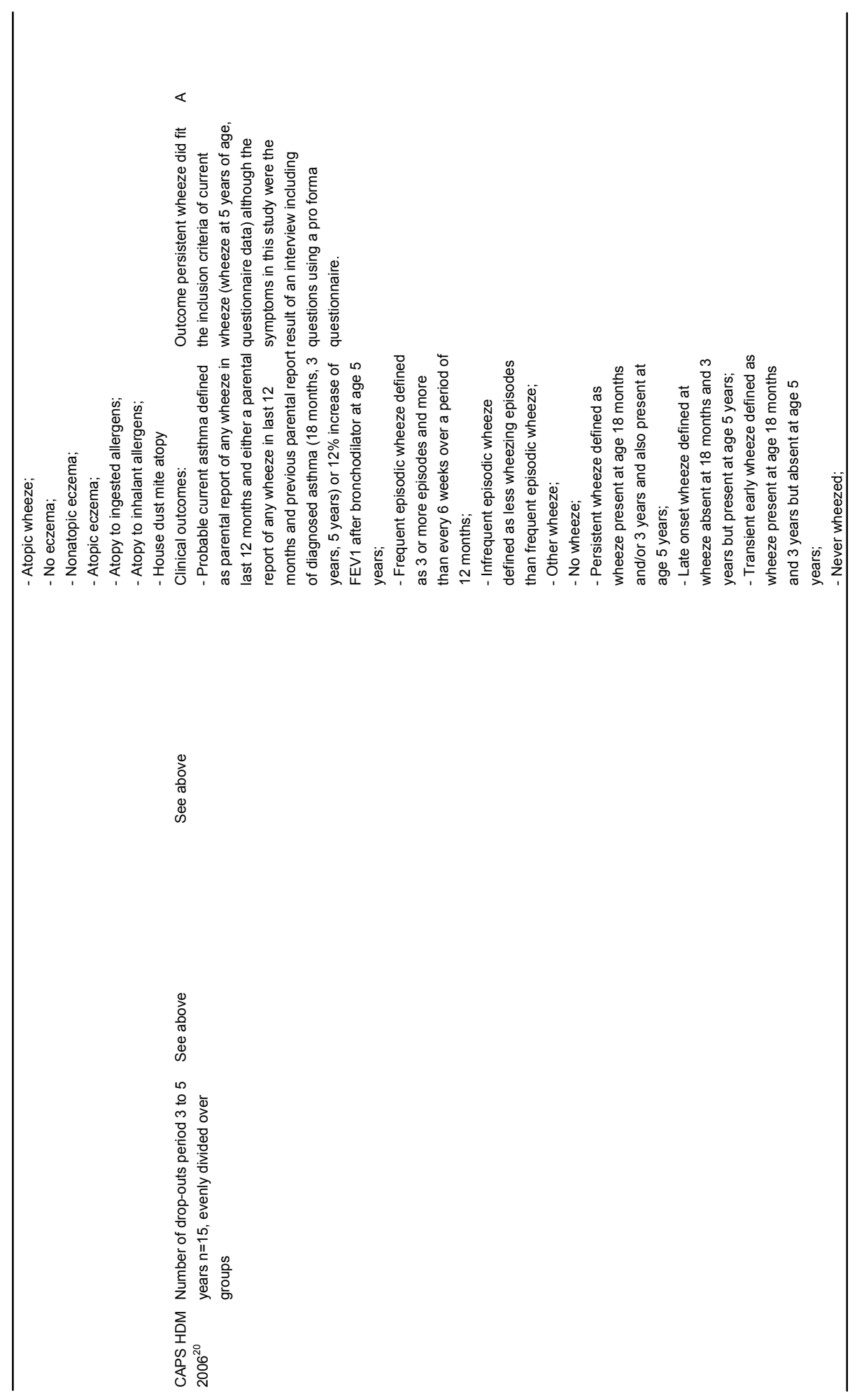




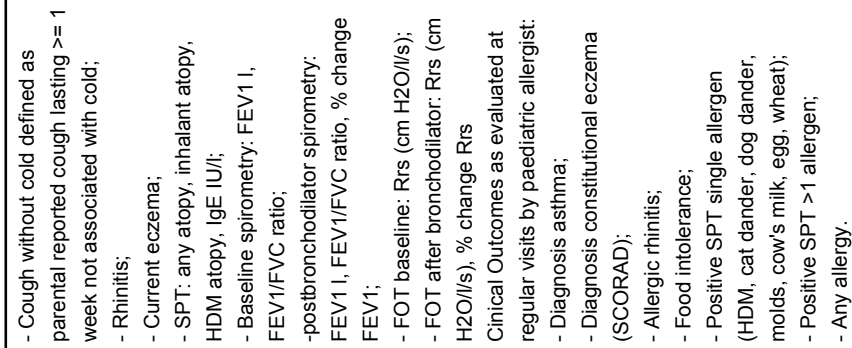
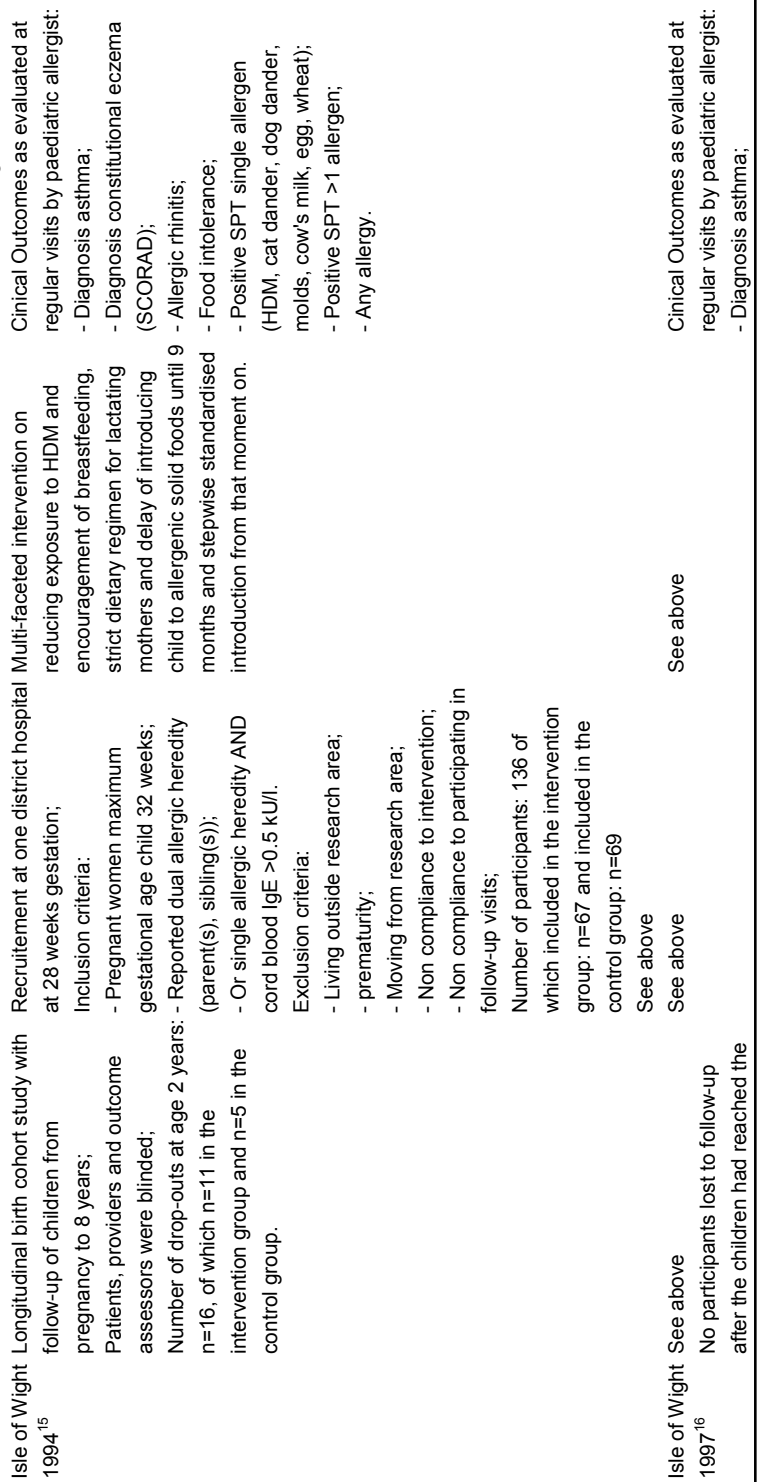
68 $\mid$ Chapter 4

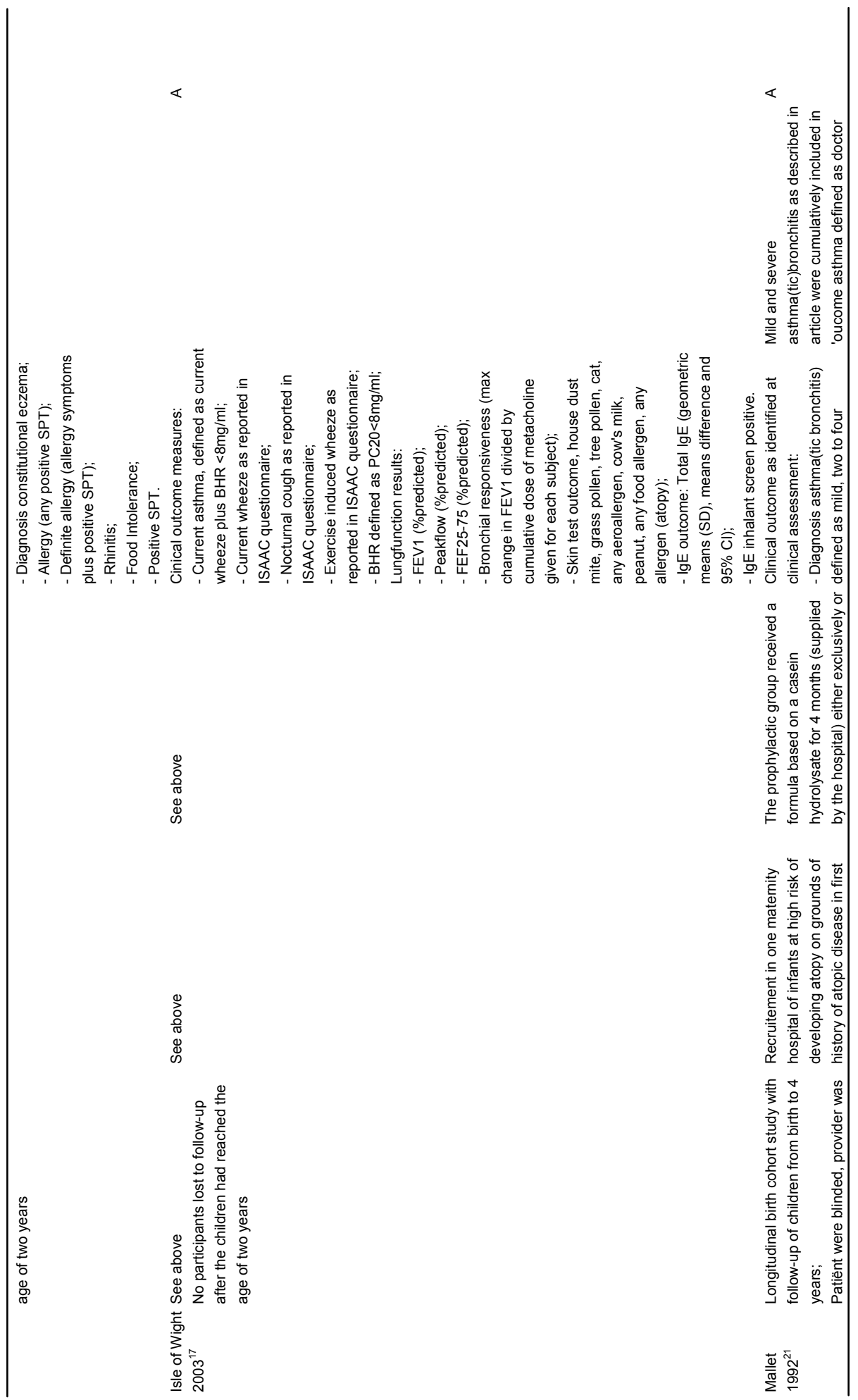



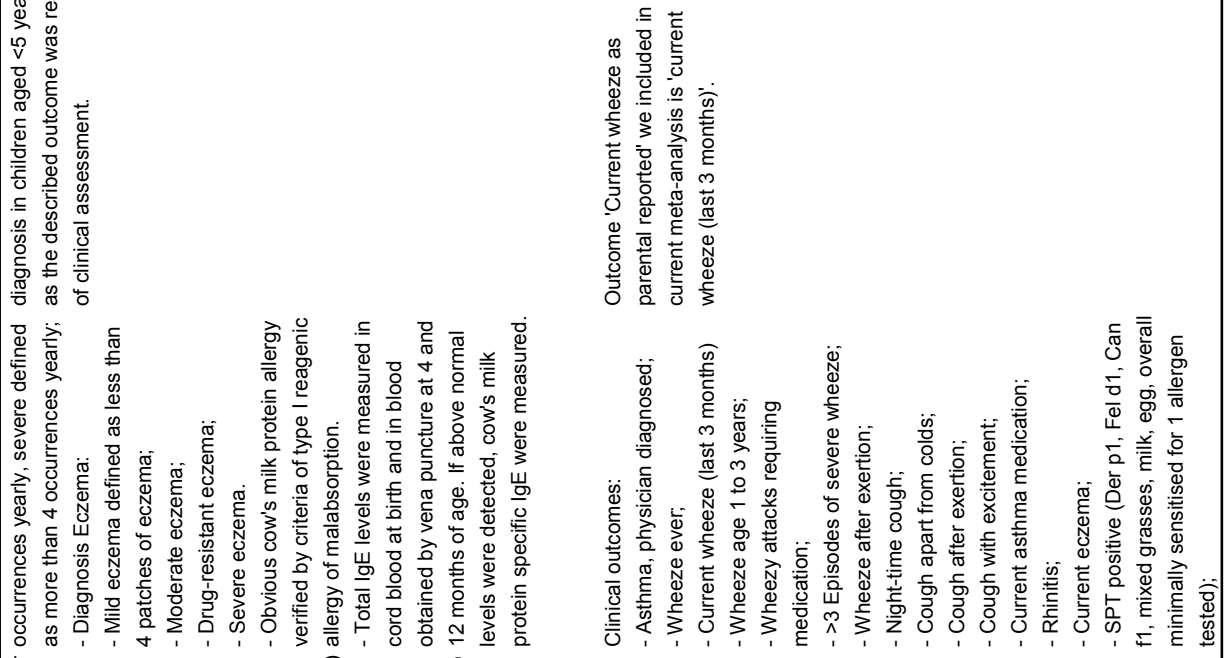

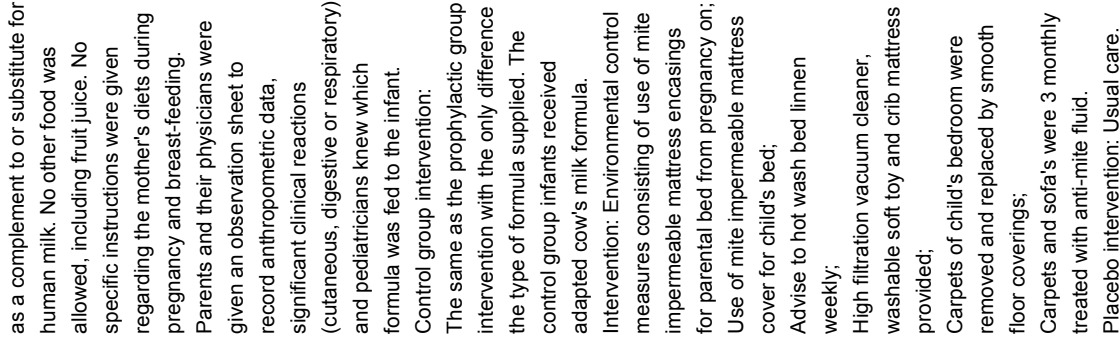
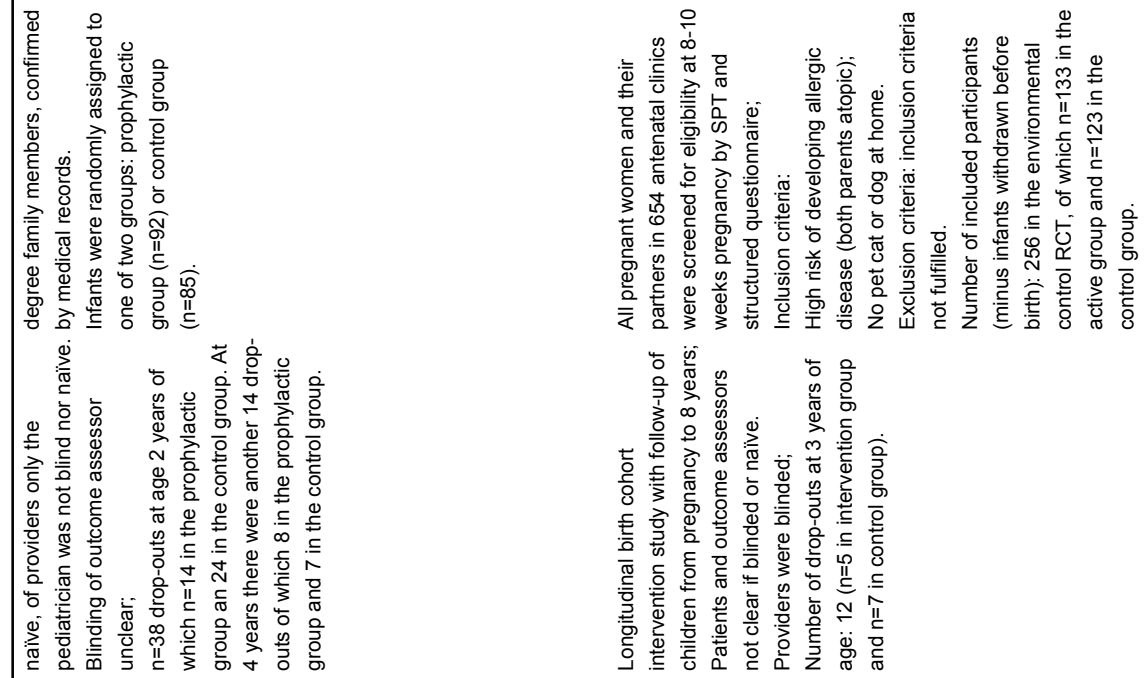
70 | Chapter 4

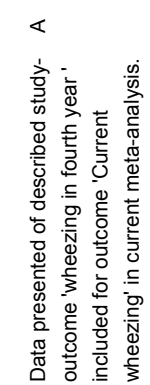

InUm

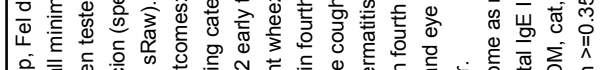

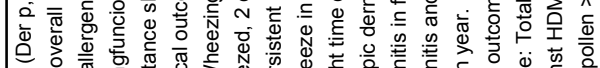

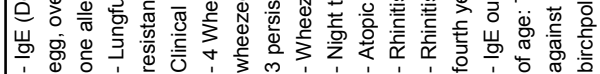

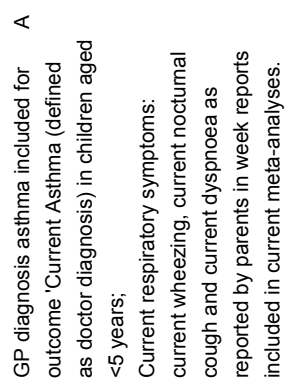

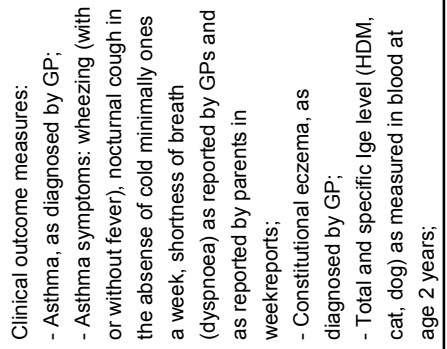

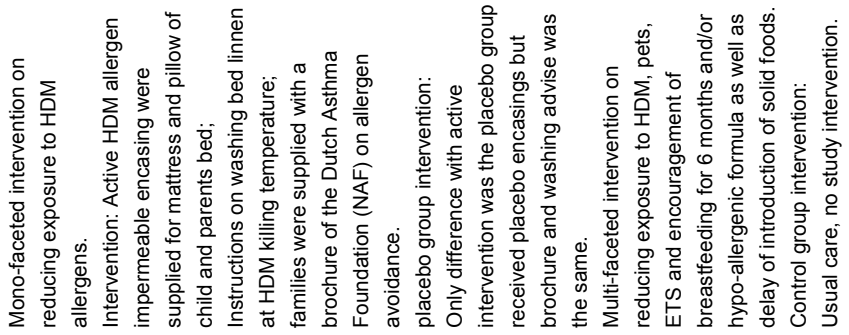

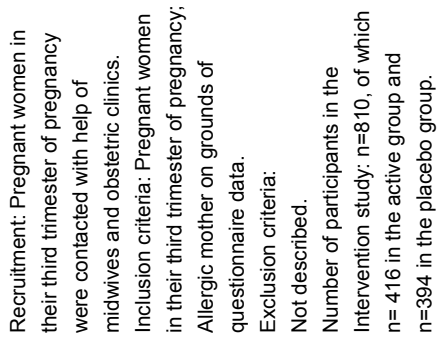

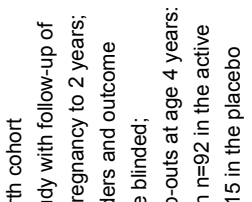

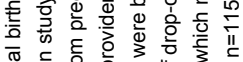

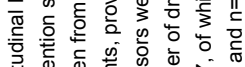

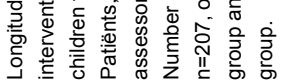

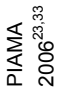

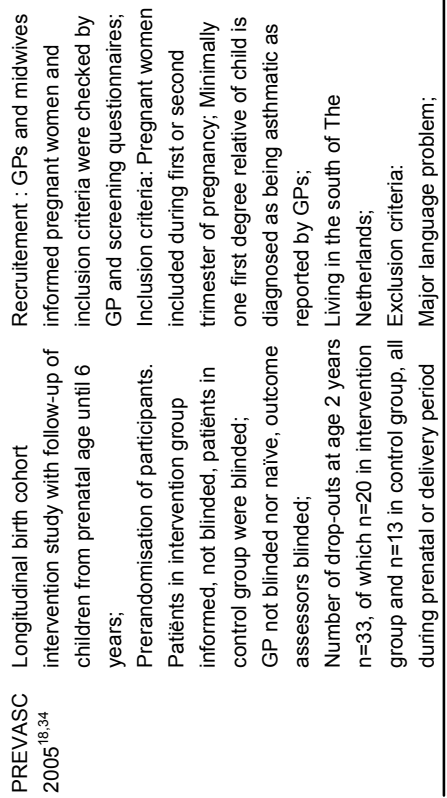




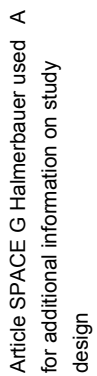

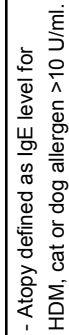

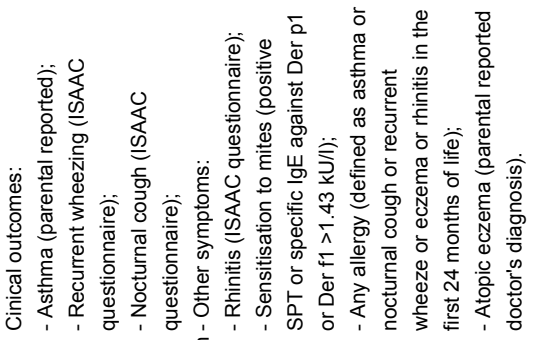

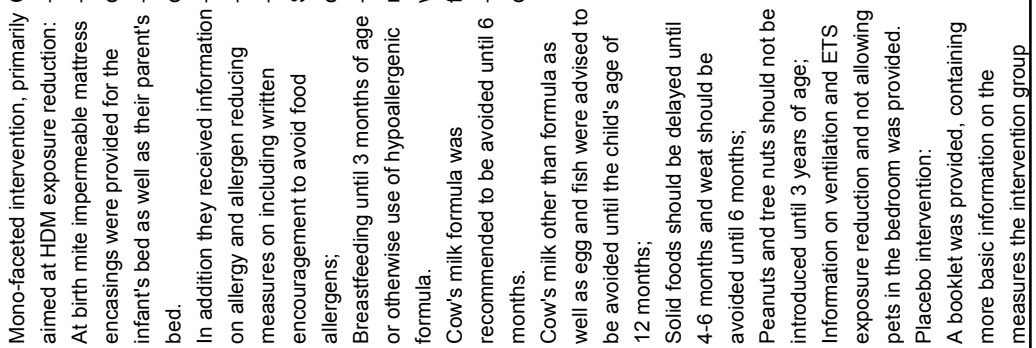

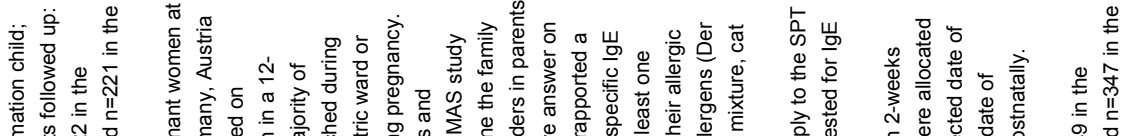

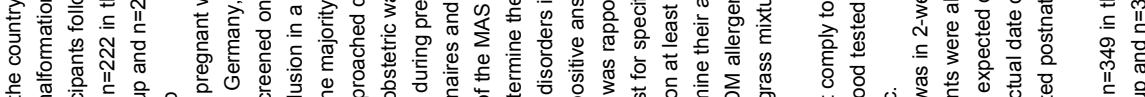

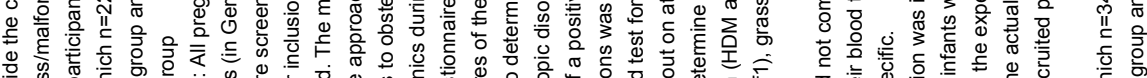

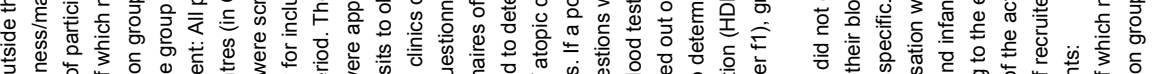

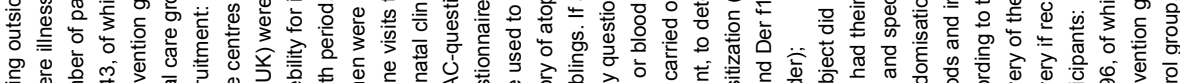

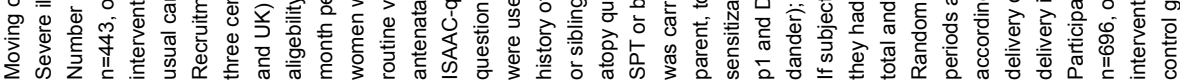

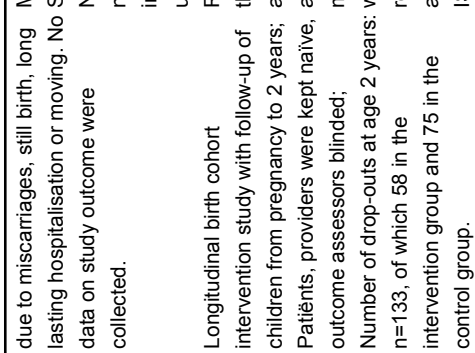

药惫 
$72 \mid$ Chapter 4

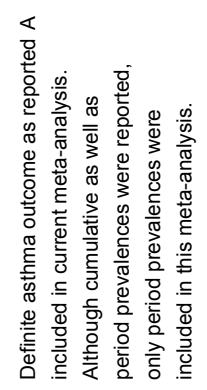

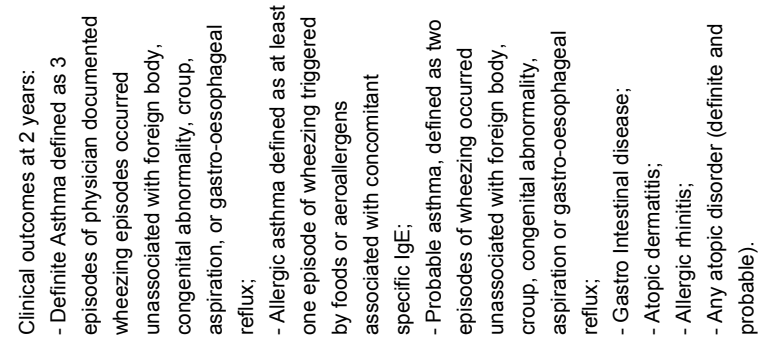

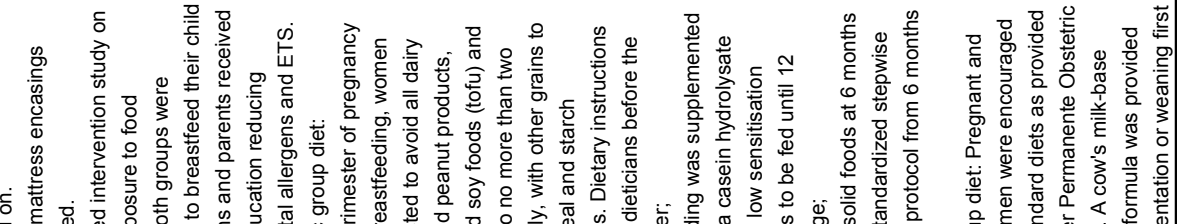

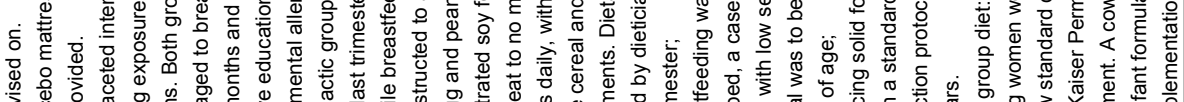

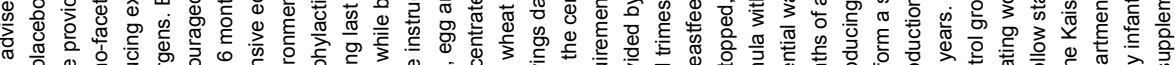

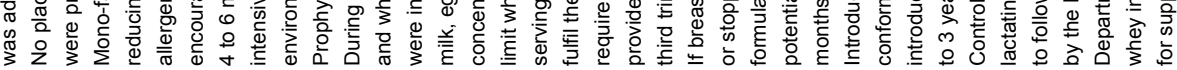

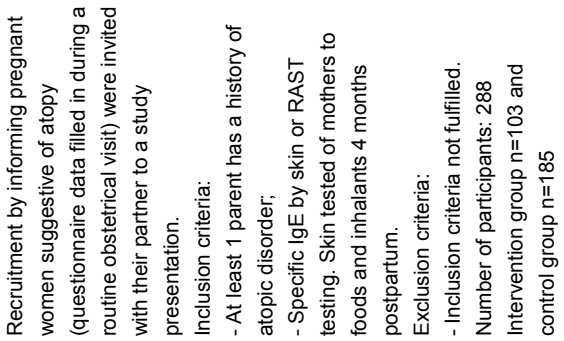

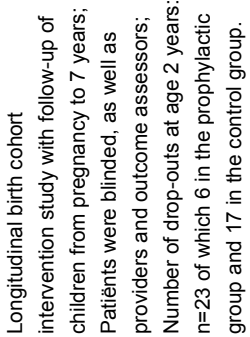

(n)

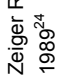


Meta-analyses: multi- or mono-faceted intervention? 73
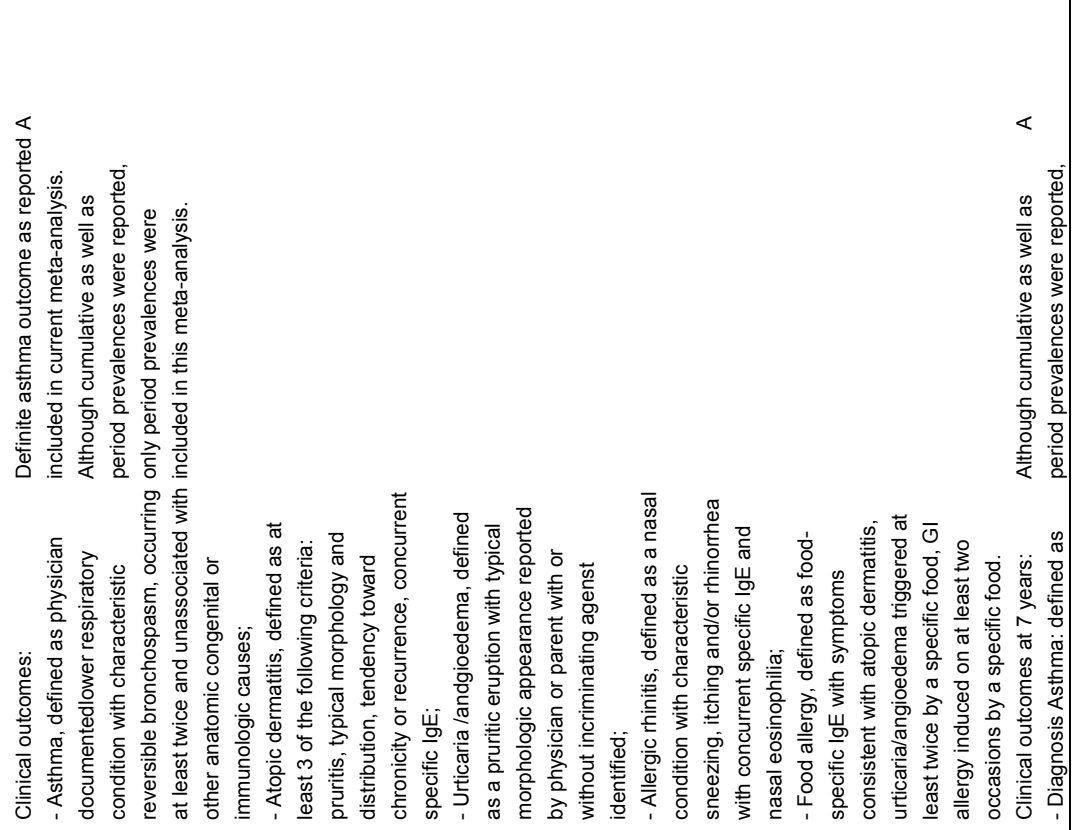

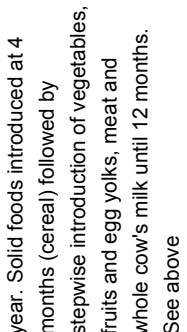

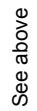

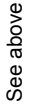

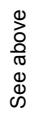

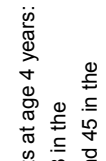

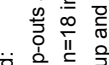

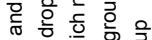

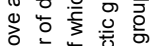

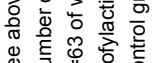

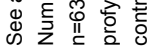

क

N 
74 Chapter 4

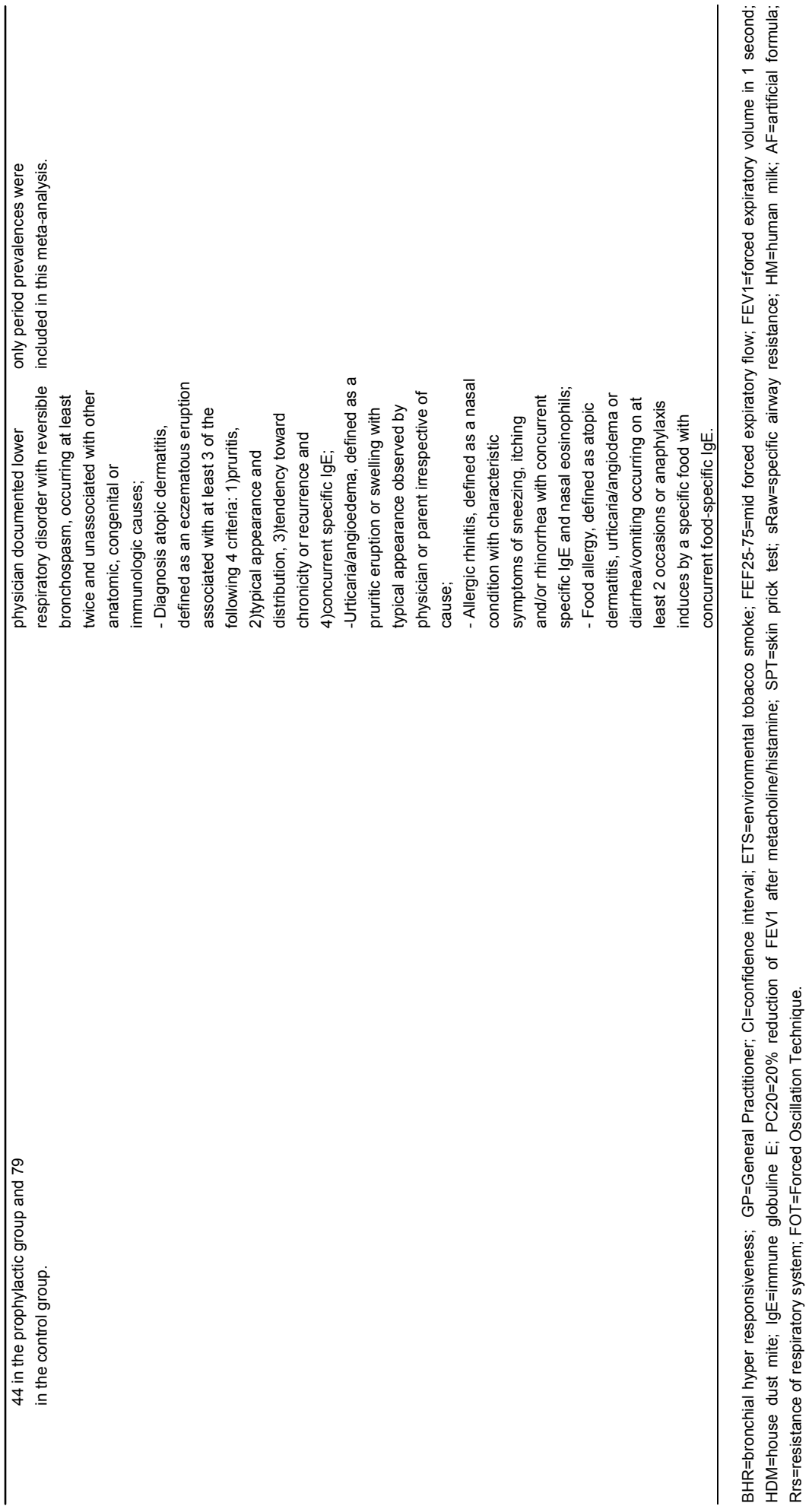




\title{
Another 22 studies were excluded for various reasons as described in the table 'Characteristics of excluded studies' (Table 4.2).
}

\author{
Table 4.2 Characteristics of excluded studies.
}

\begin{tabular}{|c|c|}
\hline Study & Reason for exclusion \\
\hline Arshad $1992^{36}$ & $\begin{array}{l}\text { Results of the Isle of Wight study on clinical outcome of children at } 1 \text { year of age } \\
\text { described. Inclusion criterion 'description of clinical effectiveness on children aged } \\
\text { minimally two years' was not fulfilled. }\end{array}$ \\
\hline Boggs $2003^{37}$ & No clinical effectiveness described \\
\hline Bottcher $2002^{38}$ & No RCT described \\
\hline Brunekreef $2002^{39}$ & $\begin{array}{l}\text { Design article of PIAMA study in which results of natural history part of PIAMA on allergen } \\
\text { exposure are described. No clinical effectiveness described }\end{array}$ \\
\hline $\begin{array}{l}\text { Canadian MedAss } \\
2005^{40}\end{array}$ & No RCT described \\
\hline Chan-Yeung $2002^{41}$ & $\begin{array}{l}\text { Results of intervention Canadian Allergy and Asthma Prevention study on allergen } \\
\text { reducing outcome. No clinical effectiveness described }\end{array}$ \\
\hline Chandra $1997^{30}$ & $\begin{array}{l}\text { Excluded because of investigations by Chandra's university (Memorial University of } \\
\text { Newfoundland) and the Canadian Broadcasting Corporation strongly suggest that the } \\
\text { published data may have been fabricated. }\end{array}$ \\
\hline Custovic $2000 a^{42}$ & $\begin{array}{l}\text { Only results of intervention nacMAAS study on allergen reducing outcome reported. No } \\
\text { clinical effectivity described }\end{array}$ \\
\hline Custovic $2000 b^{43}$ & $\begin{array}{l}\text { Results described of nacMAAS study on allergen reducing outcome. No clinical effectivity } \\
\text { described }\end{array}$ \\
\hline Custovic $2001^{44}$ & $\begin{array}{l}\text { Results of nacMaas study on clinical outcome of children at } 1 \text { year of age described. } \\
\text { Inclusion criterion 'description of clinical effectiveness on children aged minimally two } \\
\text { years' was not fulfilled. }\end{array}$ \\
\hline Dunstan $2003^{45}$ & No allergen reducing intervention studied. No clinical effectiveness described \\
\hline Johnstone $1966^{29}$ & $\begin{array}{l}\text { Study on clinical effectiveness of food allergen reducing intervention (soy formula) that } \\
\text { seemed to fit all inclusion criteria but was excluded because at least one of the items of } \\
\text { Delphi-List on quality assessment we based an inclusion criterion on was fulfilled } \\
\text { (outcome assessor was not blinded and allocation concealment was not clear). }\end{array}$ \\
\hline Kalliomaki $2001^{46}$ & $\begin{array}{l}\text { Study on clinical effectiveness of probiotics intervention, no allergen reduction and no } \\
\text { outcome asthma }\end{array}$ \\
\hline Kjellman $1979^{28}$ & $\begin{array}{l}\text { Study on clinical effectiveness of food allergen reducing intervention (soy formula) that } \\
\text { seemed to fit all inclusion criteria but was excluded because at least one of the items of } \\
\text { Delphi-List on quality assessment we based an inclusion criterion on was fulfilled } \\
\text { (outcome assessor was not blinded and allocation concealment was not clear). }\end{array}$ \\
\hline Koopman $2002^{8}$ & $\begin{array}{l}\text { Study on clinical effectiveness of mono-faceted house-dust mite reducing intervention that } \\
\text { fitted all inclusion criteria but was excluded because no point prevalences were described } \\
\text { nor supplied }\end{array}$ \\
\hline Marini $1996^{47}$ & $\begin{array}{l}\text { Multi-faceted intervention study on primary prevention of atopic manifestation but the } \\
\text { outcomes as selected for current review are not described. }\end{array}$ \\
\hline Marks $2006^{48}$ & $\begin{array}{l}\text { CAPS study dietary intervention part in which no allergen reducing manipulation so } \\
\text { inclusion criteria not fulfilled for this part of the study. House Dust Mite reducing part of } \\
\text { CAPS intervention as described in this article however is included. }\end{array}$ \\
\hline Mihrshahi $2001^{49}$ & $\begin{array}{l}\text { Article on design and research protocol of CAPS study. No clinical effectiveness } \\
\text { described }\end{array}$ \\
\hline Peat $2004^{50}$ & $\begin{array}{l}\text { CAPS study dietary intervention part in which no allergen reducing manipulation so } \\
\text { inclusion criteria not fulfilled for this part of the study. House Dust Mite reducing part of } \\
\text { CAPS intervention as described in this article however is included. }\end{array}$ \\
\hline Saarinen $1979^{51}$ & Article does not concern RCT merely natural history study on breastfeeding. \\
\hline Simpson $2003^{52}$ & Allergen reducing results of nacMAAS study described. No clinical effectivity described \\
\hline Simpson $2004^{53}$ & $\begin{array}{l}\text { Review on designs and allergen reducing outcome of RCT's on primary prevention of } \\
\text { asthma in children. No clinical effectivity described }\end{array}$ \\
\hline van Strien $2002^{54}$ & $\begin{array}{l}\text { Allergen exposure outcome in natural history part of PIAMA study reported. No clinical } \\
\text { effectiveness described }\end{array}$ \\
\hline
\end{tabular}




\section{Methodological quality of included studies}

The methodological quality of included studies is presented in the additional tables 'Quality assessment conform Delphi List', with tabulation of quality for year of follow-up (Table 4.3). The ten items in these tables concern methodological quality as described in the methods of the current review.

Table 4.3 Quality assessment conform Delphi List.

\begin{tabular}{|c|c|c|c|c|c|c|c|c|c|}
\hline & Item & $\begin{array}{c}\text { Zeiger } \\
1989- \\
1995\end{array}$ & $\begin{array}{l}\text { Mallet } \\
1992\end{array}$ & $\begin{array}{l}\text { Hide } \\
1994- \\
2003\end{array}$ & $\begin{array}{l}\text { Becker } \\
2004 \\
2005\end{array}$ & $\begin{array}{l}\text { Horak } \\
2004\end{array}$ & $\begin{array}{l}\text { Schönberger } \\
2005\end{array}$ & $\begin{array}{l}\text { Peat, } \\
\text { HDM } \\
2004 \\
2006\end{array}$ & $\begin{array}{c}\text { Corver } \\
2006\end{array}$ \\
\hline 1 & $\begin{array}{l}\text { Was a method of } \\
\text { randomisation } \\
\text { performed? }\end{array}$ & yes & yes & yes & yes & yes & yes & yes & yes \\
\hline 2 & $\begin{array}{l}\text { Was the allocation } \\
\text { concealed? }\end{array}$ & yes & yes & yes & yes & yes & yes & yes & yes \\
\hline 3 & $\begin{array}{l}\text { Blinding or naïve } \\
\text { patient? }\end{array}$ & unclear & yes & yes & yes & yes & no & no & yes \\
\hline 4 & $\begin{array}{l}\text { Blinding or naïve } \\
\text { health care } \\
\text { provider? }\end{array}$ & yes & no & yes & yes & yes & no & unclear & yes \\
\hline 5 & $\begin{array}{l}\text { Blinding or naïve } \\
\text { outcome } \\
\text { assessor? }\end{array}$ & yes & yes & yes & yes & yes & yes & yes & yes \\
\hline 6 & $\begin{array}{l}\text { Were both } \\
\text { inclusion and } \\
\text { exclusion criteria } \\
\text { specified? }\end{array}$ & yes & yes & yes & yes & yes & yes & yes & yes \\
\hline 7 & $\begin{array}{l}\text { Were the groups } \\
\text { similar at baseline } \\
\text { regarding the most } \\
\text { important } \\
\text { prognostic } \\
\text { indicators? }\end{array}$ & unclear & unclear & no & unclear & unclear & yes & yes & no \\
\hline 8 & $\begin{array}{l}\text { Did the analysis } \\
\text { include an } \\
\text { intention-to-treat } \\
\text { analyses? }\end{array}$ & no & no & no & no & no & yes & no & yes \\
\hline 9 & $\begin{array}{l}\text { Were point } \\
\text { estimates and/or } \\
\text { measures of } \\
\text { variability } \\
\text { presented for } \\
\text { primary outcome } \\
\text { measure(s)? }\end{array}$ & yes & yes & yes & yes & yes & yes & yes & yes \\
\hline 10 & $\begin{array}{l}\text { Were the primary } \\
\text { outcome measures } \\
\text { specified? }\end{array}$ & yes & yes & yes & yes & yes & yes & yes & yes \\
\hline
\end{tabular}




\section{Results}

Three multi-faceted allergen reducing intervention trials, some with an additional co-intervention (for example, environmental tobacco smoke (ETS) reduction) on prevention of asthma in children at high risk of developing asthma $(n=1124)$ and six mono-faceted allergen-reducing trials, of which again some with an additional intervention like dietary fatty acid modification, $(n=2147)$ were included. Data from these studies were pooled separately at several agespecific time points under the outcomes: 'Current asthma (defined as doctor diagnosis) in children aged <5 years'; 'Current asthma (defined as current respiratory symptoms (wheezing and/or nocturnal cough and/or dyspnoea) plus lung function criteria corresponding with clinical diagnosis asthma (BHR and/or reversibility) in children aged $\geq 5$ years'; and 'Current respiratory symptoms' (wheezing, nocturnal cough, dyspnoea) as recorded by parents/carers in questionnaires.

Adverse events were not described in any of the included studies.

\section{Specific results for individual outcomes}

Current Asthma (defined as doctor diagnosis) in children aged $<5$ years Multi-faceted intervention studies scored in favour of treatment at age two years (pooled results Canadian study ${ }^{13}$; Isle of Wight ${ }^{15}$; PREVASC ${ }^{18}$ : OR $0.7295 \% \mathrm{Cl}$ $0.54,0.97)$. At four years of age the Isle of Wight study ${ }^{16}$ was included and scored an OR of 0.56 and $95 \% \mathrm{Cl} 0.26,1.23$. The overall outcome 'Current Asthma in children aged $<5$ years last reported' resulted in an OR of $0.73(95 \%$ $\mathrm{Cl} 0.55,0.97)$. The results of multi-faceted trials on outcome current diagnosis asthma in children <5years is presented in Figure 4.1.

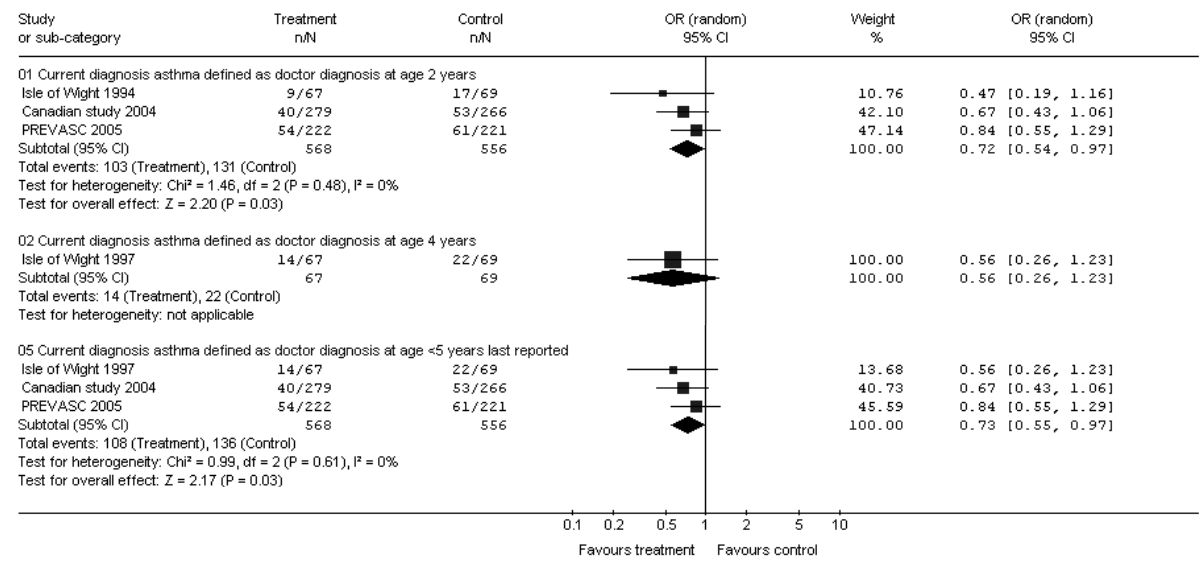

Figure 4.1 Multi-faceted interventions: outcome current diagnosis asthma $<5$ years. 
As presented in Figure 4.2 mono-faceted intervention studies did not show a significant difference compared with control when data from children at two years of age were combined from Zeiger $\mathrm{RS}^{24}$; SPACE $^{27}$; Mallet $^{21}$ (OR 1.01 $95 \% \mathrm{Cl} 0.63,1.63)$, pooled data at age three years of reported results from nacMAAS ${ }^{22}$, CAPS HDM ${ }^{19}$ (OR $\left.0.8495 \% \mathrm{Cl} 0.41,1.71\right)$ and the results of the pooling of data of studies of Mallet ${ }^{21}$ and Zeiger $^{25}$ at the age of four years (OR $1.4195 \% \mathrm{Cl} 0.52,2.54)$. Data analysed at last available assessment in children aged between two and five years did not identify a significant difference in the likelihood of physician-diagnosed asthma between treatments (OR 1.22 (95\% Cl $0.83,1.78)$.

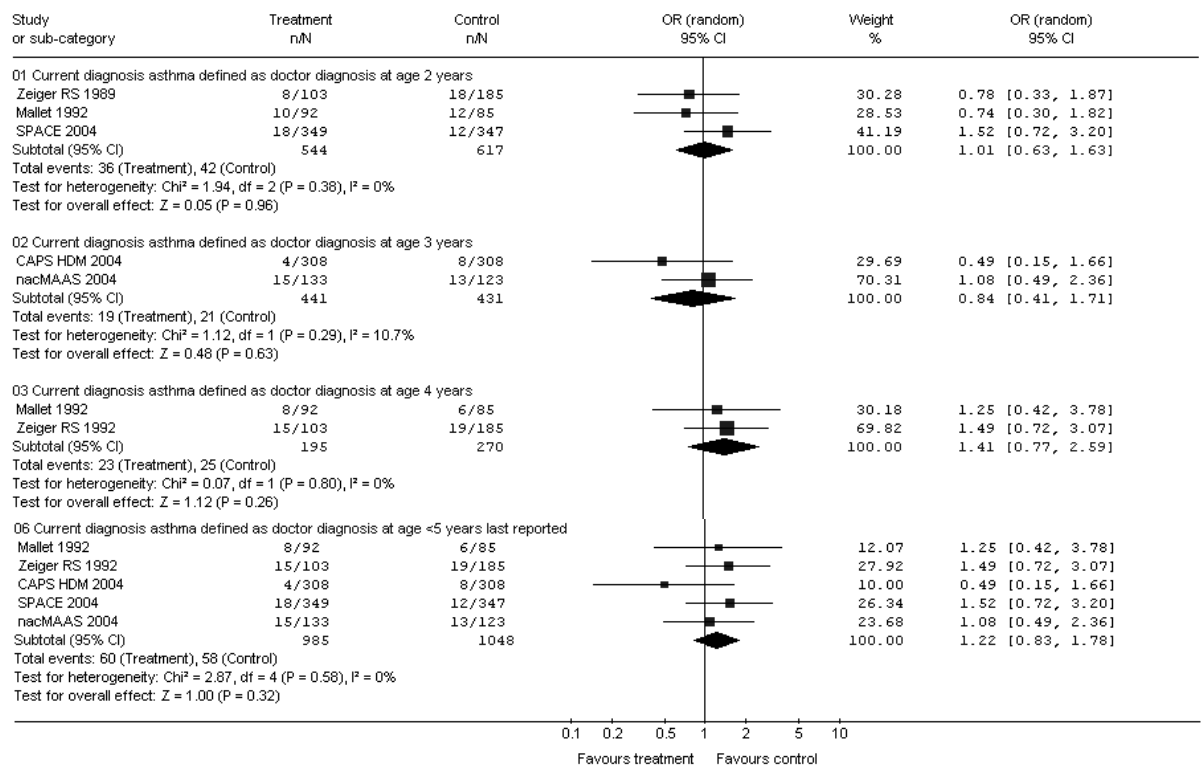

Figure 4.2 Mono-faceted interventions: outcome current diagnosis asthma $<5$ years.

The Z-test on comparison of multi-faceted and mono-faceted results on outcome 'current asthma (defined as doctor diagnosis' in children aged $<5$ years) showed a Z-score of -2.115 , which indicated a significant difference between the two types of interventions. 
Current Asthma (defined as presence of current respiratory symptoms (wheeze and/or nocturnal cough and/or dyspnoea) PLUS lung function criteria corresponding with a clinical diagnosis asthma (BHR and/or reversibility), in children aged $\geq 5$ years

As presented in Table 4.3 Multi-faceted intervention studies described results at ages seven and eight years using the definition of diagnosis asthma 'presence of current wheezing plus BHR' but these could not be age-pooled since there was only one study reporting results at age seven and one reporting results at age eight years (Canadian study ${ }^{14}$; Isle of Wight ${ }^{17}$ ). Multi-faceted intervention showed an OR for a diagnosis of asthma of OR $0.52(95 \% \mathrm{Cl} 0.32,0.84)$.

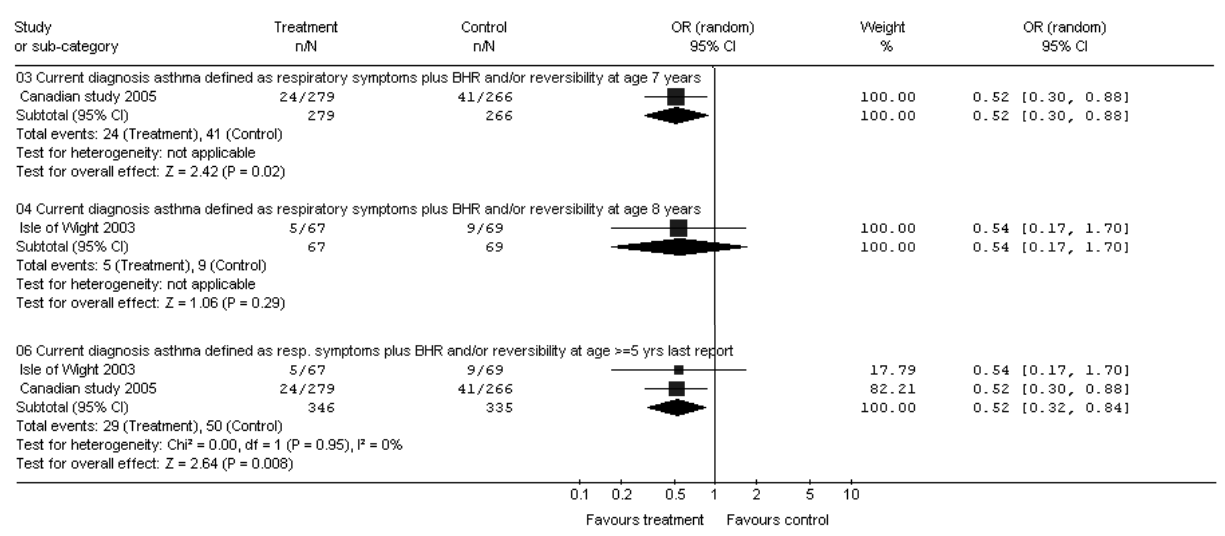

Figure 4.3 Multi-faceted interventions: outcome current diagnosis asthma $\geq 5$ years.

Two mono-faceted intervention studies reported asthma symptoms at five years and older (see Figure 4.4). Zeiger ${ }^{26}$ reported data on diagnosis asthma defined as current respiratory symptoms and reversibility at age seven years. CAPS $\mathrm{HDM}^{20}$ reported data on current respiratory symptoms and reversibility OR asthma diagnosis by health care professional at five years. Both study outcomes did not differ significantly (OR $0.86 \mathrm{Cl} 0.571 .29$ and $\mathrm{OR} 1.12 \mathrm{Cl} 0.60$ 2.11 respectively).

Current Asthma in children aged $\geq 5$ years at last assessment was not significantly different between treatment and control (OR of 0.93 with $95 \% \mathrm{Cl}$ $0.661 .31)$.

The Z-test on comparison of multi-faceted and mono-faceted results on outcome 'current asthma (defined as presence of respiratory symptoms plus lung function criteria corresponding with a clinical diagnosis asthma' showed a 
Z-score of -1.925 , which indicates there is no significant difference between the two types of interventions.

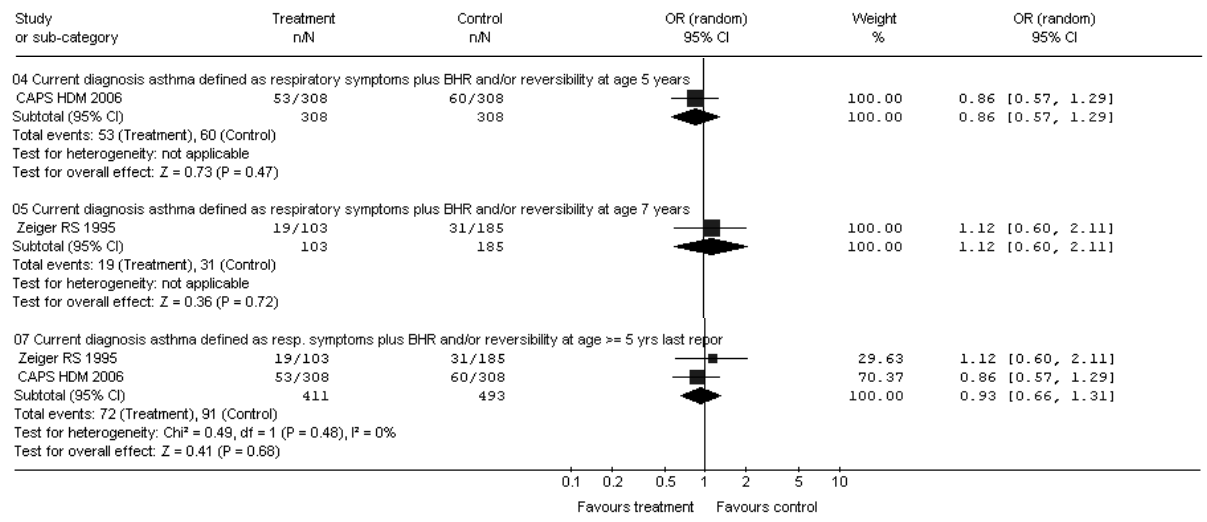

Figure 4.4 Mono-faceted interventions: outcome current diagnosis asthma $\geq 5$ years.

\section{Current respiratory symptoms}

Wheezing as described for multi-faceted interventions was reported at ages two, seven and eight years and only at age two years data could be pooled agespecifically (see Figure 4.5). The results of this pooling of data at two years were not significantly different between treatment and control (Canadian study $2004^{13}$; PREVASC $2005^{18}$ : OR $0.8195 \% \mathrm{Cl} 0.36,1.85$ ). Wheeze at last reported assessment resulted in a significant evidence in favour of treatment (Canadian study $^{14}$; Isle of Wight ${ }^{17}$; PREVASC ${ }^{18}$ : OR $0.5395 \% \mathrm{Cl} 0.35,0.81$ ).

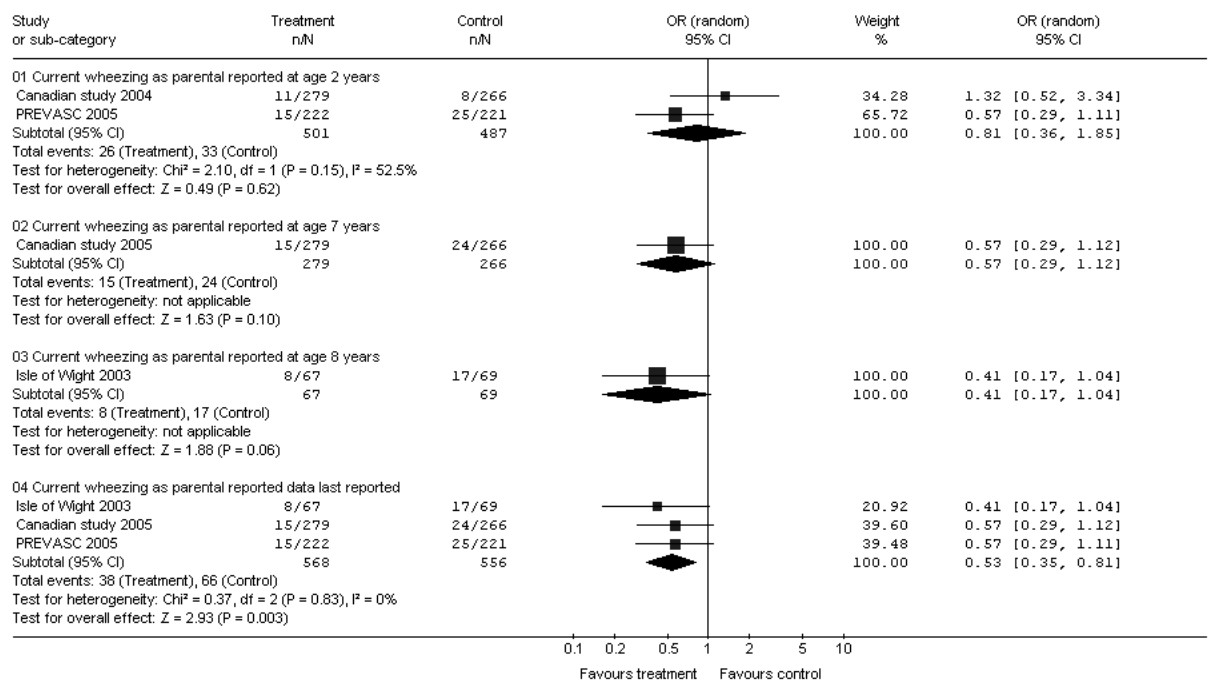

Figure 4.5 Multi-faceted interventions: outcome current wheezing. 
Outcome of mono-faceted intervention studies was described for children at ages three, four and five years (see Figure 4.6). Two studies reported data of outcome wheezing at three years of age (CAPS $\mathrm{HDM}^{19}$; nacMAAS ${ }^{22}$ ) and pooling resulted in an OR of $0.90(95 \% \mathrm{Cl} 0.63,1.31)$. Pooling of data 'Current wheezing as last reported' showed to be non-significant (nacMAAS ${ }^{22}$; PIAMA ${ }^{23}$; CAPS HDM ${ }^{20}$ : OR $\left.0.8895 \% \mathrm{Cl} 0.66,1.19\right)$.

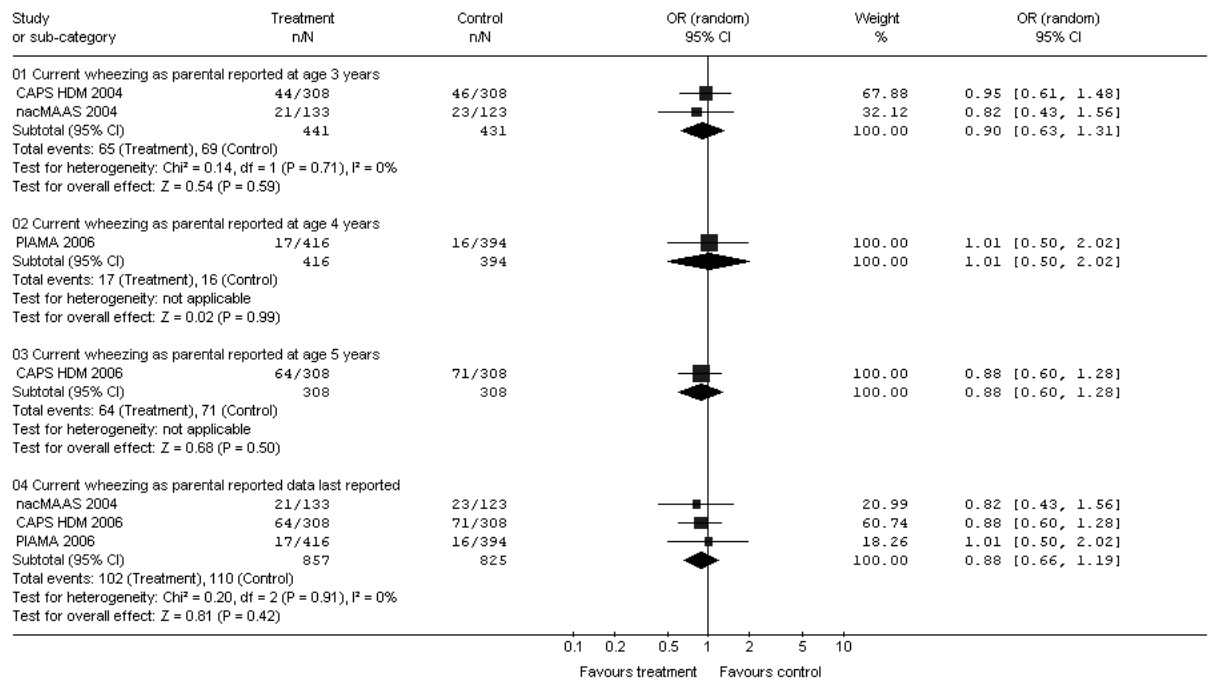

Figure 4.6 Mono-faceted interventions: outcome current wheezing.

The Z-test on comparison of multi-faceted and mono-faceted results showed a Z-score of -1.935 which indicates there is no significant difference between the two types of interventions concerning outcome 'current wheezing as last reported'.

Nocturnal cough was reported for multi-faceted intervention studies at ages two, seven and eight years (PREVASC ${ }^{18}$; Canadian study ${ }^{14}$; Isle of Wight ${ }^{17}$ ) and again could not be age-specifically pooled. Only the outcome 'current nocturnal cough as last reported' could be pooled. This pooling of last reported data showed an OR of $0.70(95 \% \mathrm{Cl} 0.43,1.17)$. The results of the multi-faceted intervention studies on outcome current nocturnal cough are presented in Figure 4.7. 


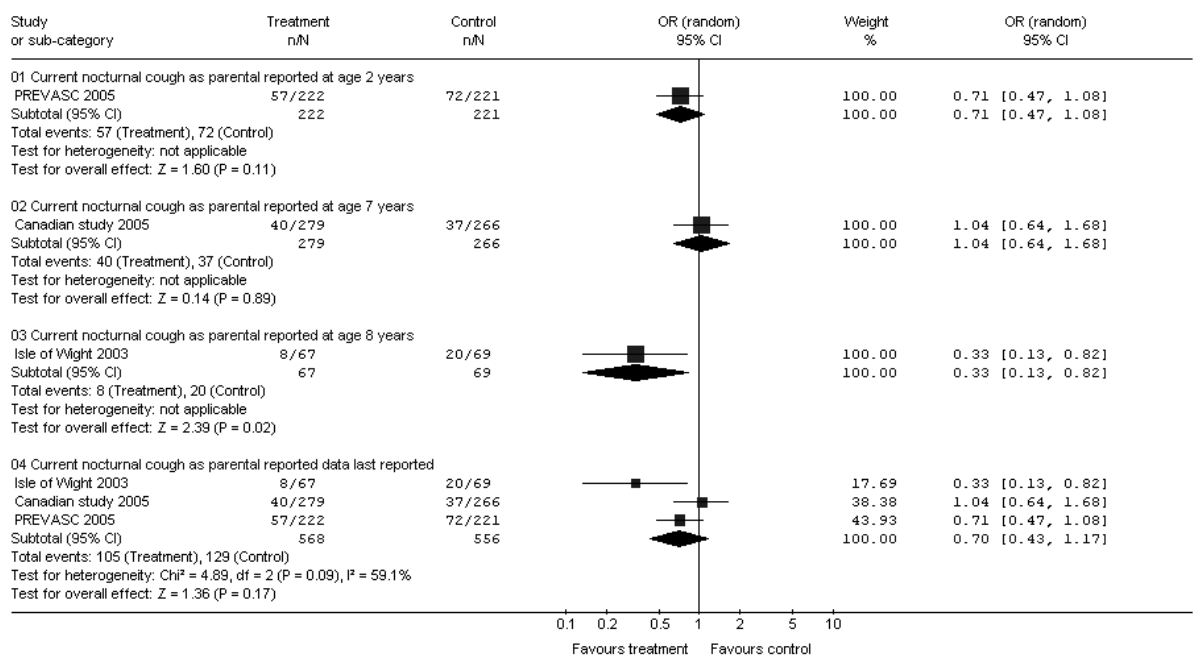

Figure 4.7 Multi-faceted interventions: outcome current nocturnal cough.

Three mono-faceted RCTs described outcome 'current nocturnal cough as reported by parents in questionnaires' (SPACE ${ }^{27}$; nacMAAS ${ }^{22}$; PIAMA $^{23}$ ). Pooling of data of these studies at two, three and four years respectively resulted in an OR of $0.99(95 \% \mathrm{Cl} 0.74,1.33)$. The results of the mono-faceted trials on outcome current nocturnal cough are presented in Figure 4.8.

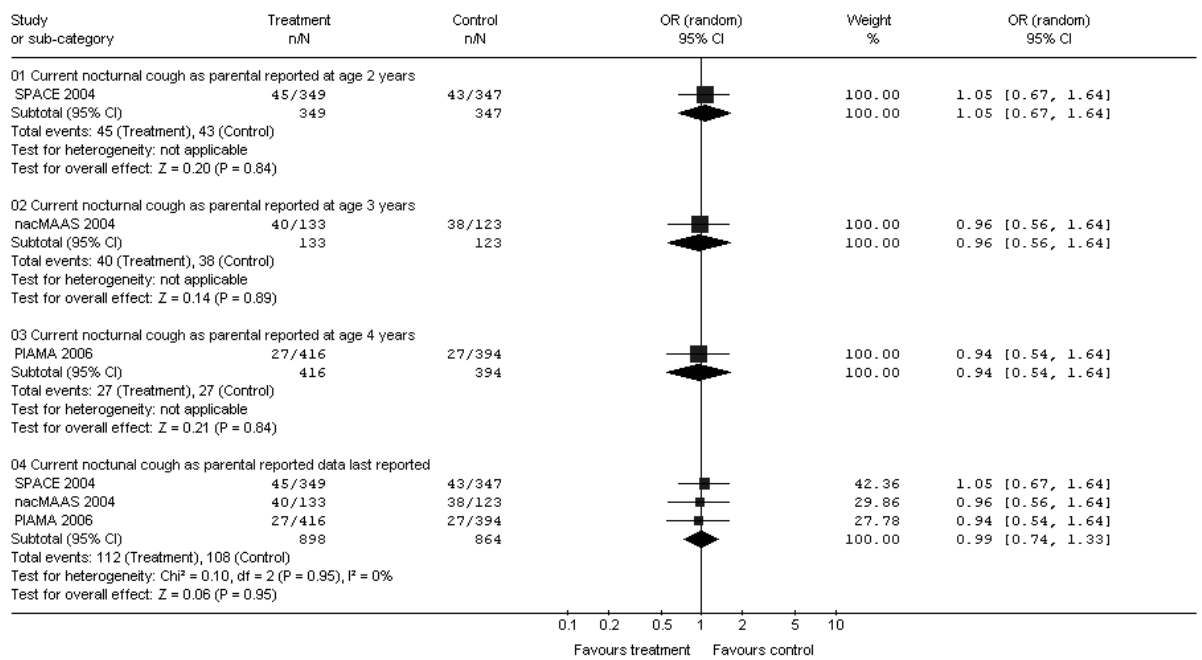

Figure 4.8 Mono-faceted interventions: outcome current nocturnal cough. 
The Z-test on comparison of multi-faceted and mono-faceted results for outcome 'current nocturnal cough as last reported' showed a Z-score of 0.149, which indicates there is no significant difference between the two types of interventions where the outcome 'current nocturnal cough' is concerned.

The only study that reported current dyspnoea as outcome was the multifaceted intervention study PREVASC. ${ }^{18}$ The age at which this outcome was reported was two years. The OR found in the PREVASC study was 0.65 with 95\% Cl 0.39, 1.08 (see Figure 4.9).

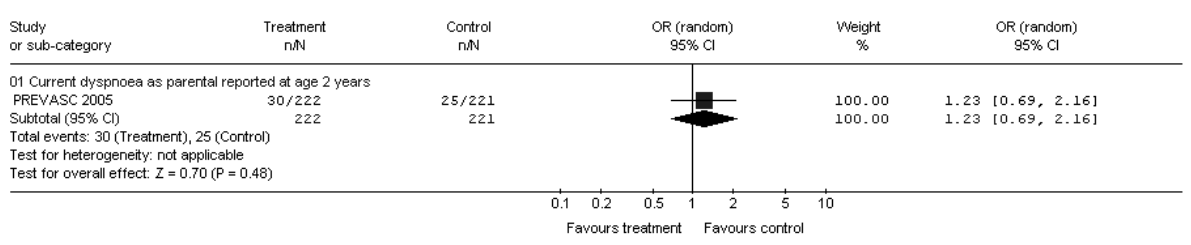

Figure 4.9 Multi-faceted intervention: outcome current dyspnoea.

\section{Sensitivity analyses}

We carried out sensitivity analyses (analyses not included in this paper) in which we sought to determine whether removing studies of post-natal intervention gave similar results to our primary analyses of all studies. The results of these analyses were compared between multi- and mono-faceted studies (Z-scores). These analyses revealed that the time of start of the intervention did not alter the direction of the results.

Stratification for duration of intervention did not result in any useful information for the research question we postulated, as comparisons of mono- and multifaceted studies were rarely possible due to large variations in duration of intervention.

\section{Discussion}

We investigated the role of different intervention-strategies (mono- or multifaceted interventions) on study outcomes pertaining to current asthma and current asthma related respiratory symptoms. We hypothesised that a multifactorial disease such as asthma can only be prevented by intervening to reduce several, or even all, causal risk factors. Allergen exposure was the primary intervention we focused on since this factor has proved to have 
significant influence on development of asthma in genetically susceptible children. ${ }^{55,56,57}$ Another reason we focused on these types of studies was that there have been numerous studies focusing on allergen reduction as primary prevention measure in children at high risk of developing asthma with negative findings. $8,19,22$ We hypothesized that the type of interventions assessed in these studies might explain these disappointing results since a lot of these studies used a mono-faceted approach. Information leading to this assumption is mainly based on results of secondary prevention strategies. ${ }^{3,4}$ To evaluate the validity of our assumption we carried out meta-analyses of mono-faceted and multifaceted allergen reducing intervention studies separately and performed Z-tests on indirect comparisons of these pooled estimates at last assessment for all outcomes pooled results of both intervention types were available.

\section{Mono-faceted intervention versus control}

The effects of mono-faceted intervention compared with control did not indicate a significant reduction in diagnosed asthma, or in any of the symptom-related endpoints we assessed.

\section{Multi-faceted intervention versus control}

Nearly all tested outcomes tended to favour treatment of multi-faceted intervention studies when pooled at specific age-time points, and when combining relevant time points (outcomes as last reported) over control. Based on the event rates in the control groups of the two studies reporting data at more than five years, 16 children would need to be treated with this form of intervention to prevent one child receiving a diagnosis of asthma after five years (Visual Rx).

Two of the multi-faceted allergen reducing intervention studies included did not only use allergen reducing study interventions but used an intervention on ETS exposure reduction as well. ${ }^{13,18}$ Reducing ETS exposure is associated with a reduction in asthma symptoms. ${ }^{58}$ Considering the low \% of parents smoking in these study groups and the absence of effect of the ETS reducing intervention, it is unlikely that this has distorted the results of the analyses carried out. It is feasible that the presence of an additional environmental intervention such as this may confound the treatment effect, particularly in families where exposure to tobacco smoke is high. Future studies which are concerned primarily with exposure to allergens and not toxicants should make provision of such an intervention in the control group so as to ensure that the independent variable is reduced exposure to allergens alone. 


\section{Indirect comparison of results}

From the comparison of Z-test scores, multiple intervention strategies were more successful than single intervention strategies when diagnosis of asthma in children less than five years of age was considered (Z-score -2.118). Z-test carried out for the outcome 'diagnosis of asthma as last reported at ages $>5$ years' showed that the comparison of mono-faceted and multi-faceted study outcome did not reach statistical significance in favour of multi-faceted interventions (Z-score -1.925). Z-scores of comparison of respiratory symptoms associated with asthma of multi-faceted and mono-faceted results at last assessment also did not reach significance either.

The statistical and clinical significance of the pooled data from seems convincing of the advantages of multi-faceted interventions over control in reducing prevalence of asthma in children. The results of the current metaanalyses indicate that asthma is likely to be prevented to a greater extent by reducing several exposures at the same time, although this observation is from an indirect comparison and as such has not been proved. The results of these meta-analyses should therefore be interpreted with caution as the method of testing the hypothesis by separate pooling of data of mono- and multi-faceted RCTs is not a direct randomised comparison. These trials all have differences in design, outcome definitions and concomitant differences in types of outcome measurements and ages at which outcome measurement was carried out.

Results of sensitivity analyses on starting point and duration of intervention showed not to alter the direction of the effect of multi- as well as mono-faceted interventions.

\section{Summary}

The hypothesis that asthma can only be prevented by reduction of exposure to multiple allergens simultaneously seems to be correct at least for current diagnosis asthma at ages $<5$ years. The non-significant outcome for the comparison of mono- and multi-faceted interventions at ages five years and older might have been caused by lack of power, difference in study outcome used in the types of studies compared or a true negative result. Multi-faceted intervention studies reported data on diagnosis of asthma defined as respiratory symptoms and BHR and mono-faceted intervention studies reported data on current diagnosis asthma defined as respiratory symptoms plus reversibility as measured by the health care professional or as measured by the study investigators. 
This apparent superiority of multiple interventions over mono-faceted intervention is sufficient to justify studies which compare differing intensities of exposure reduction. This would be an efficient way testing whether the hypothesis we have drawn from the indirect comparison formulated, would be by designing a study in which both types of interventions are performed and directly compared in the same study. Only when tested like this the criteria for direct randomised comparison will be fulfilled. To our knowledge studies designed like this have never been performed to date. Factors complicating performing such a study are the large number of participants needed to secure the power of the study, the follow-up duration of minimally six years to secure the success rate of lung function measurements and the concomitant costs. Such a study however, will be of great importance for shedding new light on preventing the development of asthma in genetically susceptible children and the current meta-analyses might inspire researchers to undertake this research.

\section{Reviewers' conclusions}

\section{Implications for practice}

The current meta-analyses provide evidence that multi-faceted interventions, characterised by dietary allergen reduction and environmental remediation, reduce the odds of a physician diagnosis of asthma later in childhood, in children who are at risk of developing childhood asthma by a half. This translates to a number needed to treat (NNT) of 16. However, the effect of multi-faceted interventions on parent reported wheeze was inconsistent and there was no evidence of benefit on nocturnal cough or dyspnoea. Monofaceted interventions were no more effective than controls in the reduction of all outcomes but there remains uncertainty as to whether multiple interventions are more effective than mono-component interventions. Children who grow up in low allergen surroundings may be at lower risk of being diagnosed with asthma but unlikely to have a lower risk of parental reported symptoms of wheeze, nocturnal cough or dyspnoea.

\section{Implications for research}

There is a pressing need for direct head-to-head comparative trials of monoand multi-faceted allergen reduction strategies. These should be administered from birth involving at least six years of follow-up. It will be of crucial importance that researchers follow the guidelines for diagnosing asthma for the study outcome, and that the diagnosing physician remains blinded to group allocation. The cost effectiveness of the intervention strategies and its possible effect on family dynamics and mental health status should be formally evaluated. 


\section{References}

1. Martinez FD. Complexities of the Genetics of Asthma. Am J Respir Crit Care Med 1997; 156:S117-22.

2. Kramer MS, Kakuma R. Maternal dietary antigen avoidance during pregnancy or lactation, or both, for preventing or treating atopic disease in the child. Cochrane Database of Systematic Reviews 2006;3:CD000133.

3. Boner AL, Niero E, Antolini I, Valletta EA. Pulmonary function and bronchial hyper-reactivity in asthmatic children with house dust mite allergy during prolonged stay in the Italian alps (Misurina, $1756 \mathrm{~m}$ ). Ann Allergy 1985;54:42-5.

4. Platts-Mills TA, Tovey ER, Mitchell EB, Moszoro H, Nock P, Wilkins SR. Reduction of bronchial hyperreactivity during prolonged allergen avoidance. Lancet 1982;2:675-8.

5. Gøtzsche PC, Johansen HK, Schmidt LM, Burr ML. Measuring inconsistency in metaanalyses. BMJ 2004;4:CD001187.

6. Killburn S, Lasserson TJ, Mc Kean M. Pet allergen control measures for allergic asthma in children and adults. Cochrane Database of Systematic Reviews 2001;(1).

7. Woodcock A, Lowe LA, Murray CS, Simpson BM, Pipis SD. Early life environmental control: effect on symptoms, sensitization, and lung function at age 3 years. Am J Respir Crit Care Med 2004;170:433-39.

8. Koopman LP, van Strien RT, Kerkhof M, Wijga A, Smit HA, de Jongste JC, Gerritsen J, Aalberse RC, Brunekreef B, Neijens HJ. Placebo-controlled Trial of House Dust Miteimpermeable Mattress Covers, Effect on symptoms in Early Childhood. Am J Respir Crit Care Med 2002;166:307-13.

9. Ninan TK, Macdonald L, Russel G. Persistent nocturnal cough in childhood: a population based study. Arch Dis Child 1995;73:403-7.

10. Verhagen AP, de Vet HCW, de Bie RA, Kessels AGH, Boers M, Bouter LM, Knipschild PG. The Delphi List. A criteria list for quality assessment of randomised clinical trials for conducting systematic reviews developed by Delphi consensus. J Clin Epidemiol 1998;51:1235-41.

11 Jadad AR, Moore RA, Carroll D, Jenkinson C, Reynolds DJ, Gavaghan DJ McQuay, H. J. Assessing the quality of reports of randomized clinical trials: is blinding necessary? Control Clin Trials 1996;17:1-12.

11. Visual Rx 2.0 [Computer program]. Cates CJ. 2003.

12. Becker A, Watson W, Fergusson A, Dimich-Ward H, Chan-Yeung M. The Canadian asthma primary prevention study: Outcomes at 2 years of age. J Allergy Clin Immunol 2004;113:650-6.

13. Chan-Yeung M, Ferguson A, Watson W, Dimich-Ward H, Rousseau R, Lilley M, DyBuncio A, Becker A. The Canadian Childhood Asthma Primary Prevention Study: Outcomes at 7 years of age. J Allergy Clin Immunol 2005;116:49-55.

14. Hide D.W., Matthews S, Matthews L, Stevens M, Ridout S, Twiselton R, Gant C and Arshad $\mathrm{SH}$. Effect of allergen avoidance in infancy on allergic manifestations at age two years. $J$ Allergy Clin Immunol 1994;93:842-6.

15. Hide DW, Matthews S, Tariq S, Arshad SH. Allergen avoidance in infancy and allergy at 4 years of age. Allergy 1996;51:89-93.

16. Arshad SH, Bateman B, Matthews SM. Primary prevention of asthma and atopy during childhood by allergen avoidance in infancy: a randomised controlled study. Thorax 2003; 58:489-93.

17. Schönberger HJAM, Dompeling E, Knottnerus JA, Maas T, Muris JWM, Weel $C$ van and Schayck CP van. The PREVASC study: the clinical effect of a multi-faceted educational intervention to prevent childhood asthma. Eur Respir J 2005;25:1-11.

18. Jennifer K, Peat HDM. Three-year outcomes of dietary fatty acid modification and house dust mite reduction in the Childhood Asthma Prevention Study. J Allergy Clin Immunol 2004; 114:807-13.

19. Marks GB, Mihrshahi S, Kemp AS, Tovey ER, Webb K, Almqvist C, Ampon RD, Crisafulli C, Belousova EG, Mellis CM, Peat JK, Leeder SR. Prevention of asthma during first 5 years of life: A randomized controlled trial. J Allergy Clin Immunol 2006;118:53-61. 
20. Mallet E, Henocq A. Long-term prevention of allergic diseases by using protein hydrolysate formula in at-risk infants. J Pediatr 1992.

21. Woodcock A, Lowe LA, Murray CS, Simpson BM, Pipis SD, Kissen P, Simpson A, Custovic A. Early Life Environmental Control: Effect on Symptoms, Sensitisation, and Lung Function at Age 3 Years. Am J Respir Crit Care Med 2004;170:433-9.

22. Corver K, Kerkhof M, Brussee JE, Brunekreef B, van Strien RT, Vos AP, Smit HA, Gerritsen J, Neijens $\mathrm{HJ}$, de Jongste JC. House dust mite allergen reduction and allergy at 4 yr: Follow up of the PIAMA study. Pediatr Allergy Immunol 2006;17:329-36.

23. Zeiger RS, Heller S, Mellon MH, Forsythe AB, O'Connor RD, Hamburger RN, Schatz M. Effect of combined matenal and infant food-allergen avoidance on development of atopy in early infancy: A randomised study. J Allergy Clin Immunol 1989;84:72-89.

24. Zeiger RS, Heller S, Mellon MH, Halsey JF, Hamburger RN, Sampson HA. Genetic and environmental factors affecting the development of atopy through age 4 in children of atopic parents: a prospective randomised study of food allergen avoidance. Pediatr Allergy Immunol 1992;3:110-27.

25. Zeiger RS, Heller S. The development and prediction of atopy in high-risk children: Follow-up at age seven years in a prospective randomised study of combined maternal and infant food allergen avoidance. J Allergy Clin Immunol 1995;95:1179-90.

26. Horak F, Matthews S, Ihorst G, Arshad SH, Frischer T, Kuehr J, Schwieger A, Forster J, SPACE study group. Effect of mite-impermeable mattress encasings and an educational package on the development of allergies in a multinational randomized, controlled birth-cohort study-24 months of the Study of Prevention of Allergy in Children in Europe [Effect of miteimpermeable mattress encasings and an educational package on the development of allergies in a multinational randomized, controlled birth-cohort study-24 months of the Study of Prevention of Allergy in Children in Europe]. Clin Exp Allergy 2004;34:1220-5.

27. Kjellman NIM, Johansson SGO. Soy versus cow's milk in infants with biparental history of atopic disease: development of atopic disease and immunoglobulins from birth to 4 years of age. Clin Allergy 1979;9:347-58.

28. Johnstone DE, Dutton AM. Dietary prophylaxis of allergic disease in children. N Engl J Med 1966;274:715-9.

29. Chandra RK. Five-Year Follow-Up of High-Risk Infants with Family History of Allergy Who were Exclusively Breast-Fed or Fed Partial Whey Hydrolysate, Soy, and Conventional Cow's Milk Formulas. J Pediatr Gastroenterol Nutr 1997;24:380-8.

30. Maas T, Dompeling E, van Schayck CP, Muris JWM, Schönberger HJAM, Wesselinig G, Platts-Mills TAE, Knottnerus JA. Birth Cohort Studies on Asthma Development. Pediatr Asthma Allergy Immunol 2005;18:201-15.

31. Chan-Yeung M, Becker A. Primary prevention of childhood asthma and allergic disorders. Curr Opin Allergy Clin Immunol 2006;6:146-51.

32. Koopman LP, van Strien RT, Kerkhof M, Wijga A, Smit HA, de Jongste JC Gerritsen J, Aalberse RC, Brunekreef B, Neijens HJ. Placebo-controlled trial of house dust miteimpermeable mattress covers: effect on symptoms in early childhood. Am J Crit Care Med 2002;166:307-13.

33. Kuiper S, Maas T, van Schayck CP, Muris JWM, Schönberger HJAM, Dompeling E, Gijsbers $B$, van Weel C, Knottnerus JA. The primary prevention of asthma in children study: Design of a multifaceted prevention program. Pediatr Allergy Immunol 2005;16:321-31.

34. Halmerbauer G, Gartner C, Schierl M, Arshad H, Dean T, Koller DY, Karmaus W, Kuehr J, Forster J, Urbanek R, Frischer T. Study on the Prevention of Allergy in Children in Europe (SPACE): Allergic sensitization at 1 year of age in a controlled trial of allergen avoidance from birth. Pediatric Allergy Immunol 2003;14:10-7.

35. Arshad SH, Matthews S, Gant C, Hide DW. Effect of allergen avoidance of development of allergic disorders in infancy. Lancet 1992;339:1493-97.

36. Boggs PB, Simon MR, Terreehorst I, Hak E, Van Wijk RG. Bed covers and Dust Mites [1] (multiple letters). New Eng J Med 2003;349:1668-71.

37. Bottcher MF, Jenmalm MC. Breastfeeding and the development of atopic disease during childhood. Clin Exp Allergy 2002;32:159-61. 
38. Brunekreef B, Smit J, De Jongste J, Neijens H, Gerritsen J, Postma D, Aalberse R, Koopman L. The Prevention and Incidence of Asthma and Mite Allergy (PIAMA) birth cohort study: Design and first results. Pediatr Allergy Immunol Suppl 2002;13:55-60.

39. Canadia Medical Association. Prevention strategies for asthma. Can Med Assoc J 2005;173(S6):S20-4.

40. Chan-Yeung M, Ferguson A, Dimic-Ward H, Watson W, Manfreda J, Becker A. Effectiveness of and compliance to intervention measures in reducing house dust and cat allergen levels. Ann Allergy Asthma Immunol 2002;88:52-8.

41. Custovic A, Simpson B, Simpson A, Hallam C, Craven M, Brutsche M, Woodcock A. Manchester Asthma an Allergy study: low-allergen environment can be achieved and maintained during pregnancy and early life. J Allergy Clin Immunol 2000;105:252-8.

42. Custovic A, Woodcock A. Clinical effects of allergen avoidance. Clin Rev Allergy Immunol 2000;18:397-419.

43. Custovic A, Simpson BM, Simpson A, Kissen P, Woodcock A. Effect of environmental manipulation in pregnancy and early life on respiratory symptoms and atopy during first year of life: A randomised trial. Lancet 2001;358:188-93.

44. Dunstan JA, Mori TA, Barden A, Beilin LJ, Taylor AL, Holt PG, Prescot SL. Fish oil supplementation in pregnancy in pregnancy modifies neonatal allergen-specific immune responses and clinical outcomes in infants at high risk of atopy: a randomized controlled trial. $\mathrm{J}$ Allergy Clin Immunol 2003;112:1178-84.

45. Kalliomaki M, Salminen S, Arvilommi H, Kero P, Koskinen P, Isolauri E. Probiotics in primary prevention of atopic disease: a randomised placebo-controlled trial. Lancet 2001;357:1076-9.

46. Marini A, Agosti M, Motta G, Mosca F. Effects of dietary and environmental prevention programme on the incidence of allergic symptoms in high atopic risk infants: three years followup. Acta Paediatrica Suppl 1996;414:1-22.

47. Marks GB, Mihrshahi S, Kemp AS, Tovey ER, Webb K, Almqvist C, Ampon RD, Crisafulli C, Belousova EG, Mellis CM, Peat JK, Leeder SR. Prevention of asthma during first 5 years of life: A randomized controlled trial. J Allergy Clin Immunol 2006;118:53-61.

48. Mihrshahi S, Peat JK, Webb K, Tovey ER, Marks GB, Mellis CM, Leeder SR. The Childhood Asthma Prevention Study (CAPS): design and research protocol of a randomised trial for the primary prevention of asthma. Control Clin Trials 2001;22:333-54.

49. Peat JK, Mihrshahi S, Kemp AS, Marks GB, Tovey ER, Webb K, Mellis CM, Leeder SR and for the Childhood Asthma Prevention Study Team. Three-year outcomes of dietary fatty acid modification and house dust mite reduction in the Childhood Asthme Prevention Study. J Allergy Clin Immunol 2004;114:807-13.

50. Saarinen UM, Kajosaari M, Backman A, Siimes MA. Prolonged Breast-Feeding as Prophylaxis for Atopic Disease. Lancet 1979;2:163-6.

51. Simpson A, Simpson B, Custovic A, Craven M, Woodcock A. Stringent environmental control in pregnancy and early life: the long-term effects on mite, cat and dog allergen. Clin Exp Allergy 2004;114:807-13.

52. Simpson A, Custovic A. Allergen avoidance in the primary prevention of asthma. Curr Opin Allergy Clin Immunol 2004;4:45-51.

53. van Strien RT, Koopman LP, Kerkhof M, Spithoven J, de Jongste JC, Gerritsen J, Neijens HJ. Mite and Pet allergen levels in homes of children born to allergic and nonallergic parents: The PIAMA study. Environ Health Perspect 2002;110:A693-8.

54. Lemanski RF Jr. Issues in understanding pediatric asthma: epidemiology and genetics. J Allergy Clin Immunol 2002;109(S6):S521-4.

55. Nelson HS, Szefler SJ, Jacobs J, Huss K, Shapiro G, Sternberg AL. The relationships among environmental allergen sensitization, allergen exposure, pulmonary function, and bronchial hyperresponsiveness in the Childhoid Asthma Management Program. J Allergy Clin Immunol 1999;104:775-85.

56. Wright AL, Taussig LM. Lessons from long-term cohort studies. Childhood asthma. Eur Respir J 1998;27:17s-22s. 
57. Stuart A, Huang N. Review of public health interventions for asthma. In: Rural and Regional Health and Aged Care Services Division, Victorian Government Department of Human Services, Melbourne, Victoria. 2004. 


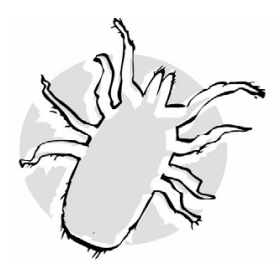

\section{Chapter 5}

\section{Distribution of House Dust Mite Allergen.}

Comparing house dust mite allergen levels in dust samples

collected from different sites on living room floors with smooth coverings
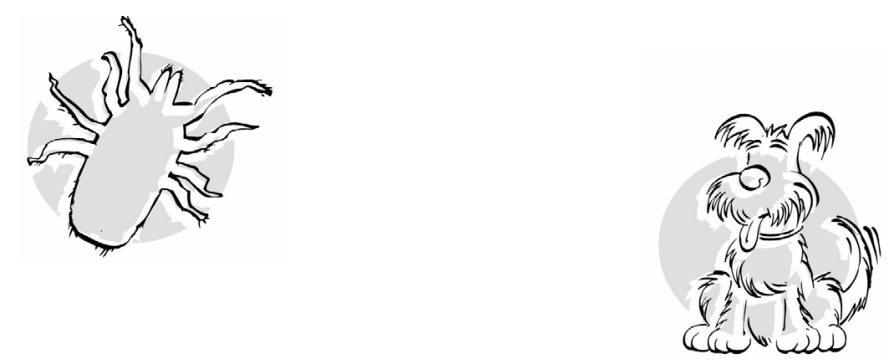

Maas T, Rovers JJM, Schönberger HJAM, van Schayck OCP Allergy 2003:58:500-502 


\section{Abstract}

\section{Background}

The distribution of house dust mite allergen (Der p1) in living rooms with smooth floor coverings, as measured in the middle compared to the border of the floor was investigated. It was hypothesized that activity causes displacement of Der $\mathrm{p} 1$, from the middle towards the border.

\section{Methods}

Dust samples from the middle and border of 50 floors with smooth coverings were collected and analysed on Der p1 content in a standardized way.

\section{Results}

Der $\mathrm{p} 1$ exposure expressed as per unit area $\left(\mathrm{ng} / \mathrm{m}^{2}\right)$ showed that border samples contained significantly more Der p1 compared to middle samples (median: 2.57 versus 0.27 respectively, $p=0.023$ ). Presence of pets and presence of more than two inhabitants both increased the difference. When expressed as per unit weight of dust $(\mathrm{ng} / \mathrm{g})$ significant differences were only detected when comparing Der p1 content of samples collected in households with three or more inhabitants (median: 2 (border) versus 53 (middle) respectively, $p=0.035$ ).

\section{Conclusions}

Der $\mathrm{p} 1$ is unequally distributed on living room floors with smooth coverings, most likely because of displacement of dust from the middle towards the border due to activity. Expression as $\mathrm{ng} / \mathrm{g}$ of dust and $\mathrm{ng} / \mathrm{m}^{2}$ showed not to be obviously interchangeable. 


\section{Introduction}

In most survey studies concerning measurement of exposure to house dust mite allergen (Der $\mathrm{p} 1$ ) in floor dust, the sampling procedure is standardized. ${ }^{1-2}$ For measurement within living rooms the recommendation was made that at least two sites should be sampled because of unequal distribution. ${ }^{3}$ However there is no uniformity about the exact sampling locations. ${ }^{4}$ The aim of the present study was to investigate whether Der $\mathrm{p} 1$ content of floor dust samples collected from sites at the border compared to sites in the middle of living rooms with smooth floor coverings are comparable. We hypothesized that activity causes displacement of dust and Der p1 mainly from the middle towards the border.

\section{Methods}

Dust samples were collected from 50 living room floors with smooth coverings. Participants were asked to make sure that one week prior to sampling, rugs if present were removed and their living room floor was not cleaned. Presence of pets in the living room and number of inhabitants were assessed. On each floor two dust samples were collected of which one at the border $\left(3 \mathrm{~m}^{2}\right.$ adjacent to the wall, one meter wide) and one as much as possible in the middle of the room $\left(3 \mathrm{~m}^{2}\right)$. It was made sure that the sampling sites were as far as possible from frequently used doors. Sampling sites were vacuumed for $2 \mathrm{~min} / \mathrm{m}^{2}$ each (vacuum cleaner $1300 \mathrm{~W}$ ). Dust was collected onto glass micro fibre filters and stored at $-12^{\circ} \mathrm{C}$ until analysis. After weighing the un-sieved dust, a $10 \%(\mathrm{w} / \mathrm{v})$ extract in borate-buffered saline with $0.1 \%$ Tween-20, $\mathrm{pH}=8.0$, was obtained by overhead rotation for two hours at room temperature. After centrifuging (ten minutes 4250 RPM), Der p1 content was determined by means of two-site monoclonal ELISA with an assay sensitivity of $2 \mathrm{ng} / \mathrm{g}$ of dust. Allergen standard 93/03 $(2500 \mathrm{ng} / \mathrm{ml}$ Derp1) was used for calculation of results. Data were expressed as $\mathrm{ng} / \mathrm{g}$ of dust and Der $\mathrm{p} 1$ content expressed as $\mathrm{ng} / \mathrm{m}^{2}$ was computed.

Untransformed Der p1 levels were used for statistical analysis, as logarithmic transformation failed to normalize the distribution. By means of the nonparametric Wilcoxon Signed Ranks Test $(\alpha=0.05)$ comparison was made between Der $\mathrm{p} 1$ levels of the two sampling sites. 


\section{Results}

In Table 5.1 and 5.2 median, range and level of significance of Der $\mathrm{p} 1$ content of middle versus border samples are presented. Table 5.1 contains data expressed as $\mathrm{ng} / \mathrm{m}^{2}$ and data expressed as $\mathrm{ng} / \mathrm{g}$ of dust are shown in Table 5.2 . Data on overall allergen content as well as on the comparison of samples collected in homes with versus those without pets and with less than three versus those with three or more inhabitants are presented.

Table 5.1 Comparison of Der $\mathrm{p} 1$ content of dust samples collected from sites in the middle and at the border of living room floors with smooth coverings expressed as per unit area $\left(\mathrm{ng} / \mathrm{m}^{2}\right)$

\begin{tabular}{lllll}
\hline & $\mathrm{n}$ & $\begin{array}{l}\text { Median (range) } \\
\text { Middle }\end{array}$ & Border & $\mathrm{p}(\alpha=0.05)$ \\
\hline $\begin{array}{l}\text { Overall data } \\
\text { More than two inhabitants }\end{array}$ & 50 & $0.27(0.0067-84.89)$ & $2.57(0.0067-161.60)$ & 0.023 \\
Yes & 23 & $0.29(0.053-84.84)$ & $4.58(0.053-83.50)$ & 0.018 \\
No & 27 & $0.25(0.0067-84.89)$ & $0.39(0.0067-161.60)$ & 0.501 \\
$\begin{array}{l}\text { Presence of pets } \\
\text { Yes }\end{array}$ & & & & \\
No & 19 & $0.29(0.053-84.89)$ & $5.76(0.093-161.60)$ & 0.009 \\
\hline
\end{tabular}

Table 5.2 Comparison of Der $\mathrm{p} 1$ content of dust samples collected from sites in the middle and at the border of living room floors with smooth coverings expressed as per unit weight of dust (ng/g).

\begin{tabular}{lllll}
\hline & $\mathrm{n}$ & $\begin{array}{l}\text { Median (range) } \\
\text { Middle }\end{array}$ & Border & $\mathrm{p}(\alpha=0.05)$ \\
\hline $\begin{array}{l}\text { Overall data } \\
\text { More than two inhabitants }\end{array}$ & 50 & $2(2-749)$ & $21(2-835)$ & 0.136 \\
$\begin{array}{l}\text { Yes } \\
\text { No }\end{array}$ & 23 & $2(2-471)$ & $53(2-835)$ & 0.035 \\
$\begin{array}{l}\text { Presence of pets } \\
\text { Yes }\end{array}$ & 27 & $2(2-749)$ & $2(2-606)$ & 0.955 \\
No & 19 & $2(2-749)$ & $53(2-606)$ & 0.124 \\
\hline
\end{tabular}

Overall more Der $\mathrm{p} 1$ was found in samples collected at the border compared to levels in the middle of the room irrespective of the way of expression $(\mathrm{ng} / \mathrm{g}$ or $\mathrm{ng} / \mathrm{m}^{2}$ ). However, when expressed as $\mathrm{ng} / \mathrm{g}$ of dust, the difference appeared not to be significant $(p=0.136)$ in contrast with expression as $n g / \mathrm{m}^{2}$.

The median overall Der $\mathrm{p} 1$ content, expressed as $\mathrm{ng} / \mathrm{m}^{2}$, in middle samples versus samples at the border was 0.27 and 2.57 respectively $(p=0.023)$. In households where pets were allowed to stay in the living room $(n=19)$ and in those that were occupied by more than two inhabitants $(n=23)$ the difference of Der p1 content showed to be larger than the difference in overall Der p1 
content, again irrespective of the way of expression. A significant difference between the median Der p1 content in samples collected at the border as compared to the middle of the room in households with three or more inhabitants was demonstrated when expressed as $\mathrm{ng} / \mathrm{m}^{2}$ as well as $\mathrm{ng} / \mathrm{g}$ dust $(p=0.018$ and $p=0.035$ respectively). As was the case when comparing middle and border samples on overall Der p1 content, presence of pets showed to differ significantly only when data were expressed as $n g / m^{2}\left(n g / m^{2} p=0.009\right.$, $\mathrm{ng} / \mathrm{g} \mathrm{p}=0.124)$.

\section{Discussion}

The results of the present study show that on smooth floor coverings there actually does seem to be a clear pattern of distribution of Der $\mathrm{p} 1$, for we found significantly greater amounts of Der $\mathrm{p} 1$ at the border compared to areas in the middle of the living room floor. Earlier research on the distribution of Der p1 within carpeted living rooms did not show a consistent pattern of distribution of Der $\mathrm{p} 1$, although a great variation of Der $\mathrm{p} 1$ levels between areas on the floor was found. ${ }^{5}$

Although there's still much unclear about factors affecting the distribution of house dust mites, ${ }^{6}$ our findings suggest that on floors with smooth coverings activity favours displacement of Der p1 towards the border. As was hypothesized Der $\mathrm{p} 1$ levels in the middle of the room showed to be less than at the border and distribution is increased when more inhabitants or pets are present.

It is of further interest whether allergen content of dust should be expressed as $\mathrm{ng} / \mathrm{m}^{2}$ or as $\mathrm{ng} / \mathrm{g}$ of dust. In epidemiological studies expression as $\mathrm{ng} / \mathrm{g}$ of dust is considered to be suitable, however in intervention studies expression as $\mathrm{ng} / \mathrm{m}^{2}$ is recommended. ${ }^{2}$ In addition, the suggestion has been made that these methods for expression can be interchanged. ${ }^{7}$ In the present study however this was not the case, as variation of the amount of dust $(\mathrm{g}$ ) between different sampling areas on the living room floor lead to different results when Der $\mathrm{p} 1$ content was expressed as $\mathrm{ng} / \mathrm{g}$ of dust. Where a statistically significant difference was detected between middle and border samples when expressed as $\mathrm{ng} / \mathrm{m}^{2}$, no significant difference was detected when overall data were expressed as $\mathrm{ng} / \mathrm{g}$ of dust. Possibly the lack of significance can be explained by the smaller range of Der $\mathrm{p} 1$ results when expressed as $\mathrm{ng} / \mathrm{g}$ of dust. However, the expression as $\mathrm{ng} / \mathrm{m} 2$ does reflect the actual amount of Der $\mathrm{p} 1$ present at the sampled area whereas the expression as $\mathrm{ng} / \mathrm{g}$ of dust merely reflects the concentration of Der p1 in floor dust.

We conclude that Der $\mathrm{p} 1$ content of dust samples taken from middle and border sites on the living room floor differ significantly when expressed as $\mathrm{ng} / \mathrm{m}^{2}$, most 
likely because of displacement of dust from the middle towards the border due to activity by inhabitants and pets. When expressed as $\mathrm{ng} / \mathrm{g}$ of dust, a statistically significant difference was determined only when comparing data on Der p1 content in samples collected in households with three or more inhabitants. We suggest that Der $\mathrm{p} 1$ content expressed as $\mathrm{ng} / \mathrm{g}$ of dust and $\mathrm{ng} / \mathrm{m}^{2}$ cannot obviously be interchanged. Given this knowledge and the plausibility that Der $\mathrm{p} 1$ expressed as $\mathrm{ng} / \mathrm{m}^{2}$ does reflect the actual allergen exposure our study results do underline the use of the expression as $\mathrm{ng} / \mathrm{m}^{2}$ in studies in which Der $\mathrm{p} 1$ exposure is a possible determining factor. 


\section{References}

1. Platts-Mills TAE, Thomas W, Aalberse RC, Vervloet D, Chapman MD. Dust mite allergens and asthma: Report of a second international workshop. J Allergy Clin Immunol 1992;89:1046-60.

2. Luczynska CM. Identification and quantification of mite allergens. Allergy 1998;53(S48):54-7.

3. Marks GB, Tovey ER, Peat JK, Salome CM, Woolcock AJ. Variability and repeatability of house dust mite allergen measurement: implications for study design and interpretation. Clin Exp Allergy 1995;25:1190-7.

4. Hill MR. Quantification of house dust mite populations. Allergy 1998;53(S48):18-23.

5. Simpson A, Hassall R, Custovic A, Woodcock A. Variability of house-dust-mite allergen levels within carpets. Allergy 1998;53:602-7.

6. Colloff MJ. Practical and theoretical aspects of the ecology of house dust mites (Acari: Pyroglyphidae) in relation to the study of mite-mediated allergy. Rev Med Vet Entomol 1991; 79:611-29.

7. Custovic A, Taggart SCO, McL Niven R, Woodcock A. Evaluating exposure to mite allergens. J Allergy Clin Immunol 1995;96:134-5. 



\section{Chapter 6}

Do common infections influence the development of asthma and allergy?

About confirming or rejecting the hygiene hypothesis

Maas T, Verduin EP, Muris JWM, Dompeling E, Damoiseaux JCMG, Kuiper S, Vaes JJ, Wesseling G, Knottnerus JA, van Schayck OCP Submitted 


\section{Abstract}

\section{Background}

The hygiene hypothesis assumes that infections in early childhood keep the developing immune system from becoming unbalanced and therefore from developing allergic diseases.

\section{Objective}

To assess the relationship between the occurrence of upper respiratory tract (URT) and gastrointestinal $(\mathrm{Gl})$ infections, and the development of asthma in the first four to six years of life.

\section{Methods}

The relationship between infections and the occurrence of asthma was studied in 443 high risk children of the PREVASC cohort. The number of episodes of common cold and diarrhoea were the independent variables. Dependent variables were a general practitioners' diagnosis of asthma, asthmatic symptoms at age four to six and total and specific $\lg E$ at age six.

\section{Results}

Regression analyses showed no significant relationship between asthma diagnosis and common cold nor diarrhoea. The number of episodes of diarrhoea however was found to be related to the occurrence of asthma symptoms at age four to six $(\mathrm{OR}=1.240, \mathrm{Cl} 1.085$ to 1.417$)$. The number of episodes of common cold showed to be inversely related to total IgE at age six $(B=-0.080, \mathrm{Cl}-0.134$ to -0.027 ). Diarrhoea showed to be related to the level of specific IgE against HDM allergens $(\mathrm{OR}=0.690, \mathrm{Cl} 0.483$ to 0.984$)$.

\section{Conclusion}

This study does not provide evidence for the assumption that the development of asthma is prevented by URT or GI infections in children at high risk of developing asthma. The infections although seemed to influence atopy. 


\section{Introduction}

Asthma is a multi-factorial disease that is thought to be caused by genetic factors as well as by environmental influences. In the past decade the hygiene hypothesis ${ }^{1}$, describing the effects of infections on allergy and asthma development, gained popularity. This hypothesis states that infections might keep the developing immune system from becoming unbalanced and so from developing a predisposition to allergic diseases like asthma.

After the hygiene hypothesis was launched, several studies were carried out to try to confirm this immunological theory, as well as to come up with the clinical evidence to underpin this hypothesis. The immune deviation theory, explaining the immunological background of the hygiene hypothesis, was first described for humans by Holt and colleagues. ${ }^{2-4}$ Whereas children usually are born with a T-helper cell type 2 (Th2) polarised immune system, exposure to viral infections, known for their T-helper cell type 1 (Th1) stimulating effect, was hypothesized to cause the immune system to deviate towards the non-allergic mode within the first 2 years of life. ${ }^{2-4}$ Recent evidence suggests that this protective effect might be mediated by regulatory $T$ lymphocytes (Treg). The Treg reaction results in inhibition of both Th1 and Th2 response.,

Previous studies investigating the hygiene hypothesis in children were retrospective studies concerning the influences of proxy variables for infection load such as day-care attendance and older siblings. ${ }^{7-13}$ The link between these variables and the hygiene hypothesis is that those children that come in contact with older children on a regular basis are more exposed to different pathogens at a younger age and are likely to develop more common infections. Golding and Peters first described the sibling, or birth-order, effect in $1986 .{ }^{14}$ They found a significant negative effect on the occurrence of eczema and hay fever in relation to the number of older siblings. They concluded that more older siblings might protect a child against the development of asthma.

Based on multiple prospective studies on the clinical effect of specific viruses on allergic disease, published opinions on the influence of infectious disease in childhood have taken on a more cautious tone in recent years. ${ }^{15}$ Although positive as well as negative results have been published, a summary of these results does not support any firm conclusion that infections do have a clear effect on the development of atopic diseases. ${ }^{16,17}$

We had access to prospectively collected data for episodes of common cold and diarrhoea from children at high risk of developing asthma, who had been followed up from prenatal age to the age of six years in the PREVASC study, a randomised controlled multi-faceted trial on the primary PREVention of ASthma in Children at high risk of developing asthma. ${ }^{18,19}$ These data might contribute to our knowledge of the effects infectious diseases may have on allergy and asthma development. 
The current research question is a post-hoc research question within the scope of the PREVASC study. ${ }^{18}$ The question posed in this manuscript is: What is the relationship between the proxy parameters of URT infections (common cold) and gastrointestinal infections (diarrhoea associated with fever), and the development of asthma (at age four to six) and allergy (at age six, based on lgE level) in children at high risk of developing asthma?

\section{Methods}

The PREVASC database, which contains data for 443 participating children followed up from birth until six years of age, was used to answer the current research question. ${ }^{18}$ This $\mathrm{RCT}$ was designed to answer the research question if asthma can be prevented in children at risk of developing asthma by making use of an educational intervention aimed at reducing the exposure to environmental factors like allergens and tobacco smoke. The PREVASC study recruited children with a high risk of developing asthma during the prenatal period and randomised them to either 1) a control group $(n=221)$, receiving usual care; or 2) an intervention group $(n=222)$ in which families received instructions from nurses on how to reduce the exposure of newborns to mite, pet and food allergens, as well as to passive smoking. 'High risk' was defined as 'at least one first-degree family member (i.e., the pregnant woman, the biological father of the unborn child or a full sibling) suffering from GP-registered asthma'. ${ }^{18}$ Randomisation and blinding was done in zip-code clusters at the general practitioners' (GP) practice level in order to minimise the probability of exchange of information between participants.

The primary outcome variable evaluated in the present post-hoc research question was the diagnosis of asthma in the first four to six years of life as prospectively reported by GPs. The PREVASC study collected GP diagnoses, as well as symptoms. For the measurement of symptoms suggestive of asthma as reported by parents questionnaires based on the International Study of Asthma and Allergies in Childhood were used. ${ }^{20}$ Parents were asked to complete these questionnaires.

Total and specific Immunoglobulin E ( $\mathrm{IgE}$ ) serum levels were measured to be used as additional information on the development of allergy. The specific lgE levels measured in the PREVASC study were aimed at house dust mite, cat and dog allergens. The samples the serum was derived from were obtained by finger prick tests (capillary blood) in children at age six. The samples were absorbed on filter paper. These analyses were performed by Sanquin, The Netherlands. ${ }^{21} \mathrm{lgE}$ levels above the threshold value $25 \mathrm{IU} / \mathrm{ml}$ for total $\mathrm{IgE}$ and above $0.35 \mathrm{IU} / \mathrm{ml}$ for specific IgE were analysed. 
A complete review of the methods of the PREVASC study is given in the articles by Schönberger et al. and Kuiper et al. ${ }^{18,19}$

The independent variables used to answer our research question were: the number of episodes of common cold and of diarrhoea associated with fever in the first two years of the child's life as prospectively registered by parents in weekly reports.

The primary outcome variable was the diagnosis of asthma (GP diagnosis at age four to six). The other outcome variables were symptoms associated with asthma (wheezing, nocturnal coughing and dyspnoea) in the first four to six years as prospectively registered by the parents in questionnaires and/or the GP (0/1) and total and specific (house dust mite) lgE serum level at age six.

The confounding proxy variables for infection load that were included were based on earlier studies, proxy variables for infection load: older sibling(s) (0/1) and day-care attendance ever $(0 / 1) .^{7-12,22,23}$ Other confounding variables included were gender (boy 0/1) and the mother's history of asthma (GP reported 0/1), any siblings with a history of asthma (GP reported 0/1), group allocation in the PREVASC-study (intervention group 0/1) as well as the possible confounding exposure factors: the number of weeks the children were breastfed (exclusive or in combination with artificial formula and/or solid foods), the smoking status of mothers during pregnancy $(0 / 1)$, the smoking status of parents during the first year of the child's life (0/1), HDM (Der p1), cat (Fel d1) and dog (Can f1) allergen exposure level as measured in dust samples collected from the mattresses of parents and children at age six months, expressed as $\mu \mathrm{g} / \mathrm{m}^{2}$, and the presence of a cat or dog in the household $(0 / 1)$.

\section{Statistics}

Regression analyses were carried out using the Statistical Package for the Social Sciences (SPSS) for Windows version 15.0.

The development of asthma was registered by the GP (diagnosis and symptoms, 0/1) and parents (symptoms, 0/1); these data were tested in logistic regression analyses. The total IgE serum level was log normal transformed to obtain a normal distribution for linear multiple regression analyses. The specific IgE levels (HDM, cat and dog) were dichotomised above or below the level associated with allergic disease: $0.35 \mathrm{IU} / \mathrm{ml}$. Logistic regression analyses were carried out for the outcomes on the specific lgE levels.

Infection load, number of episodes of common cold and diarrhoea remained mandatory in the logistic model even if they had no statistically significant relationship with the outcome variables. The number of episodes of diarrhoea associated with fever the children experienced during the first two years of life was included in a single variable. To protect the analyses from loosing too many cases in the analyses two variables on the number of episodes of common cold 
were included. The variable with the least influence was removed from the model.

Using a backward procedure we excluded step-by-step those variables that were shown not to influence the outcome variable $(p<0.100)$.

Due to missing values and the deletion of several variables in the regression analyses, outcomes may not be given for the entire cohort. The number of participants still eligible for analysis will be mentioned in the title of every table.

\section{Results}

A total of 476 families were included in the study; 242 families in the intervention group and 234 families in the control group. Loss to follow-up until age six was 23 in the intervention group and 14 in the control group. Text Box 6.1 contains information on the participants flow of the PREVASC trial as used for answering the ad hoc research question described in the current article.

\section{Prevalence data}

Prevalence data of variables included in the analyses are presented in Table 6.1.

\section{Diagnosis of asthma}

No significant relationship between the number of infections and the diagnosis of asthma was found (Table 6.2).

The presence of older siblings and day-care attendance showed not to be related to the diagnosis of asthma.

\section{Asthmatic symptoms}

The number of episodes of diarrhoea associated with fever showed to be positively related to the development of asthmatic symptoms (Table 6.3). Common cold however, was not related to the development of asthmatic symptoms. Day care attendance and the exposure to Der p1 on the child's mattress showed a positive trend with the development of symptoms associated with asthma, whereas none of the other variables included in the analysis showed to be of influence.

The influence of common cold and diarrhoea on the total IgE level is presented in Table 6.4. The number of episodes of common cold during the first 12 months of life was inversely related to total $\lg E$ at age six, as was the presence of a dog in the household. None of the other variables included in the analysis did influence the total IgE level at age six. 


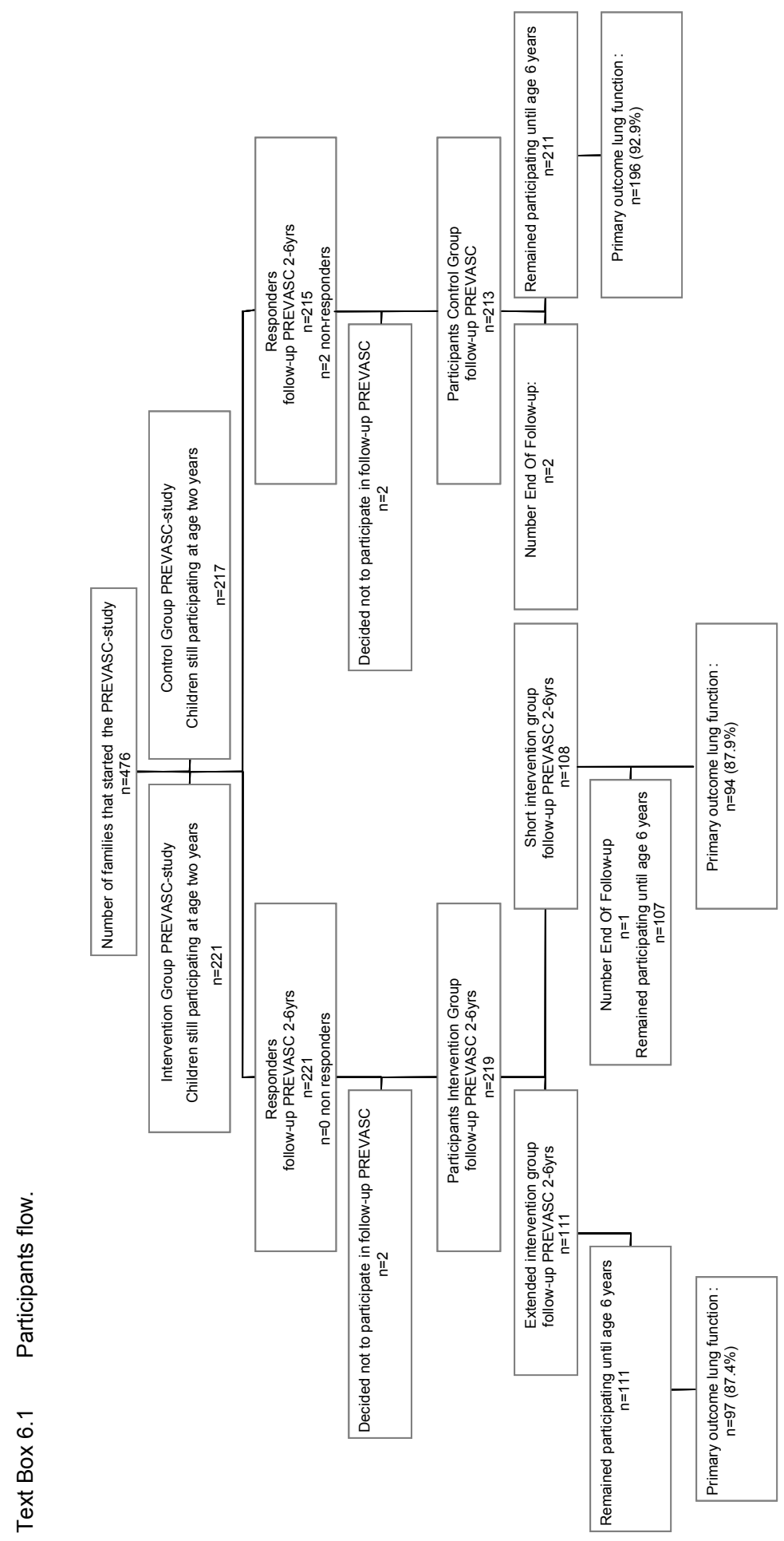


Table 6.1 Prevalence of variables included in the analyses.

\begin{tabular}{|c|c|c|c|c|c|}
\hline Variable & $(n) n / N$ & $\%$ & median & minimum & maximum \\
\hline $\begin{array}{l}\text { Common cold during } 1^{\text {st }} \text { year of child's } \\
\text { life (episodes) }\end{array}$ & $431 / 443$ & 97.3 & 15 & 0 & 49 \\
\hline $\begin{array}{l}\text { Common cold during } 2^{\text {nd }} \text { year of child's } \\
\text { life (episodes) }\end{array}$ & $326 / 443$ & 73.6 & 12 & 0 & 44 \\
\hline $\begin{array}{l}\text { Diarrhoea plus fever during } 1^{\text {st }} \text { two } \\
\text { years of child's life (episodes) }\end{array}$ & $373 / 443$ & 84.2 & 1 & 0 & 12 \\
\hline Diagnosis asthma age 4 to $6(0 / 1)$ & $30 / 383$ & 7.8 & 0 & 0 & 1 \\
\hline Asthma symptoms age 4 to $6(0 / 1)$ & $146 / 418$ & 34.9 & 0 & 0 & 1 \\
\hline Total IgE serum level IU/ml & $367 / 443$ & 82.8 & 0.01 & 0.01 & 8604.15 \\
\hline $\begin{array}{l}\text { House dust mite allergen specific lgE } \\
\text { above } 0.25 \mathrm{IU} / \mathrm{ml}(0 / 1)\end{array}$ & $55 / 302$ & 18.2 & 0 & 0 & 1 \\
\hline Any older siblings (0/1) & $272 / 443$ & 61.4 & 1 & 0 & 1 \\
\hline Day-care attendance $(0 / 1)$ & $163 / 407$ & 40.0 & 0 & 0 & 1 \\
\hline Presence of a cat $(0 / 1)$ & $52 / 443$ & 11.7 & 0 & 0 & 1 \\
\hline Presence of a dog $(0 / 1)$ & $84 / 443$ & 19.0 & 0 & 0 & 1 \\
\hline Derp1 exposure level $\mu \mathrm{g} / \mathrm{m}^{2}$ & $414 / 443$ & 93.5 & 0.0104 & 0.00 & 142.33 \\
\hline Fel d1 exposure level $\mu \mathrm{g} / \mathrm{m}^{2}$ & $414 / 443$ & 93.5 & 0.0314 & 0.00 & 47.48 \\
\hline Can f1 exposure level $\mu \mathrm{g} / \mathrm{m}^{2}$ & $414 / 443$ & 93.5 & 0.0125 & 0.00 & 32.56 \\
\hline Gender (boy 0/1) & $230 / 443$ & 51.9 & 1 & 0 & 1 \\
\hline Mother's history of asthma (0/1) & $229 / 443$ & 52.0 & 1 & 0 & 1 \\
\hline $\begin{array}{l}\text { Any sibling with a history of asthma } \\
(0 / 1)\end{array}$ & $178 / 277$ & 64.3 & 1 & 0 & 1 \\
\hline Number of weeks breastfed & $350 / 443$ & 79.0 & 13.5 & 0 & 52 \\
\hline $\begin{array}{l}\text { Smoking status of mother during } \\
\text { pregnancy }(0 / 1)\end{array}$ & $40 / 440$ & 9.0 & 0 & 0 & 1 \\
\hline $\begin{array}{l}\text { Smoking status of parents during } 1^{\text {st }} \\
\text { year of child's life }(0 / 1)\end{array}$ & $118 / 404$ & 29.2 & 0 & 0 & 1 \\
\hline Study group allocation (intervention 0/1) & $222 / 443$ & 50.1 & $\mathrm{x}$ & 0 & 1 \\
\hline
\end{tabular}

Table 6.2 GP-diagnosed asthma at age four to six: contribution of episodes of infections (logistic regression) $(\mathrm{n}=289)$.

\begin{tabular}{lcccc}
\hline Variable & Coefficient (B) & Odds ratio & $95 \% \mathrm{Cl}$ for OR & $\mathrm{P}$ value \\
\hline $\begin{array}{l}\text { Common cold during } 2^{\text {nd }} \text { year } \\
\text { (episodes) }\end{array}$ & 0.014 & 1.014 & $0.964 / 1.067$ & 0.588 \\
Diarrhoea plus fever (episodes) & -0.040 & 0.960 & $0.722 / 1.278$ & 0.781 \\
\hline
\end{tabular}

Table 6.3 Asthma symptoms at age four to six $(n=337)$ : possible determinants (logistic regression).

\begin{tabular}{lcccc}
\hline Variable & Coefficient (B) & Odds ratio & $95 \%$ Cl for OR & P value \\
\hline $\begin{array}{l}\text { Common cold during } 1^{\text {st }} \text { year } \\
\text { (episodes) }\end{array}$ & -0.011 & 0.989 & $0.965 / 1.013$ & 0.989 \\
Diarrhoea plus fever (episodes) & 0.215 & 1.240 & $1.085 / 1.417$ & 0.002 \\
Day-care attendance (0/1) & 0.446 & 1.562 & $0.973 / 2.508$ & 0.065 \\
Der p1 level mattress child $\mu \mathrm{g} / \mathrm{m}^{2}$ & 0.141 & 1.151 & $0.977 / 1.356$ & 0.092 \\
\hline
\end{tabular}


Table 6.4 Total $\lg E$ at age six years $(n=317)$ : relationship with exposure (multiple linear regression).

\begin{tabular}{lccc}
\hline Variable & Coefficient $(\mathrm{B})$ & $95 \% \mathrm{Cl}$ for B & $\mathrm{P}$ value \\
\hline Common cold during $1^{\text {st }}$ year (episodes) & $\mathbf{- 0 . 0 8 0}$ & $-0.134 /-0.027$ & $\mathbf{0 . 0 0 3}$ \\
Diarrhoea (episodes) & -0.134 & $-0.422 / 0.155$ & 0.353 \\
Dog in the household (0/1) & $\mathbf{- 1 . 7 2 9}$ & $-3.077 /-0.381$ & $\mathbf{0 . 0 1 2}$ \\
\hline
\end{tabular}

\section{Specific IgE levels}

The influence of infections on the outcome variables cat and dog specific IgE were not analysed as these variables did show to be above the reference value in only 9 and $6.5 \%$ of cases. Results of the analyses on the influence of infection on the HDM specific IgE levels are presented in Table 6.5. The number of episodes of diarrhoea was associated with a reduction of HDM specific IgE level. The number of episodes of common cold showed a positive trend with HDM specific IgE level. The presence of a sibling diagnosed with asthma was inversely related to HDM specific lgE.

Table 6.5 Specific IgE HDM (above or below $0.35 \mathrm{IU} / \mathrm{ml}$ ) at age six $(n=126)$ : possible determinants (logistic regression).

\begin{tabular}{lcccc}
\hline Variable & Coefficient (B) & Odds ratio & $95 \%$ Cl for OR & P value \\
\hline Common cold during $2^{\text {nd }}$ year & 0.050 & 1.051 & $0.991 / 1.115$ & 0.095 \\
(episodes) & & & & \\
Diarrhoea plus fever (episodes) & -0.372 & 0.690 & $0.483 / 0.984$ & 0.041 \\
Breastfeeding (weeks) & 0.026 & 1.026 & $0.997 / 1.055$ & 0.075 \\
Sibling(s) diagnosed with asthma (0/1) & -1.740 & 0.175 & $0.062 / 0.497$ & 0.001 \\
Dog in the household (0/1) & -1.907 & 0.149 & $0.017 / 1.293$ & 0.084 \\
\hline
\end{tabular}

\section{Discussion}

Our findings do not support the hypothesis that URT infections (common cold) or GI infections (diarrhoea) would teach the developing immune system to arm itself against the development of asthma and asthma-like symptoms. We observed no significant relationship between the number of episodes of URT or $\mathrm{Gl}$ infections, and the diagnosis of asthma at the age of four to six years.

Although often described to influence the development of atopy, siblings and day-care attendance did not show to influence the development of atopy in our analyses. We separately included the sibling variables 'any sibling 0/1' as well as a variable 'number of siblings categorised as 0,1 or $\geq 2$ ' in the multiple regression analyses to be sure we did not miss any information. Only when a sibling was diagnosed with asthma there was an inverse relationship with the 
outcome HDM specific IgE. This variable does not represent a proxy measure for infection load but might be correlated with the genetic susceptibility of the child. The commonly held assumption that day-care attendance and the number of siblings are proxy variables for infection load may not apply to the subgroup of children at high risk of developing asthma.

It might be possible that we found no relationship between asthma diagnosis and URT infection (common cold) or GI infection (diarrhoea) because the symptoms of these common infections as reported by the parents were not suitable proxy measures for infection load. Although the results we presented might be true, they could have been the result of a lack of power. However, our results seem to be in line with the results of Harris et al. ${ }^{24}$ They found no relationship between early-life infections and subsequent respiratory disease in later life.

Our results show that more infections with common cold in early life are associated with a lower level of total IgE. Atopic diseases are characterised by Th2, and IgE responses to common environmental and food allergens. IgE levels are extremely low in non-atopic individuals, suggesting that $\lg \mathrm{E}$ production is under the regulation of the immune system. One of the reasons behind the lack of atopy in healthy individuals is the activity of regulatory $T$ cells, which prevent naïve $T$ helper cell precursors from acquiring a differentiated Th2 phenotype. $^{25}$ Our results could suggest that, although we did not find a relationship with asthma diagnosis or symptoms, URT infections might well influence atopy. Common cold did show a negative relationship with total IgE and diarrhoea did show an inverse relationship with HDM specific lgE.

These results seem to be in line with part of the recently launched hypothesis of Holt et al. ${ }^{26}$ They assume that respiratory tract infection can have dualistic effects, in particular via promoting resistance to atopy (lowering $\operatorname{lgE}$ development). At the same time they describe URT infections might stimulate the development of asthma through a pathway extrinsic to the immune system. This last mentioned part of their hypothesis was not confirmed in the current study.

\section{Conclusions}

The present data do not support the hypothesis that infections teach the developing immune system to arm itself either against the diagnosis of asthma, or against the development of asthma-like symptoms.

Common cold had an inverse relationship with the total lgE level. The number of episodes of diarrhoea associated with fever was inversely related to specific IgE for house dust mite allergens. These results suggest that URT infections might influence atopy development (total lgE). 


\section{References}

1. Strachan DP. Hay fever, hygiene, and household size. BMJ 1989;29:1259-60.

2. Holt PG, Sly PD. Interactions between respiratory tract infection and atopy in the aetiology of asthma. Eur Respir J 2002;19:538-45.

3. Prescott SL, Macaubas C, Smallacombe T, Holt BJ, Sly PD, Holt PG. Development of allergen-specific T-cell memory in atopic and normal children. Lancet 1999;353:196-200.

4. Prescott SL, Macaubas C, Holt BJ, Smallacombe TB, Loh R, Sly PD, Holt PG. Transplacental priming of the human immune system to environmental allergens: Universal skewing of initial T cell responses toward the Th2 cytokine profile. J Immunol 1998;160:4730-7.

5. Gale EA, A missing link in the hygiene hypothesis? Diabetologia 2002;45:588-94.

6. Ling EM, Smith T, Nguyen XD, Pridgeon C, Dallman M, Arbery J, Carr VA, Robinson DS. Relation of CD4+CD25+ regulatory T-cell suppression of allergen-driven T-cell activation to atopic status and expression of allergic disease. Lancet ISE: 1474 547X 2004; 363:608-15.

7. Ball TM, Castro-Rodriguez JA, Griffith KA, Holberg CJ, Martinez FD, Wright AL. Siblings, daycare attendance, and the risk of asthma and wheezing during childhood. N Eng J Med 2000; 343:538-43.

8. Matricardi PM, Franzinelli F, Franco A, Caprio G, Murru F, Cioffi D, Ferrigno L, Palermo A, Ciccarelli N, Rosmini F. Sibship size, birth order, and atopy in 11,371 Italian young men. J Allergy Clin Immunol 1998;101:439-44.

9. Benn CS, Melbye M, Wohlfahrt J, Bjorkstein B, Aaby P. Cohort study of sibling effect, infectious diseases and the risk of atopic dermatitis during first 18 months of life. BMJ 2004; 328:1223.

10. Svanes C, Jarvis D, Chinn S, Omenaas E, Gulsvik A, Burney P. Early exposure to children in family and day care as related to sdult asthma and hay fever: results from the European Community Respiratory Health Survey. Thorax 2002;57:945-50.

11. Infante-Rivard C, Amre D, Gautrin D, Malo JL. Family size, day-care attendance, and breastfeeding in relation to the incidence of childhood asthma. Am J Epidemiol 2001;153: 653-8.

12. Koopman LP, Smit HA, Heijnen ML, Wijga A, van Strien RT, Kerkhof M, Gerritsen J, Brunekreef B, de Jongste JC, Neijens HJ. Respiratory infections in infants: interaction of parental allergy, child care, and siblings-The PIAMA study. Pediatrics 2001;108:943-8.

13. Mc Keever TM, Lewis SA, Smith C, CollinsJ, Heatlie H, Frischer M, Hubbard R. Early exposure to infections and antibiotics and the incidence of allergic disease: a birth cohort study eith the West Midlands General Practice Research Database, J Allergy Clin Immunol 2002;109:43-50.

14. Golding J, Peters T. Eczema and Hay fever. In: Butler N, R Golding, J, editor. From birth to fice, a study of the health and haviour of Britain's 5 year olds. Oxford: Pergamon Press. 1986: 171-86.

15. Gern JE, Rosenthal LA, Sorkness RL, Lemanske RF Jr. Effects of viral respiratory infections on lung development and childhood asthma, J Allergy Clin Immunol 2005; 115:668-74.

16. Borchers AT, Keen CL, Gershwin ME. Hope for the hygiene hypothesis: when the dirt hits the fan. J Asthma 2005; 42:225-47.

17. Platts-Mills TA, Erwin E, Heymann P, Woodfolk J. Is the hygiene hypothesis still a viable explanation for the increasing prevalence of asthma? Allergy 2005;60(S79):25-31.

18. Schönberger HJ, Dompeling E, Knottnerus JA, Maas T, Muris JW, van Weel C, van Schayck CP.. The PREVASC study: the clinical effect of a multifaceted educational intervention to prevent childhood asthma. Eur Resp J 2005;25:660-70.

19. Kuiper S, Maas T, van Schayck CP, Muris JW, Schönberger HJ, Dompeling E, Gijsbers B, van Weel C, Knottnerus JA, PREVASC group. The primary prevention of asthma in children study: design of a multifaceted prevention program. Pediatr Allergy Immunol 2005;16:321-31.

20. Asher MI, Keil U, Anderson HR, Beasley R, Crane J, Martinez F, Mitchell EA, Pearce N, Sibbald B, Stewart AW, Strachan D, Weiland SK, Williams HC. 
21. International Study of Asthma and Allergies in Childhood (ISAAC) rationale and methods, European Respiratory Physiology 1995;8:483-91.

22. Stapel SO, Eysink PE, Vrieze J, Aalberse RC. IgE testing in capillairy blood, Pediatr Allergy Immunol 2004;15:230-3

23. Lemanske RF. Viral infections and asthma inception, J Allergy Clin Immunol 2004;114: 1023-6.

24. Ma X, Buffer PA, Wiemels JL. Selvin S, Metayer C, Loh M, Does MB, Wiencke KJ. Ethnic difference in daycare attendance, early infections, and risk of childhood acute lymphoblastic leukaemia, Cancer Epidemiol Biomarkers Prev 2005;14:1928-34.

25. Harris JM, Mills P, White C, Moffat S, Newman Taylor AJ, Cullinan P. Recorded infections and antibiotics in early life; associations with allergy in UK children and their parents. Thorax 2007; 62:631-7.

26. Curotto de Lafaille MA, Lafaille JJ. The role of regulatory T cells in allergy. Springer seminars in immunopathology 2004;25:295-310.

27. Holt PG, Upham JW, Sly PD. Contemporaneous maturation of immunologic and respiratory functions during early childhood. Implications for development of asthma prevention strategies, J Allergy Clin Immunol 2005;116:16-24. 


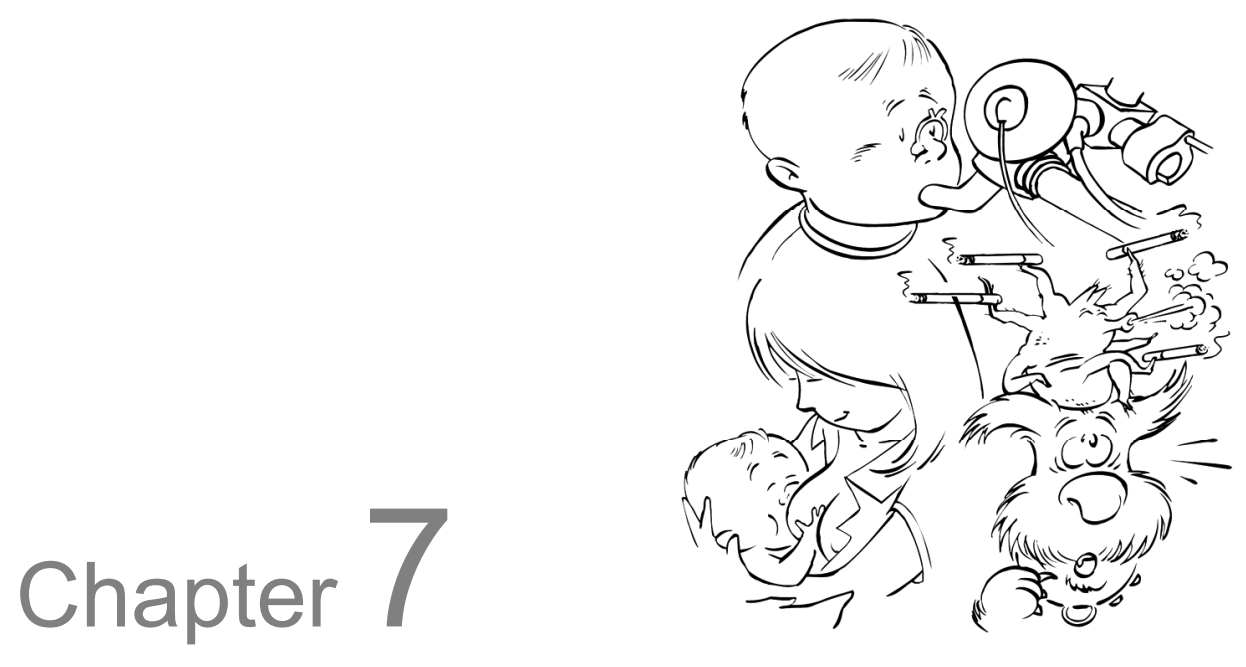

Effectiveness of the PREVASC multi-faceted randomised controlled trial on primary prevention of asthma in children at high risk; results at four and six years of age

Maas T, Dompeling E, Muris JWM, Wesseling G, Knottnerus JA, van Schayck CP

Submitted 


\section{Abstract}

Aim

To show the effectiveness of the PREVASC intervention on primary PREVention of ASthma in genetically predisposed Children through the reduction of multiple environmental exposures. In this paper we will describe the outcome of the exposure-reducing interventions, as well as the clinical effectiveness as measured at ages four and six.

\section{Methods}

Children susceptible to developing asthma on grounds of genetic predisposition were included during prenatal life. These children were randomly assigned to an intervention group (IG) or a control group (CG) and followed from prenatal life until the age of six. The results at age two were published earlier. The number of children we followed up until age six was $n=219$ in the IG and $\mathrm{n}=213$ in the CG. We offered an intervention focused on a simultaneous reduction of multiple environmental exposures such as food allergens, inhalant allergens and environmental tobacco smoke (ETS), suitable for implementation in daily general practice.

At age four the clinical outcomes evaluated were asthma, asthma symptoms (wheezing, nocturnal coughing, dyspnoea) and atopic dermatitis as registered by general practitioners and parents (questionnaire data). At age six the main outcome asthma status was categorized by a predefined algorithm (no asthma, possible asthma, current asthma). The categorization of this asthma status was based on spirometry and symptoms as prospectively reported by parents and general practitioners.

A multiple logistic regression analysis, not based on study group comparisons, were carried out for assessment of the influence of individual intervention elements on the development of asthma at age six.

\section{Results}

The exposure to both food allergens and inhalant allergens was significantly lower in the IG as compared to the CG. The food intervention was very successful in reducing exposure to cow's milk and solid foods. In $84 / 205$ children in the IG (41.0\%) versus $25 / 217$ in the CG $(11.5 \%), p<0.001)$ the exposure to cow's milk and solid food was successfully reduced. No differences for breastfeeding practices have been observed between groups. Inhalant allergen exposure was significantly reduced in the IG as compared to the CG (house dust mite [HDM] allergen level IG $82.62 \mathrm{ng} / \mathrm{m}^{2}$ versus CG $124.36 \mathrm{ng} / \mathrm{m}^{2}$ [p=0.043], cat allergen level IG $13.48 \mathrm{ng} / \mathrm{m}^{2}$ versus CG $21.68 \mathrm{ng} / \mathrm{m}^{2}$ $[p=0.037]$, dog allergen level IG $48.83 \mathrm{ng} / \mathrm{m}^{2}$ versus CG $88.88 \mathrm{ng} / \mathrm{m}^{2}[\mathrm{p}=0.012]$. There were no differences in ETS exposure between groups.

Although the exposure outcome showed to be significantly reduced in the IG, the clinical outcome was not shown to be statistically different between groups. In the CG $25.9 \%$ of children were diagnosed with current asthma as opposed to $29.7 \%$ of children in the IG, $50.6 \%$ of children in the CG versus $46.5 \%$ in the IG were categorized as having possible asthma, and $23.5 \%$ versus $23.8 \%$ were shown to have no current asthma at all $(p=0.491)$. The logistic multiple regression analysis showed that breastfeeding and an HDM allergen level below the group median $(0.6606 \mu \mathrm{g} / \mathrm{g})$ have a statistically significant reducing effect on the development of asthma.

\section{Conclusion}

The PREVASC multi-faceted intervention was not clinically effective. Only minimal room for improvement for the ETS- and HDM-reducing interventions was shown. Besides this lack of room for improvement, compliance might have played a part in the lack of effectiveness, especially for the breastfeeding promoting intervention and the HDM allergen reducing intervention. 


\section{Introduction}

Over the past decades the prevalence of asthma in children has increased substantially. ${ }^{1,2}$ This increase in asthma prevalence has led researchers to turn their interest towards elucidating the cause of this increase and the possibilities for preventing the development of asthma in susceptible children.

It is unlikely that the increase in prevalence of asthma in this relatively short period of time has been caused by genetic factors. The development of asthma seems to be a result of gene-environment interaction. ${ }^{3}$ Allergen exposure is one of the environmental factors seemingly associated with the development of asthma.

Several randomised controlled trials (RCTs) are currently studying reduction in food and/or inhalant allergen exposure. The types of interventions studied are either mono-faceted, focused on one (allergen) exposure, or multi-faceted, focused on multiple exposures. Since asthma is a multi-factorial disease, it seems likely that asthma might be prevented to a greater extent if multiple exposures were simultaneously reduced. ${ }^{4}$ The majority of RCTs investigating allergen exposure reduction, in terms of a preventive intervention for asthma development in children, are using a mono-faceted approach. ${ }^{5-14}$ The only three multi-faceted intervention studies are the Isle of Wight study, the Canadian Childhood Asthma Primary Prevention Study and the PREVention of ASthma in Children (PREVASC) study. ${ }^{15-17}$ These multi-faceted RCTs all reported significant results in favour of treatment on allergen exposure data and clinical observations. ${ }^{15,18-25}$ These results showed that changing multiple environmental factors may, to some extent, prevent asthma (or asthma symptoms) from developing in genetically susceptible children. Differences between the three multi-faceted studies lay in the different baseline house dust mite (HDM) exposure levels, and the focus of the three multi-faceted RCTs. The Isle of Wight study and the Canadian Childhood Asthma Primary Prevention Study focused less on feasibility and implementation than did the PREVASC study. In addition to the general intervention recommendations supplied, both the Canadian and Isle of Wight study had regular contact with parents concerning performance of the intervention measures so as to improve compliance. This is a different approach from that followed in the PREVASC study. In the PREVASC study the intervention was aimed at educating parents on how to lower the allergen exposure of their child by a method easy to implement in daily general practice, taking into account the busy schedules of general practitioners (GPs) and practical nurses.

An initial report on the clinical effectiveness of the PREVASC intervention was already published when the children reached age two. ${ }^{25}$ In the present paper we will be reporting the outcome of the PREVASC study as measured at ages four and six. 
The research questions of the current study are:

1. What is the clinical effectiveness of a combination of prenatally started measures, aimed at reducing exposure to inhalant and food allergens as well as Environmental Tobacco Smoke (ETS) on primary prevention of asthma in genetically susceptible children?

2. Does the intervention's duration (extended or short) have any effect on the development of asthma in genetically susceptible children?

3. What is the effect of the environmental factors included in the PREVASC multi-faceted intervention on the outcome asthma as measured at age six?

\section{Methods}

\section{Design}

The PREVASC study on PREVention of Asthma in Children at high risk of developing asthma is a randomised controlled trial using a multi-faceted intervention for reduction of environmental exposures: inhalant and food allergens, as well as ETS. The design of the PREVASC programme, including the present study, plus the rationale behind the study, was described by Schönberger et al. $1998^{26}, 2005^{25}$ and Kuiper et al. $2005 .^{17}$ In the present paper we will specifically describe the parts relevant to outcome at ages four and six.

\section{Study population}

Children at high risk of developing asthma were included during prenatal life. Families were randomly assigned to an IG or a CG. The CG was not offered any specific intervention, but received the usual care in accordance with the standards of the Dutch Society of General Practitioners (NHG).

During home visits the IG was offered an educational intervention in which parents were coached to reduce their child's exposure to inhalant allergens, food allergens and ETS. The IG received HDM-impermeable encasings for the beds of the parents and participating child (mattress plus pillow and duvet, or infant's sleeping bag) and received advice on measures for reducing their child's inhalant allergen exposure (HDM and pet allergens). Recommendations on food allergen reducing measures were based on the promotion of exclusive breastfeeding during the first six months of life without any other milk feeding or introduction of solids. If mothers were not able to act upon the breastfeeding recommendations, they were offered the opportunity to buy hypoallergenic artificial formula (HAF, nutrilon pepti, Nutricia, The Netherlands) at the price of regular formula so there would not be a financial barrier to compliance. For the ETS-exposure part of the intervention, parents were coached to quit smoking using the Minimal Intervention Strategy (MIS) developed by the Dutch 
organization STIVORO. ${ }^{27,28}$ In addition, parents were also advised to keep their child away from smoking areas.

To obtain information on the optimal intervention duration we compared the effects of two different periods of intervention. For this purpose the children in the IG were randomly assigned to one of two groups at the age of two. The two groups that resulted from this second randomisation were the extended-IG $(n=111)$, in which the intervention was continued until age six, and the short-IG $(n=108)$, in which the intervention stopped at age two. The extended IG received the intervention treatment concerning the diminishing of inhalant allergen exposure including advice on how to reduce exposure to ETS and HDM allergen. For reduction of HDM allergen exposure MiteCare special soft HDMImpermeable bedding encasings for the child's bed were supplied (Sanalife, The Netherlands). The families were kept uninformed as to the group they were allocated to. Both intervention subgroups were aware of the possibility that they might receive placebo bedding encasings for their child after the second randomisation. The families were not aware of the exact differences between the groups as this would have un-blinded the intervention.

\section{Measurement of outcome during the whole study period}

Every year around their child's birthday, parents were asked to complete questionnaires on their child's health (based on the ISAAC questionnaire ${ }^{29}$ ) as well as exposure to inhalant allergens and ETS. GPs prospectively recorded symptoms, medication and diagnoses related to allergy and asthma for the participating children throughout the study period. At the age of two and four, research assistants made home visits during which exposure measures were assessed. During the home visit at age two, the research assistant put new encasings on the child's mattress, duvet and pillow (either HDM-impermeable or placebo). In the extended-IG recommendations on reducing exposure to ETS and inhalant allergens were reiterated. A finger prick blood sample was collected within the first ten days after birth and at ages one, two, four and six to determine total and specific Immune globuline $E(\lg E)$ concentrations in the child's blood. ${ }^{30}$

\section{Primary outcome measured at age six}

At age six, the child's lung function was measured to assess the primary study outcome current asthma-status, including forced expiratory volume in one second (FEV1) before and after bronchodilatation, forced vital capacity (FVC), tiffeneau index (FEV1/FVC) and bronchial hyper reactivity (PC20). All children were invited to visit the lung-function laboratory of the Maastricht University Hospital (azM) when they reached the age of six. 
We used a predefined automated algorithm for determining the asthma status of participating children in which they were assigned to one of the three following groups (see Text Box 7.1):

1. No current asthma, 2. Possible asthma, 3. Current asthma.

The information used for this categorization was based on both lung-function results and symptoms reported by GPs and parents. If participants were unable to visit the lung-function laboratory, they were offered the opportunity to have the spirometry performed by a research assistant at home. The equipment used for home determination of lung function was technically the same as the spirometer used in the hospital (Flowscreen II, VIASYS Healthcare The Netherlands BV). Histamine-provocation testing (bronchial hyperreactivity test) and Nitric Oxide (NO) measurement could not be performed during the home visits.

After the algorithm program was finished, data for two specific groups of children were separately and independently evaluated by two experts ([paediatric] pulmonologists):

- Children that inhaled corticosteroids and were not assigned to the current asthma group were evaluated by pulmonologists because of the greater chance of lung-function deviations not being measurable when the asthma was medication-regulated;

- Children that had their lung function measured in the home situation when being assigned to the 'possible asthma' group were discussed by pulmonologists, since no PC20 measurement was possible outside the laboratory. The lack of PC20 outcome resulted in incomplete information on lung-function status.

The pulmonologists were supplied with all the data collected during the study period. In those cases where the pulmonologists did not reach a consensus on the group in which a child should be categorized, a GP experienced in paediatric pulmonology made the final categorization.

\section{Secondary study outcomes}

- FEV1 and FVC, both expressed as percentages, predicted PC20, reversibility and fractional exhaled nitric oxide ((fe)NO);

- Doctor's diagnosis of asthma and the asthma symptoms of wheezing, nocturnal coughing and dyspnoea, as reported by the GP at ages 3-4 and 5-6;

- Asthma symptoms of wheezing, nocturnal coughing and dyspnoea, as reported by parents in questionnaires at ages 3-4 and 5-6;

- Asthma medication (overall), inhaled corticosteroids, beta 2 sympaticomimetics, anticholinergics, antihistamines prescribed by the GP at ages 3-4 and 5-6;

- Total IgE and specific $\lg E \mathrm{IU} / \mathrm{ml}$ at ages four and six. 
Text Box 7.1 Criteria used for determining asthma status by algorithm PREVASC.

\author{
A) No Current Asthma \\ Lung function results: \\ FEV1/FVC $>\%$ predicted-2 SD \\ AND reversibility $<9 \%$ difference between pre and post bronchodilator FEV1 $\%$ predicted \\ AND PC20 $>8 \mathrm{mg} / \mathrm{ml}$ histamine. \\ Symptoms questionnaire \\ None of the following symptoms is registered:
}

Question: Has your child ever experienced an episode of wheezing at the age of 4 to 6 years?

NO.

Question: Did your child ever experience an episode of dyspnoea at the age of 4 to 6 years? NO .

Question: Did your child ever experience an episode of nocturnal cough not associated with common cold or airways infection at the age of 4 to 6 years? NO.

General Practitioners registration 4-6 years

All of the following conditions are fulfilled:

Expiratory wheezing is never reported;

Wheezing not associated with exertion is never reported;

Night time cough is reported maximally once;

Dyspnoea not associated with exertion never reported.

\title{
B) Possible Asthma
}

No current asthma but either:

Current asthma symptoms reported (see current asthma) but no lung function deviations measured (see no asthma);

Or:

Lung function deviations measured (see current asthma) but no current asthma symptoms reported (see no asthma).

\section{C) Current Asthma}

Lung function results:

FEV1/FVC $(\mathrm{ml}) \leq \%$ predicted-2 SD

AND reversibility $\leq 9 \%$ difference FEV1 \%predicted pre and post bronchodilator AND/OR PC20 $\leq 8 \mathrm{mg} / \mathrm{ml}$ histamine.

Symptoms questionnaire 5 and 6 years

Minimally 1 of the following symptoms is registered:

Question: Has your child ever experienced an episode of wheezing as of the age of 4 to 6 years? YES.

Question: How often did your child wheeze during this period in total? 1-3,

4-12 or $>12$.

Question: How often did wheezing cause your child to wake up? 0 to 1 night/ week or 1 or more nights/week.

1. Question: Did your child ever experience an episode of dyspnoea at the age of 4 to 6 years? YES

2. Question: How often did your child experience an episode of dyspnoea during this period in total? 1-3, 4-12 or $>12$.

3. Question: How often did your child wake up because of dyspnoea? 0 to $1 \mathrm{night} /$ week or 1 or more nights/week.

4. Question: Did your child ever experience an episode of nocturnal cough not associated with common cold or airways infection at the age of 4 to 6 years? YES.

5. Question: How often did your child experience an episode of nocturnal cough not associated with common cold or airways infection? 1 or more nights/week.

General Practitioners (GPs) registration 4-6 years

Minimally one of the following conditions is fulfilled:

Expiratory wheezing is registered minimally once;

Wheezing not associated with exertion is registered minimally once;

Night time cough is registered several times (minimum 2);

Dyspnoea not associated with exertion is registered minimally once. 


\section{Statistical aspects}

\section{Power calculation}

Based on the longitudinal study results of Saarinen et al. $1995,{ }^{30}$ a minimum amount of 194 infants in both the intervention and the CG was required to be able to detect a reduction of the asthma incidence by at least $30 \%$ (taking into account a type I error of 0.05 and a power of 0.80 ). SPSS for Windows version 15 was used to perform the statistical analyses.

Analysis of differences between the total IG and CG, as well as separate analyses on differences between the extended-IG and the short-IG as compared to controls, were carried out for all outcomes tested.

Kruskal-Wallis tests were used for evaluating differences between groups in terms of the primary outcome. Pearson $\mathrm{Chi}^{2}$ tests were performed to test if there were any differences between groups for nominal exposure outcome, questionnaire data and data on symptoms and diagnoses as reported by GPs. The ordinal data on inhalant allergen exposure, breastfeeding practice, use of HDM-impermeable mattress encasings and separate lung-function parameters was evaluated for group differences by carrying out Mann-Whitney U tests.

To determine the effect of all the environmental factors included in the intervention (research question 3), we carried out a multiple logistic regression analysis independent of group allocation. With this analysis we tested the influence of the separate environmental factors on the combined outcome of 'current asthma' or 'possible asthma', as compared to the group of children categorized as having 'no asthma'.

The independent variables included in the logistic regression analysis were those that showed to be related to the tested asthma outcome (chi-square tests, $\mathrm{p}<0.100)$. A backward procedure was followed.

\section{Results}

\section{Participants}

A total of 443 children, all at high risk of developing asthma on grounds of a genetic predisposition in first-degree relatives (mother and/or father and/or sibling[s] diagnosed as asthmatics) were included in the PREVASC study. The children were included between January 1, 1997, and January 1, 2000, during pregnancy with the help of GPs and midwives, and were followed up until age six. They were randomly assigned to an IG $(n=222)$ or a CG $(n=221)$. The extended-IG comprised of $n=111$ children, whereas the short IG consisted of $\mathrm{n}=108$ children.

A flow chart of participants in the PREVASC study presented in Text Box 7.2 shows that the number of children lost to follow-up has been less than $10 \%$ since the start of the study (45/476). 


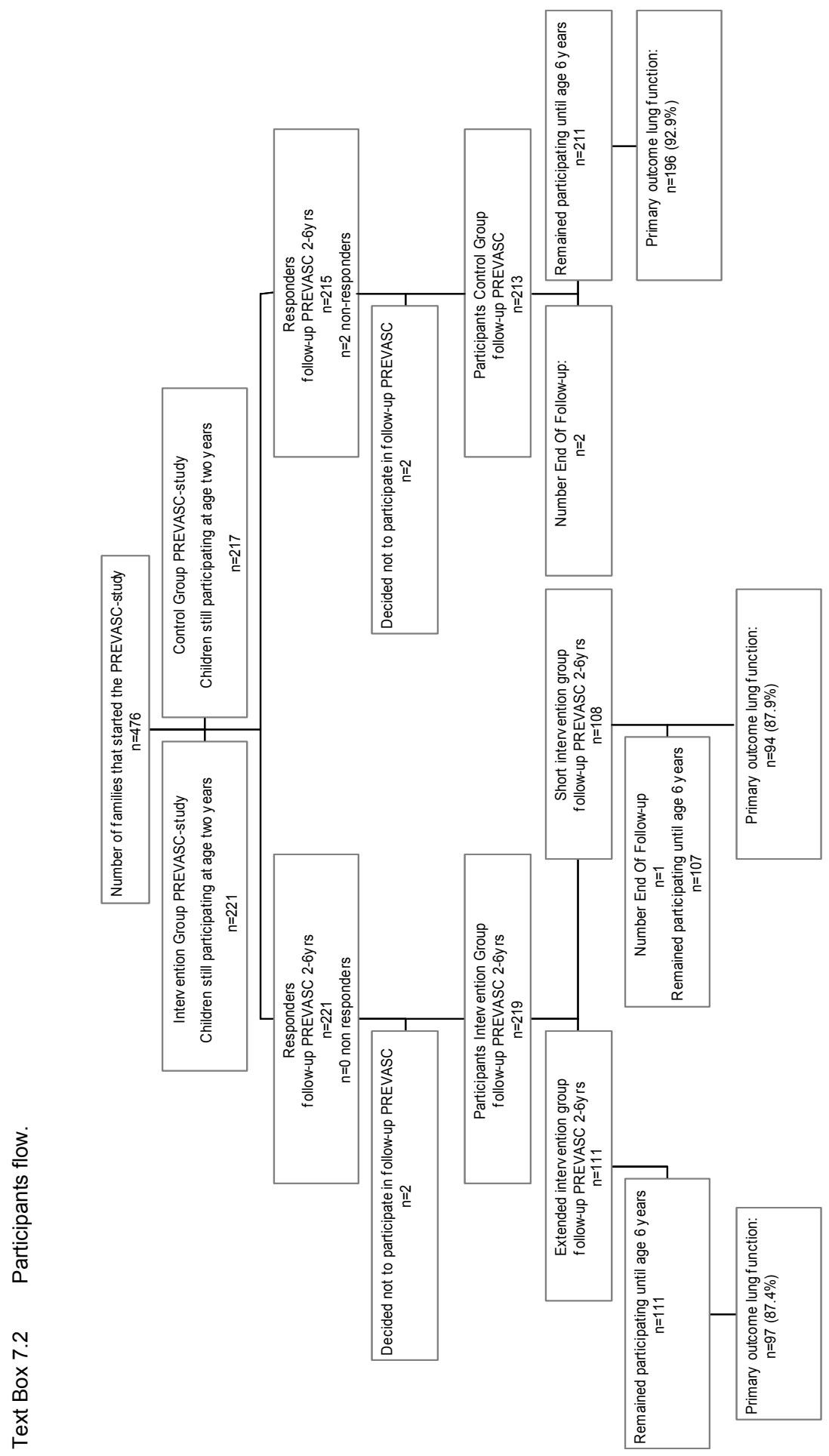




\section{Exposure outcome}

Table 7.1 presents the differences in results of exposure outcome in the IG(s) versus the CG. The number of cases offered feeding in accordance with research intervention recommendations (breastfeeding and/or HAF without introduction of solids during the first six months of life) differed significantly in favour of the IG. The percentage of children exclusively breastfed and/or fed with hypo-allergenic formula during the first six months of life was higher in the IG as compared to the CG. Another finding was that children in the IG were significantly more often introduced to solids after they had reached the age of six months as compared to children in the CG.

Table 7.1 Environmental exposures at age four and six years: Comparison of intervention group as a whole, and short intervention group as well as extended intervention group separately, versus the control group.

\begin{tabular}{|c|c|c|c|c|}
\hline & $\begin{array}{l}\text { Control group } \\
\mathrm{n} / \mathrm{N} \\
(\%)\end{array}$ & $\begin{array}{l}\text { Intervention group } \\
\mathrm{n} / \mathrm{N}(\%) \\
\text { Asymp. Sig. } \\
\text { 2-sided }\end{array}$ & $\begin{array}{l}\text { Extended Intervention } \\
\mathrm{n} / \mathrm{N}(\%) \\
\text { Asymp. Sig. } \\
\text { 2-sided }\end{array}$ & $\begin{array}{l}\text { Short Intervention } \\
\mathrm{n} / \mathrm{N}(\%) \\
\text { Asymp. Sig. } \\
\text { 2-sided }\end{array}$ \\
\hline $\begin{array}{l}\text { Exclusively breastfed and/or hypo- } \\
\text { allergenic bottle fed } 26 \text { wks plus } \\
\text { introduction solids }>6 \text { months }^{\wedge}\end{array}$ & $25 / 217(12.0)$ & $\begin{array}{l}84 / 203(41.4) \\
<0.001\end{array}$ & $\begin{array}{l}48 / 103(46.6) \\
<0.001\end{array}$ & $\begin{array}{l}36 / 100(36.0) \\
<0.001\end{array}$ \\
\hline $\begin{array}{l}\text { Exclusively breastfed and/or hypo- } \\
\text { allergenic bottle fed } 26 \text { wks }^{\wedge}\end{array}$ & $49 / 219(22.4)$ & $\begin{array}{l}115 / 208(55.3) \\
<0.001\end{array}$ & $\begin{array}{l}61 / 108(56.5) \\
<0.001\end{array}$ & $\begin{array}{l}54 / 100(54.0) \\
<0.001\end{array}$ \\
\hline Exclusively breastfed 26 wks $^{\wedge}$ & $25 / 217(12.0)$ & $\begin{array}{l}21 / 217(9.7) \\
0.450\end{array}$ & $\begin{array}{l}14 / 110(12.7) \\
0.857\end{array}$ & $\begin{array}{l}7 / 107(6.5) \\
0.125\end{array}$ \\
\hline Initially breastfed^ & $162 / 207(79.7)$ & $\begin{array}{l}175 / 215(81.4) \\
0.662\end{array}$ & $\begin{array}{l}89 / 110(81.7) \\
0.636\end{array}$ & $\begin{array}{l}85 / 105(81.0) \\
0.749\end{array}$ \\
\hline $\begin{array}{l}\text { Exclusively breastfed, median } \\
\text { number of weeks }{ }^{*}\end{array}$ & 7 & $\begin{array}{l}7 \\
0.738\end{array}$ & $\begin{array}{l}7.5 \\
0.746\end{array}$ & $\begin{array}{l}7.5 \\
0.427\end{array}$ \\
\hline $\begin{array}{l}\text { Breastfed overall, median number } \\
\text { of weeks* }\end{array}$ & 13 & $\begin{array}{l}12 \\
0.635\end{array}$ & $\begin{array}{l}14 \\
0.932\end{array}$ & $\begin{array}{l}10 \\
0.318\end{array}$ \\
\hline Introduction solids $>6$ months $^{\wedge}$ & $58 / 208(27.9)$ & $\begin{array}{l}142 / 204(69.6) \\
<0.001\end{array}$ & $\begin{array}{l}76 / 102(74.5) \\
<0.001\end{array}$ & $\begin{array}{l}66 / 102(64.7) \\
<0.001\end{array}$ \\
\hline Mother smoked inside age $4 \mathrm{yrs}^{\wedge}$ & $16 / 201(8.0)$ & $\begin{array}{l}24 / 206(11.7) \\
0.211\end{array}$ & $\begin{array}{l}8 / 107(7.5) \\
0.880\end{array}$ & $\begin{array}{l}16 / 99(16.2) \\
0.030\end{array}$ \\
\hline Father smoked inside age $4 \mathrm{yrs}^{\wedge}$ & $24 / 200(12.0)$ & $\begin{array}{l}30 / 206(14.6) \\
0.447\end{array}$ & $\begin{array}{l}12 / 107(11.2) \\
0.839\end{array}$ & $\begin{array}{l}18 / 99(18.2) \\
0.084\end{array}$ \\
\hline Mother smoked inside age $6 \mathrm{yrs}^{\wedge}$ & 14/152 (9.2) & $\begin{array}{l}13 / 158(8.2) \\
0.786\end{array}$ & $\begin{array}{l}6 / 82(7.3) \\
0.621\end{array}$ & $\begin{array}{l}7 / 76(9.2) \\
1.000\end{array}$ \\
\hline Father smoked inside age $6 \mathrm{yrs}^{\wedge}$ & $21 / 152(13.8)$ & $\begin{array}{l}16 / 158(10.1) \\
0.338\end{array}$ & $\begin{array}{l}8 / 82(9.8) \\
0.369\end{array}$ & $\begin{array}{l}8 / 76(10.5) \\
0.482\end{array}$ \\
\hline Furry pets kept inside age $4 \mathrm{yrs}^{\wedge}$ & $61 / 200(30.5)$ & $\begin{array}{l}44 / 204(21.6) \\
0.041\end{array}$ & $\begin{array}{l}21 / 107(19.6) \\
0.040\end{array}$ & $\begin{array}{l}23 / 97(23.7) \\
0.223\end{array}$ \\
\hline Furry pets kept inside age $6 \mathrm{yrs}^{\wedge}$ & $65 / 198(32.8)$ & $\begin{array}{l}47 / 185(25.4) \\
0.111\end{array}$ & $\begin{array}{l}21 / 95(22.1) \\
0.053\end{array}$ & $\begin{array}{l}26 / 90(28.9) \\
0.471\end{array}$ \\
\hline
\end{tabular}

${ }^{\wedge}$ Pearson $\mathrm{Chi}^{2}$ test carried out; *Mann-Whitney $\mathrm{U}$ test carried out 
However, IG mothers started breastfeeding their child as often as CG mothers did, and no statistical significance was reached for exclusive breastfeeding during the first six months of life.

Environmental tobacco smoke exposure, defined as 'number of smoking mothers' and 'number of smoking fathers', did not differ between the total IG and the CG. The number of smoking mothers in the short IG, however, was shown to be significantly higher than that in the CG. The results of ETS exposure are presented in Table 7.1.

Furry pets were more often kept indoors in control-group families as compared to intervention-group families at age four (as was the case at age two), but not at age six (Table 7.1). A similar result was found in the separate comparison of the extended-IG and the CG.

\section{Inhalant allergen exposure}

HDM allergen Der p1, as well as cat allergen Fel d1 and dog allergen Can f1, were tested for differences in levels between groups. Statistical significance was reached for all inhalant allergen exposure data in favour of the total IG and the extended-IG as compared to controls (Table 7.2). No differences were detected for allergen levels in terms of the comparison of the short-IG versus the CG.

Table 7.2 Inhalant allergen exposure levels at age four years: Comparison of intervention group as a whole, as well as the short intervention group and extended intervention group separately versus the control group

\begin{tabular}{|c|c|c|c|c|}
\hline & $\begin{array}{l}\text { Control } \\
\text { group } \\
\text { Median }\end{array}$ & $\begin{array}{l}\text { Intervention } \\
\text { group } \\
\text { Median } \\
\text { Asymp. Sig. } \\
\text { 2-sided }\end{array}$ & $\begin{array}{l}\text { Extended } \\
\text { Intervention } \\
\text { Median } \\
\text { Asymp. Sig. } \\
\text { 2-sided }\end{array}$ & $\begin{array}{l}\text { Short } \\
\text { Intervention } \\
\text { Median } \\
\text { Asymp. Sig. } \\
\text { 2-sided }\end{array}$ \\
\hline Der $\mathrm{p} 1 \mathrm{ng} / \mathrm{m}^{2}$ & 124.36 & $\begin{array}{l}82.62 \\
0.043\end{array}$ & $\begin{array}{l}65.79 \\
0.007\end{array}$ & $\begin{array}{l}119.98 \\
0.558\end{array}$ \\
\hline Fel $\mathrm{d} 1 \mathrm{ng} / \mathrm{m}^{2}$ & 21.66 & $\begin{array}{l}13.48 \\
0.037\end{array}$ & $\begin{array}{l}6.21 \\
<0.001\end{array}$ & $\begin{array}{l}21.53 \\
0.692\end{array}$ \\
\hline Can $\mathrm{f} 1 \mathrm{ng} / \mathrm{m}^{2}$ & 88.88 & $\begin{array}{l}48.83 \\
0.012\end{array}$ & $\begin{array}{l}37.65 \\
0.002\end{array}$ & $\begin{array}{l}87.19 \\
0.307\end{array}$ \\
\hline $\begin{array}{l}\text { Use of HDM impermeable mattress } \\
\text { covers, number of years }\end{array}$ & 0.6 & $\begin{array}{l}2.9 \\
<0.001\end{array}$ & $\begin{array}{l}3.5 \\
<0.001\end{array}$ & $\begin{array}{l}2.2 \\
<0.001\end{array}$ \\
\hline
\end{tabular}

Mann-Whitney $U$ tests carried out for all outcomes presented in this table 


\section{Clinical outcome}

\section{Primary outcome asthma resulting from the PREVASC algorithm}

No differences in the occurrence of current asthma were shown between groups. Also, no differences were observed between groups on separate lungfunction parameters (Tables 7.3 and 7.4).

Table 7.3 Asthma at age six years: Comparing cases in the separate intervention groups versus controls.

\begin{tabular}{|c|c|c|c|c|}
\hline & $\begin{array}{l}\text { Control group } \\
\mathrm{n} / \mathrm{N}(\%)\end{array}$ & $\begin{array}{l}\text { Intervention group } \\
\mathrm{n} / \mathrm{N}(\%)\end{array}$ & $\begin{array}{l}\text { Extended } \\
\text { intervention group } \\
\mathrm{n} / \mathrm{N}(\%)\end{array}$ & $\begin{array}{l}\text { Short intervention } \\
\text { group } \\
\text { n/N }(\%)\end{array}$ \\
\hline Current asthma & $44 / 170(25.9)$ & $51 / 172(29.7)$ & $23 / 86(26.7)$ & $28 / 86(32.6)$ \\
\hline Possible asthma & $86 / 170(50.6)$ & $80 / 172(46.5)$ & $43 / 86(50.0)$ & $37 / 86(43.0)$ \\
\hline No current asthma & $40 / 170(23.5)$ & $41 / 172(23.8)$ & $20 / 86(23.3)$ & $21 / 86(24.4)$ \\
\hline Asymp. Sig. 2-sided & & 0.645 & 0.853 & 0.491 \\
\hline
\end{tabular}

Only those cases that could be categorized on grounds of the algorithm asthma were included in these Kruskal-Wallis analyses (for algorithm asthma PREVASC project see Text Box 7.1).

Table 7.4 Lung function parameters: Comparing cases in the separate intervention groups versus controls.

\begin{tabular}{|c|c|c|c|c|}
\hline & $\begin{array}{l}\text { Control group } \\
\text { median }\end{array}$ & $\begin{array}{l}\text { Intervention group } \\
\text { Median } \\
\text { Asymp. Sig. } \\
\text { 2-sided }\end{array}$ & $\begin{array}{l}\text { Extended Intervention } \\
\text { Median } \\
\text { Asymp. Sig. } \\
\text { 2-sided }\end{array}$ & $\begin{array}{l}\text { Short Intervention } \\
\text { Median } \\
\text { Asymp. Sig. } \\
\text { 2-sided }\end{array}$ \\
\hline$\overline{(\mathrm{FE}) \mathrm{NO}}$ & 11.80 & $\begin{array}{l}10.80 \\
p=0.491\end{array}$ & $\begin{array}{l}10.80 \\
p=0.956\end{array}$ & $\begin{array}{l}10.80 \\
p=0.272\end{array}$ \\
\hline FEV1 \% predicted & 107.05 & $\begin{array}{l}109.0 \\
p=0.280\end{array}$ & $\begin{array}{l}109.0 \\
p=0.484\end{array}$ & $\begin{array}{l}109.30 \\
p=0.345\end{array}$ \\
\hline FVC $\%$ predicted & 99.80 & $\begin{array}{l}100.80 \\
p=0.456\end{array}$ & $\begin{array}{l}100.70 \\
p=0.678\end{array}$ & $\begin{array}{l}102.0 \\
p=0.506\end{array}$ \\
\hline Tiffeneau index & 93.26 & $\begin{array}{l}93.29 \\
p=0.766\end{array}$ & $\begin{array}{l}93.18 \\
p=0.443\end{array}$ & $\begin{array}{l}93.54 \\
p=0.763\end{array}$ \\
\hline PC20 & 4.56 & $\begin{array}{l}4.11 \\
p=0.310\end{array}$ & $\begin{array}{l}4.07 \\
p=0.141\end{array}$ & $\begin{array}{l}4.42 \\
p=0.733\end{array}$ \\
\hline Reversibility (\%) & 3.62 & $\begin{array}{l}4.57 \\
p=0.936\end{array}$ & $\begin{array}{l}5.71 \\
p=0.765\end{array}$ & $\begin{array}{l}3.54 \\
p=0.737\end{array}$ \\
\hline
\end{tabular}

Mann-Whitney U tests carried out for all outcomes presented in this table 


\section{Questionnaire data}

Equal numbers of children in the IG and CG were shown to be diagnosed with asthma and asthma symptoms at both ages four and six (Table 7.5). Comparable results were shown for the separate analyses of the intervention subgroups versus the CG.

Table 7.5 Questionnaire data on asthma and asthma symptoms at age four and six years: Comparing intervention group as a whole, and extended intervention group as well as short intervention group separately, versus control group

\begin{tabular}{|c|c|c|c|c|}
\hline & $\begin{array}{l}\text { Control group } \\
\mathrm{n} / \mathrm{N}(\%)\end{array}$ & $\begin{array}{l}\text { Intervention group } \\
\mathrm{n} / \mathrm{N}(\%) \\
\text { Asymp. Sign. } \\
\text { 2-sided }\end{array}$ & $\begin{array}{l}\text { Extended } \\
\text { intervention } \\
\mathrm{n} / \mathrm{N}(\%) \\
\text { Asymp. Sign. } \\
\text { 2-sided }\end{array}$ & $\begin{array}{l}\text { Short intervention } \\
\text { groupgroup } \mathrm{n} / \mathrm{N}(\%) \\
\text { Asymp. Sign. } \\
\text { 2-sided }\end{array}$ \\
\hline Asthma mentioned by & 18/201 (9.0) & $16 / 206(7.8)$ & 10/107 (9.3) & $6 / 99(6.1)$ \\
\hline GP at age $4 y r s$ & & 0.665 & 0.910 & 0.385 \\
\hline Wheezing & 43/201 (21.4) & $39 / 206(18.9)$ & 18/107 (16.8) & $21 / 99(21.2)$ \\
\hline age $4 \mathrm{yrs}$ & & 0.536 & 0.338 & 0.971 \\
\hline $\begin{array}{l}\text { Nocturnal cough } \\
\text { age } 4 \text { yrs }\end{array}$ & 49/201 (24.4) & $\begin{array}{l}62 / 206(30.1) \\
0.195\end{array}$ & $\begin{array}{l}31 / 107(29.0) \\
0.381\end{array}$ & $\begin{array}{l}31 / 99(31.3) \\
0.202\end{array}$ \\
\hline $\begin{array}{l}\text { Dyspnoea } \\
\text { age } 4 y r s\end{array}$ & $43 / 201(21.4)$ & $\begin{array}{l}42 / 206(20.4) \\
0.803\end{array}$ & $\begin{array}{l}25 / 107(23.4) \\
0.691\end{array}$ & $\begin{array}{l}17 / 99(17.2) \\
0.390\end{array}$ \\
\hline $\begin{array}{l}\text { Asthma mentioned by } \\
\text { GP at age 6yrs }\end{array}$ & $32 / 184(17.4)$ & $\begin{array}{l}36 / 185(19.5) \\
0.608\end{array}$ & $\begin{array}{l}18 / 95(18.9) \\
0.795\end{array}$ & $\begin{array}{l}18 / 90(20.0) \\
0.643\end{array}$ \\
\hline $\begin{array}{l}\text { Wheezing } \\
\text { at age 6yrs }\end{array}$ & 27/185 (14.6) & $\begin{array}{l}27 / 183(14.8) \\
0.966\end{array}$ & $\begin{array}{l}12 / 93(12.9) \\
0.664\end{array}$ & $\begin{array}{l}15 / 90(16.7) \\
0.694\end{array}$ \\
\hline $\begin{array}{l}\text { Nocturnal cough } \\
\text { age 6yrs }\end{array}$ & 48/185 (25.9) & $\begin{array}{l}43 / 185(23.2) \\
0.546\end{array}$ & $\begin{array}{l}48 / 182(26.4) \\
0.240\end{array}$ & $\begin{array}{l}24 / 90(26.7) \\
0.959\end{array}$ \\
\hline $\begin{array}{l}\text { Dyspnoea } \\
\text { age } 6 y r s\end{array}$ & 35/185 (18.9) & $\begin{array}{l}32 / 185(17.3) \\
0.685\end{array}$ & $\begin{array}{l}14 / 95(14.7) \\
0.410\end{array}$ & $\begin{array}{l}18 / 90(20.0) \\
0.795\end{array}$ \\
\hline
\end{tabular}

$\mathrm{Chi}^{2}$ tests carried out for all outcomes presented in this table

\section{Data prospectively registered by GPs}

Most comparisons of data prospectively registered by GPs did not reach statistical significance (Table 7.6). However, statistically significant results were observed for wheezing and dyspnoea at age six. Children in the short-IG visited their GP more often for wheezing symptoms $(p=0.022)$ and symptoms of dyspnoea ( $p=0.007)$ as compared to controls.

Inhaled corticosteroids, beta $_{2}$ sympaticomimetics, anticholinergics and antihistamines were as often prescribed to children in the IG as compared to controls at ages four and six (ever prescribed: yes or no). At age six, however, GPs were shown to have prescribed inhaled corticosteroids more often for cases in the short-IG than for children in the CG $(13.2 \%$ versus $5.3 \% p=0.022)$. 
Table 7.6 General practitioners registration of asthma and asthma symptoms at age four and six years: Comparing intervention group as a whole, extended intervention group and short intervention group separately versus control group

\begin{tabular}{|c|c|c|c|c|}
\hline & $\begin{array}{l}\text { Control group } \\
\mathrm{n} / \mathrm{N}(\%)\end{array}$ & $\begin{array}{l}\text { Intervention group } \\
\text { n/N (\%) } \\
\text { Asymp. Sign. } \\
\text { 2-sided }\end{array}$ & $\begin{array}{l}\text { Extended } \\
\text { intervention group } \\
\text { n/N (\%) } \\
\text { Asymp. Sign. } \\
\text { 2-sided }\end{array}$ & $\begin{array}{l}\text { Short intervention } \\
\text { group n/N (\%) } \\
\text { Asymp. Sign. } \\
\text { 2-sided }\end{array}$ \\
\hline $\begin{array}{l}\text { Asthma diagnosis } \\
\text { age 4yrs }\end{array}$ & 11/194 (5.9) & $\begin{array}{l}9 / 201(4.5) \\
0.589\end{array}$ & $\begin{array}{l}5 / 106(4.7) \\
0.725\end{array}$ & $\begin{array}{l}4 / 95(4.2) \\
0.599\end{array}$ \\
\hline $\begin{array}{l}\text { Wheezing } \\
\text { age 4yrs }\end{array}$ & 7/192 (3.6) & $\begin{array}{l}7 / 199(3.5) \\
0.946\end{array}$ & $\begin{array}{l}2 / 106(1.9) \\
0.396\end{array}$ & $\begin{array}{l}5 / 93(5.4) \\
0.495\end{array}$ \\
\hline $\begin{array}{l}\text { Nocturnal cough } \\
\text { age } 4 \text { yrs }\end{array}$ & 25/195 (12.8) & $\begin{array}{l}21 / 201(10.4) \\
0.461\end{array}$ & $\begin{array}{l}8 / 106(7.5) \\
0.196\end{array}$ & $\begin{array}{l}13 / 95(13.7) \\
0.754\end{array}$ \\
\hline $\begin{array}{l}\text { Dyspnoea } \\
\text { age } 4 \text { yrs }\end{array}$ & $3 / 193(1.6)$ & $\begin{array}{l}7 / 201(3.5) \\
0.224\end{array}$ & $\begin{array}{l}3 / 106(2.8) \\
0.452\end{array}$ & $\begin{array}{l}4 / 95(4.2) \\
0.169\end{array}$ \\
\hline $\begin{array}{l}\text { Asthma diagnosis } \\
\text { age } 6 y r s\end{array}$ & 7/188 (3.7) & $\begin{array}{l}7 / 196(3.6) \\
0.937\end{array}$ & $\begin{array}{l}6 / 106(5.7) \\
0.438\end{array}$ & $\begin{array}{l}1 / 90(1.1) \\
0.223\end{array}$ \\
\hline $\begin{array}{l}\text { Wheezing } \\
\text { at age 6yrs }\end{array}$ & $1 / 188(0.5)$ & $\begin{array}{l}6 / 196(3.1) \\
0.064\end{array}$ & $\begin{array}{l}2 / 106(1.9) \\
0.267\end{array}$ & $\begin{array}{l}4 / 90(4.4) \\
0.022\end{array}$ \\
\hline $\begin{array}{l}\text { Nocturnal cough } \\
\text { at age } 6 \mathrm{yrs}\end{array}$ & $10 / 189(5.3)$ & $\begin{array}{l}12 / 196(6.1) \\
0.725\end{array}$ & $\begin{array}{l}6 / 106(5.7) \\
0.893\end{array}$ & $\begin{array}{l}6 / 90(6.7) \\
0.644\end{array}$ \\
\hline $\begin{array}{l}\text { Dyspnoea } \\
\text { at age 6yrs }\end{array}$ & $1 / 188(0.5)$ & $\begin{array}{l}8 / 196(4.1) \\
0.022\end{array}$ & $\begin{array}{l}3 / 106(2.8) \\
0.102\end{array}$ & $\begin{array}{l}5 / 90(5.6) \\
0.007\end{array}$ \\
\hline
\end{tabular}

$\mathrm{Chi}^{2}$ tests carried out for all outcomes presented in this table

Total and specific IgE levels were similar between groups at ages four and six, except for the comparison of the extended-IG with the CG, for the total IgE level at age four. Children in the extended-IG were shown to have a lower total IgE level as compared to controls $(p=0.035)$.

\section{Logistic regression analysis}

The variables that were most suitable for inclusion in the logistic regression analysis were the variables Der $\mathrm{p} 1$ level above or below the group median expressed as $\mathrm{ng} / \mathrm{g}$ dust (1/0), number of weeks exclusively breastfed expressed in quartiles, and having a mother that ever had asthma (1/0)

The number of children included in the logistic regression analysis showed to be 269. Since not all participants agreed with carrying out lung-function tests $(n=43)$, some lung-function measurements could not be performed for all children due to child-specific circumstances (for instance behavioural problems or non-asthma related disease); and some independent data were lacking, the number of subjects in the multiple-regression analyses was reduced to 269 out of 387 children followed up until age six (69.5\%). As participating children did not differ from non-participants no selection bias occurred. The results showed that those children who had been exclusively breastfed were protected from 
developing current or possible asthma (when compared to never exclusively breastfed) as measured at age six $(p=0.017)$. Those children that were exclusively breastfed for 8-17 weeks were protected from developing asthma, $\mathrm{p}=0.003$, OR=0.271 (Cl 0.1130 .645$)$. When exclusively breastfed for 18-26 weeks a protective trend was shown: $p=0.076$, OR 0.443 (Cl 0.180 1.088)). Children that were exclusively breastfed for 1 to 7 weeks on the other hand, showed not to have any benefit from breastfeeding as compared to the reference group ( $p=0.409, \mathrm{Cl} 0.261$ 1.731). A HDM exposure level, (Der $p 1)$ below the group median $0.6606 \mu \mathrm{g} / \mathrm{g}$, showed to protect children from developing asthma $(p=0.026$, above median: OR=1.962 (1.082; 3.555)). Having a mother that ever had been diagnosed with asthma did not show to have a statistically significant influence on the development of asthma in children at high risk.

\section{Discussion}

The results of the first part of the PREVASC study described in 2005 showed that the PREVASC research intervention was effective in reducing the development of asthma symptoms to some extent. Wheezing, nocturnal coughing and dyspnoea were shown to be less frequently reported for children in the IG as opposed to the CG. ${ }^{25}$

However, the results shown after four and six years in this paper do not confirm the hypothesis that asthma and asthma symptoms can be prevented by reducing multiple exposures (ETS, HDM allergen, cow's milk). Although the intervention was shown to be reasonably effective in reducing exposure to both inhalant and food allergens, these measures were not clinically effective as measured at ages four and six.

In a recent meta-analysis we tested whether single-intervention strategies or multi-faceted interventions for reduction of allergen exposure in children at high risk of developing asthma would be more effective for the primary prevention of asthma. ${ }^{4}$ We found that multi-faceted interventions were significantly more effective than mono-faceted interventions, although this result was not applicable for current asthma symptoms (wheezing, nocturnal coughing and dyspnoea).

Comparable studies carried out in Canada and the United Kingdom (Isle of Wight study) seemed to support the hypothesis that multi-faceted allergen reduction might prevent the development of asthma in susceptible children. What could explain the discrepancy between these studies and the present study is the low number of families complying with our recommendation. Families we supplied with HDM-impermeable covers during the whole study period of six years were shown not to have used them consistently (median 3.5 
years). The reason for this low compliance might have been that we informed the parents that they had a $50 \%$ chance of having received placebo mattress encasings for their child's bed as of age two. During the first part of the PREVASC study, when all IG families were told they had received miteimpermeable bedding encasings, the compliance was nearly $100 \%$. If the families had used the HDM-impermeable encasings during the whole study period as expected, the median exposure level in the IG(s) would probably have been lower. The HDM allergen exposure level in the Netherlands as measured in the present study is shown to be low. The HDM-exposure levels in the Canadian, but even more so in the Isle of Wight study, were shown to be much higher than the levels we measured in the PREVASC study. In the Isle of Wight study the exposure levels were reduced from approximately $25 \mu \mathrm{g} / \mathrm{g}$ of dust during pregnancy to $6 \mu \mathrm{g} / \mathrm{g}$ of dust after birth, ${ }^{19}$ while in the Canadian Childhood Asthma Primary Prevention Study a reduction from $1.5 \mu \mathrm{g} / \mathrm{g}$ of dust to $0.8 \mu \mathrm{g} / \mathrm{g}$ of dust was established. ${ }^{16}$ The PREVASC study intervention realized a median reduction of Der p1 level from $0.7 \mu \mathrm{g} / \mathrm{g}$ of dust to approximately $0.2 \mu \mathrm{g} / \mathrm{g}$ of dust after one year of intervention (back to $0.7 \mu \mathrm{g} / \mathrm{g}$ after four years).

The cow's milk avoidance measure of the PREVASC intervention was partly successful. However, the most important part of the intervention (the recommendation to exclusively breastfeed the infants during the first six months of life) did not result in significant differences between groups. The cow's milk avoidance properties of HAF are known to be as good as those of human milk. In the PREVASC study HAF was used as replacement for human milk by a significantly greater number of families in the IG. It is plausible that the most important benefit for breastfeeding infants instead of using artificial formula is that breastfeeding not only reduces exposure of infants to cow's milk, but also provides the child with important components that might strengthen their immune and digestive systems, such as secretory $\lg A$, cytokines, polyunsaturated fatty acids, prebiotics and lysosyme. ${ }^{31-34}$ So this part of the intervention was not as successful as could have been possible.

Little room for improvement for ETS-exposure reduction might have caused the ETS-reducing intervention part to fail. In the IG $10.8 \%$ of mothers smoked during pregnancy. The ETS-exposure in the IG was not significantly reduced compared to the CG. We did not offer parents the use of aids like nicotine chewing gum to make their quitting efforts more successful. Advising parents to quit smoking, of course, is a sensible way of intervening for ETS-exposure reduction. In households where a minimum of one member is diagnosed as having asthma, however, these recommendations are likely to have been given quite often already, possibly leaving less room for improvement.

The Canadian Childhood Asthma Primary Prevention Study appeared to have the same problem of little room for improvement and lack of success for the ETS-reducing intervention part. $^{16}$ The failing ETS-reducing intervention 
therefore is unlikely to be the cause of the huge difference in effectiveness between the Canadian and the PREVASC study.

\section{HDM allergen avoidance and breastfeeding: Results of the logistic regression analyses}

In spite of the extremely low median levels of HDM allergen at baseline, the results of the logistic regression analysis showed that inhalant allergen reduction had a preventive effect on the development of asthma. Possibly the results of our intervention would have been more successful when we would have put more effort in stimulating compliance with the use of the HDMimpermeable encasings.

Another profound result of the logistic regression analysis was the preventive influence of breastfeeding. The lack of compliance with the breastfeeding part of the intervention might have been another reason why we were not able to confirm the hypothesis. In the Canadian Childhood Asthma Primary Prevention Study the parents were more compliant with the breastfeeding recommendations than was the case in the PREVASC study. In the Canadian study more children in the IG were breastfed at eight months of age as compared to children in the CG $(61 \%$ versus $50 \%, p=0.02)$.

The breastfeeding-recommendation study of Gijsbers et al. tailored the breastfeeding intervention part, as used in the present study, more intensively; our own intervention failed to strengthen the women to stand up to the difficulties they encountered. ${ }^{35}$ In the present study, a large number of women in both groups started breastfeeding their child but, for whatever reason, did not continue to do so through the age of six months. By the time women start working - in the Netherlands usually by the time their child is three months old most mothers in our study had stopped breastfeeding their child. Although breastfeeding is encouraged in the Netherlands, (employers are obliged to make sure breastfeeding mothers have sufficient time and a private room to express milk), breastfeeding is shown to be very difficult for mothers to combine with their work. ${ }^{36}$ Another reason why mothers who start breastfeeding stop before the child is six months old is that they often do not get the social support they need. ${ }^{35,36}$

In the study of Gijsbers et al., the breastfeeding brochure of the PREVASC study was evaluated and improved. A total of $48 \%$ of children in the IG was exclusively breastfed for six months as opposed to $27 \%$ of children in the CG $(p=0.03){ }^{37}$ By using the tailored version of the PREVASC breastfeeding intervention the number of children exclusively breastfed in the study of Gijsbers et al., raised the number of children exclusively breastfed by $21 \%$ as opposed to the CG. 
The feeding-intervention part of the PREVASC study differed from the interventions of the Canadian Childhood Asthma Primary Prevention Study and the Isle of Wight study to some extent. Apart from advising parents to exclusively breastfeed their child for six or nine months, their feeding intervention consisted of more recommendations. During (pregnancy and) lactation, participating mothers were advised to follow a strict dietary regimen that excluded dairy products and nuts. ${ }^{15,16}$ Parents also received specific advice on how to start introducing solid food. They were dissuaded from feeding their child food that was known to be highly allergenic, such as dairy products, fish, other seafood, eggs, nuts, soy, peanuts and oranges, during at least the first 12 months, and they were advised when to introduce these foods (dairy products and soy from the age of nine months, wheat at ten months and eggs at eleven months). This extensive advice on how to reduce food allergens might have been of crucial importance for the prevention of asthmatic complaints.

\section{Does the intervention's duration have any effect on the prevention of asthma in susceptible children?}

The inhalant allergen exposure levels were significantly lower in the extendedIG. However, this did not result in differences in clinical outcome. The present study is the only study ever carried out in which two multi-faceted interventions of different duration were compared. Since our intervention was shown not to have led to sufficient compliance in all aspects, the intervention-duration issue remains undecided.

\section{Intervention strategy aimed at implementation in daily general practice}

With our intervention we aimed at educating parents on how to lower their child's environmental exposure by a method suitable for implementation in daily general practice.

The results of the logistic regression analysis have shown that parts of our intervention (aimed at breastfeeding promotion and HDM allergen reduction) did have reducing effects on the development of asthma. These effects were not shown when comparing the randomised study groups. Possibly this was due to the intervention strategy chosen, which was aimed at a feasible implementation in general practice taking into account the busy schedules of GPs and practice nurses.

One related effect of the presumed consequences of the intervention strategy was the disappointing compliance with the intervention recommendations. Both the Isle of Wight study and the Canadian Childhood Asthma Primary Prevention Study supplied parents with additional advice on how to reduce exposure to HDM (encasings plus repeated mite-killing treatment) and food allergens 
(breastfeeding promotion, HAF use, plus diet instructions for mothers and children) and thus asked for more effort from the part of the parents. This might have caused parents to comply more extensively with the recommendations supplied. Besides these additional recommendations, the Isle of Wight study group contacted parents regularly to support compliance with the intervention.

\section{Conclusions}

In the present study no differences in asthma outcome were shown between groups, nor were any differences observed between groups on the separate lung-function parameters used in the algorithm. The exposure to inhalant and food allergens (with the exception of breastfeeding), however, was shown to have been significantly lowered by the intervention coeffias compared to controls.

The lack of effect from the ETS-reducing intervention, the low compliance with the breastfeeding intervention and the disappointing compliance with the HDM allergen reducing intervention may explain the absence of clinical efficacy.

So far the hypothesis does seem to have been confirmed by other multi-faceted intervention studies. Country-specific circumstances, as well as the fact that our intervention was not sufficiently aimed at enhancing compliance, might have played a role in the lack of clinical effectiveness. 


\section{References}

1. Warner JA, Jones AC, Miles EA, Colwell BM, Warner JO. Prenatal origins of asthma and allergy. Ciba Found Symp 1997;206:220-8; discussion 228-32.

2. Mommers M, Gielkens-Sijstermans C, Swaen GM, van Schayck CP. Trends in the prevalence of respiratory symptoms and treatment in Dutch children over a 12 year period: results of the fourth consecutive survey. Thorax 2005;60:97-9.

3. Martinez FD. Complexities of the genetics of asthma. Am J Respir Crit Care Med 1997;156:S117-22.

4. Schayck van CP, Maas T, Kaper J, Knottnerus JA, Sheikh A. Is there any role for allergen avoidance in the primary prevention of childhood asthma? J Allergy Clin Immunol 2006;119:1322-8.

5. Peat JK, Mihrshahi S, Kemp AS, Marks GB, Tovey ER, Webb K, Mellis CM, Leeder SR. Three-year outcomes of dietary fatty acid modification and house dust mite reduction in the Childhood Asthma Prevention Study. J Allergy Clin Immunol 2004;114:807-13.

6. Mallet E, Henocq A. Long-term prevention of allergic diseases by using protein hydrolysate formula in at-risk infants. J Pediatr 1992;121:S95-100.

7. Woodcock A, Lowe LA, Murray CS, Simpson BM, Pipis SD, Kissen P, Simpson A, Custovic A; NAC Manchester Asthma and Allergy Study Group. Early life environmental control: effect on symptoms, sensitization, and lung function at age 3 years. Am J Respir Crit Care Med 2004;170:433-9.

8. Zeiger RS, Heller S, Mellon MH, Forsythe AB, O'Connor RD, Hamburger RN, Schatz M. Effect of combined maternal and infant food-allergen avoidance on development of atopy in early infancy: a randomized study. J Allergy Clin Immunol 1989;84:72-89.

9. Zeiger RS, Heller S. The development and prediction of atopy in high-risk children: follow-up at age seven years in a prospective randomized study of combined maternal and infant food allergen avoidance. J Allergy Clin Immunol 1995;95:1179-90.

10. Brunekreef B, Smit J, de Jongste J, Neijens H, Gerritsen J, Postma D, Aalberse R, Koopman L, Kerkhof M, Wilga A, van Strien R. The prevention and incidence of asthma and mite allergy (PIAMA) birth cohort study: design and first results. Pediatr Allergy Immunol 2002;13 Suppl 15:55-60.

11. Custovic A, Simpson BM, Simpson A, Kissen P, Woodcock A. Effect of environmental manipulation in pregnancy and early life on respiratory symptoms and atopy during first year of life: a randomised trial. Lancet 2001;358:188-93.

12. Koopman LP, van Strien RT, Kerkhof M, Wijga A, Smit HA, de Jongste JC, Gerritsen J, Aalberse RC, Brunekreef B, Neijens HJ; Prevention and Incidence of Asthma and Mite Allergy (PIAMA) Study. Placebo-controlled trial of house dust mite-impermeable mattress covers: effect on symptoms in early childhood. Am J Respir Crit Care Med 2002;166:307-13.

13. Marks GB, Mihrshahi S, Kemp AS, Tovey ER, Webb K, Almqvist C, Ampon RD, Crisafulli D, Belousova EG, Mellis CM, Peat JK, Leeder SR. Prevention of asthma during the first 5 years of life: a randomized controlled trial. J Allergy Clin Immunol 2006;118:53-61.

14. Mallet E, Henocq A. Long-term prevention of allergic diseases by using protein hydrolysate formula in at-risk infants. J Pediatr 1992;121:S95-100.

15. Arshad SH, Matthews S, Gant C, Hide DW. Effect of allergen avoidance on development of allergic disorders in infancy. Lancet 1992;339:1493-7.

16. Chan-Yeung M, Manfreda J, Dimich-Ward H, Ferguson A, Watson W, Becker A. A randomized controlled study on the effectiveness of a multifaceted intervention program in the primary prevention of asthma in high-risk infants. Arch Pediatr Adolesc Med 2000;154:657-63.

17. Kuiper S, Maas T, van Schayck CP, Muris JW, Schönberger HJ, Dompeling E, Gijsbers B, van Weel C, Knottnerus JA; PREVASC group. The primary prevention of asthma in children study: design of a multifaceted prevention program. Pediatr Allergy Immunol 2005;16:321-31.

18. Arshad SH, Bateman B, Matthews SM. Primary prevention of asthma and atopy during childhood by allergen avoidance in infancy: a randomised controlled study. Thorax 2003;58:489-93. 
19. Arshad SH, Hide DW. Effect of environmental factors on the development of allergic disorders in infancy. J Allergy Clin Immunol 1992;90:235-41.

20. Arshad SH, Stevens M, Hide DW. The effect of genetic and environmental factors on the prevalence of allergic disorders at the age of two years. Clin Exp Allergy 1993;23:504-11.

21. Becker A, Watson W, Ferguson A, Dimich-Ward H, Chan-Yeung M. The Canadian asthma primary prevention study: outcomes at 2 years of age. J Allergy Clin Immunol 2004;113:650-6.

22. Chan-Yeung M, Ferguson A, Watson W, Dimich-Ward H, Rousseau R, Lilley M, Dybuncio A, Becker A. The Canadian Childhood Asthma Primary Prevention Study: outcomes at 7 years of age. J Allergy Clin Immunol 2005;116:49-55.

23. Hide DW, Matthews S, Matthews L, Stevens M, Ridout S, Twiselton R, Gant C, Arshad SH. Effect of allergen avoidance in infancy on allergic manifestations at age two years. J Allergy Clin Immunol 1994;93:842-6.

24. Hide DW, Matthews S, Tariq S, Arshad SH. Allergen avoidance in infancy and allergy at 4 years of age. Allergy 1996;51:89-93.

25. Schonberger HJ, Dompeling E, Knottnerus JA, Maas T, Muris JW, van Weel C, van Schayck CP. The PREVASC study: the clinical effect of a multifaceted educational intervention to prevent childhood asthma. Eur Respir J 2005;25:660-70.

26. Schönberger $\mathrm{H}$, Schayck $\mathrm{Cv}$. Prevention of asthma in genetically predisposed children in primary care-from clinical efficacy to a feasible intervention programme. Clin. Exp. Allergy 1998;28:1325-1331.

27. Willemsen MC, Gorts CA, Van Soelen P, Jonkers R, Hilberink SR. Exposure to environmental tobacco smoke (ETS) and determinants of support for complete smoking bans in psychiatric settings. Tob Control 2004;13:180-5.

28. van Deursen J. [Nurses can point out to parents the adverse effects for young children. Campaign against passive smoking]. Tvz 1997;107:551-2.

29. Jenkins MA, Clarke JR, Carlin JB, Robertson CF, Hopper JL, Dalton MF, Holst DP, Choi K, Giles GG. Validation of questionnaire and bronchial hyperresponsiveness against respiratory physician assessment in the diagnosis of asthma. Int J Epidemiol 1996;25:609-16.

30. Saarinen UM, Kajosaari M. Breastfeeding as prophylaxis against atopic disease: prospective follow-up study until 17 years old [see comments]. Lancet 1995; 346:1065-9.

31. Stapel SO, Eysink PE, Vrieze J, Aalberse RC. IgE testing in capillary blood. Pediatric Allergy Immunol 2004;15:230-3.

32. Penders J, Thijs C, Vink C, Stelma FF, Snijders B, Kummeling I, van den Brandt PA, Stobberingh EE. Factors influencing the composition of the intestinal microbiota in early infancy. Pediatrics 2006; 118:511-21.

33. Schanler RJ, Garza C, Nichols BL. Fortified mothers' milk for very low birth weight infants: results of growth and nutrient balance studies. J Pediatr 1985; 107:437-45.

34. Schanler RJ, Hurst NM, Lau C. The use of human milk and breastfeeding in premature infants. Clin Perinatol 1999; 26:379-98, vii.

35. Schanler RJ, Oh W. Composition of breast milk obtained from mothers of premature infants as compared to breast milk obtained from donors. J Pediatr 1980; 96:679-81.

36. Gijsbers B, Mesters I, Knottnerus JA, Legtenberg AHG, Schayck van CP. Factors influencing breastfeeding practices and postponement of solid food to prevent allergic disease in high-risk children: results from an explorative study. Patient Education and Counseling 2004.

37. Bulk-Bunschoten AM, van Bodegom S, Reerink JD, Pasker-de Jong PC, de Groot CJ. Reluctance to continue breastfeeding in The Netherlands. Acta Paediatr 2001; 90:1047-53.

38. Gijsbers B, Mesters I, Knottnerus J, Kester A, Schayck van CP. The success of an Educational Program to Promote Exclusice Breastfeeding for 6 Months in Families with a History of Asthma: A Randomized Controlled Trial. Pediatr Allergy Immunol 2006; 19:214-22. 



\section{Chapter 8}

General discussion

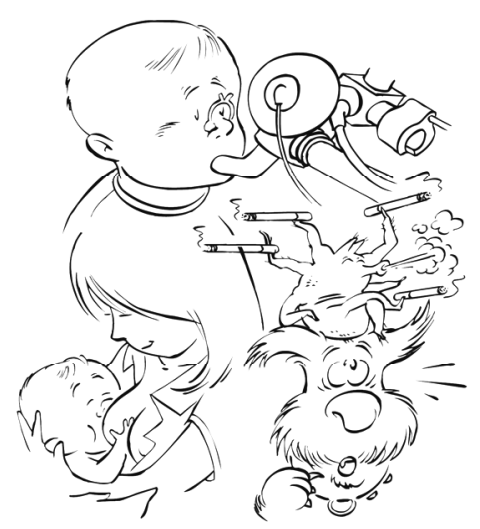




\section{Introduction}

In this chapter the results of the PREVASC-study, the methodological considerations, added value of the current thesis, conclusions and recommendations for clinical practice and further research are described.

\section{The PREVASC trial: The Present thesis}

The primary aim of this thesis (PREVention of Asthma in Children) was to investigate whether asthma could be prevented in children with a familial predisposition for asthma where at least one of their first-degree family members has been diagnosed with asthma.

Four hundred and seventy-six pregnant women were initially included with the help of general practitioners (GPs), midwives and gynaecologists. The number of children followed up resulting from these pregnancies until the age of two was 443. Randomisation allocated 222 children to the intervention group (IG) and 221 to the control group (CG). Ninety-eight percent of participants $(n=432)$ decided to extend their participation in the PREVASC study when their child was two years of age (IG $n=219$ and $C G n=213$ ). Four hundred twenty nine of were followed up until the age of six $(96.8 \%$ of 443$)$ and of 342 lung function was objectively measured $(77.2 \%$ of 443$)$. The results at two years of age have been published previously. ${ }^{1}$

The intervention offered from pregnancy onward was focused on educating parents about the multiple measures for optimising their child's exposure to environmental circumstances associated with asthma. The measures focused on were lowering exposure to inhalant allergens and food allergens, breastfeeding promotion and reduction of exposure to environmental tobacco smoke (ETS).

Two secondary research questions were included, focusing on 1) the difference in effect when two different intervention periods are compared and 2) the effect of environmental factors on the outcome asthma at age six independent of group allocation. To gather information on the optimal intervention duration, the effects of an extended intervention in which the intervention was continued until the age of six $(n=111)$ was compared with a short intervention in which that intervention stopped at two years of age $(n=108)$. To ensure group blinding, these latter received placebo bedding encasings. The extended-intervention group received intervention treatment for decreasing inhalant allergen exposure, including recommendations and House Dust Mite (HDM) allergen impermeable bedding encasings for the child's bed. They also received recommendations on how to reduce exposure to ETS. The families were kept uninformed about the group they were allocated to. The families were unaware 
of the exact differences between the groups, as this would have un-blinded the intervention.

The main outcome was asthma status at age six as categorized by a predefined algorithm (no asthma, possible asthma, current asthma). The categorization of the asthma status was based on spirometry and symptoms, as prospectively reported by parents and GPs. In cases the algorithm was not able to classify subjects an expert panel gave the final diagnosis.

\section{PREVASC programme}

Two randomised clinical trials (RCTs) and one cohort study were part of the PREVASC programme on PREVention of ASthma in Children. The study described in this thesis was the first project carried out in this research programme. In addition to this RCT, another trial, carried out by Gijsbers et al., was part of the programme, and focused on whether optimizing the PREVASC intervention would lead to increased adherence. The cohort study included in the PREVASC programme is the study carried out by Kuiper et al. In this part of the programme, data on the PREVASC trial control group (children with a familial predisposition for asthma in first-degree family members) and a cohort of children with no genetic predisposition was evaluated. Based on these data, an estimate would then be made of the predictive value of a positive family history of asthma (as assessed in the prenatal period by the GP) on the development of childhood asthma. The health-economic benefits of high-risk identification and primary prevention of asthma were also studied in that part of the study.

\section{Research on asthma development in children at high risk}

In recent years, several birth cohort studies and intervention studies on asthma development in children at high risk of developing asthma have been carried out. The majority of these studies focused on exposures such as HDM allergens, pet allergens, food allergens and ETS. Designs vary from cohort studies to RCTs. Cohort studies are of particular importance as explorative studies on the role played by specific exposures. Knowledge resulting from these studies has been used in RCTs that are primarily focused on the effectiveness of specific interventions. Proof of the effectiveness of interventions based on results of cohort studies thereby is provided by RCTs. The ongoing RCTs are comparable to a certain extend, and so it is important to compare the effect of the intervention(s) on development of asthma in susceptible children 
and to pool the data from these studies, thereby increasing the strength of the results.

Intervention strategies used in RCTs on allergen reduction are either focused on exposure to one single allergen, referred to as mono-faceted interventions, or focused on reduction of multiple allergens simultaneously, so-called multifaceted interventions. As asthma is a multi-factorial disease, we assumed that simultaneous decrease of exposure to allergens of inhalant and food origin, might lead to a reduction in children developing asthma. Mono-faceted interventions could therefore be less successful. We separately pooled data of mono-faceted intervention studies and multi-faceted intervention studies. Indirect comparison between these treatments indeed suggested that multiple interventions were more successful in reducing the development of asthma in children than mono-interventions. However, the effect of multi-faceted interventions on parent-reported wheezing was inconsistent, and there was no beneficial effect on nocturnal coughing. Mono-faceted interventions were no more effective than controls in the reduction of all outcomes.

Since the results of the meta-analyses showed that multi-faceted interventions were more effective than mono-faceted intervention strategies, we assume that the hypothesis that asthma could best be prevented by reducing exposure to multiple allergens might be correct. However, as the meta-analyses performed were not randomised comparisons and the effects on respiratory symptoms were not consistent, we suggest designing a new study in which both types of interventions are performed simultaneously. To our knowledge, no other studies are ongoing in which both intervention strategies are randomly compared. Such a study would be of great importance in shedding new light on preventing the development of asthma in children susceptible to developing asthma.

\section{Results of the present multi-faceted intervention study PREVASC}

In the present study no differences in asthma outcome were shown between groups. There were also no differences observed between groups as far as the separate lung function parameters were concerned. The exposure to inhalant allergens as well as food allergens however, was significantly lowered by the intervention supplied by the study. The absence of clinical efficacy may be explained by the lack of effect from the ETS-reducing intervention, the low compliance with the breastfeeding intervention, the low room for improvement in the HDM allergen exposure level, and the disappointing compliance with the HDM allergen-reducing intervention.

So far, the hypothesis seems to be supported by other multi-faceted intervention studies. Country specific circumstances as well as the fact that our 
intervention was aimed at implementation in real life and thereby less focused on enhancing compliance might have played a part in the lack of clinical effectiveness.

\section{Compliance with the PREVASC intervention}

- For the HDM allergen-reducing intervention, the second randomisation implied a change of design. We informed both intervention subgroups about the possibility that they might be receiving placebo bedding encasings for their child as of age two. This seems to have resulted in a decrease in the use of HDM-impermeable bedding encasings. In the first part of the PREVASC study, all participants of the intervention group were informed that they had received HDM-impermeable bedding encasings until their child turned two. In this first part of the study, nearly a hundred percent of the families in the intervention group used the covers constantly. As of age two, when they were randomly assigned to the differing intervention duration groups, the use of the encasings was shown to have drastically decreased. The total use of the encasings reached a median number of 3.5 years in the extendedintervention group and 2.2 years in the short intervention group.

- The breastfeeding promoting intervention showed to have failed to strengthen the women to stand up against the difficulties they encountered with prolonged breastfeeding. ${ }^{2}$ Emotional support, the support offered by partners, family and friends, as well as the practical and theoretical skills of breastfeeding lacked in the PREVASC participants as was shown in the study of Gijsbers et al.

- The ETS exposure part of the intervention was not convincing or effective enough for parents to quit smoking. We did not offer parents the use of aids like for instance nicotine chewing gum to make their quitting efforts more successful. Advising parents to quit smoking, is a sensible way of intervening for ETS exposure reduction. In households where at least one member is diagnosed with asthma, however, these recommendations are likely to have already been given quite often, possibly leaving little room for improvement.

It was shown that breastfeeding and a HDM allergen exposure equal to or lower than the group median $(0.6606 \mu \mathrm{g} / \mathrm{g})$ reduced the chances of developing asthma. These results were the outcome of a multiple logistic regression analysis on the effect of the environmental exposures intervened on in the PREVASC study, when both study groups were combined,. No effectiveness for low exposure to ETS was shown, possibly due to the low percentage of children being raised in a household with parents who smoked. 


\section{House dust mite allergen reduction}

In the studies on reducing inhalant allergens, the interventions focused primarily on allergens originating from house dust mite (Dermatophagoides Pteronyssinus [Der p1] and Dermatophagoides Farinae [Der f1], also referred to as European dust mite allergen and American dust mite allergen, respectively). On the basis of the results of a pilot study we performed, ${ }^{3}$ we concluded that Der $\mathrm{p} 1$ is unequally distributed on living room floors with smooth coverings, most likely because of displacement of dust from the middle to the edge due to activity. Expression as $\mathrm{ng} / \mathrm{g}$ of dust and $\mathrm{ng} / \mathrm{m}^{2}$ showed that they were not interchangeable.

\section{The hygiene hypothesis}

A very popular hypothesis is the hygiene hypothesis that assumes that infections might help the developing immune system from becoming unbalanced and from developing a predisposition towards allergic diseases such as asthma.

Conflicting results have been published thus far and a summary of these results does not support any firm conclusion that infections do have a clear effect on the development of atopic diseases and asthma. ${ }^{4,5}$

To find out whether the results of the PREVASC study did or did not support the hygiene hypothesis, we evaluated data on the relationship of respiratory and gastrointestinal infections (common cold and diarrhoea associated with fever), in relation to the development of asthma in the first four to six years of life.

The results of our linear and logistic regression analyses on the influence of infections on the development of asthma and asthma symptoms showed no concordance with the hygiene hypothesis. The PREVASC-data therefore do not supply evidence for the assumption that infections in susceptible children can protect against the development of asthma. Our results suggest however that common cold and diarrhoea might well influence atopy. Common cold did show a negative relationship with total $\operatorname{lgE}$ and diarrhoea did show an inverse relationship with HDM specific IgE.

A limitation of our study is the lack of information concerning the type of pathogen the child was infected with. As we had to make use of the facilities and logistics of a community based trial with another primary research question, no microbiological essays could be performed. In future studies further determination of specific pathogens is recommended. 


\section{Methodological considerations}

In the current thesis some issues are addressed as these might have had its influence on the outcome at ages four and six years. Some of these issues were already reported in the thesis of $\mathrm{Dr}$ Schönberger, the researcher of the first part of the PREVASC study (pregnancy to two years of age). ${ }^{6}$

\section{Inclusion of pregnant women carrying a child at high risk of developing asthma}

Pregnant women were included in the PREVASC-study when the child they were carrying was supposed to be genetically predisposed. As genetic predisposition is not possible to define during prenatal life, positive family history of asthma was chosen as proxy measure of genetic predisposition.

Allocation of families to the intervention group or control group was carried out by means of pre-randomisation in clusters based on ZIP-code of domicile of the participants in combination with the location of the general practice attended. The GPs did inform their eligible patients about the study and supplied them with study information. Pre-randomisation in clusters was chosen to prevent contamination to occur when GPs would be treating patients from both groups. It was assumed that cluster randomisation would also prevent spontaneous intervention behaviour in the control group because of unwanted exchange of information on the preventive measures between groups in the waiting room of the GP, or in the neighbourhood. Intervention group families did show to have higher inhalant allergen exposure levels as opposed to the control group at baseline (IG $148 \mathrm{ng} / \mathrm{m}^{2}$, CG $\left.79 \mathrm{ng} / \mathrm{m}^{2}, \mathrm{p}<0.001\right)$. After one year of intervention the difference in Der $p 1$ exposure level between groups showed to be inverted (IG $17 \mathrm{ng} / \mathrm{m}^{2}$ and CG $79 \mathrm{ng} / \mathrm{m}^{2}, \mathrm{p}<0.001$ ). The difference in baseline levels of Der $\mathrm{p} 1$ exposure between groups might have been caused by the seasonal influence on the mite exposure level as more intervention group families were enrolled during autumn and winter as compared to control group families. Apart from this control group mothers showed to be of higher educational level. There were no other differences at baseline on family history of asthma, smoking behaviour of parents, furry pets in the household, type of house lived in (its age) and number of first pregnancies.

The number of smoking parents was under-represented in the PREVASCstudy. The reason for under-representation of smoking mothers could be that they chose not to participate because they did not want anyone to be informed about their smoking habits as this is known to be harmful for the health of their unborn child. However it is well possible that women in genetically predisposed families smoked less than other pregnant women in The Netherlands as they might already have been aware of the health risks of (passive) smoking. 


\section{Collection of health outcomes}

Children's lung function at age six was measured to assess the primary study outcome of their current asthma, including forced expiratory volume in one second (FEV1) before and after bronchodilatation, forced expiratory vital capacity (FVC), tiffeneau index (FEV1/FVC ratio) and bronchial hyper responsiveness (PC20 histamine). All children were invited to visit the lungfunction laboratory of the Maastricht University Hospital (azM) when they reached the age of six.

A predefined automated algorithm was used for determining the asthma status of participating children, in which they were assigned to one of three following groups:

1 no asthma

2 possible asthma

3 current asthma

The information used for this categorization was based on both lung-function results and symptoms reported by GPs and parents. If participants were unable to visit the lung-function laboratory, they were given the opportunity of having the spirometry performed during a home visit by a research assistant. There were no differences between the groups whose lung function was measured in the home situation compared with the laboratory. The equipment used for home determination of lung function was technically the same as the spirometer used in the hospital (Flow screen, Viasys healthcare The Netherlands, Bilthoven). Histamine provocation testing and NO measurement, however, could not be included in the home visits.

Symptom outcomes as prospectively reported by GPs was collected. The GPs completed standardized (computerized) registration forms during or immediately after the participating children visited their offices. This form of health-outcome collection is a valid method, since GPs are trained to recognize asthma symptoms. Bias might have occurred, as parents and GPs were not blinded for the intervention. This could have influenced their symptom reporting, diagnostic labelling and treatment to the participants of both groups.

Another way of collecting health outcomes was by parents' completing weekly reports during the first two years of their child's life, and yearly questionnaires (based on validated ISAAC questionnaires ${ }^{7}$ ) from birth onwards. The health outcome as reported by parents, of course, might be liable to some subjectivity, but since only a maximum of twenty percent of all illnesses experienced by children reaches the GP or other doctors, this was considered to be a method necessary for the collection of a total package of health outcomes. ${ }^{8}$

In the Isle of Wight study and the Canadian Childhood Asthma Primary Prevention Study, data prospectively reported by GPs was not available. In 
these studies the symptom outcome was dependent on the symptoms as reported by parents in questionnaires.

\section{Collection of exposure outcomes}

Inhalant allergen exposure in the present study was assessed by sampling settled dust during pregnancy one year after the first measurement at ages two and four. Only for the first two measurements were dust samples collected in the living room (two open play sites were sampled and, if a carpet was present on a floor with smooth coverings, both floor coverings were sampled), as well as on the parental mattress. When the children had the age of two and four, a dust sample was collected from the child's mattress. Mattresses were sampled without the bedding, with the exception of HDM-impermeable bedding, if this was in use. Sampling sites were vacuumed for $2 \mathrm{~min} / \mathrm{m}^{2}$ each (using a $1300 \mathrm{~W}$ vacuum cleaner). Dust was collected onto glass micro fibre filters and stored at $-12^{\circ} \mathrm{C}$ until analysis. The samples were analysed for Der p1, Fel d1 and Can f1 content by the Laboratory for Biological Agentia at the Technical University Eindhoven in the Netherlands. There is some discussion as to the best way of sampling mattresses, the bedding or the bare mattress. However this is not a relevant discussion point within a trial, as long as the method of sampling used is not dependent on group allocation. In international research the sampling methods are not always described extensively. For comparability of study outcome a thorough description of the sampling method is crucial. Different methods are available for measuring the exposure level of inhalant allergens. Airborne allergen samples or allergen levels in settled dust are the methods used in research. ${ }^{9,10}$ In fact, for mite and cat allergens, the relationship between airborne levels and dust samples is extremely variable. ${ }^{9,10}$ Although each circumstance might pose specific requirements for the preferred sampling method used, measurement of allergen exposure from collected dust samples is considered the best method available. ${ }^{11}$

For measurements in living rooms it is recommended that at least two sites are sampled because of unequal distribution. ${ }^{12}$ However, there is no uniformity about the exact sampling locations. ${ }^{13}$ It is important in studies that the sampling procedure is be standardized so study comparisons can be made. ${ }^{14,15}$

The expression of inhalant allergen exposure most used is $\mathrm{ng} / \mathrm{g}$ of dust. However, the expression $\mathrm{ng} / \mathrm{m}^{2}$ reflects the actual amount of Der $\mathrm{p} 1$ present at the sampled area, whereas the expression $\mathrm{ng} / \mathrm{g}$ of dust merely reflects the concentration of allergen in floor dust. One probable cause that Der $\mathrm{p} 1 \mathrm{ng} / \mathrm{g}$ is more commonly used is that the exposure levels above $2 \mu \mathrm{g} / \mathrm{g}$ of dust and 10 $\mu \mathrm{g} / \mathrm{g}$ of dust are described as being associated with an increased risk of sensitisation and asthma, ${ }^{16}$ while no reference exposure levels are known for 
Der $\mathrm{p} 1$ expressed as $\mathrm{ng} / \mathrm{m}^{2}$. As the expression of Der $\mathrm{p} 1$ as $\mathrm{ng} / \mathrm{m}^{2}$ reflects the actual exposure level, this might be a better exposure expression than $\mathrm{ng} / \mathrm{g}$.

It is arguable whether settled dust as collected from mattresses does in fact reflect the actual allergen exposure. We decided therefore to only measure allergen exposure at ages two and four sampled from mattresses as described, since the bed is the location where one-third of the time is spent within a 24hour period. Babies and toddlers are more likely to come in contact with inhalant allergens from the living room floor, since they are usually crawling.

We considered that the objective measurement of inhalant allergen exposure in settled dust was the most valid way of collecting exposure data. We used questionnaires for collecting data on washing, airing, ventilating and other behavioural information associated with allergen exposure.

Another issue that we encountered is the influence of uncertainty on the compliance with an intervention. This was shown for the inhalant allergen exposure reducing intervention from age two onwards. As parents were informed to have a $50 \%$ chance of having received placebo mattress encasings they showed to be less compliant than when told they had received HDM impermeable encasings. Honesty and ethical correctness in this case did result in a reduction of compliance by a half (100\% until age two as opposed to $48.3 \%$ from age two to age six).

Food allergen exposure was measured in weekly reports completed by the parents for children aged $0-2$. In addition to this method of data gathering, questionnaires were used when the child was aged six months. In our opinion the weekly reports were the most valid method to collect exposure to food allergen, because it is associated with a very low recall bias, as long as parents filled out the reports weekly as we asked them to. However, some participants tended to forget to complete the weekly reports in this period of the child's life, which is a relatively busy and intensive time for young parents. Parents who did not send us the reports in time (every three months) received a telephone call reminding them to do so. Data collected after calling parents to remind them to completed the weekly reports, is are assumed to have been subject to more recall bias as compared to the reports that were completed weekly.

Exposure to ETS was measured by yearly questionnaires. Although results of a validation study have shown that exposure classification based on questionnaire data is likely to be reasonably valid, it is arguable whether questioning parents on the ETS exposure of their child is a valid method of information extraction on smoking exposure of a child. We could have chosen to measure cotinine levels in urine of children as a measure for actual ETS exposure. Since collecting urine samples of children that are not potty-trained is such a nuisance and we had already asked parents to do so much, we did not 
want to burden them with collecting urine samples regularly from their child by supplying them with an adhesive plastic pouch. Another important reason we chose not to include this measurement was because of the relatively high additional costs associated with cotinine measurements.

\section{What this research adds}

The current trial will not change the guidelines on primary prevention of asthma in susceptible children. The results are not in concordance with outcome of comparable studies although post-hoc analyses showed breastfeeding and reduction of HDM allergen exposure both seem to have an effect on asthma development in susceptible children.

What the PREVASC trial has taught us is that the trial intervention cannot be recommended for use in general practice in the Netherlands. Country specific circumstances (e.g. low HDM allergen exposure levels in the Netherlands) as well as the fact that our intervention was aimed at implementation in real life and thereby less focused on enhancing compliance might have played a role in the lack of clinical effectiveness. This resulted an insufficient reduction of exposure to environmental factors.

If the multi-faceted intervention is optimised with improved compliance, the outcome will give more decisive answers on the question if asthma can be prevented in susceptible children by reducing environmental exposures. The study of Gijsbers et al. already showed how optimising an intervention results in increased compliance.

We therefore do advise to perform a study aimed at prevention of asthma in susceptible children by using an optimised intervention on reduction of environmental exposures preferably in multiple countries with differing room for improvement. This type of research is necessary for the generalization of results.

\section{Conclusions}

1. The PREVASC trial did not result in reduction of asthma in susceptible children. Aside from the possibility that reducing environmental allergen exposure truly does not prevent asthma development, other explanations might be:

a. Low levels of HDM allergen and ETS exposure (low room for improvement);

b. The fact that the PREVASC intervention was aimed at implementation in real life and thereby was less focused on enhancing compliance. 
2. Although the current trial did not support the results of the meta-analyses carried out in this thesis, asthma seems to be best prevented in high-risk children by intervening on multiple allergen exposures simultaneously.

3. Post-hoc analysis of PREVASC data has indicated that asthma might be prevented when a child is exposed to low levels of HDM allergen exposure. Also breastfeeding seemed to have a preventive effect. Other exposures did not indicate to play any role in the development of asthma in susceptible children.

4.PREVASC-data do not supply evidence for the assumption that infections in susceptible children can protect against the development of asthma and atopy.

\section{Recommendations}

\section{Clinical practice}

Although the current trial did not support the results of the meta-analyses, asthma seems to be best prevented in high-risk children by intervening on multiple allergen exposures simultaneously. This would imply that health care professionals during pregnancy and just after birth of children at high risk of developing asthma need to advise parents on measures for reducing their child's contact with multiple environmental exposures simultaneously in order to reduce the likelihood of developing asthma later in childhood. Children who grow up in low-allergen surroundings may be at lower risk of developing asthma.

\section{Future research}

We would call for a multi-faceted intervention study on the reduction of environmental exposures in which several countries with different baseline exposure levels co-operate. Stimulating compliance to the intervention would have to receive sufficient attention.

Another recommendation resulting from the present thesis is to perform a study in which multi-faceted and mono-faceted interventions on the reduction of allergen exposure are randomly compared. Only when such a study has been carried out a more definite conclusion might be drawn concerning the preference of intervention types (mono-faceted or multi-faceted) in the primary prevention of asthma in children at risk. 
We would propose that these research recommendations are combined in one and the same (large) longitudinal trial. We are aware that the factors complicating the performance of such a study are the large number of participants needed to ensure the power of the study, the follow-up duration of a minimum of six years to ensure the success rate of lung-function measurements and the concomitant costs. Because of its presumed impact on asthma care, however the importance of such a study is expected to counterbalance these complicating factors. 


\section{References}

1. Schönberger HJ, Dompeling E, Knottnerus JA, Maas T, Muris JW, van Weel C, van Schayck CP. The PREVASC study: the clinical effect of a multifaceted educational intervention to prevent childhood asthma. Eur Respir J 2005;25:660-70.

2. Gijsbers B, Mesters I, Knottnerus JA, Legtenberg AHG, Schayck van CP. Factors influencing breastfeeding practices and postponement of solid food to prevent allergic disease in high-risk children: results from an explorative study. Patient Education and Counseling 2004.

3. Maas T, Rovers JJ, Schönberger HJ, Schayck CP. Distribution of house dust mite allergen: comparing house dust mite allergen levels in dust samples collected from different sites on living room floors with smooth coverings. Allergy 2003;58:500-2.

4. Borchers AT, Keen CL, Gershwin ME. Hope for the hygiene hypothesis: when the dirt hits the fan. J Asthma 2005;42:225-47.

5. Platts-Mills TA, Erwin E, Heymann P, Woodfolk J. Is the hygiene hypothesis still a viable explanation for the increased prevalence of asthma? Allergy 2005;60 Suppl 79:25-31.

6. Schönberger $\mathrm{H}$. Towards (primary) prevention of childhood asthma in primary care: Maastricht University, 2003.

7. Jenkins MA, Clarke JR, Carlin JB, Robertson CF, Hopper JL, Dalton MF, Holst DP, Choi K, Giles GG. Validation of questionnaire and bronchial hyper responsiveness against respiratory physician assessment in the diagnosis of asthma. Int J Epidemiol 1996;25:609-16.

8. Bruijnzeels MA, Foets M, van der Wouden JC, van den Heuvel WJ, Prins A. Everyday symptoms in childhood: occurrence and general practitioner consultation rates. British journal of general practice the journal of the Royal College of General Practitioners 1998;48:880-4.

9. Swanson MC, Campbell AR, Klauck MJ, Reed CE. Correlations between levels of mite and cat allergens in settled and airborne dust. J Allergy Clin Immunol 1989;83:776-83.

10. Custovic A, Simpson B, Simpson A, Hallam C, Craven M, Woodcock A. Relationship between mite, cat, and dog allergens in reservoir dust and ambient air. Allergy 1999;54:612-6.

11. Tovey ER, Mitakakis TZ, Sercombe JK, Vanlaar CH, Marks GB. Four methods of sampling for dust mite allergen: differences in 'dust'. Allergy 2003;58:790-4.

12. Marks GB, Tovey ER, Peat JK, Salome CM, Woolcock AJ. Variability and repeatability of house dust mite allergen measurement: implications for study design and interpretation. Clin Exp Allergy 1995;25:1190-7.

13. Hill MR. Quantification of house-dust-mite populations. Allergy 1998;53(48 Suppl):18-23.

14. Platts-Mills TA, Thomas WR, Aalberse RC, Vervloet D, Champman MD. Dust mite allergens and asthma: report of a second international workshop. J Allergy Clin Immunol 1992;89: 1046-60.

15. Luczynska CM. Identification and quantification of mite allergens. Allergy 1998;53(S48):54-7.

16. Sporik R, Holgate ST, Platts-Mills TA, Cogswell JJ. Exposure to house-dust mite allergen (Der $\mathrm{pl}$ ) and the development of asthma in childhood. A prospective study. $\mathrm{N}$ Engl J Med 1990;323:502-7. 
Summary

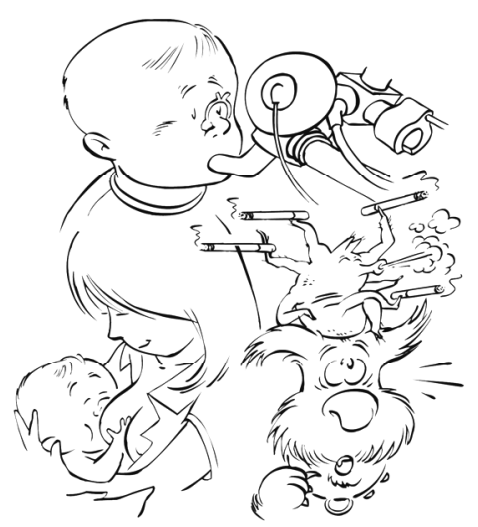


148 


\section{Summary}

Asthma is the most common chronic disease in childhood and although it often can be treated successfully, asthma can have major consequences for children's well-being. ${ }^{1-4}$ In developed countries a five-fold increase in the prevalence of asthma has been observed between 1980 and 2000. This tendency seems to have reversed thereafter. ${ }^{5}$ The most recently observed (2006) prevalence of asthma in children aged five to eight years was approximately 5.7 to $10.5 \%$.,

In the current thesis the PREVASC study on the primary prevention of asthma in children susceptible to the development of asthma is described. Being a disease that is associated with both genetic and environmental factors ${ }^{8}$, children, however genetically predisposed, may not develop asthma when environmental exposures are adequately reduced. The hypothesis studied in the current research is that asthma might be prevented in children with a genetic predisposition by educating parents about multiple measures for optimising their child's exposure to environmental factors associated with asthma (multi-faceted intervention). The intervention used in the PREVASC study was based on a simultaneous reduction of exposure to environmental factors such as inhalant and food allergens, stimulating breastfeeding, and decreasing the exposure to environmental tobacco smoke. Secondary research questions the PREVASC study focused on were the optimal duration of the intervention offered (short versus extended intervention duration) and the effect of the environmental factors included in the PREVASC intervention on the outcome asthma as measured at age six. Details on the design are described in chapter 3.

Chapter 2 describes the lack of explanation for what could have caused the rise in prevalence. Assuming that the prevalence may be decreased by reducing exposure to environmental factors, several birth cohort studies are being (or have been) carried out all over the world. Thirteen cohort studies and six randomised controlled trials focusing on the relationship between allergen exposure (solely or in combination with other environmental exposures) and asthma development in children were identified.

Similarities and differences between designs and variable sets are described as basis for carrying out a meta-analysis. ${ }^{9}$

It was concluded that randomised controlled trials are best candidates for inclusion in a meta-analysis. Four trials were evaluated to be particularly suitable because of similarities in their study designs: The Isle of Wight study, the Canadian Allergy and Asthma Project, the CAPS-study and the PREVASCproject. These four all recommend multi-faceted interventions. 
In chapter 3 it is described that the PREVASC study was the first study in the research program on prevention of asthma in children of the Maastricht University. The PREVASC study was also the first (and up until now the only) multi-faceted intervention study carried out in The Netherlands that focused on the primary prevention of asthma in children by intervening on allergen exposure.

A total of 888 Infants were prenatally included in the research program for answering several research questions. ${ }^{10}$ By the time of inclusion the mothers were 3-7 months pregnant. Twenty-seven Infants were excluded from the study and 21 dropped out. Of the remaining 840 infants 532 had a first-degree familial predisposition of asthma (high-risk group), whereas a reference group of 308 infants was not predisposed for asthma in the first degree (low-risk group).

The PREVASC study was set up to evaluate the effectiveness of a prenatally started multi-faceted intervention on prevention of asthma. A high-risk group of children was included during pregnancy and they were allocated to either an intervention group $(n=222)$ or a control group $(n=221)$. The infants were followed from the prenatal stage until they reached the age of six years. At this age lung function measurements were carried out. Children were categorised in one of 3 lung function groups (no asthma, possible asthma, current asthma). This categorisation was based on lung function outcome as well as prospectively reported symptoms by parents and general practitioners. The exposure outcome the research focussed upon was determined by standardised measurements and questionnaires completed by parents.

The results of this study are described in chapter 7 .

A meta-analysis comparing mono-faceted and multi-faceted interventions is presented in chapter 4 . The research question posed was whether a simultaneous reduction of multiple exposures will lead to better asthma outcome than single allergen reduction in genetically predisposed children. Some evidence is leading to the assumption that asthma is associated with exposure to allergens. ${ }^{11,12}$ Based on the theoretical consideration that asthma is a multi-factorial disease, it is hypothesised that prevention might only prove effective if most or all relevant environmental factors are simultaneously avoided (multi-faceted intervention).

The effect(s) of mono-faceted and multi-faceted interventions, focussing on preventing asthma and asthma symptoms in children by optimising allergen exposure, were assessed when compared with control interventions. ${ }^{13}$

Eligible studies were screened on relevant results for the current meta-analysis. Studies were included in the analyses when the primary outcome 'current diagnosis asthma' and/or one of the secondary outcomes 'current respiratory symptoms: wheezing, nocturnal cough and dyspnoea' were described. Three multi-faceted and six mono-faceted intervention studies that described their 
results at various intervals met the entry criteria. These studies together randomised 3271 children.

Multi-faceted and mono-faceted intervention studies were pooled separately and an indirect comparison of their effects was performed.

The available evidence suggests that multi-faceted interventions characterised by dietary allergen reduction and environmental remediation reduce the likelihood of a current diagnosis of asthma at ages $<5$ years, whereas the evidence of mono-intervention studies does not indicate a statistically significant difference with control. The results of statistical comparison of outcome of multifaceted and mono-faceted interventions favoured multi-faceted intervention strategies (diagnosis asthma in children <5 years: Z-score -2.118). Z-test comparison in diagnosis of asthma in children five years and older was not significant between multiple and single interventions (Z-score -1.925).

The effect of multi-faceted interventions on parent reported wheeze was inconsistent and no beneficial effect on nocturnal cough or dyspnoea was found. Mono-faceted interventions were no more effective than controls in the reduction of all outcomes.

Uncertainty remains as to whether multiple interventions are more effective than mono-component interventions. The lack of difference between mono- and multi-faceted interventions on outcome diagnosis asthma at ages five years and older might be real, but on the other hand might have been caused by lack of power (too small number of studies / participants included) or by the difference in study outcome used in the studies compared.

The findings warrant further direct comparison between multiple- and monofaceted interventions at reducing the prevalence of asthma in children. Since the current meta analyses are not randomised comparisons, we recommend that a new study which assesses both types of interventions is undertaken. There are no studies ongoing to our knowledge in which both intervention strategies are randomly compared. Such a study will be of great importance for shedding new light on preventing the development of asthma in genetically susceptible children.

In chapter 5 a pilot study on the distribution of the house dust mite allergen on living room floors with smooth coverings is described.

In most studies concerning measurement of exposure to house dust mite allergen in floor dust, the sampling procedure is standardised. ${ }^{12,}{ }^{14}$ For measurement within living rooms at least two sites should be sampled because of unequal distribution. ${ }^{15}$ However, there is no consensus about the exact sampling locations. ${ }^{16}$

In this study it is assumed that standardisation of sampling sites surely does matter as daily life activity causes displacement of dust and house dust mite allergen mainly from the middle towards the border of the floor. 
As was hypothesised, house dust mite allergen levels sampled in the middle of the room showed to be lower than at the border and the difference was larger when more inhabitants or pets were present (more activity).

It is of further interest whether allergen content of dust should be expressed as $\mathrm{ng} / \mathrm{m}^{2}$ or as $\mathrm{ng} / \mathrm{g}$ of dust. In research the expression of the level of house dust mite allergen as $\mathrm{ng} / \mathrm{g}$ of dust is used most often. Although it is generally assumed that both types of expression can be interchanged ${ }^{17}$, our research did not underline this assumption. Where a statistically significant difference was detected between middle and border samples when expressed as $\mathrm{ng} / \mathrm{m}^{2}$, no significant difference was detected when overall data were expressed as $\mathrm{ng} / \mathrm{g}$ of dust. The lack of significance can possibly be explained by the smaller range of house dust mite allergen levels when expressed as $\mathrm{ng} / \mathrm{g}$ of dust. We concluded that house dust mite allergen content expressed as $\mathrm{ng} / \mathrm{g}$ of dust and $\mathrm{ng} / \mathrm{m}^{2}$ therefore cannot obviously be interchanged. In households where small amounts of dust are present, but in these small amounts the concentration of allergen is high (high exposure when expressed as $\mathrm{ng} / \mathrm{g}$ of dust), the actual exposure will be low on the contrary. We therefore state that expression of exposure to house dust mite allergen will be better estimated when presentation as $\mathrm{ng} / \mathrm{m}^{2}$ is used. This will be especially important in studies in which house dust mite allergen exposure is a possible determining factor.

The hygiene hypothesis assumes infections in early childhood keep the developing immune system from becoming unbalanced and therefore from developing allergic diseases. ${ }^{18}$ In chapter 6 this popular hypothesis is evaluated by making use of data collected by parents and general practitioners of the 443 children included in the PREVASC-cohort.

The number of episodes of common cold and diarrhoea associated with fever were the parental reported infection variables used as independent predictors. Outcome variables were a general practitioners' diagnosis of asthma, asthmatic symptoms at age four to six and total and specific immune globulin $E(\lg E)$ at age six.

The results showed that the more episodes of common cold were reported, the lower the total IgE level measured. Episodes of diarrhoea associated with fever showed to be related to a decrease of the specific IgE level for house dust mite allergens. As IgE is an important diagnostic factor for allergy ${ }^{19}$, the results of the current analyses suggest that infections might play a preventive role in the development of allergy.

The analyses however showed NOT to support the hypothesis that infections teach the developing immune system to arm itself either against the development of asthma or asthma-like symptoms in children at high risk of developing asthma. 
It might be possible that no relationship between asthma diagnosis or asthma symptoms, common cold and diarrhoea was found because the symptoms of these common infections as reported by the parents were not suitable measures for infection load.

The results of the PREVASC study-intervention are described in chapter 7 . The children that could be followed up until the age of six were invited to participate in lung function measurements. This accounted for 219 children in the intervention group (IG) and 215 children in the control group (CG).

The intervention offered was focussed on a simultaneous optimisation of multiple environmental exposures such as breast feeding, food allergens, inhalant allergens and environmental tobacco smoke. The intervention used was suitable for direct implementation in general practice.

The IG was divided into two subgroups: a short IG in which children received the intervention from pregnancy to 2 years of age $(n=108)$, and an extended IG $(n=111)$ in which children received the intervention up until six years of age.

Primary outcome of the study was asthma diagnosis at age six categorised by a predefined algorithm (no asthma, possible asthma or current asthma). The categorisation was based on lung function outcome as well as health reports of general practitioners and parents.

For answering the primary research question the IG as a whole was compared with the CG. Comparisons of the separate IG subgroups with the CG were carried out for answering the secondary research question on the intervention duration.

A multiple logistic regression analysis was carried out to assess the influence of individual intervention elements on the development of asthma.

The PREVASC study intervention resulted in a statistically significant reduction of exposure of the IG to food allergens at six months $(p<0.001)$ and inhalant allergens at age four (Der $p 1 p=0.012$, Fel d1 $p=0.037$, Can $f 1 p=0.043$ ) but no differences were observed where the exposure to pet $(p=0.111)$ and environmental tobacco smoke $(p=0.786)$ were evaluated at six years of age.

Although the exposure outcome showed to be significantly reduced in the IG, the clinical outcome was not shown to be statistically different between groups. Neither the IG as a whole (0.645), nor the separate IGs $(p=0.491, p=0.853)$ showed to have different clinical outcome as compared to the CG.

Therefore it was concluded that the PREVASC intervention was not effective in reducing the development of asthma in children at risk and it was not possible to define optimal intervention duration. The room for improvement for reducing the exposure to house dust mite allergen and exposure to environmental tobacco smoke was limited, as the baseline exposure to these factors showed to be very low. Aside from these observations lack of compliance might have played a part in the absence of clinical effectiveness, especially for the 
breastfeeding promoting intervention and the house dust mite allergen reducing intervention.

The analysis on the influence of the individual intervention elements (secondary research question 2) revealed that breastfeeding and house dust mite allergen exposure were of particular importance in the PREVASC intervention. These particular parts of the intervention however showed not to have resulted in a desirable exposure outcome.

The only two comparable studies were carried out in Canada and the United Kingdom and seemed to support the hypothesis that multi-faceted allergen reduction might prevent the development of asthma in susceptible children. The discrepancy between these studies and the present study might be explained by the low number of families complying with our recommendations. Possibly the results of our intervention would have been more successful when we would have put more effort in stimulating compliance with the use of the house dust mite impermeable encasings and the promotion of breastfeeding.

A general discussion of the present thesis is provided in chapter 8 . In this chapter the results of the PREVASC-study, the methodological considerations, added value of the current thesis, conclusions and recommendations for clinical practice and further research are described.

\section{What could be concluded from the current thesis?}

1. The PREVASC trial did not result in reduction of asthma in susceptible children. Aside from the possibility that reducing environmental allergen exposure truly does not prevent asthma development, other explanations might be:

a. Low levels of house dust mite allergen and environmental tobacco smoke exposure (low room for improvement);

b. The fact that the PREVASC intervention was aimed at implementation in real life and thereby was less focused on enhancing compliance.

2. Although the current trial did not support the results of the meta-analyses carried out in this thesis, asthma seems to be best prevented in high-risk children by intervening on multiple allergen exposures simultaneously.

3. Post-hoc analysis of PREVASC data has indicated that asthma might be prevented when a child is exposed to low levels of house dust mite allergen exposure. Also breastfeeding seemed to have a preventive effect. Other exposures did not indicate to play any role in the development of asthma in susceptible children.

4. PREVASC-data do not supply evidence for the assumption that infections in susceptible children can protect against the development of asthma and atopy. 


\section{What this research adds?}

The current trial will not change the guidelines on primary prevention of asthma in susceptible children. What the PREVASC trial has taught us is that the trial intervention cannot be recommended for use in general practice in the Netherlands. Country specific circumstances (e.g. low house dust mite allergen exposure levels in the Netherlands) as well as the fact that our intervention was aimed at implementation in real life and thereby less focused on enhancing compliance might have played a role in the lack of clinical effectiveness. This resulted in insufficient reduction of exposure to environmental factors.

If the multi-faceted intervention is optimised with improved compliance, the outcome will give more decisive answers on the question if asthma can be prevented in susceptible children by reducing environmental exposures. The study of Gijsbers et al. already showed how optimising an intervention results in increased compliance.

We therefore do advise to perform a study aimed at prevention of asthma in susceptible children by using an optimised intervention on reduction of environmental exposures preferably in multiple countries with differing room for improvement. This type of research is necessary for the generalisation of results.

\section{Recommendations for clinical practice}

Although the current trial did not support the results of the meta-analyses, asthma seems to be best prevented in high-risk children by intervening on multiple allergen exposures simultaneously. We therefore recommend for primary care providers to advice parents of children susceptible to develop asthma to create an overall low allergen environment for their children.

\section{Recommendations for future research}

A large longitudinal study might be set up in which the following research question will be answered:

$\checkmark \quad$ Is a multi-faceted allergen reducing intervention on primary prevention of asthma in susceptible children more effective than its mono-faceted counterpart?

Performing a multi-faceted intervention as well as several mono-faceted interventions on the reduction of (food and inhalant) allergen exposures in which several countries with different baseline exposure levels co-operate is recommended. Stimulating compliance to the interventions used would have to receive enough attention.

In a study like this, multi-faceted and mono-faceted interventions on the reduction of allergen exposure should be randomly compared. Only when such 
a study has been carried out more definite conclusions can be drawn concerning the possibility and/or preference of intervention types (mono-faceted or multi-faceted) in the primary prevention of asthma in children at risk. 


\section{References}

1. von Mutius E. The burden of childhood asthma. Arch Dis Child 2000; 82 Suppl 2:II2-5.

2. Blackman JA, Gurka MJ. Developmental and behavioural comorbidities of asthma in children.

3. Dahl R. Systemic side effects of inhaled corticosteroids in patients with asthma. Respir Med 2006;100:1307-17.

4. van Gent R, van Essen LE, Rovers MM, Kimpen JL, van der Ent CK, de Meer G. Quality of life in children with undiagnosed and diagnosed asthma. Eur J Pediatr 2007; 166:843-8.

5. van Schayck CP, Smit HA. The prevalence of asthma in children: a reversing trend. Eur Respir J 2005;26:647-50.

6. Bjerg-Backlund A, Perzanowski MS, Platts-Mills T, Sandstrom T, Lundback B, Ronmark E. Asthma during the primary school ages--prevalence, remission and the impact of allergic sensitization. Allergy 2006;61:549-55.

7. Hermann C, De Fine Olivarius N, Host A, Begtrup K, Hollnagel H. Prevalence, severity and determinants of asthma in Danish five-year-olds. Acta Paediatr 2006;95:1182-90.

8. Martinez FD. Complexities of the genetics of asthma. Am J Respir Crit Care Med 1997; 156:S117-22.

9. Maas T, Dompeling E, Schayck van CP, Muris J, Schönberger H, Wesseling G, Platts-Mills TAE, Knottnerus JA. Birth cohort studies on asthma development. Pediatr Asthma, Allergy, Immunol 2005;18:201-15.

10. Kuiper S, Maas T, van Schayck CP, Muris JW, Schönberger HJ, Dompeling E, Gijsbers B, van Weel C, Knottnerus JA. The primary prevention of asthma in children study: design of a multifaceted prevention program. Pediatr Allergy Immunol 2005;16:321-31.

11. Boner AL, Niero E, Antolini I, Valletta EA, Gaburro D. Pulmonary function and bronchial hyperreactivity in asthmatic children with house dust mite allergy during prolonged stay in the Italian Alps (Misurina, $1756 \mathrm{~m}$ ). Ann Allergy 1985;54:42-5.

12. Platts-Mills TA, Thomas WR, Aalberse RC, Vervloet D, Champman MD. Dust mite allergens and asthma: report of a second international workshop. J Allergy Clin Immunol 1992;89: 1046-60.

13. Maas T, Kaper J, Sheikh A, Knottnerus JA, Wesseling G, Dompeling E, Muris JWM, van Schayck CP. Mono and multifaceted allergen reduction interventions for preventing asthma in children at high risk of developing asthma. Cochrane Database Syst Rev 2007.

14. Luczynska CM. Identification and quantification of mite allergens. Allergy 1998; 53:54-7.

15. Marks GB, Tovey ER, Peat JK, Salome CM, Woolcock AJ. Variability and repeatability of house dust mite allergen measurement: implications for study design and interpretation. Clin Exp Allergy 1995;25:1190-7.

16. Hill MR. Quantification of house-dust-mite populations. Allergy 1998;53:18-23.

17. Custovic A, Taggart SC, Niven RM, Woodcock A. Evaluating exposure to mite allergens. J Allergy Clin Immunol 1995;96:134-5.

18. Strachan DP. Hay fever, hygiene, and household size. Bmj 1989; 299:1259-60.

19. (CVZ) CVZ. Immunoglobuline E (IgE) / Allergeen-specifiek IgE. In: Diagnostisch Kompas; 2003. 

Samenvatting

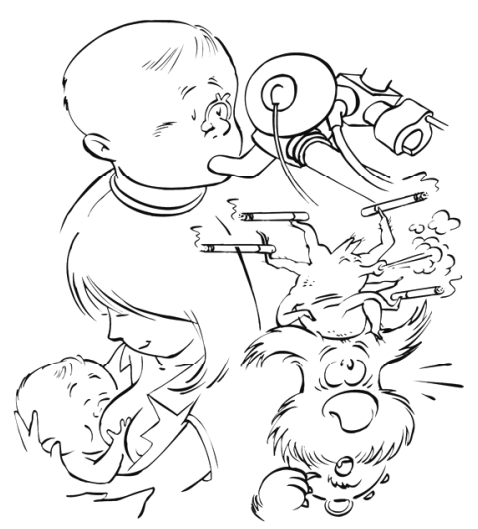


160 


\section{Samenvatting}

\section{Algemene inleiding}

Astma is de meest voorkomende chronische ziekte bij kinderen en hoewel astma over het algemeen succesvol behandeld kan worden, is er met name bij kinderen voldoende reden om er alles aan te doen astma te voorkomen. Het belang van preventie van astma is groot aangezien de gevolgen van astma voor een kind vaak erg beangstigend zijn. ${ }^{1-3}$ Astma heeft bij kinderen dan ook grote consequenties voor de ervaren kwaliteit van leven. ${ }^{4}$

Het voorkomen van astma in westerse landen is enorm gestegen in de periode van 1980 tot 2000 maar lijkt te zijn gedaald in de periode na $2000 .{ }^{5}$ De laatste metingen van de gegevens betreffende het voorkomen van astma in ontwikkelde landen werden in 2006 gedaan in Scandinavië. In deze onderzoeken werd aangetoond dat het aantal patiënten met astma in de leeftijd van vijf tot acht jaar rond de 5.7 tot $10.5 \%$ lag. ${ }^{6,7}$

In dit proefschrift wordt de PREVASK studie beschreven, een onderzoek naar de preventie van astma bij kinderen met een verhoogde kans deze ziekte te ontwikkelen. Het ontstaan van astma wordt geassocieerd met zowel erfelijke factoren als omgevingsfactoren ${ }^{8}$, en aangenomen wordt dat kinderen met een erfelijke aanleg astma te ontwikkelen mogelijk geen astma zullen krijgen als omgevingsfactoren worden geoptimaliseerd. Dit laatste heeft geleid tot de hypothese van het PREVASK onderzoek: Astma kan voorkomen worden bij familiaal belaste kinderen door de ouders voor te lichten over manieren waarop ze de blootstelling van hun kind aan meerdere omgevingsfactoren simultaan kunnen optimaliseren. De interventie die gehanteerd werd in het PREVASK onderzoek is gebaseerd op de vermindering van de blootstelling aan omgevingsfactoren als inhalatieallergenen, voedingsallergenen en sigarettenrook evenals het stimuleren van het geven van borstvoeding (meervoudige interventie). Secundaire onderzoeksvragen van het PREVASK onderzoek waren gericht op de optimale duur van de interventie (kortdurende of uitgebreide interventie) en de mate van invloed van elk van de omgevingsfactoren waarop geïntervenieerd werd, op de uitkomstmaat astma.

Details van het design van het PREVASK onderzoek zijn beschreven in hoofdstuk 3.

\section{Geboortecohort studies naar de preventie van astma bij kinderen}

In hoofdstuk 2 wordt beschreven dat de oorzaak van de stijging van de prevalentie van het aantal astma gevallen niet duidelijk is. Er vanuit gaande dat de blootstelling aan allergenen een belangrijke rol spelen zijn verschillende geboortecohort studies opgezet (of zijn reeds afgerond) over de hele wereld. 
Dertien cohort studies en zes gerandomiseerd gecontroleerde trials gericht op de relatie tussen de blootstelling aan allergenen (enkelvoudig of in combinatie met andere blootstellingen) en de ontwikkeling van astma werden geïdentificeerd.

Overeenkomsten en verschillen tussen de designs en sets van variabelen werden beschreven als voorbereiding op het uitvoeren van een zogenoemde meta-analyse. ${ }^{9}$ In een meta-analyse worden de resultaten van verschillende onderzoeken samengevoegd waardoor de onderzoekspopulatie groter wordt en de uitkomsten meer kracht krijgen.

Conclusie was dat gerandomiseerd gecontroleerde onderzoeken (Isle of Wight studie, Canadese allergie en astma bij kinderen studie, CAPS studie en de PREVASK studie) de beste kandidaten zijn voor opname in een meta-analyse. Deze onderzoeken maken namelijk alle drie gebruik van een meervoudige interventie.

\section{Onderzoeksprogramma naar preventie van astma bij kinderen}

In hoofdstuk 3 is beschreven dat de PREVASK studie de eerste studie is binnen het onderzoeksprogramma naar de preventie van astma bij kinderen, dat wordt uitgevoerd door onderzoekers van de Universiteit Maastricht. Deze studie is tevens de eerste (en tot nu toe de enige) Nederlandse meervoudige interventie studie gericht op de primaire preventie van astma bij kinderen waarbij wordt ingegrepen in de blootstelling aan omgevingsfactoren.

In het volledige onderzoeksprogramma werden in totaal 888 kinderen prenataal ingesloten om de verschillende onderzoeksvragen te beantwoorden. ${ }^{10}$ Op het moment van insluiting waren de moeders 3-7 maanden zwanger. Zevenentwintig kinderen werden uitgesloten en 21 vielen uit op enig moment na insluiting. De gegevens van 840 kinderen konden worden gebruikt voor beantwoording van de onderzoeksvragen. Van deze kinderen was de grootste groep erfelijk belast voor het ontwikkelen van astma op enig moment in hun leven (532 kinderen, hoogrisico groep). Een groep van 308 kinderen had een laag risico om astma te ontwikkelen.

De PREVASK studie is opgezet voor de evaluatie van de effectiviteit van een prenataal gestarte meervoudige interventie. Kinderen met een verhoogd risico om astma te ontwikkelen op grond van voorkomen van astma in het gezin werden gevolgd vanaf de zwangerschap. Deze kinderen werden op grond van toeval ingedeeld in een interventiegroep (IG 222 kinderen) waaraan een meervoudige interventie werd aangeboden, of een controlegroep (CG 221 kinderen) waarin de reguliere zorg tijdens zwangerschap en kinderleeftijd werd gehanteerd. Deelnemende kinderen werden gevolgd totdat zij de leeftijd van zes jaar bereikten. Op deze leeftijd kregen ze een longfunctiemeting en werden ze ingedeeld in een van de drie astmagroepen (geen astma, mogelijk astma, zeker astma). Deze categorisering werd gebaseerd op de uitkomst van de 
longfunctiemeting en symptomen die prospectief longitudinaal gerapporteerd werden door ouders en huisartsen. De uitkomsten van de blootstelling aan de omgevingsfactoren waarop het onderzoek zich richtte werden met behulp van gestandaardiseerde metingen geobjectiveerd en gerelateerde factoren (gedrag) werden gerapporteerd door de ouders in vragenlijsten.

De resultaten van deze studie zijn beschreven in hoofdstuk 7 .

\section{Meta-analyse}

Hoofdstuk 4 beschrijft een meta-analyse uitgevoerd met als doel te verduidelijken of astma, een ziekte die wordt veroorzaakt door zowel erfelijkeals omgevingsfactoren ${ }^{8}$, voorkomen kan worden door een enkelvoudige allergeen reducerende interventie aan te bieden aan kinderen met een hoog risico op het ontwikkelen van astma. Er zijn duidelijke aanwijzingen dat prikkelende stoffen (allergenen) geassocieerd zijn met het ontstaan van astma. $^{11,12}$ Onderzocht is in de huidige studie of meervoudige interventies, interventies gericht op simultane optimalisering van meerdere prikkelende factoren, vaker leiden tot een preventief effect.

Om deze aanname te toetsen werden de samengevoegde resultaten van enkelvoudige interventiestudies en meervoudige interventiestudies statistisch getoetst. $^{13}$ De studies waren allen gericht op optimalisering van blootstelling aan allergenen ter voorkoming van astma en astmasymptomen bij kinderen met een verhoogd risico op het ontwikkelen van astma.

$\mathrm{Om}$ in aanmerking te komen voor opname in deze meta-analyse moesten studies minimaal het eindpunt astma getoetst hebben bij kinderen met een verhoogd risico op het ontstaan van astma. Indien gerapporteerd, werden ook gegevens met betrekking tot astma symptomen geëvalueerd (piepen, nachtelijk hoesten, kortademigheid). Drie meervoudige interventie studies, gericht op optimalisering van blootstelling aan meerdere factoren (voedings- en inhalatieallergenen), en zes enkelvoudige interventiestudies (reductie van blootstelling aan een enkel allergeen), voldeden aan de criteria. Deze studies hadden gezamenlijk 3271 deelnemers.

Studies van de beide interventietypen werden groepsgewijs geanalyseerd. Vervolgens werd een statistische vergelijking gemaakt van de gepoolde resultaten van primaire preventie studies die gebruik maakten van een meervoudige of een enkelvoudige interventie.

Meervoudige interventies verminderden de kans op het ontstaan van astma bij kinderen in de leeftijd van twee tot vijf jaar significant succesvoller. Effecten van meervoudige interventies op de diagnose astma in de leeftijd van vijf jaar en ouder bleken echter niet significant te verschillen van de effecten van enkelvoudige interventies. Deze uitkomst zou correct kunnen zijn maar het is niet onwaarschijnlijk dat de afwezigheid van significantie veroorzaakt is doordat 
er te weinig studies ( $n=2$ per interventietype) en/of een te klein aantal proefpersonen konden worden vergeleken. Daarnaast werden er in de beide typen interventiestudies verschillende manieren van diagnosestelling gehanteerd die de vergelijking bemoeilijkten.

De effecten van meervoudige interventiestudies op de preventie van piepen waren niet consistent en deze interventies bleken niet effectief in het voorkomen van nachtelijk hoesten of kortademigheid. Enkelvoudige interventies bleken in geen geval effectiever dan usual care. Geconcludeerd werd dat er geen statistisch significant verschil kon worden aangetoond tussen de resultaten van beide groepen interventies met betrekking tot het voorkomen van astma symptomen.

Hoewel meervoudige interventies effectiever leken dan enkelvoudige interventies bij de preventie van astma blijft er onzekerheid over deze uitkomst. De analyses die gedaan zijn in het huidige proefschrift waren indirect van aard, wat betekent dat beide interventietypen niet in één en hetzelfde onderzoek werden uitgevoerd. Gevolg hiervan zijn mogelijke verschillen in basisblootstelling, insluitcriteria en uitkomstparameters. De resultaten van de uitgevoerde meta-analyse zijn echter een duidelijke indicatie dat meervoudige interventies bij astmapreventie mogelijk effectiever zijn dan enkelvoudige interventies. Een krachtiger uitspraak zou gedaan kunnen worden wanneer een nieuw onderzoek opgezet wordt waarin beide interventietypen worden opgenomen. Een onderzoek waarin de effecten van een meervoudige interventie én enkelvoudige interventies gericht op allergeenreductie gerandomiseerd worden vergeleken, is tot op heden niet uitgevoerd. Dergelijk onderzoek zou naar ons inzicht van groot belang zijn om duidelijkheid te krijgen over de beste manier om astma en astmasymptomen te voorkómen door de blootstelling aan allergenen te optimaliseren bij kinderen met een verhoogd risico.

\section{Verspreiding van huisstofmijt allergeen over gladde vloeren}

Eén van de omgevingsfactoren die verband lijkt te houden met het ontstaan van astma is de blootstelling aan huisstofmijtallergeen. Hoofdstuk 5 behandelt de studie waarin de verspreiding van huisstofmijtallergeen in woonkamers met gladde vloeren onderzocht werd. Bij de meeste studies waarin de blootstelling aan huisstofmijtallergeen in vloerstof wordt gemeten, is de methode van meting gestandaardiseerd. ${ }^{14,15}$ Daarbij valt echter op dat er geen uniformiteit is in de plaatsen waar de metingen verricht worden. ${ }^{16}$ Wel is bekend dat de spreiding van huisstofmijtallergeen niet gelijkmatig verdeeld is over de vloer en dat daarom minimaal twee plekken op de vloer gemonsterd zouden moeten worden. $^{17}$

Aangenomen werd dat de huisstofmijtallergenen voornamelijk van het midden naar de rand van de kamer worden verplaatst door activiteit in de woonkamer. 
Om deze aanname te toetsen werden er stofmonsters genomen in woonkamers met gladde vloeren op locaties in het midden en de zijkant van de kamer. Uit de stofmonsters die afgenomen werden bleek inderdaad dat de hoeveelheden huisstofmijtallergeen lager waren in het midden van de woonkamer ten opzichte van de hoeveelheden aanwezig aan de randen. Daarnaast bleek dat verplaatsing van de hoeveelheden huisstofmijtallergeen meer voorkwam in huishoudens waarin meerdere huisgenoten of huisdieren aanwezig waren (meer activiteit).

Naast deze waarneming is het interessant te bediscussiëren of de hoeveelheden huisstofmijtallergeen beter uitgedrukt zouden kunnen worden in $\mathrm{ng} / \mathrm{m}^{2}$ of als $\mathrm{ng} / \mathrm{g}$ stof. Over het algemeen wordt bepleit dat beide manieren van uitdrukken vergelijkbaar zouden zijn. ${ }^{18}$ Echter, in dit onderzoek werd wel een statistisch significant verschil gevonden tussen stofmonsters genomen in het midden en monsters genomen aan de rand van de woonkamer wanneer de uitslagen werden uitgedrukt in $\mathrm{ng} / \mathrm{m}^{2}$. Er bleek geen verschil te zijn tussen de verschillende locaties van meting wanneer de uitkomsten uitgedrukt werden in $\mathrm{ng} / \mathrm{g}$ stof.

Een mogelijke verklaring voor deze waarneming kan zijn dat de variatie in huisstofmijtallergeen hoeveelheden kleiner is wanneer deze zijn uitgedrukt als $\mathrm{ng} / \mathrm{g}$ stof. Hoewel in wetenschappelijk onderzoek meestal de uitdrukking als $\mathrm{ng} / \mathrm{g}$ stof wordt gehanteerd zijn wij van mening dat deze allergeen hoeveelheden - in onderzoek waarin dit allergeen een belangrijke voorspellende waarde wordt toegedicht - beter uitgedrukt kunnen worden als $\mathrm{ng} / \mathrm{m}^{2}$. In woonkamers waarin weinig stof ligt, kan per gram stof namelijk wel een hoge concentratie allergeen aanwezig zijn, terwijl in dit geval de blootstelling in werkelijkheid laag blijft. Wanneer uitgedrukt in $\mathrm{ng} / \mathrm{g}$ stof zou kunnen worden gesuggereerd dat er een hoge concentratie werd gemeten.

\section{Preventief effect van infecties op jonge leeftijd}

De hygiëne hypothese is een zeer populaire theorie dat infecties die voorkomen tijdens het jonge leven van kinderen het nog in ontwikkeling zijnde immuunsysteem beschermen tegen het ontstaan van allergie en astma. ${ }^{19}$ In hoofdstuk 6 wordt deze hypothese geëvalueerd door gebruik te maken van data die verzameld zijn door de ouders en huisartsen van de kinderen die deelnamen aan het PREVASK onderzoek.

Het aantal episodes van verkoudheid en diarree geassocieerd met koorts, waren de infectievariabelen die gebruikt werden. De uitkomstvariabelen waren de door de huisartsen gerapporteerde diagnose astma en astma symptomen in de leeftijd van vier tot zes jaar en het totaal en specifiek Immuunglobuline $E$ $(\lg E)$ op zes jarige leeftijd. IgE is een belangrijke factor die gebruikt wordt bij de diagnostiek van allergie. ${ }^{20}$ 
Uit de analyses bleek dat hoe meer episodes van verkoudheid werden gerapporteerd door de ouders, hoe lager het IgE niveau was dat werd gemeten in het bloed van de kinderen. Episodes van diarree met koorts bleken ditzelfde effect te hebben op het specifiek IgE gericht op huisstofmijt allergenen.

Conclusies die we konden trekken uit de uitgevoerde analyses zijn dat infecties het ontstaan van allergie mogelijk voorkomen maar dat een dergelijk preventief effect NIET geobserveerd werd als het gaat om het ontstaan van astma of astma symptomen bij kinderen met een hoog risico hierop.

Mogelijk is het uitblijven van een preventief effect van infecties op astma en astma symptomen in dit onderzoek er het gevolg van dat we de gerapporteerde en niet de objectief vastgestelde infecties hebben gebruikt in de analyses. Het is daarnaast ook mogelijk dat er te weinig waarnemingen waren waarop de conclusies gebaseerd konden worden (power probleem).

\section{Resultaten van de PREVASK interventie}

De resultaten van de PREVASK interventie zijn beschreven in hoofdstuk 7. De aanname dat astma voorkomen zou kunnen worden bij familiaal belaste kinderen door meerdere omgevingsfactoren simultaan te optimaliseren werd getoetst.

Naast de effectiviteit van de interventie op de mate van blootstelling aan de omgevingsfactoren waarop de interventie zich richtte, werd de klinische effectiviteit zoals gemeten op vier en zesjarige leeftijd beschreven (hoofdvraagstelling).

Resultaten van de secundaire onderzoeksvraagstellingen gericht op 1) de optimale interventieduur en 2) de invloed van de individuele omgevingsfactoren waarop de interventie was gericht (borstvoeding, voedingsallergenen, inhalatieallergenen, sigarettenrook) werden eveneens vermeld.

De interventie die aangeboden werd was gericht op de simultane optimalisering van de blootstelling aan de omgevingsfactoren borstvoeding, voedselallergenen, inhalatieallergenen en passief roken. De interventie was zo opgezet dat deze direct geïmplementeerd zou kunnen worden in de huisartspraktijk.

Tot hun tweede levensjaar kregen alle kinderen in de interventiegroep (IG) dezelfde interventie aangeboden en vanaf dat moment werd een splitsing gemaakt, wederom op grond van het lot, in een lange IG en een korte IG. Aan gezinnen in de korte IG $(n=108)$ werden vanaf twee jaar geen maatregelen meer geadviseerd die de blootstelling aan de omgevingsfactoren zouden optimaliseren. De gezinnen in de lange IG $(n=111)$ daarentegen kregen nog steeds adviezen over de optimalisering van de blootstellingen waarop het onderzoek zich richtte. Aan gezinnen in de controlegroep (CG) werd de reguliere zorg aangeboden. 
Die kinderen die bleven deelnemen tot hun zesde levensjaar werden uitgenodigd om longfunctiemetingen te laten verrichten (mede) op grond waarvan kon worden vastgesteld of ze astma hadden ontwikkeld of niet. Het aantal kinderen, dat deelnam tot hun zesde levensjaar was 219 in de IG and 215 in de CG (>90\% van de initieel ingesloten kinderen).

De primaire uitkomstmaat was de diagnose astma zoals gemeten op zes jarige leeftijd. Nadat de longfunctiemetingen uitgevoerd waren, werden de kinderen gecategoriseerd in een van de drie astmagroepen (geen astma, mogelijk astma, zeker astma) door een vooraf opgesteld algoritme. De categorisering vond plaats op grond van de longfunctie-uitslagen, prospectief geregistreerde gezondheidsgegevens gerapporteerd door de huisartsen en door de ouders (gezondheidsvragenlijsten).

De groepen die op grond van hun astmastatus werden vergeleken voor beantwoording van de hoofdvraagstelling waren de IG in zijn totaliteit en de CG. Daarnaast werd de CG vergeleken met de beide afzonderlijke interventiegroepen voor beantwoording van de secundaire vraagstelling over de optimale interventieduur.

Een logistische regressie analyse werd uitgevoerd voor beantwoording van de secundaire vraagstelling over de invloed van de afzonderlijke omgevingsfactoren die onderdeel waren van de inteventie, op de ontwikkeling van astma zoals gemeten op zes jarige leeftijd.

De resultaten van het PREVASK onderzoek toonden aan dat de interventie, in vergelijking tot de CG gegevens, succesvol was in het reduceren van de blootstelling aan voedselallergenen en inhalatieallergenen. De interventie gericht op vermindering van de blootstelling aan huisdieren en sigarettenrook was niet effectief.

Hoewel de blootstelling voor een belangrijk deel effectief was gebleken, werden er geen statistisch significante verschillen waargenomen op grond van de uitkomstmaat astma bij vergelijking van de studiegroepen (IGtotaal versus CG, IGkort versus CG, IGlang versus CG).

We hebben dan ook moeten concluderen dat de interventie niet effectief was in het reduceren van de ontwikkeling van astma bij kinderen die hierop vanwege hun familiale achtergrond een hoger risico hadden. De interventie werd niet in voldoende mate gevolgd door de ouders waardoor de vraagstelling betreffende de optimale interventieduur niet beantwoord kon worden.

De blootstelling aan huisstofmijtallergeen en sigarettenrook bleken reeds bij start van het onderzoek erg laag te zijn. Hierdoor was de ruimte voor verbetering voor deze interventie onderdelen klein / onvoldoende. Behalve deze waarneming bleek er ook sprake te zijn van onvoldoende therapietrouw bij het uitvoeren van de borstvoedingstimulerende interventie en de huisstofmijt allergeen reducerende interventie. 
De resultaten van de vraagstelling gericht op de effectiviteit van de individuele interventie elementen (secundaire vraagstelling 2) lieten zien dat juist deze factoren van belang waren in de preventie van astma bij kinderen met een verhoogd risico om astma te ontwikkelen.

In Engeland en Canada zijn vergelijkbare studies uitgevoerd die de hypothese dat meervoudige interventies gericht op optimalisering van omgevingsfactoren de ontwikkeling van astma zou voorkomen WEL onderschrijven. Mogelijk heeft het gebrek aan voldoende ruimte voor verbetering van de huisstofmijt allergeen blootstelling en de afwezigheid van voldoende therapietrouw met de borstvoedings- en hoezenadviezen geleid tot het verschil in uitslag tussen de PREVASK studie en de overige meervoudige interventiestudies. Mogelijk zouden de resultaten van de PREVASK interventie de hypothese wél hebben kunnen bewijzen als er meer aandacht was gegeven aan het stimuleren van de interventietrouw / therapietrouw.

\section{Slotbeschouwing}

Een slotbeschouwing betreffende de onderwerpen opgenomen in het huidige proefschrift is beschreven in hoofdstuk 8 . In dit hoofdstuk worden de resultaten van de PREVASK-studie beschreven. Er wordt een kritische blik geworpen op de methodologie en de toegevoegde waarde van het huidige proefschrift en ook de conclusies en aanbevelingen voor de huisartspraktijk en verder onderzoek krijgen aandacht.

Wat kan er geconcludeerd worden uit het onderzoek gepresenteerd in het huidige proefschrift?

1. Het PREVASK onderzoek heeft niet geresulteerd in de preventie van astma bij familiaal belaste kinderen. Dit resultaat zou kunnen betekenen dat astma niet voorkomen kan worden door het optimaliseren van omgevingsfactoren. Gezien de positieve resultaten van vergelijkbare onderzoeken bestaat ook de mogelijkheid dat onderstaande factoren een belangrijke rol hebben gespeeld bij het uitblijven van een preventief effect:

a.Gebrek aan voldoende ruimte voor verbetering van de niveaus van blootstelling aan huisstofmijtallergeen en sigarettenrook;

b. Het feit dat de PREVASK-interventie vooral gericht was op implementatie in de dagelijkse huisartspraktijk en niet voldoende gericht was op bevordering van trouw aan de interventiemaatregelen.

2. Hoewel het PREVASK onderzoek de resultaten van de uitgevoerde metaanalyse die wordt beschreven in het huidige proefschrift niet bevestigt, lijkt astma het beste voorkomen te kunnen worden bij hoogrisico kinderen door de blootstelling aan verschillende allergenen gelijktijdig te reduceren.

3. Posthoc analyses van de PREVASK gegevens hebben duidelijk gemaakt dat astma voorkomen kan worden door de blootstelling aan huisstofmijtallergeen 
te reduceren en ook borstvoeding bleek een preventief effect te hebben op de ontwikkeling van astma bij familiaal belaste kinderen.

4.PREVASK gegevens leiden niet tot bewijs voor de aanname dat infecties bij familiaal belaste kinderen het ontstaan van astma zouden kunnen voorkomen.

\section{Wat voegt dit onderzoek toe?}

Het PREVASK onderzoek draagt niet bij aan enige verandering van richtlijnen aangaande de primaire preventie van astma bij hoogrisico kinderen. Wat de PREVASK studie ons heeft geleerd is dat de gebruikte onderzoeksinterventie niet kan worden aanbevolen voor gebruik in de huisartspraktijk in Nederland ter voorkoming van astma bij kinderen.

Het is aannemelijk dat omstandigheden specifiek voor de Nederlandse situatie (met name de lage blootstelling aan huisstofmijt allergeen) een rol hebben gespeeld in het gebrek aan effectiviteit van de interventie. De onderzoeksinterventie was gericht op implementatie in de reguliere huisartspraktijk en daardoor minder gericht op het bevorderen van de therapietrouw. Dit kan een rol hebben gespeeld in het gebrek aan klinische effectiviteit. Dit alles heeft mogelijk geleid tot een te lage reductie van blootstelling aan omgevingsfactoren.

De studie uitgevoerd door Gijsbers en collega's heeft reeds aangetoond hoe een geoptimaliseerde interventie resulteert in een verhoogde therapietrouw. Om deze reden adviseren wij om de PREVASK studie-interventie te optimaliseren ter bevordering van de therapietrouw waarin bij voorkeur meerdere landen met een verschillende blootstelling, en dus verschillende ruimte voor verbetering aan de te onderzoeken omgevingsfactoren, samenwerken. Dit type onderzoek is van groot belang voor de generaliseerbaarheid van de resultaten van het preventieve astmaonderzoek.

\section{Aanbevelingen voor de klinische praktijk}

Hoewel de PREVASK studie de resultaten van de in dit proefschrift uitgevoerde meta-analyse niet onderschrijft, lijkt het aannemelijk dat astma het beste voorkomen kan worden door gebruik te maken van een meervoudige interventie waarbij allergeenblootstellingen simultaan gereduceerd worden. Kinderen die opgroeien in een omgeving waarin zij blootgesteld worden aan lage allergeenwaarden lijken een kleiner risico te lopen astma te ontwikkelen.

\section{Aanbevelingen voor toekomstig onderzoek}

Een grote langlopende studie waarin de onderstaande onderzoeksvraag wordt beantwoord wordt aanbevolen: 
$\checkmark \quad$ Heeft een meervoudige allergeenreducerende interventie inderdaad, zoals de meta-analyse impliceert, de voorkeur boven een enkelvoudige allergeenreducerende interventie ter voorkoming van astma bij kinderen met een verhoogd risico astma te ontwikkelen?

Aanbevolen wordt een onderzoek uit te voeren waarin zowel een meervoudige interventie als ook verschillende enkelvoudige interventies gericht op vermindering van blootstelling aan allergenen worden uitgevoerd. Van groot belang is dat aan een dergelijke studie meerdere landen met verschillende allergeen basisniveaus bijdragen zodat er voldoende ruimte voor verbetering is. Het stimuleren van de therapietrouw dient bij beide interventietypen evenveel aandacht te krijgen. Alleen op deze manier zullen de verschillende interventietypen gerandomiseerd vergeleken kunnen worden en zal een duidelijke uitspraak gedaan kunnen worden over de mogelijkheid en/of een eventuele voorkeur voor een meervoudige- of enkelvoudige allergeenreducerende interventie ter voorkoming van astma bij familiaal belaste kinderen. 


\section{References}

1. Blackman JA, Gurka MJ. Developmental and behavioral comorbidities of asthma in children. J Dev Behav Pediatr 2007;28:92-9.

2. Dahl R. Systemic side effects of inhaled corticosteroids in patients with asthma. Respir Med 2006; 100:1307-17.

3. von Mutius E. The burden of childhood asthma. Arch Dis Child 2000; 82(S2):II2-5.

4. van Gent R, van Essen LE, Rovers MM, Kimpen JL, van der Ent CK, de Meer G. Quality of life in children with undiagnosed and diagnosed asthma. Eur J Pediatr 2007;166:843-8.

5. van Schayck CP, Smit HA. The prevalence of asthma in children: a reversing trend. Eur Respir J 2005;26:647-50.

6. Bjerg-Backlund A, Perzanowski MS, Platts-Mills T, Sandstrom T, Lundback B, Ronmark E. Asthma during the primary school ages--prevalence, remission and the impact of allergic sensitization. Allergy 2006;61:549-55.

7. Hermann C, De Fine Olivarius N, Host A, Begtrup K, Hollnagel H. Prevalence, severity and determinants of asthma in Danish five-year-olds. Acta Paediatr 2006;95:1182-90.

8. Martinez FD. Complexities of the genetics of asthma. Am J Respir Crit Care Med 1997; 156:S117-22.

9. Maas T, Dompeling E, Schayck van CP, Muris J, Schonberger H, Wesseling G, Platts-Mills TAE, Knottnerus JA.. Birth cohort studies on asthma development. Pediatr Asthma, Allergy, Immunol 2005; 18:201-15.

10. Kuiper S, Maas T, van Schayck CP, Muris JW, Schonberger HJ, Dompeling E, Gijsbers B, van Weel C, Knottnerus JA. The primary prevention of asthma in children study: design of a multifaceted prevention program. Pediatr Allergy Immunol 2005;16:321-31.

11. Boner AL, Niero E, Antolini I, Valletta EA, Gaburro D. Pulmonary function and bronchial hyperreactivity in asthmatic children with house dust mite allergy during prolonged stay in the Italian Alps (Misurina, $1756 \mathrm{~m}$ ). Ann Allergy 1985;54:42-5.

12. Platts-Mills TA, Tovey ER, Mitchell EB, Moszoro H, Nock P, Wilkins SR. Reduction of bronchial hyperreactivity during prolonged allergen avoidance. Lancet 1982;2:675-8.

13. Maas T, Kaper J, Sheikh A, Knottnerus JA, Wesseling G, Dompeling E, Muris JWM, van Schayck $\mathrm{CP}$. Mono and multifaceted allergen reduction interventions for preventing asthma in children at high risk of developing asthma. Cochrane Database Syst Rev 2007.

14. Luczynska CM. Identification and quantification of mite allergens. Allergy 1998;53:54-7.

15. Platts-Mills TA, Thomas WR, Aalberse RC, Vervloet D, Champman MD. Dust mite allergens and asthma: report of a second international workshop. J Allergy Clin Immunol 1992;89: 1046-60.

16. Hill MR. Quantification of house-dust-mite populations. Allergy 1998;53:18-23.

17. Marks GB, Tovey ER, Peat JK, Salome CM, Woolcock AJ. Variability and repeatability of house dust mite allergen measurement: implications for study design and interpretation. Clin Exp Allergy 1995;25:1190-7.

18. Custovic A, Taggart SC, Niven RM, Woodcock A. Evaluating exposure to mite allergens. J Allergy Clin Immunol 1995;96:134-5.

19. Strachan DP. Hay fever, hygiene, and household size. Bmj 1989;299:1259-60.

20. (CVZ) CVZ. Immunoglobuline E (IgE) / Allergeen-specifiek IgE. In: Diagnostisch Kompas; 2003. 

List of publications 
174 


\section{List of publications}

1. Maas $T$, Rovers JJ, Schönberger HJ, Schayck CP. Distribution of house dust mite allergen: comparing house dust mite allergen levels in dust samples collected from different sites on living room floors with smooth coverings. Allergy 2003;58:500-502

2. Schönberger HJ, Maas T, Dompeling E, Pisters J, Sijbrandij J, van der Heide S, Knottnerus AJ, van Weel C, van Schayck OP. Environmental exposure reduction in high-risk newborns: where do we start? Ann Allergy Asthma Immunol 2003;91:531-538

3. Schönberger HJ, Maas T, Dompeling E, Knottnerus JA, van Weel C, van Schayck CP. Compliance of asthmatic families with a primary prevention programme of asthma and effectiveness of measures to reduce inhalant allergens-a randomised trial. Clin Exp Allergy. 2004;34:1024-1031

4. Schönberger HJ, Dompeling E, Knottnerus JA, Maas T, Muris JW, van Weel C, van Schayck CP. The PREVASC study: the clinical effect of a multifaceted educational intervention to prevent childhood asthma. Eur Resp J 2005;25:606-670

5. Kuiper S, Maas T, van Schayck CP, Muris JW, Schönberger HJ, Dompeling E, Gijsbers B, van Weel C, Knottnerus JA; PREVASC group. The primary prevention of asthma in children study: design of a multifaceted prevention program. Pediatr Allergy Immunol. 2005;16:321-331

6. Maas T, Dompeling E, van Schayck CP, Muris JWM, Schönberger HJAM, Wesseling G, Platts-Mills TAE, Knottnerus JA. Birth Cohort Studies on Asthma Development. Pediatr Asthma Allergy Immunol. 2005;18:201-215

7. Maas T, Kaper J, Sheikh A, Knottnerus JA, Wesseling G, Dompeling E, Muris JWM, van Schayck CP. Meta-analyses of multi- and mono-faceted birth cohort randomised controlled trials on prevention of asthma by allergen reduction (inhalant and/or food allergens) in children at high risk of developing asthma. Cochrane Library. Accepted February 2007

8. van Schayck CP, Maas T, Kaper J, Knottnerus AJ, Sheikh A. Is there any role for allergen avoidance in the primary prevention of childhood asthma? $\mathrm{J}$ Allergy Clin Immunol 2007;111:1323-1328

9. van Merode T, Maas T, Twellaar M, Kester A, van Schayck CP. Genderspecific differences in the prevention of asthma-like symptoms in high-risk infants. Pediatr Allergy Immunol. 2007;18:196-200

10. Kuiper S, van Schayck CP, Knottnerus JA, Muris JWM, Kester ADM, Schönberger HJ, Maas T, Wesseling G, Dompeling E. Family history modifies the effect of day-care on respiratory morbidity in preschool children. Submitted British Medical Journal 
11. Maas T, Verduin E, Muris JWM, Dompeling E, Damoiseaux JGMC, Kuiper $S$, Vaes JJ, Wesseling G, Knottnerus JA, van Schayck CP. Do Common Infections Influence the Development of Asthma and Allergy? Confirming or rejecting the hygiene hypothesis. Submitted Pediatr Allergy Immunol

12. Maas T, Dompeling E, Muris JWM, Wesseling G, Knottnerus JA, van Schayck CP. Effectiveness of the PREVASC multi-faceted randomised controlled trial on primary prevention of asthma in children at high risk; results at four and six years of age. Submitted British Medical Journal 
Dankwoord 
178 


\section{Dankwoord}

\section{Waar het begon}

Mijn loopbaan bij PREVASC startte doordat ik llse van Beerendonk, een bekende uit mijn jeugd, tegenkwam in de universiteit waar ik op dat moment studeerde. Ze werkte bij PREVASC als onderzoeksassistente en tipte me dat ze op zoek waren naar een verpleegkundige met consultatiebureau ervaring. Ik solliciteerde en werd aangenomen als preventieverpleegkundige. De aanstellingen bij het onderzoek volgden elkaar vervolgens naadloos op via onderzoeksassistente tot onderzoeker. En nu sta ik hier! Ilse bedankt voor je bijdrage aan die eerste stap. We hebben een leuke tijd gehad samen, toch een beetje dat gevoel van oude jongens (ahum meisjes) krentenbrood................

\section{Kring van wijzen}

Het PREVASC onderzoek werd geleid door Professor Onno van Schayck en Professor André Knottnerus. Huub Schönberger was de onderzoeker van het eerste deel van het project (zwangerschap tot twee jarige leeftijd).

Onno, ik heb je positivistische instelling en geloof in mogelijkheden zeer gewaardeerd. Jou wil ik bedanken omdat ik zonder jou waarschijnlijk niet zou zijn gekomen waar ik nu sta. André, ik heb je als een hele prettige, uitermate slimme en menselijke begeleider ervaren. Mijn grote dank hiervoor. Huub, je was samen met de bovengenoemde professoren de grondlegger van PREVASC. Bedankt voor het leggen van de bodem voor het onderzoek.

Leden van de projectgroep van het onderzoek waren mijn co-promotoren kinderlongarts Edward Dompeling en longarts Geertjan Wesseling en daarnaast maakte huisarts Jean Muris deel uit van de groep van begeleiders. Edward, jou heb ik ervaren als een zeer menselijke begeleider. Dank je voor je deskundigheid, betrokkenheid en oog voor de mens achter de promovendus. Geertjan, jij werd pas in een laat stadium opgenomen in de projectgroep. Met name bij de eindmeting heb je een belangrijke rol gespeeld. Dank je dat je deze cruciale fase samen met Edward en Jean zo goed hebt begeleid. Jean, alleen een huisarts was voldoende toegerust om het eerstelijns karakter van het onderzoek te waarborgen.

Het onderzoek werd op afstand begeleid door de begeleidingscommissie. Tijdens onze vergaderingen in Utrecht werden waardevolle en vooral ook bruikbare opmerkingen gemaakt. Zeer veel dank hiervoor. 


\section{De hoofdrolspelers binnen het onderzoek}

Uiteraard wil ik de deelnemers van het PREVASC onderzoek bedanken. Ruim 400 gezinnen hebben met veel inzet meegewerkt aan deze studie vanaf de zwangerschap totdat hun kind zes jaar was. Er zijn weinig langlopende onderzoeken die zo'n betrokken deelnemersgroep hebben als de PREVASCdeelnemers voor ons zijn geweest. Een uitvalspercentage van minder dan $5 \%$ van start tot einde $(6,5$ jaar per gezin) is uniek!

De deelnemers werden veelal met de hulp van hun huisarts geïncludeerd in het onderzoek (ruim 250 huisartspraktijken werkten mee!). Bedankt voor de hulp bij de inclusie en het aanleveren van de prospectief gestandaardiseerde gegevens die van grote waarde waren bij zowel secundaire als primaire outcome. De academische huisartsengroepen verbonden aan de universiteiten van Maastricht (RNH) en Nijmegen (NMP) wil ik hierbij speciaal noemen.

\section{PREVASC meer dan een onderzoek alleen}

PREVASC was niet alleen de naam van het onderzoek dat ik uitvoerde. PREVASC is tevens de naam van de onderzoekslijn naar preventie van astma bij kinderen waarin naast het in dit proefschrift beschreven onderzoek ook een aantal gelieerde projecten zijn opgenomen. De onderzoekers Lisette van den Bemt en Annemiek Nijholt van het at Risk onderzoek, Barbara Gijsbers van FOCUS en Sandra Kuiper van het RAKKER project met hun assistentes Mayke Jilderda, Anita Legtenberg en Kitty van der Meer waren mijn collega's binnen de PREVASC onderzoekslijn. We hebben indien van toepassing de onderzoeken op elkaar afgestemd wat onze samenwerking tot een zeer vruchtbare heeft gemaakt! Karin Manders was mijn eerste 'maatje' binnen PREVASC. Karin, met jou heb ik ook ontzettend graag samengewerkt. Je legde eenzelfde traject binnen PREVASC af als ik van verpleegkundige naar onderzoeker. Ook jou wil ik bedanken voor je gezelschap, collegialiteit en vooral ook vriendschappelijke contact.

Omdat (uitkomstmaat) astma pas op 6-jarige leeftijd objectief gemeten kan worden zijn we verder gegaan met het vervolgtraject van PREVASC (twee tot zes jaar). Het onderzoek werd gekenmerkt door vooral veel veldwerk door onderzoeksmedewerkers (al dan niet met een verpleegkundige achtergrond) die de gezinnen regelmatig thuis bezochten. Inke Schaap, Cindy Brink, Twanny Rouwhorst, Ellie de Vree, Marjan Terhaar, Marjori Rovers (jij hebt hele bijzondere rol gespeeld als deelnemer én onderzoeksverpleegkundige!), Gerti van Driel en Kitty van der Meer. Kitty, aan jou ook een speciaal woordje omdat wij niet altijd op dezelfde golflengte zaten. Ik wil je bij deze nogmaals zeggen dat ik je inzet voor het onderzoek zeer zeker heb gewaardeerd. Heel fijn dat jij een van de PREVASC-Kitties wilde zijn! De andere Kittie was uiteraard Kittie Coolen. We hebben samen de doorstart van twee naar zes jaar gemaakt. Kittie, 
ik kon er altijd van op aan dat alles dat jij aanpakte goed gebeurde. We waren echt een team dus ik vond het ook erg jammer dat je ons team moest verlaten. Gelukkig heb je een hele leuke baan gevonden bij het MEMIC waar je nu ook weer een spilfunctie vervult.

Gelukkig kwam er na het afscheid van Kittie, weer een fantastische onderzoeksassistente het team versterken. Waar Kittie de begin- en middenfase van het onderzoek heeft ondersteund, heeft Karen Groot de eindfase voor haar rekening genomen. Karen je hebt binnen PREVASC de kinderen begeleid bij de longfunctiemetingen. Je hebt heel vakkundig je rol vervuld. Ik had het alleen nooit kunnen redden allemaal. Heel erg bedankt voor je waardevolle bijdrage aan het onderzoek! Een onderzoeksassistente die Karen heeft opgevolgd was Susanne Hanssen. Jij hielp naast PREVASC ook andere projecten tot een succesvol einde brengen. Bedankt dat je er was. Renske Bottema kwam ons team versterken toen we gevraagd werden mee te werken aan een groot genetica-onderzoek op het gebied van astma (Allergenic). Naast werk voor Allergenic, waar je zelf op zal gaan promoveren, hielp je ook bij de begeleiding van gezinnen bij de longfunctie meting van PREVASC. Je was een plezierige collega en deed belangrijk werk voor ons beider projecten!

\section{Secretaresses zijn managers}

Buiten de mensen die ik al noemde zijn er nog veel meer die hun bijdrage hebben geleverd aan PREVASC: De secretaresses Anne-Marie Korsten en Annemarie Spaninks wil ik hierbij speciaal benoemen. Annemarie Spaninks, goud ben je waard geweest voor het onderzoek! Jammer dat ons afscheid zo abrupt moest zijn en zo definitief............ Ik had graag nog veel langer met je samengewerkt.

Anne-Marie Korsten was er vanaf het eerste uur. Je hebt de beginfase van het PREVASC onderzoek secretarieel begeleid en wij zijn sinds die tijd, met wisselende intensiteit, ook als vrienden verder gegaan. Je ligt me persoonlijk na aan het hart maar je hebt ook veel voor het onderzoek betekent. Deze combinatie was voor mij het perfecte excuus om je te vragen naast mij te komen 'staan' als een van mijn paranimfen. Naast secretariële werkzaamheden in de eerste fase van PREVASC heb je ook regelmatig hand en span diensten gedaan voor de tweede fase van PREVASC. Bedankt dat je mijn vriendin wil zijn. Kim Luyten is ook een secretaresse die haar licht heeft laten schijnen over PREVASC. Kim je had tijdens je periode bij PREVASC een bezige baan als persoonlijk secretaresse van André en drijvende kracht van het Journal of Clinical Epidemiology. Je hebt voor PREVASC je taken uitgebreid door te helpen bij de dataverzameling in de breedste zin van het woord. Je bent een 
grote en vooral ook plezierige kracht en vakkundige assistente geweest voor het onderzoek. Dank je wel!

Data-invoer en -beheer door MEMIC voor het PREVASC onderzoek werd door Jacqueline Pisters vakkundig aangestuurd. Naast Jacqueline zijn ook de dames van de data-invoer, Jildou Sijbrandij en Alfons Schroten, aangestuurd door Annemie Mordant van grote waarde geweest. Dank je!

\section{Eindmeting van longfunctie op zes jarige leeftijd}

De longfunctiemetingen werden uitgevoerd in het academisch ziekenhuis Maastricht. De medewerkers van het longfunctielaboratorium die hierbij een hoofdrol hebben gespeeld wil ik speciaal bedanken: Marie-José Jaspers, Judith Baars Manon Broekhuizen, Hedwich Wildeveld en secretaresses Monique Ramaekers en Esther Warnier. Jullie hebben alles rondom de longfunctiemetingen bij de kindjes van PREVASC in het azM op jullie kundige schouders genomen. Bedankt daarvoor! Marie-José, jou wil ik speciaal bedanken. Dankzij jou kon ik leren zelfstanding longfunctiemetingen uit te voeren bij de kindjes die niet naar Maastricht konden komen. Ik heb veel van je geleerd.

Er zijn naast de hierboven genoemden vele andere medewerkers geweest die hebben bijgedragen aan het PREVASC onderzoek. Vaak waren het onderzoeksassistentes die naast hun eigen werkzaamheden incidenteel bij het project hebben geholpen. Hoewel ik jullie niet met naam benoem in dit dankwoord kan ik jullie zeker zeggen dat deze hulp er zeker toe heeft bijgedragen dat het project succesvol is afgerond. Nogmaals bedankt!

Deze dank wil ik ook uitbrengen aan de uitzendkrachten Peter van Schayck, Anja Crounse en Rick Hoen. Ook jullie waren van grote waarde voor het project, bedankt!

Ook Jeroen Rovers, Jacqueline Vaes, Janneke Peeters, Marcos Gallegos, Yolanda Dennert, Marjolein Hutten en Esther Verduin hebben een waardevolle bijdrage geleverd aan het onderzoek tijdens hun stage. Ook mijn dank aan jullie.

\section{Collega's huisartsgeneeskunde}

Rest mij nog alle collega's te bedankten waarmee ik heb samengewerkt in mijn tijd bij huisartsgeneeskunde. Het zijn er te veel om een persoonlijk woordje van dank over te schrijven. Mijn kamergenoten waar ik met veel plezier, en soms zelfs vriendschap, heb samengewerkt wil ik hier wel persoonlijk noemen: Als eerste natuurlijk Judith Sieben die vanaf 1999 tot 2005 de kamer met mij deelde en waarmee het contact zich ontwikkelde van collega naar vriendin. Straks ben 
jij een van mijn para-nimfen en zullen we wederom een (werk)kamer met elkaar delen. Ik hoop dat het net zo vertrouwd zal voelen als ik gewend ben met jou in mijn aanwezigheid.......... Jochen Cals was de tweede kamergenoot in mijn PREVASC periode. We praten vast wel weer eens gezellig na......... Yvonne Winants, ik heb je inbreng altijd als zeer waardevol en welkom ervaren.

\section{De cirkel is rond............}

Hoewel het erg voorspoedig leek te lopen is het bij mij niet altijd vanzelfsprekend gegaan. Het is een enorme veldslag geweest om juist de laatste fase van dit proefschrift tot een acceptabel einde te brengen. ledereen om mij heen, familie, vrienden en collega's, weet dat ik ziek ben en koste wat kost doorzet om maar niet toe te hoeven geven dat ik beperkingen heb ten gevolge van mijn gezondheid. Reden is voor mij evident: Op mijn leeftijd hoef je niet zo voorzichtig met energie om te moeten gaan. Je moet kunnen genieten! Opbouwen van een nieuwe fase in je leven en lekker onbezorgd zijn. Jammer, zo ligt het bij mij niet............. Ik ga ervoor een nieuwe functie te vinden waarin ik geen beperkingen zal ondervinden van mijn gezondheid en vooral ook van betekenis kan zijn voor anderen via zorg en/of wetenschap. Dus waar het mee begon, zorg (verpleging) en wetenschap, komt weer terug in deze fase. De cirkel is rond.

\section{Oost west thuis best}

Mijn vrienden, het thuisfront en mijn ouderlijk gezin wil ik graag bedanken voor hun steun tijdens de looptijd van het project. Natuurlijk een speciaal woordje voor mijn eigen gezin dat bestaat uit Xavier, Rafael en Isha: Zonder jullie zou ik dit proefschrift niet eens hebben WILLEN schrijven. Jullie zijn mijn leven.......... 

About the author 


\section{About the author}

Tanja Maas was born in Nuenen on September $7^{\text {th }}, 1972$. She moved to Weert with her family and completed her secondary education (MAVO) in this town at 'Het Bisschoppelijk College'. She completed intermediate vocational nursing education (MDGOvp) in Maastricht followed by higher vocational nursing education (HBOv, cum laude) in Sittard. Tanja switched her education from nursing to Biological Health Science at the Maastricht University (UM). Her master's thesis focused on the influence of the type of infant feeding, human milk or artificial formula, on growth in early childhood (0-3 years). It was hypothesised that the known difference in milk fatty acid composition would influence length, weight and head-circumference increment. She kept working part-time as a nurse in community care, maternity care and occasional nursing jobs in a home for the elderly or those intellectually disabled. During the last year of her university study (1997) she started working as a research nurse for the PREVASC project on prevention of asthma in genetically predisposed children at high-risk of developing asthma (follow-up from pregnancy to two years). She was appointed to carry out home visits to the participating families from pregnancy onwards. During these home visits she offered the advisory intervention and carried out research measurements. In 1998 she started working as research assistant and finally (2000) she was appointed as PhDstudent carrying out the study as presented in the current thesis (PREVASC, follow-up from two to six years). At the moment she is thinking about making a switch from epidemiological asthma research to a different field of expertise. Her personal happiness lies in her life with her husband Xavier Camp and their children Rafael and Isha. 